Tense and Text in Classical Arabic 


\section{Studies in \\ Semitic Languages and Linguistics}

Editorial Board

A.D. Rubin and C.M.H. Versteegh

VOLUME 85

The titles published in this series are listed at brill.com/ssl 


\title{
Tense and Text in Classical Arabic
}

\author{
A Discourse-oriented Study of \\ the Classical Arabic Tense System
}

By

Michal Marmorstein

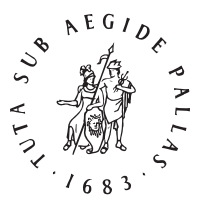

B R I L L

LEIDEN | BOSTON 
This is an open access title distributed under the terms of the Creative Commons Attribution-Noncommercial-NonDerivative 3.0 Unported (CC-BY-NC-ND 3.0) License, which permits any non- commercial use, and distribution, provided no alterations are made and the original author(s) and source are credited.

Want or need Open Access? Brill Open offers you the choice to make your research freely accessible online in exchange for a publication charge. Review your various options on brill.com/brill-open.

Typeface for the Latin, Greek, and Cyrillic scripts: “Brill”. See and download: brill.com/brill-typeface.

\section{ISSN 0081-8461}

IS BN 978-90-04-30747-6 (hardback)

ISBN 978-90-04-31048-3 (e-book)

Copyright 2016 by Michal Marmorstein.

This work is published by Koninklijke Brill NV. Koninklijke Brill NV incorporates the imprints Brill, Brill Hes \& De Graaf, Brill Nijhoff, Brill Rodopi and Hotei Publishing.

Koninklijke Brill NV reserves the right to protect the publication against unauthorized use and to authorize dissemination by means of offprints, legitimate photocopies, microform editions, reprints, translations, and secondary information sources, such as abstracting and indexing services including databases. Requests for commercial re-use, use of parts of the publication, and/or translations must be addressed to Koninklijke Brill NV.

This book is printed on acid-free paper and produced in a sustainable manner. 


\section{Contents}

Acknowledgements IX

1 Introduction 1

1.1 The Problem 1

1.2 Autonomous or Contextual Meaning(s) of the Verb 4

1.3 The Method 8

1.3.1 Methodological Principles 8

1.3.2 An Outline of the Analytical Procedure 11

1.4 Language and Corpus Definition 13

1.4.1 Classical Arabic 13

1.4.2 Classical Arabic Prose 14

1.5 The Structure and Scope of the Study 18

1.6 Technical Remarks 19

2 The Verb in Arabic Grammatical Tradition 20

2.1 Two Frames of Discussion 20

2.2 The Semantological Frame 20

2.3 The Grammatical Frame 24

2.3.1 'i'rāb and binā' 24

2.3.2 The Term al-muḍāric 27

2.4 Summary $3^{2}$

3 The Verb in Arabistic Literature 34

3.1 The Verbal System in Arabic and Semitic 34

3.2 The Question of Tense or Aspect 36

$3 \cdot 3$ Summary 39

4 The Structure of Context 41

4.1 The Conceptualization of Context 41

4.2 Deictic Reference 44

4.3 Text Types 47

4.4 Interdependency $5^{2}$

4.5 Clause Types 56

4.6 Lexical Classes $5^{8}$

4.7 Summary 60 
5 The Verbal Inventory 61

5.1 Inventory of Forms 61

5.2 Indicative Verbal Forms 62

5.2.1 Simple Forms 62

5.2.2 Modified Forms 64

5.2.2.1 The Modifier qad 65

5.2.2.2 The Modifier la- 67

5.2.2.3 The Modifier sawfa/sa- 68

5.2.3 Compound Forms 68

5.3 Modal Verbal Forms 71

5.4 Negated Verbal Forms 73

$5 \cdot 5$ Summary 75

6 The Syntagmatic Structure of the Clause $\quad 76$

6.1 The Inter-clausal Syntagm $\quad 76$

6.1.2 Dependency Status $\quad 76$

6.1.3 Linking Devices 78

6.2 The Intra-clausal Syntagm 82

6.2.1 Word Order and Agreement 82

6.2.2 Clausal Operators 83

6.2.2.1 Operators of Embedded Clauses 84

6.2.2.2 Operators of Non-embedded Clauses 86

6.3 Summary 88

7 The Verbal Paradigm in Embedded Clauses 89

7.1 Preliminaries 89

7.2 Substantival (Content) 'anna-clauses 90

7.3 Adjectival/Relative Clauses 96

7.3.1 llad̄ì-clauses 96

7.3.2 Asyndetic Adjectival Clauses 100

7.3.3 mā-clauses 105

7.3.4 man-clauses 111

7.4 Adverbial hịna-clauses $\quad 115$

$7 \cdot 5$ Summary 117

8 The Predicative Paradigm 119

8.1 Preliminaries 119

8.2 Verbal complexes 121

8.2.1 kāna-compounds 123

8.2.2 Modifying Verbs 131 
8.2.3 Motion and State Verbs 134

8.2.4 Perception and Permission Verbs 140

8.2.5 Speech Verbs 145

8.3 Circumstantial Clauses 145

8.4 Mutually Dependent Clauses $\quad 1^{1}$

8.4.1 Setting Clauses $15^{2}$

8.4.2 Presentative Clauses 154

8.5 Summary 155

9 The Verbal Paradigm in the Dialogue 158

9.1 Preliminaries 158

9.2 Declarative Clauses 161

9.2.1 Plain Declaratives 163

9.2.2 Argumentative 'inna-clauses 173

9.2.3 Asseverative'innala-clauses 175

9.2.4 Negative Clauses 177

9.3 Performative Clauses 182

9.4 Optative Clauses 185

9.5 Interrogative Clauses 188

9.6 Summary 192

10 The Verbal Paradigm in the Narrative 194

10.1 Preliminaries 194

10.2 The Main-line: fáala-initiated Chains 198

10.2.1 The facala CONN-fa'ala Pattern 198

10.2.2 The fa'ala yaf'alu/fā'ilan Pattern 200

10.2.3 The fa'ala fa-yaf'alu Pattern 202

10.3 The Background 208

10.3.1 Free and Dependent Clauses 209

10.3.2 Eventive and Descriptive Background 211

10.4 Setting-presentative Constructions 214

10.4.1 Setting and Preposed Temporal Clauses 215

10.4.2 Presentative Clauses 217

10.5 Generic Narratives 218

10.6 Summary 220

11 The Verbal Paradigm in the Generic Utterance 221

11.1 Preliminaries 221

11.2 The Structure of Generic Clauses 224

11.3 Indicative Verbal Forms in Generic Clauses 224 
11.4 Modal Verbal Forms in Generic Clauses 232

11.5 Summary 232

12 Conclusions 234

References 241

Index 253 


\section{Acknowledgements}

This study is an adaptation of my Ph.D. dissertation. I would like to thank the many individuals who have helped me during various stages of this work.

I am grateful to my late mentor, Gideon Goldenberg. I had the rare good fortune of being a student of this great person and scholar. His humanistic approach to language, and life in general, will always be a model for me to pursue. This work is dedicated to his memory.

No standard thanks could express my gratitude to Eran Cohen, my teacher and mentor from day one at the Hebrew University. I am grateful for his constant support and guidance, for teaching me the highest standards of scholarly work and instilling in me the confidence to pursue my own path of thinking.

Special thanks are due to my teachers and friends from the Department of Linguistics at the Hebrew University. I thank, in particular, Eitan Grossman, for many instructive conversations on linguistic issues and wise advice in general, and for assisting me on so many occasions; Ariel Shisha-Halevy, for teaching me critical linguistic thinking and for always taking the time to discuss with me the most challenging questions; and Moshe Taube, for his most generous support in the final stages of preparing this work for publication. I am also grateful to my friend Guy Ron-Gilboa, from the Department of Arabic Language and Literature at the Hebrew University, for carefully reading this work and offering his invaluable comments.

My sincere thanks also go to the Department of Linguistics at Georgetown University, where I was a Visiting Researcher during the academic year 20122013. I thank, in particular, my friend Ruth Kramer, who welcomed me into the department, and Heidi Hamilton, who has taught me the essence of discourseoriented work.

Acknowledgements are also due to my colleagues and friends from the Department of Semitic and Egyptian Languages and Literatures at the Catholic University of America, where I was a Research Fellow during the 2013-2014 academic year. I wish to thank, in particular, Edward Cook, Fr. Sidney Griffith, Monica Blancherd, and Ryann Craig.

I give thanks, too, to Roni Henkin, from the Hebrew Language Department at Ben-Gurion Universtiy, for suggesting important improvements to this work, and for her encouragement and support.

I wish to thank the two anonymous reviewers of this work for their comments and suggestions. Thanks are also due to Brill's editors, Marjolein Schaake and Maarten Frieswijk, for being exceptionally responsive and helpful. 
I owe an infinite debt of gratitude to my parents, Marian and Mariana Schwartzbart, from whom I inherited the love for language and without whom I could never have the privilege of pursuing academic life.

Finally, my deepest gratitude is due to my beloved family. My husband Oren, my solid rock of confidence and strength, who provided endless love, support, and tolerance to long hours of work, and our daughter Danielle, who lit our lives and made everything in them worthwhile. 


\section{Introduction}

This is a discourse-oriented study of the indicative tenses of Classical Arabic. The pivot of the analysis is the verbal form yaf'alu and the functional paradigms associated with it. The study is based on a large and varied corpus of Classical Arabic prose, composed or compiled by the end of the tenth century CE.

\subsection{The Problem}

The syntactic analysis of the verbal system in Classical Arabic is considered by many to be a difficult endeavor. ${ }^{1}$ Grammars of Classical Arabic present a relatively compact system, consisting of only two main tenses or states: a 'perfect' and an 'imperfect'; then a list, specifying a great number of uses of both tenses, is usually appended. ${ }^{2}$ The beginner student is puzzled: how should the perfect and imperfect be understood? Under which conditions is the perfect 'past' or 'perfect', or something entirely different such as 'gnomic' or 'optative'? When is the imperfect used as an 'imperfect' and when does it serve to indicate 'present-future'? The advanced student, on the other hand, is intrigued: how is it that all these functions are carried out by only two forms? What is the ultimate meaning of these forms? How should one formulate the logic underlying the system as a whole?

Indeed, these types of questions have been the focal interest of generations of Arabists for the past two hundred years. When it comes to the tense system, Western scholars have departed to a great extent from their Arab predecessors, whose views of the problem were considered to be too simplistic in terms of their semantic analysis, and too obscure as far as their terminology was concerned. The insights offered by the Arab grammatical tradition were for the most part disregarded.

Many suggestions have been raised to resolve the intricate problem of the Classical Arabic tense system. However different the analyses may be, they all

1 Thus Reckendorf, Syntaktischen Verhältnisse, 1, 52, in a much-quoted passage, says: Wenn man die Schwierigkeit syntaktischer Probleme nach dem Grad der Schwierigkeit, die syntaktischen Formen nachzufühlen, bemessen will, so ist die Tempuslehre das schwierigste Kapitel der semit. Syntax.

2 E.g. Wright, Grammar, $2,1 \mathrm{ff}$.

(C) MICHAL MARMORSTEIN, 2016 | DOI: 10.1163/9789004310483_002

This is an open access chapter distributed under the terms of the Creative Commons

Attribution-Noncommercial-Non-Derivative 3.0 Unported (CC-BY-NC-ND) License 
start out from the basic premise that the tense system of Classical Arabic is based on an opposition between two forms: the suffixed facal- $a$ and the circumfixed $y$-af'al-u. The problem which these analyses set out to resolve is defining the real essence of the semantic opposition marked by fa'ala and yaf'alu. Indeed, they aim to identify the temporal/aspectual/modal/other meaning which these forms are designed to convey.

In the present study I wish to take a different path. The problem, as I see it, is not semantic, but rather theoretical and methodological. It resides in the premise that the Classical Arabic tense system has a binary structure and that this structure corresponds to an asymmetrical opposition at the content level. This premise is clearly refuted when considering the following facts:

(a) The opposition between fa'ala and yaf'alu is not found in every syntactic or textual environment. In fact, there are quite a few clausal and textual environments where these forms do not form part of the same substitution class. For instance, in conditional clauses fa'ala commutes with the jussive, whereas in setting and circumstantial clauses yaf'alu commutes with the participle (see below 8.4.1). Or considering, for example, narrative texts: facala, as is well known, is the narrative, plot-carrying, form. It does not interchange with yaf'alu in this environment the same way as, say, the passé simple and imparfait in French may interchange. In fact, yaf'alu is never a free form in the narrative, but always dependent upon a previous fa'ala form. Thus, the opposition between yaf'alu and fa'ala is not only constrained to certain types of clauses, but also cannot always be accounted for at the same level of syntactic analysis.

(b) The tense system consists of forms other than fa'cala and yaf'alu. Although the verbal system is not rich in forms, Arabic is known for its productive mechanism of modification and augmentation of the simple forms. In fact, not only fa'ala and yaf'alu, but also the participle, the modified qadfa'ala and sa-yaf'alu, and the compounds kānafa'ala and kānayaf'alu, among other combinations, are part of the system of oppositions constituting the indicative tenses in Classical Arabic. ${ }^{3}$

(c) The meaning of fa'ala and yaf'alu is not a single, basic, and fixed one. This point, which is perhaps the most important one, is supported by a more general argument, namely, that the meaning of a verb, or to be more precise, its function or value, is not equivalent to a plain notion or idea. The 'basic', 'general', or 'absolute' meaning of a form is only found

3 Cf. also Goldenberg, Semitic Languages, $205 \mathrm{ff}$. 
at a very abstract level of semantic analysis. In practice, the meanings of a form are always determined with respect to a given opposition in a given context of communication. Obviously, there may be an historical and/or associative links between various meanings of a form; however, these do not necessarily boil down to a single notion, nor can they always be reconciled by means of logical derivation. Rather than a single, basic, and fixed meaning, what we do find in practice is a cluster of meanings emerging from the interaction of the form with various lexical, syntactic, textual, and pragmatic elements of the context.

An empiric investigation and a careful analysis of the data shows that the functional opposition between fa'ala and yaf'alu is not as pervasive as taken to be, and that both forms are used to indicate a number of meanings. Overlooking these facts or undermining them, we are at risk of moving too far from the linguistic reality we set out to describe in the first place. What is the merit of a neat and elegant analysis if it is only half-true or if it only works sometimes? How would it help the puzzled student in understanding the text? Surely, as the history of Arabic linguistics has shown, yet another analysis of this kind will not put an end to the controversy over the basic meaning of the forms, which by now has become a notorious characteristic of the Tempuslehre in Arabic grammar.

If indeed we acknowledge that there is not one, basic, and fixed meaning to pursue, but rather a cluster of meanings, and that the system is not built upon a binary opposition between fa'ala and yaf'alu, then a whole new set of questions opens up. What is the syntactic distribution of fa'ala and yaf'alu? What are the verbal paradigms they are associated with? In which syntactic and textual environments are these paradigms found? What types of meanings are expressed by the verbal forms and how are these affected by the context? What are the syntactic and semantic relations between the various paradigms? Notice that this last question calls for a synthesis of the more local or contextdependent findings; the goal, however, is not to reduce these into a clear-cut, absolute resolution - i.e., to identify the meaning of fa'ala and yaf'alu - but to identify the mechanism, the system of functional relations underlying the use of the tenses in Classical Arabic.

In the present study I wish, then, to reframe the discussion of the Classical Arabic tense system as follows:

(a) Rather than focusing on the presumed dichotomy between fa'ala and yaf'alu, I aim to define the relations between all the forms constituting the ensemble of the indicative tenses. 
(b) I do not treat fa'ala as the semantic pivot or marked element, in respect to which the unmarked or neutral yaf'alu is defined (e.g., perfect : imperfect, past : non-past, certain : uncertain). Rather, I take yaf'alu as the starting point of my investigation, precisely because of its indefinite semantic character, which calls for an inspection of the extended pattern in which the verbal form is realized.

(c) The unit under examination is not the plain verbal form, but the verbal form within a well-defined syntactic or textual context. My basic assumption is that language always occurs in context, thus, rather than an absolute meaning, I aim to define the functions of the verbal form as they emerge in different contexts.

(d) The shift of focus, from the invariant meaning of the verbal form to its contextual meanings, should not be taken as a fragmentation of the discussion. The system as a whole is coherent and displays a certain logic; however, this logic is not to be sought in some autonomous meaning of its parts, but in the regularities of their distribution and paradigmatic relations with each other.

\section{2 Autonomous or Contextual Meaning(s) of the Verb}

Theories of language position themselves quite differently with respect to the following question: is there an exclusive, isomorphic relation between grammatical forms and their meanings? Does each form have a single invariantgeneral or basic-meaning, common to all of its uses in specific contexts? Although this question bears on nearly every grammatical element in the language, linguists in the twentieth century have been contemplating and debating it most often in connection to the semantic analysis of the verb.

In traditional linguistics, a positive answer to the question of semantic invariance was considered as self-evident: 'the search for the Gesamtbedeutung of each tense', as Binnick points out, 'was the assumed task of the traditional grammarian'.4 This general meaning was understood as an absolute concept (e.g. 'past'), controlling all of the normal or typical uses of the verb, i.e., all of the uses that could be logically reconciled with that concept. According to this view, atypical uses of the verb proceed from the context and do not form part of its core meaning.

4 Binnick, Time and the Verb, 104. 
This position does not seem to have gone out of fashion also in modern times. Comrie, for instance, advocates the view that 'tenses have meanings definable independently of particular contexts. ${ }^{5}$ While admitting that tenses may well 'receive particular interpretations in particular contexts', Comrie holds that 'these are always explainable in terms of the interaction of contextindependent meaning and context, and do not therefore form part of the meaning of the tense category in question. ${ }^{6}$ For Comrie, then, the problem is resolved by assuming the existence of an autonomous grammatical system which, though coming to interact with the context or discourse (in whatever sense he ascribes to these concepts), is not affected by them.

As a theoretical construct, the concept of Gesamtbedeutung was elaborated to the utmost by Jakobson, in his influential works on the verb and other grammatical categories in Russian. ${ }^{7}$ Semantic invariance, according to Jakobson, is inherent to the structure of language as a communicative system: the proper production and adequate interpretation of grammatical forms would not be possible if they were not associated with semantic constants. ${ }^{8}$ Jakobson did not only advance the theoretical postulate of semantic invariance, but also proposed a methodological framework to account for it. According to this framework, the invariant meaning of a form is not absolute, but relational and oppositional: it is determined in contrast to the meaning of another form, constituting its binary pair. In a given syntactic environment, one member of the pair is semantically 'marked' (i.e., more specific and delimited), while the other is 'unmarked'. The concept of markedness also explains the relationship between the invariant meaning of the form - as defined in respect to its mutual opposite — and its distribution and use within specific contexts. ${ }^{9}$

While it is indisputable that language, as a vehicle of communication, consists of some content that is equally shared by the communicating parties, the exact semantic nature of this content and the ways in which it is organized and

5 Comrie, Tense, 28.

6 Ibid.

7 E.g. Jakobson, Shifters; Cf. also the introduction of Waugh to the volume Invariance and Variation, reviewing the main theoretical issues brought up in Jakobson's work on the topic.

8 García, Grasping the Nettle, 33-34, provides a logical explanation to the phenomenon of invariance, arguing that ' $[. .$.$] open-ended communication among human beings presupposes$ the infinite [...] exploitation of finite sources. The fundamental reason, then, for assuming that any linguistic unit must make a constant and invariant contribution to communication are (cognitive) considerations of economy: the principle of invariance can be viewed as a particular instantiation of that distinctness on which all of language depends'.

9 For an elaborate definition of the concept of markedness, see Waugh, Marked and Unmarked. 
processed, specifically in relation to the context of interaction, remain hard to determine. As is often pointed out, the difficulty in positing semantic invariance is to find formulations that are neither too narrow and specific to cover all of the uses of the form, nor too general and abstract to account for its uses in actual practice. While there may be competing analyses of invariant meanings, there are no clear and obvious criteria to decide which is more pertinent and correct. Another intricate issue has to do with the postulation of binary oppositions and the concept of markedness. In many cases, grammatical systems involve more than just two members, and the semantic oppositions marked by these are far more delicate than a simple dichotomy can capture. Moreover, the identification of a certain form as semantically marked (e.g., 'past' or 'perfective' vs. 'non-past' or 'imperfective') relies ultimately on its high distribution in a specific context where it is pragmatically unmarked (e.g. 'narrative'). It is hard to tell, therefore, which part of the meaning of a form consists of its semantic core and which is imparted by the context (the fact that the terms 'past' and 'narrative form' are often used interchangeably attests, inter alia, to this reality).

Invariant meanings of grammatical forms are generally assigned to the referential or ideational level of the functional-semantic system. ${ }^{10}$ In the traditional —and still most prevalent — view, the grammatical category of the verb is essentially associated with the concept of time, as defined in logical terms: ${ }^{11}$ verbal forms are designed to indicate temporal relevance (or its absence), the explicit or external location in time, or the implicit or internal unfolding of time. ${ }^{12}$ Some modern linguists, though coming to acknowledge the great many functions which verbs fulfill in actual discourse, still consider time reference as the primary meaning of the verb. ${ }^{13}$ This meaning interacts with various elements at the higher, textual or expressive levels, so that more specific meanings of the verbal form are produced in particular contexts. ${ }^{14}$ Only a few suggestions

10 For an exception, see Waugh, Tense-Aspect, who regards also the verb's pragmatic and textual meanings as invariants.

11 For a basic and straightforward outline of this view, see Comrie, Tense, $2 \mathrm{ff}$.

12 Cf. Guillaume, Immanence et transcendance; Comrie, Aspect, 5.

13 E.g., Monville-Burston and Waugh, Multiple Meanings, in discussing the contextual meanings of the present tense in Modern French, start out by saying that 'as a general rule, one can say that the French tense system is dominated by considerations of deictic placement in time' (183).

14 Halliday and Hasan, Cohesion, $26 \mathrm{ff}$., present an hierarchical model of the functionalsemantic system, in which tense is located at the 'ideational' level and not assigned any 'interpersonal' or 'textual' roles; Fleischman, Theory of Tense-Aspect, departs to some 
have been made to invert the hierarchy and identify the textual or discursive functions of the verb as constitutive components of its meaning. Hopper, for instance, maintains that the essential role of tense-aspect morphology is to mark the fundamental and universal distinction between foreground and background. ${ }^{15}$ A yet more radical approach, notably advanced by Weinrich, suggests to 'forget all about time and aspect.' ${ }^{16}$ According to Weinrich, the primary function of the verb is pragmatic in nature: the verb is designed to mark the discursive or narrative 'speech-situation' in which the interlocutors are engaged (see also below 10.1).

The variety of opinions and analyses presented above evidences a real theoretical and methodological difficulty to deal with the multi-functionality of the category of the verb. Evidently, different assumptions regarding the question of autonomous meaning vs. contextual meanings of the verb underlie each analysis. At yet a deeper level, these assumptions derive from the linguist's conceptualization of that part of the language which consists of its system, i.e., that part which in Saussurean terms is designated as la langue. In this work, a rather broad understanding of this concept is implemented: in my view, the goal is not to reach a definition of the general meaning of the verb, but rather to analyze all that is generalizable and thus systematic in a context where a verbal form occurs, at the syntactic, lexical, semantic, and pragmatic levels. Temporal distinctions are one component in the overall meaning of the verb; however, as will be further shown in this work, they are neither the only component, nor a privileged one. A close inspection of the text shows that there are symbiotic relations between the verbal forms and the contexts of their use, so that the meaning of a form is also determined by the extended syntactic unit in which it is realized, the lexical content realized by it, and the discursive conditions of its realization.

\footnotetext{
extent from this view by acknowledging that 'the functions of tense-aspect categories in narrative are not limited to these basic referential meanings; rather, tense and aspect do as much if not more of their work in the two pragmatic components (textual and expressive) and in the metalinguistic component' (78).

15 Hopper, Aspect and Foregrounding.

16 Weinrich, Tense and Time, 32.
} 


\subsubsection{Methodological Principles}

The present work is a descriptive and synchronic study of the system of the indicative tenses, as this emerges from an empirical examination of a welldefined corpus of Classical Arabic prose.

The methodology used in this study is interdisciplinary in nature, influenced by several schools of linguistic theory. It fundamentally draws on concepts developed in early (European) Structuralism, specifically as presented in de Saussure's Cours de linguistique générale, and further shaped by the Prague school and other linguistic circles, such as the Copenhagen school. ${ }^{17}$ Furthermore, this study draws on applications and elaboration of this theory in descriptions of specific, Semitic and other, languages. ${ }^{18}$ In these works, analytical problems not fully addressed by early structural linguists, specifically problems of syntactic analysis above the clause unit, are dealt with. Indeed, supra-clausal structures, cohesion, and texture have become the focus of interest of later linguists, working in the frameworks of Text-Linguistics and Discourse Analysis. It is important to note that these labels, as with Structuralism, have come to subsume different, even contrasting, approaches to the study of language or discourse. These various approaches are often grouped into two main paradigms, conventionally designated as 'formal' and 'functional'. At a rather general level of abstraction, one may say that in a formal perspective, language is studied as a self-contained system of rules, while in a functional perspective, language is studied as an instrument shaped by and used for communicative purposes. ${ }^{19}$

17 See de Saussure, Cours; Vachek, The Linguistic School; Hjelmslev, Prolegomena.

18 Notably Shisha-Halevy, Coptic Grammatical Categories, Structural Sketches and Topics. Further solidification of structural analysis methodology is found in Cohen, Modal System and Syntax of Neo-Aramaic.

19 For a detailed discussion of the distinction between the 'formal' and the 'functional' paradigms, see Dik, Functional Grammar, $2 \mathrm{ff}$., and Schiffrin, Approaches, $20 \mathrm{ff}$. It is important to note that Structuralism, specifically in its later American manifestations, is often taken to be synonymous with formal linguistics. Yet, it should be reminded that in its earlier continental manifestations, and specifically as shaped by the Prague school, structural linguistics was oriented toward the functional aspects of language. As Vachek, The Linguistic School, 6-7, points out: '[...] the Prague movement claimed for its approach not only the epithet "structuralist" (pointing out that no element of language can be duly evaluated if considered in isolation from the other elements of that same language) but the epithet "functionalist" as well [...] according to the Prague conception language is not a self-contained whole, hermetically separated from the extra-lingual reality, but, in fact, its main function is to react to and refer to this reality'. 
As the title of this work suggests, the analysis proposed here follows the latter paradigm: it is not concerned with the construction of an abstract semantosyntactic system, but with discovering and describing regularities in language as used in actual communications. ${ }^{20}$

In this study, I describe syntactic units of various size and order, at the clause level and above it. Since larger units are not just accumulations of smaller units but exhibit a distinct internal organization, they have been regarded as structural units in their own right. I did not decide a-priori which units to describe, but sought for any unit which is systematic, i.e., which is regular, consistent, and common enough to form part of the system represented in Classical Arabic prose. In this frame, not only simple clauses or constituents of clauses were included (e.g., declarative or predicative clauses), but also whole textual units, such as narratives. To be sure, there are considerable differences between the analysis of micro-syntactic and macro-syntactic units, specifically as far as the import of the extra-linguistic and meta-linguistic components are concerned. Nevertheless, rather than excluding each other, these two practices were taken here as complementary, each dealing with questions of a different scope.

In the following, I will shortly present the main concepts and principles which make up the approach implemented in this study:

The sign-Language is a semiotic system. The linguistic sign consists of a relation between form (signifier) and function (signified). Signs range from simple morphemes to complex syntactic structures. The analysis of signs is commensurate with their degree of complexity, so that a complex sign, e.g., a clausal pattern, can be described at a number of syntactic, semantic, and pragmatic levels. Simple signs constituting a more complex sign are referred to as 'elements' or 'components'.

The syntagm and the paradigm - The systemic coordinates by which the linguistic sign is defined.

The syntagm is a phrasal, clausal, or textual sequence in which a given sign is located in speech. The syntagmatic relation is realized through the compati-

20 Cf. Brown and Yule, Discourse Analysis, 22-23, discussion of 'rules' vs. 'regularities'. The authors define regularity as 'a linguistic feature which occurs in a definable environment with a significant frequency'; the discourse analyst, like the descriptive linguist, 'will attempt to describe the linguistic forms which occur in his data, relative to the environments in which they occur'. 
bility and inter-dependence of the adjacent constituents in the sequence. The distribution of a sign amounts to all the syntagms in which it can occur, i.e., to its syntagmatic identity.

The paradigm is a functional slot in a sequence (syntagm) in which a class of signs figures. The paradigmatic relation is realized through the commutability of the signs which occur in the same functional slot. The signs may pertain to different formal classes (e.g., nouns and verbs), or to be of different order (e.g., noun-phrases and clauses). For example, in the syntagm $g \check{g} a ̉ a$ Zaydun räkiban 'Zayd came riding' the participle rākiban functions as a circumstantial expression. The verbal form yaf'alu may occupy the same position as the participle in this syntagm and function as a circumstantial clause, e.g., $g \bar{g} \vec{a} a$ Zaydun yarkabu 'Zayd came riding'. Since the participle and the verb fulfill the same function in the given sequence, they are considered to be paradigmatic.

The function - The value of a sign (i.e., the signifier-signified entity) is relative: it is determined with respect to its paradigm, i.e., by opposition to other signs which may occupy the same functional slot in the sequence. In this technical sense, 'function' may refer to both the semantic content of a form and its pragmatic use. A function is distinct from a 'notion', which is an abstract category definable in positive terms. The term 'meaning' is used here in a more general and less technical fashion, to refer to both functions and notions.

Paradigmatic opposition and featural opposition-The function of a sign is determined with respect to an opposition, paradigmatic and/or featural. The first was explained above as the substitution of a class of signs in a given location in the sequence. However, some complex signs do not form part of a substitution class in the conventional sense. I refer specifically to complexclause constructions (e.g., setting-presentative constructions, see below 8.4.1) or to text units (e.g., narrative chains, see below 10.2) which do not simply commute with other complex signs. Rather, they can be defined in contrast to other signs of the same order, using a selection of pertinent features. Featural opposition is useful, though not necessary, in defining signs of whatever size; however, in the case of complex signs like text types, it is the only analytical procedure by which these can be evaluated.

Text-Text is any type of record of verbal communication. I use the technical term text type to refer to the cohesive structure underlying a certain segment of text. A detailed discussion of the concept of text types is found below in 4.3. 
Context-The term 'context' may designate various aspects of the communicative situation in respect to which a certain text is interpreted. Context may refer to extra-linguistic aspects such as the general knowledge of the interlocutors or the nature of the social interaction, or to linguistic elements such as the immediate sequence of the text or its overall structure. Given that in this work a corpus of classical literature is studied, it is the latter textual and structural features that are viewed as the most accessible and relevant to the analysis. In chapter 4, a model of context as a structural construct is outlined. This model accounts for the referential (deictic), textural, syntactic, and lexical parameters which factor in the actualization and interpretation of a certain segment of text. Occasionally, I may use the terms surrounding context, to refer to the adjacent stretch of text (also known as co-text), and context of situation, to refer to extra-linguistic aspects of the communication.

\subsubsection{An Outline of the Analytical Procedure}

This study is based on data gathered from a relatively large corpus of Classical Arabic prose (around 2000 printed pages). The database, organized in Access Forms, records over 5500 examples extracted from the corpus. The examples were sorted into four groups according to the minimal verbal form they cite: yaf'alu, fa'ala, qad fa'ala and the participle. qadfa'ala, though formally a modification of fa'ala, was considered as a minimal form due to its distinct functional identity vis-à-vis fa'ala (see below 5.2.2.1). Each group also comprises the compound formations of the minimal forms.

Below, two records (henceforth R1 and R2) are presented as an illustration of the analytical procedure applied in this study. Each record has an ID number. The Reference slot indicates the textual source and the page number from which the example was extracted. Both records cite examples from the same page in the Kitāb al-Magia $\bar{z} \bar{\imath}$ text:

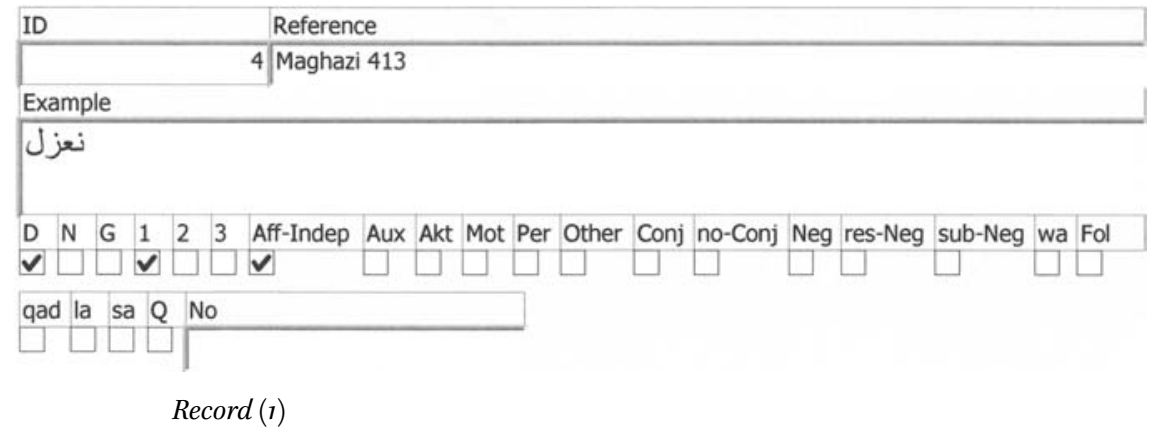




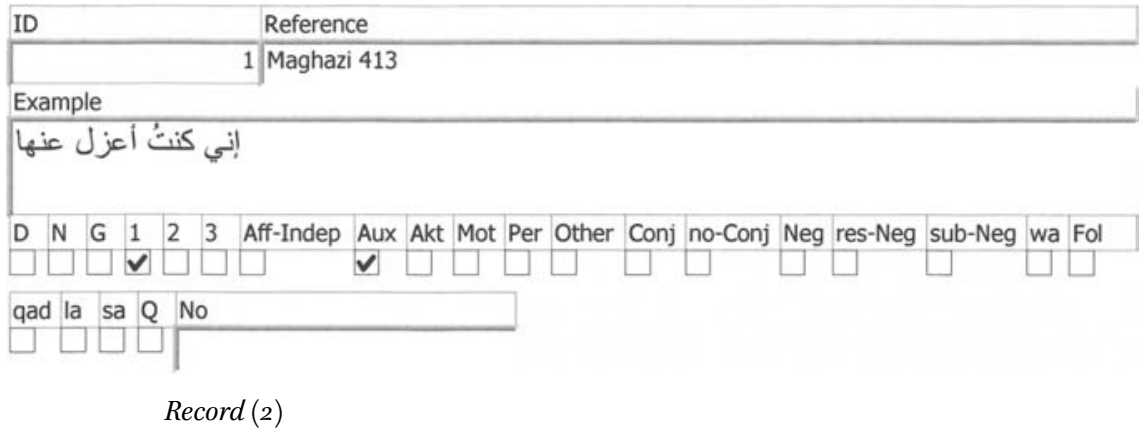

The Example slot cites (in the Arabic script) the shortest stretch of text relevant for the analysis. Thus, R1 cites the one word clause na'zilu 'we will abstain' (lit. 'separate ourselves'), while R2 cites a larger unit comprising the compound kuntu 'a 'zilu 'I was abstaining' in which the targeted yaf'alu is realized. The rest of the Form contains a checklist of features in respect to which the verbal form is profiled. The boxes $\mathrm{D}, \mathrm{N}$ and $\mathrm{G}$, abbreviating 'dialogue', 'narrative' and 'generic' respectively, refer to the overall text type. In R1, D is checked since the example is a dialogue clause; in $\mathrm{R} 2$, none of the text types boxes are checked since the targeted form is embedded, thus not relating directly (but only through its matrix clause) to the text level. The boxes 1, 2, 3, refer to the person of the targeted form. The box Aff-Indep, abbreviating 'affirmative-independent', is mutually exclusive with Neg, res-Neg, sub-Neg and Q, abbreviating 'negation', 'restricted negation' (e.g. 'illā-clauses), 'subordinate negation' and 'question', and also with Aux, Akt, Mot, Per, Other, representing types of matrix verbs initiating verbal complexes, viz., 'auxiliary', 'aktionsart' (modification), 'motion', 'perception' or other verb. In R1, the Aff-Indep box is checked, whereas in R2 the Aux box is checked. Also incompatible with Aff-Indep are the boxes referring to various types of explicit and implicit operators initiating non-independent clauses, viz., Conj(unction) and no-Conj(unction), the connective wa ( $w a-)$ and a Following location in the sequence. The last three boxes are specific to yaf'alu and refer to possible modifications of the form, via qad, la (la-) or sa ( $s a-$, sawfa). Special remarks are occasionally inserted in the Notes slot.

The features presented above were worked out in the course of my examination and analysis of the data. They reflect my understanding of the pertinent elements in the discursive, textual, and syntactic context which interact with the grammatical form of the verb. They do not exhaust all the pertinent elements. For instance, lexical classes were sorted manually, after the data was gathered and processed. Also in regard to some syntactic features, a further classification of the tokens needed to be carried out (e.g., the breaking down 
of the 'conjunction' category to substantival, adjectival, and adverbial clauses). To be sure, in every segment of speech, far more features are involved in the dynamic construction and interpretation of its meaning. The static procedure presented above is inevitably selective and approximative, focusing on those features which are taken to lie at the heart of a structural analysis of the text.

\subsection{Language and Corpus Definition}

\subsubsection{Classical Arabic}

There is no strict consensus on the definition of Classical Arabic, specifically on the demarcation of its initial and final boundaries. According to a narrow definition, Classical Arabic designates the 'poetic koine' that emerged in pre- and early-Islamic Arabia and was described by the Arab grammarians of the eighth century, called by them al-Arabiyya. ${ }^{21}$ According to a broader definition, Classical Arabic designates the Kultursprache used for literary and formal purposes from the early centuries of Islam to the revival of modern literary Arabic in the nineteenth century CE. ${ }^{22}$ Thus Classical Arabic has come to indicate both a formative stage in the history of Arabic and the standard which evolved from it and continued to serve as the model of elevated and eloquent ( fuṣ. $\bar{a})$, mostly written, Arabic until fairly recent times..$^{23}$ In both these senses, Classical Arabic contrasts with the Arabic vernaculars of the so-called Neo-Arabic type.

Besides obvious differences in the vocabulary, Classical Arabic is distinct from the Arabic dialects with regard to some phonemic, morphophonemic, and syntactic features. ${ }^{24}$ Admittedly, the most important of these is the phe-

21 Cf. Fleisch, L'arabe classique, 4; Fischer, Classical Arabic, 397. The origins of Classical Arabic are a matter of an unsettled dispute among Arabists; specifically, the scholars are divided as to whether Classical Arabic was ever used as the spoken language of certain Bedouin tribes or rather was it a standard literary idiom from its very start, cf. Rabin, Ancient West-Arabian, $17 \mathrm{ff}$, and more recently Levin, Spoken Language.

Rabin, Ancient West-Arabian, 3, proposes to distinguish between 'Classical Arabic', as the language of pre-Islamic poetry, and 'Literary Arabic', as the standardized international language of the Abbasid empire.

In the Arabophone world, a strict functional distinction between standard Arabic and colloquial Arabic was strongly kept until recent decades. Yet, in some countries, notably in Egypt, the penetration of the dialect into the literary and formal domains is constantly increasing, thus challenging the old balance between al-lugia al-fuṣhā and al-lugia al'ämmiyya.

24 Fischer, Classical Arabic, 397-398. 
nomenon of 'irā $b$, i.e., the change of the endings of the noun and the circumfixed verbal pattern, characteristic of Classical (or Old) Arabic only. Interestingly, some of the texts on which the norms of Classical Arabic were established, specifically the Qur'ân and the ancient poetry, show occasional deviations from these norms, due to the influence of the dialects in background. For this reason, the Qurān and the ancient poetry are sometimes classified as 'Pre-Classical' or 'Pre-Standardized' Arabic; by the same token, later texts introducing some grammatical and lexical innovations are classified as 'PostClassical' Arabic. ${ }^{25}$ Ideally, texts rendered in 'proper' Classical Arabic should have been intact and shown no deviations from the strict norms established by the grammarians. Yet, such texts can scarcely be found: even if minor and random, nearly every composition in Classical Arabic includes some linguistic peculiarities, motivated by the preservation of an archaic ('pre-classical') form, or by the (deliberate or overlooked) intrusion of dialectal forms. It is obvious, then, that 'Classical Arabic' does not designate a pristine form of the language, but rather a well-preserved standardized variety of Arabic. The fact that Classical Arabic is a prestigious standard language is reflected in its highly homogenous, regular, and stable morphosyntactic structure.

\subsubsection{Classical Arabic Prose}

The corpus examined in this study includes prose excerpts from a variety of literary works, composed or compiled between the eighth and the tenth centuries CE. In the common periodization of Arabic literature, this span of time is considered the golden age of pre-modern Arabic prose. ${ }^{26}$ Fostered by the intellectually-minded early Abbasid rulers, this was the time when foundational compositions in all fields of humanities were created, new literary forms and techniques were established, and older traditions were given the shape in which they entered wide circulation. Indeed, this was the time when writing in Classical Arabic has reached its fullest scope, extending from the traditional fields of religion and poetry to administration and the growing fields of science and belles-lettres. In the course of this process, new genres and styles were developed for the expression of different types of discourse: ordinary and oratory, expository and narrative. However different, all these share in common the (relatively) fluent and less patterned style of prose, standing in clear contrast to the metered and rhymed style of the ancient poetry, and to some extent, of the Qur'ān.

25 Ibid., 399 ff.

26 Cf. Brockelmann, $G A L, 1,14,106 \mathrm{ff}$; Gibb, Arabic Literature, $46 \mathrm{ff}$. 
A characteristic feature of works in Classical Arabic prose is that they do not consist of prose only. ${ }^{27}$ Prose passages are often juxtaposed with poetry or conflated with verses from the Qur'ann. In this study, I have disregarded those parts of the text which are not written in prose. With one exception, the adaptation of Kalila wa-Dimna from Pahlavi, all the works included in the examined corpus are of Arabic provenance and are considered to be masterpieces of the Arab culture. In listing the works, we may sort them into three general fields:

History - While history is transmitted also in belletristic works (e.g., the stories of 'ayyām al-'arab 'the battles of the pre-Islamic Arab tribes' in the Kitāb al'A $\dot{g} \bar{a} n \bar{\imath})$ and in hadīt collections, in Arabic literature, there have evolved specific genres dedicated to the documentation of historical matter. These can be roughly divided into earlier works, collecting records about the Prophet's life (sira) and military expeditions (majg $\bar{a} z \bar{\imath})$, and later works, in which the writing of annalistic history (ta'inh) comes to the fore. In the examined corpus, the first are represented by the foundational work of Ibn Hišām (after Ibn 'Isḥāq), Sìrat Sayyidīna Muhammad Rasūl Allāh ('The life of our Master Muḥammad the Messenger of God') and that of al-Wāqidī, Kitāb al-Majīāzi ('The book of expeditions'), and the latter by the chronicles of al-Tabarī, Ta'rîh al-rusul wa-lmulük ('The history of the messengers and the kings').

Tradition-Closely related to the field of history, hadit collections are yet another fundamental branch of Arabic literature. While the sira is concerned with the recording of the Prophet's life, the hadit is concerned with the sayings and doings of the Prophet in relation to particular issues and occasions which, in this framework, obtain the force of a binding doctrine, second only to the Qur'ān. In the examined corpus, the hadìt is represented by the authoritative

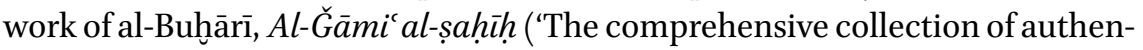
tic reports').

Belles-lettres-As far as themes and artistic expression are concerned, belletristic prose is by far the most broad and diversified among the three fields mentioned. It is therefore hard to give a definitive description of this genre in Classical Arabic. Still, what one may safely argue is that the uniqueness of

27 Leder and Kilpatrik, Classical Arabic Prose, 2, define classical Arabic prose literature as follows: 'works principally in prose, in which there is a pervasive concern with artistic expression as well as the communication of information'. The juxtaposing of prose and poetry is, according to the authors, 'one of the characteristic features of this literature'. 
Classical Arabic belles-lettres resides in the artful combination of encyclopedic content and didactic aims, with an entertaining style and a highly embellished language, all encapsulated in the traditional name of this type of literature, namely, 'adab. ${ }^{28}$ The works examined in this study include translated and original compositions, as well as compilations of existing traditions. These include the famous animal fables of Indian provenance, Kalïla wa-Dimna, translated and adapted from Pahlavi to Arabic by Ibn al-Muqaffa'; two works by al-Ǧāhịiz, the most important figure in classical Arabic literature, Kitāb al-Buhalä' ('The book of misers') and Kitāb al-Hayawān ('The book of animals'), in which anecdotes related to the general topics of 'misers' and 'animals' are collected; Ibn Qutayba's literary thesaurus 'Uyün al-'ahbār ('The springs of knowledge'); Ran-

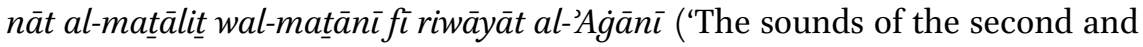
third cords in the traditions of the songs'), an abridgment of Kitāb al-'Ágāni ('The book of songs'), the great anthology on poets, singers and poetry by 'Abū al-Farağ al-'Ișbahānī.

For the purpose of quick orientation, the following table listing the titles of the works, their authors, and the edition used in this study, is appended (full details are given in the references section):

\begin{tabular}{|c|c|c|}
\hline Title and abbreviation & Author/compiler & Editor \\
\hline Sìrat Sayyidīna Muhammad Rasūl Allāh (Sïra) & Ibn Hišām (d. 834) & Wüstenfeld \\
\hline 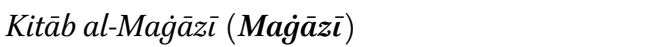 & al-Wāqidī (d. 823) & Jones \\
\hline Ta'rīh al-rusul wa-l-mulūk (Ta'rīh) & al-Ṭabarī (d. 923) & De Goeje \\
\hline Al-Ğāmical-șaḥiḥ (Șaḥiḥ) & al-Buhārī (d. 87o) & Krehl \\
\hline Kalīla wa-Dimna (Kalīla wa-Dimna) & Ibn al-Muqaffa' (d. 757) & Cheikho \\
\hline Kitāb al-Buhalä' (Buhalä') & lel_čāhiz (d 860) & 'Abd al-Sātir \\
\hline Kitāb al-Hayawān (Hayawān) & di-ud!̣t (u. ovg) & Hārūn \\
\hline 'Uyūn al-'ahbāar ('Uyūn) & Ibn Qutayba (d. 889) & Ṭawīl/Qamīhạa \\
\hline 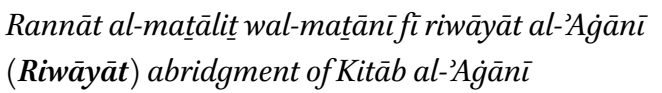 & al-'Iṣbahānī (d. 967) & Șâliḥānī \\
\hline
\end{tabular}

28 For a discussion of the term 'adab, its development, and the notions it has come to convey, see Bonebakker, 'Adab. After much contemplation, the author arrives at a rather technical definition of 'adab, based on 'one particular aspect of the 'Abbasid meaning of $a d a b$, such as the "passive" meaning of "the literary scholarship of a cultivated man" presented in systemic form' (30). 
Although the texts mentioned above are concerned with a wide variety of contents, the corpus as a whole shows a great uniformity, not only in its language, but also in the literary techniques and the overall organization of the texts. While linguistic uniformity is rather obvious, given that all writers were masters of the Classical Arabic standard, literary uniformity is not as predictable, but may be explained by the more or less concomitant development of the various genres mentioned above and their influence on each other. It is far beyond the scope of this study to go into the details of this development; however, I would like to point out one important fact that I deem as relevant to a linguistic analysis of these texts such as proposed here. In the majority of the works, text units are enclosed within the external frame (or frames) of their transmission, so that bits of text are bracketed and separated from each other by a chain of transmitters ('isnād), specifying the source(s) of the texts or the situation in which they were gathered. This practice is obviously pertinent in the fields of history and tradition, where the veracity of the 'ahbār 'reported accounts' relies on the authenticity of their transmission. However, one finds similar structures of transmission also in belletristic prose, where the related narrative, even if fictional, is also anchored in the reality of a certain individual, the author or some other transmitter. The organization of narratives as short 'ahba a r conveys the impression of authenticity and keeps the reader conscious of what may be described as the situation of narration. ${ }^{29}$ This external framing of the text bears on the issue of temporal reference and our interpretation of the verbal forms, as will be further discussed in this work (see below 4.3 and 10.2.1).

It remains to say something about the preference of prose over poetry in this study. Considering its idiosyncratic and often obscure nature, some modern scholars have argued against the priority given to poetry in the Arabic grammatical tradition. According to their view, the study of Classical Arabic syntax would have a greater validity if based on its more 'normal' and predictable, hence generalizable, manifestations in prose. ${ }^{30} \mathrm{I}$, too, find prose easier to handle in the study of syntactic phenomena, at the clause level and above it. Yet, I do not regard such a study as generally valid for all the manifestations of Classical Arabic. As I hope to show in this study, language and text are interdependent and mutually constitutive, so that the study of classical Arabic prose

29 According to Leder and Kilpatrik, Classical Arabic Prose, 11, the 'purported relation to reality is suggested by the term 'ahba $r$, which means "news", and the impression is strengthened by the fact that the narratives are ascribed to eye-witnesses or reporters close to the events in question'. 
is essentially the study of Classical Arabic prose language. Although part of the findings may well accord with what one finds in poetry, I do maintain that the study of Arabic's poetic syntax deserves its own consideration, specifically the intriguing phenomena brought about by the predominance of the verse's structure over that of the simple clause.

\subsection{The Structure and Scope of the Study}

This study is divided into three parts. The first part is introductory: it comprises the general introduction in chapter 1 and the discussion of the relevant medieval and modern literature in the following two chapters: chapter 2 presents the Arab grammarians views as to the semantological nature of the verb and its distinctive grammatical features; chapter 3 reviews the ongoing dispute over the semantic opposition marked by the two basic verbal forms fa'ala and yaf'alu in the Arabistic literature.

In the second part of the study the structural components of the analysis are presented and discussed. In chapter 4, I propose a model of the structure of context, comprising five components: referential (deictic), textual, macrosyntactic (supra-clausal), micro-syntactic (clausal) and lexical. In chapter 5 , I present the inventory of the verbal forms in Classical Arabic. The classification breaks down into (a) affirmative and negated forms, (b) indicative (modally unmarked) and modal forms, and (c) simple, modified, and compound forms. In chapter 6, I discuss the exponents of the inter-clausal and the intra-clausal syntagm in which the verbal form is realized. These include conjunctions, clausal operators, word order, and subject-predicate agreement patterns.

The third part of the study presents an empiric examination and analysis of the verbal paradigms at the clause level and at the text level. Chapter 7 discusses the semantic oppositions marked by the verbal forms in a selection of substantival, adjectival, and adverbial embedded clauses. Chapter 8 discusses the paradigm of yaf'alu, the participle, and qad fa'ala which function as predicative forms in complex predications. Chapter 9 discusses the main functions of the verbal forms in dialogue texts, and specifically, their role in signaling a variety of inter-subjective categories such as: emotional involvement, personal identification, cognitive evaluation, current relevance and actuality, directness and rapport. Chapter 10 discusses the main types of clauses that are found in Classical Arabic narratives: plot-line fáala-initiated chains, free and dependent, eventive and descriptive background units, and setting-presentative constructions, which contribute to the creation of dramatic effect in the narrative. Chapter 11 discusses verbal generic utterances in Classical Arabic, and exam- 
ines the distinction between the non-episodic yaf'alu and the episodic fa'ala, as well as 'normative' generics in which the modal forms are used. Final conclusions and synthesis are presented in Chapter 12.

Though this study focuses on the system of the indicative tenses in Classical Arabic, brief mention of the modal forms is made in chapter 5 , when surveying the entire inventory of the verbal forms in Classical Arabic. Moreover, the functions of some modal forms are discussed in chapter 11 in connection to generic clauses. It is important to note that the material presented in this study is based on data found in the corpus. There is no attempt to encompass all that is reported to exist in grammars of Classical Arabic.

\subsection{Technical Remarks}

The Arabic material in this work is rendered in a fully vocalized phonemic transcription. The transcription follows the DMG (Deutsche Morgenländische Gesellschaft) system. Notice also the following conventions:

- Word units are internally divided, using hyphens, to the lexical units they consist of;

- In connected speech, the silent alifal-wașl is not transcribed;

- In connected speech, the definite article is always rendered as $l$ - and separated with a hyphen from the defined noun;

- Long vowels not indicated in the Arabic script are marked in the transcription (including length of the third person singular bound pronoun and of the demonstrative morpheme $h \bar{a}$ );

- Final long vowels (including alif maqșūra) are always represented by the long vowels signs, viz.: $\bar{u}, \bar{a}$ and $\bar{l}$;

- In connected speech, final word syntactic vocalization ('ir $r a \bar{b})$ is fully indicated;

- Auxiliary vowels are separated with a hyphen from the preceding word unit;

- In the translation of the examples, proper names of people and places which have an accepted form in English retain their English form (e.g., Noah, Mecca); other names are accurately transcribed (e.g. 'Abū Sufyān).

The Arabic verbal forms are referred to either by their Latin conventional names (e.g. imperative) or by their morphological patterns. The latter are given in the first stem, third person masculine singular (e.g. yaf'alu). 


\section{The Verb in Arabic Grammatical Tradition}

\subsection{Two Frames of Discussion}

The category of the fil 'verb' is discussed in the Arabic grammatical tradition within two frames: (a) the general classification of the three parts of speech and (b) the grammatical characterization of each part of speech. In Sïbawayhi's $K i t a \bar{b}$ these two frames are kept distinct: the first chapter is dedicated to the exposition of the types of kalim 'words' in Arabic, whereas the second chapter deals with the 'ir $r a \bar{b}$ 'declension' distinguishing between these types. Later grammarians, though not maintaining such a neat separation in practice, further develop the 'rational' and 'descriptive' methods to distinguish the three parts of speech: ${ }^{1}$ the first is concerned with their internal essence ( $\underline{d} \bar{a} t$, hadd), the latter with their distinctive features ('alāmāt). In the following, these two frames of discussion, here labeled the semantological and the grammatical, will be presented.

\subsection{The Semantological Frame}

Sībawayhi's Kitāb opens with the exposition of the three parts of speech: the ism 'noun', the fil 'verb' and the harf 'particle'.2 Admittedly, this tripartite classification has its sources in the Greek grammatical tradition, which in itself was influenced by Greek philosophy. ${ }^{3}$ Although Sìbawayhi refers to the three types of words in Arabic, later grammarians stress that this taxonomy is universal in nature and follows from the internal essence of each type of word. ${ }^{4}$ According to Ibn al-'Anbārī, the tripartite division is the only one possible, since

1 According to Weiss, Parts of Speech, 23-24, the Arab grammarians employed two methods of distinguishing the three parts of speech: a 'descriptive' and a 'rational' one. The first is inductive and concerned with the 'observed features' of the parts of speech, whereas the latter in non-empirical and relies upon 'pure reflection'.

2 Sībawayhi, Kitāb, 1, 1.

3 For a discussion of the influence of Greek grammar on the theory of the three parts of speech in Arabic grammatical tradition, see Versteegh, Greek Elements, chapter 3.

4 Cf. al-Mubarrad, Muqtaḍab, 1, 141; Ibn Yaī̌š, Šarh al-Mufașsal, 4, 205.

(C) MICHAL MARMORSTEIN, 2016 | DOI: 10.1163/9789004310483_003

This is an open access chapter distributed under the terms of the Creative Commons

Attribution-Noncommercial-Non-Derivative 3.o Unported (CC-BY-NC-ND) License 
it exhausts all the expressions in language, those thinkable and imaginable. ${ }^{5}$ Universal and given as it is, al-Zağğăğì argues that the classification of noun, verb, and particle cannot be supported by (external) evidence, but can only be conceived by the mind's intuition. ${ }^{6}$

The rationale underlying the division into noun, verb, and particle is not presented in a systematic way in the Kitāb. In chapter one, the nature of the noun and the particle are not explained at all, but only illustrated. The verb, on the other hand, is defined as a morphological pattern derived from the verbal noun, which is 'constructed to [indicate] what has gone, what will be and has not happened [yet], and what [still] is and has not stopped.' ${ }^{7}$ In this preliminary definition, Sibawayhi clearly repeats the classic conception of the three physical times. Later on, in chapter ten, we are told that the verb is designed to indicate both the meanings of hadat 'happening' and zamān 'time.8 For later grammarians, it is this double meaning of the verb which constitutes its hallmark vis-à-vis the noun and the particle. Thus, Ibn al-Sarrāğ defines the noun as 'that which indicates a single meaning' whereas the verb

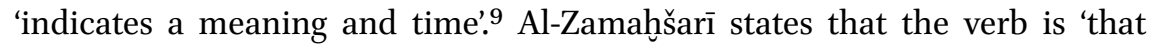
[word] which indicates an event coupled with [the expression of] time.' ${ }^{10} \mathrm{~A}$ further systematization of these definitions, employing the features of $m a^{\prime} n \bar{a}$ fìnafsi-hī 'meaning in itself' and iqtirān bi-zamān 'coupled with time', is found in late grammars, such as al-Suyūțī's Ham' al-hawāmi'. Al-Suyūṭī distinguishes between the three parts of speech by assigning them either a positive or a privative value of the two features. The verb, characterized by a positive value of both features, is distinct from the noun, which is not 'coupled with time', and from the particle, which indicates 'a meaning in something else (ma'na $f^{\prime} \iota$ gayri-hī).'.

Sībawayhi's discussion of the temporal meaning of the verbs may appear to be inconsistent at first sight. In chapter one he mentions three intervals of time indicated by three verbal forms: the past indicated by fa'ala, the future indicated by if'al ('in ordering') and yaf'alu ('in reporting'), and the present indicated, too, by yaf'alu. In chapter ten, however, Sỉbawayhi speaks of only two

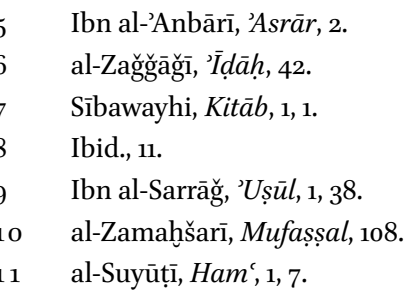


times, the past ( mā mad̄a min-a l-zamāni) and the future (māyastaqbilu min-a l-zamāni), the first is illustrated by dahaba and the latter by sa-yadhabu. The fact that Sỉbawayhi 'designed a system with three tenses', although 'there are only two verbal forms' in Arabic, is regarded by Versteegh as 'remarkable.12 Also for Mosel, Sỉbawayhi's inconsistency in counting the tenses is quite peculiar, and may suggest that rather than time, Sïbawayhi recognized that the tenses in Arabic signify, in fact, aspect. ${ }^{13}$ A close examination of the context in both chapters seems, however, to obviate the need for such far-reaching conclusions. In chapter one, Sibawayhi states the common conception as to the three intervals of time and the corresponding three types of verbs. Since a complete rigorous analysis of the tense system is not intended at this point, there is nothing remarkable in having the future marked by two forms, or having yaf'alu standing for both present and future. In chapter ten, however, the starting point is different: Sībawayhi is concerned with explicating a basic grammatical phenomenon, namely, the transitivity of the verb and its formal exponents, i.e., the assigning of the accusative case to nouns governed by the verb. In this context, Sïbawayhi uses plain and unequivocal examples to demonstrate his argument that verbs, by indicating time themselves, govern time-denoting nouns. Thus dahaba is adduced to illustrate a past verb governing a noun such as 'amsi 'yesterday', while sa-yadhabu (rather than the ambiguous yadhabu) is adduced to illustrate a future verb governing a noun such as gadan 'tomorrow'. For Sībawayhi, it appears, the trinity of tenses is not holy: when discussing the issue of transitivity and the grammatical effect of the verb on time-denoting nouns, he may do with the dichotomy of 'past' and 'non-past'; elsewhere, when referring to the trichotomy of time, he mentions the three types of verbs corresponding to it (see below 2.3).

While Sïbawayhi is hardly concerned with the logical concept of time per se, later grammarians - probably due to the increasing influence of Greek logicdiscuss at length the concept of three times and the way in which the Arabic verbal system may be adapted to it. In general, the grammarians maintain that the verb is designed to express events and time; time may be either past, present, or future. ${ }^{14}$ Time, as expressed by verbs, is relative in nature. Al'Astarābādī, for instance, makes it plain that the past form indicates time qabla zamāni talaffuzi-ka bi-hī 'prior to the time you pronounce it'. ${ }^{15}$ Ibn Ya'īš, too,

\footnotetext{
12 Versteegh, Greek Elements, 77.

13 Mosel, Syntaktische Terminologie, 32.

14 Cf. Ibn al-Sarrāğg, 'Ușūl, 1, 38 .

15 al-'Astarābādīi, Šarh al-Käfiya, 4, 7.
} 
explains that the time of the verb is relative to the time of the utterance, so that the past exists prior to it, the future exists later than it, and the present coincides with it. ${ }^{16}$

While the past and the future are considered to be relatively solid concepts, in the sense that they refer to well-delimited physical domains, the present domain is fuzzier and vague, thereby harder to perceive and define. ${ }^{17}$ Some grammarians, like Ibn Ya ${ }^{-1 ̌ s}$, argue that the present is the interval which separates (tafșilu) the past from the future. ${ }^{18}$ Others, like al-'Astarābādīi, see the present as residing in 'both sides of the now', i.e., as consisting of both past and future parts..$^{19} \mathrm{~A}$ third option is to discard the concept of present altogether. Thus, al-Zağğăğì admits of only two times, past and future; the present is not an interval in itself, but constitutes the first part ('awwal) of the future. ${ }^{20}$ The terminology employed also attests to the unequal status of the three times: the past and the future are consistently referred to as al-mādī and al-mustaqbal, respectively; the present, by contrast, is variously referred to as al-hädir 'the present', al-hâal 'the current' or al-dä'im 'the continual. ${ }^{21}$

The longwinded debate over the ontological definition of the present was not just philosophical entertainment for the Arab grammarians. The fact that Arabic has only one indicative verbal form to indicate both present and future posed a real challenge for them in terms of their overall theoretical framework. The explanations to this fact vary among the grammarians. Ibn al-Sarrāğ contends that yaf'alu is essentially a present form, since the present time is more 'entitled' to the plain form, being the only interval which exists in effect. ${ }^{22} \mathrm{Al}-Z a g$ ğgağà presents the opposite view: since the flow of time starts with the future (proceeding to the past), yaf'alu is genuinely a future form which may also refer to the present, conceived by al-Zağğăğì as the first part of the future. ${ }^{23}$ For al-'Astarābādī the problem is settled by assuming that the

16 Ibn Ya'ī̌s, Šarḥ al-Mufașșal, 4, 207.

17 Greek thinking apparently had much influence on the Arabic theory of time. Cf. Versteegh, Greek Elements, 75-76, for a short discussion of the category of present in Greek grammar and logic.

18 Ibn Ya īšs̆, Šarḥ al-Mufașṣal, 4, 207.

19 al-'Astarābād̄ī, Šarh al-Käfiya, 4, 12.

20 al-Zağğāḡì, 'Ị̇̂ăh, $86 \mathrm{ff}$.

21 Since time is essentially a haraka 'movement', the latter term, al-dã̉im, is severely criticized by some grammarians, cf. al-Zağǧăğī, 'Ị̇̂ahh, 86, specifically the editor's footnote on this page.

22 Ibn al-Sarrāğ, 'Ușūl, 1, 39.

23 al-Zağğāğì, 'Ị̇̂ăh, 87. Al-Zağğāăīi, however, appears to contradict himself when claiming 
present marked by yaf'alu is not strictly delimited, but consists of 'many successive times. ${ }^{24}$

Evidently, at the time when Greek philosophy penetrated their intellectual world, the Arab grammarians could not overlook the discrepancy between the universal model of three times and the bipartite system found in Arabic (when excluding if' $a l$, the imperative). Since no grammatical phenomenon is arbitrary but all phenomena follow from a well-designed order, the Arab grammarians sought to explain the dual nature of yaf'alu by employing the tools of structural hierarchy and logical derivation. In contrast, Sïbawayhi, who predated the extensive penetration of Greek thinking into Arabic linguistics, does not betray in his Kitāb any interest in such ontological questions. Rather, shortly after presenting the three types of words, Sībawayhi moves on to deal with their distinct grammatical properties, specifically with their relative ability to inflect. In this frame, a whole more original and insightful treatment of yaf'alu is to be found.

\subsection{The Grammatical Frame}

\subsection{1 'i 'rāb and binā'}

The basic distinction between the three types of words is briefly stated and illustrated in the first chapter of the Kitāb. In chapter two, Sībawayhi discusses the main grammatical phenomenon with respect to which the three types of words are distinguished. This phenomenon is generally described as mağa $\bar{a} \bar{\imath}$ 'awähiri l-kalimi 'the ways of the endings of the words.' ${ }^{25}$ According to Sībawayhi, all types of words may be defined with respect to two opposite concepts: 'ir $\bar{a} b$ 'declension' and bin $\bar{a}$ ' 'no-declension' (lit. 'fixed structure'). The 'ir $r \bar{a} b$ is realized through the changing of the word's final vowel or morpheme, due to the effect ('amal) of a certain grammatical operator ('ämil). The bina $\bar{a}$, by contrast, is ultimately marked by final vowellessness, and more generally, by the word's unchanged final vowel or morpheme. The 'i'rāb and $b i n \bar{a}$ ' determine, in fact, a scale upon which all types of words can be placed. There are two sets of terms distinguishing the final vowels which mark 'i'räb from those

that the present is the first part of the future ('awwalan 'awwalan) while the future is the first of times ('awwalu l-waqti l-mustaqbalu); if this is the case, then the present should have been considered the last part of the future.

25 Sībawayhi, Kitāb, 1, 1. 
marking bin $\bar{a}$, although both refer to the same vowel quality. These terms are presented in the table below:

TABLE 2.1 Two sets of terms for final vowels in the Kitāb

Vowel quality 'írāb (declension) binā' (no-declension)

\begin{tabular}{lll}
\hline$u$ & raf‘ & damm \\
$a$ & nașb & faț. \\
$i$ & ğarr & kasr \\
$\varnothing$ & ğazm & waqf \\
\hline
\end{tabular}

The 'ir $r \bar{b} b$ is not equally exercised by all words. In fact, the three types of words are distinct in their relative ability (or, in later terminology, haqq 'right') to undergo declension. ${ }^{26}$ Nouns are typically declinable and thus may end in $r a f^{c}$ ('nominative'), nașb ('accusative'), or ğarr ('genitive'). ${ }^{27}$ Particles are typically indeclinable and thus end in waqf (lit. 'pause'), or in one of the fixed vowels, i.e., damm, fath, or kasr. Verbs hold a middle position between nouns and particles: some are declinable, some are indeclinable but end in a vowel, and some are indeclinable and vowelless. The declinable verbs end either in $r a f^{\prime}$ ('indicative'), viz. yaf'al-u, nașb ('subjunctive'), viz. yaf'al-a, or ğazm ('jussive', lit. 'apocopate form'), viz. yaf'al- $\varnothing$; those which are indeclinable end in fath, viz. fa'al-a, ${ }^{28}$ or in waqf, viz. if'al. The table below illustrates the relative position of each type of word on the scale of declension:

26 E.g. Ibn al-Sarrāğ, 'Ușūl, 1, 5o: wa-'am 'anna l-i'irāba 'inda-hum haqqu-hū 'an yakūna li-l'asmā'i duna l-'af'äli wa-l-hurüfi 'Know that the declension for them (i.e. the Arabs) is due to the nouns but not to the verbs and the particles'.

27 Nouns which are fully declinable are termed by Sībawayhi 'asmä'mutamakkina, i.e., nouns which are 'firmly established in the nominal character', see Levin, Kalima, 432. Some nouns are indeclinable and thus end in a fixed vowel. For instance, the noun kayfa 'how' ends in fath.

28 The form fa'ala may come in the place of a simple adjective or interchange with al-mudāar al-mağzūm (in conditionals), thus it bears some resemblance to both the noun and the 'resembling verb', cf. Sībawayhi, Kitāb, 1, 2-3. For this reason it does not end in waqf but gets closer to declension by ending in fath. See also below 2.3.2. 
$\operatorname{bin} \bar{a}^{\prime} \leftarrow$

Particle

$\leftarrow$ Verb $\rightarrow$

Noun

$\min$ from, of

$b i$ - in

$\begin{aligned} \text { if al fa'al-a } & {[\text { lan }] \text { yaf } f^{\prime} a l-\boldsymbol{a} } \\ & {[\text { lam }] \text { yaf'al- } \varnothing }\end{aligned}$

hādā Zayd-un

This is $\mathrm{Z}$.

ra'aytu Zayd-an

I saw $\mathrm{Z}$.

marartu bi-Zayd-in I passed by $\mathrm{z}$.

Although nouns and verbs are two distinct types of words, Sibawayhi uses the same terms to refer to both the nominal 'case endings' and the verbal 'moods' (to the exclusion of ğarr and ğazm which are not shared by both word classes). This is explained by the fact that, as far as their declension is concerned, all word classes form part of the same system, whether they are essentially declinable, like nouns, or declinable only by virtue of analogy to nouns and extension of the system, like verbs. Considering the opposite end of the scale, the same logic holds true: the inability to decline is essentially associated with particles, yet it may also characterize verbs which depart from the group of declinable verbs and thus come closer to the prototypical indeclinable particle. ${ }^{29}$

Sībawayhi's 'scalar' approach, adopted by later grammarians, is indeed very useful: it not only defines the prototypes of declinable and indeclinable words, but also accommodates the intermediate forms characteristic of verbs. As mentioned above, the verbs are divided into three kinds: the pattern initiated by prefixes (hurūfal-zawä'id) is fully declinable, the pattern ending in a fixed - $a$ shows a weak declension, and the pattern initiated by no prefixes and ending in no vowel is totally deprived of declension. Notice that in this division, the final $\varnothing$ of $y a f^{\prime} a l$, which stands in (formal) opposition to the endings $-u$ and $-a$, is ascribed a different value than the final $\varnothing$ of if $a l$, standing for sheer vowellessness. Sībawayhi defines the declinable verbal pattern as al-'af'äl almuḍāri'a li-'asmāà al-fāilìna 'the verbs resembling the agent nouns/participles', and terms it in short al-fil al-mudâric, or simply, al-mudāric ${ }^{30}$ This has become

29 Sïbawayhi, Kitāb, 1, 3, explains that the imperative idrib 'Hit!' is assigned the waqf due to the fact that ba'udat min-a l-mudāriati bu'da kam wa-id min-a l-mutamakkinati " [the imperative] is so distanced from the resembling [declinable] verbs as [the indeclinable vowelless-ending nouns] kam and 'id are distanced from the fully declinable nouns'. According to Sībawayhi, Kitāb, 1, 2, indeclinable nouns 'resemble' (muḍ̄ari'a) particles. 
the common name of the pattern yaf'alu in the grammatical tradition, alongside $a l-m \bar{a} d \bar{\imath}$ 'the past' and al-'amr 'the imperative', designating the patterns fa'ala and if'al, respectively. While the latter terms, referring to the semantic meaning of the verbal patterns, are rather self-evident, al-mudāaric 'the resembling' is a less obvious term. In order to fully understand the grammatical theory encapsulated in it, I will turn now to examine the ways in which this term was employed in the Kitāb and in later grammars.

\subsubsection{The Term al-muḍāric}

In his Lexique-index, Troupeau enumerates over a hundred instances of the verb dẹra'a and its derivatives in the Kitāb. ${ }^{31}$ As is generally the case, Sībawayhi uses the dēra' $a$-terms without explaining their technical meaning. Later grammarians, however, felt obliged to explain the less obvious term diāra'a by adducing its synonym šăbaha 'to be like, resemble'. Some even go on to provide

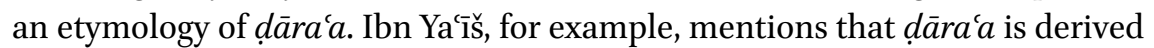
from the word $d a r^{\text {' }}$ 'udder'. The association of $d \bar{a} r a^{\prime} a$ and $d a r^{\prime}$ is explained by an extension (and abstraction) of the narrow sense of two twin-lambs meeting in the sheep's udder to suck ( ad $^{\prime}$, a close etymon in itself). ${ }^{32}$ Whatever the real value of this etymology may be, it is clear that for later grammarians d̦āra' $a$ and its derivatives were not transparent and therefore had to be explained. With the exception of al-mudāaric', the dêara'a-terms, as Carter noticed, were not used much after Sỉbawayhi, giving way to the more common term šābaha and its cognates. ${ }^{33}$

In the Kitāb, however, d̦āra'a and its derivatives are extensively used. Sībawayhi describes a mudāara'a 'resemblance' between different kinds of elements at all levels of linguistic analysis. The term mud̄ära'a may refer to either phonological assimilation, analogical word formation, or similar syntactic behavior. The later mudâra'a is the most elusive and abstract; no doubt, it takes a keen eye as that of Sibawayhi to identify syntactic resemblance between elements so different as, for example, the conditional particles and the agent noun. ${ }^{34}$ Going over the instances where mudāra'a is used to signify syntactic resemblance, it becomes apparent that the nature of the mudāara àt is quite diverse, as well as the motives which bring them about.

Obviously, mudāara'a is but one of a host of terms used by Sībawayhi to refer to different kinds of analogy and similarity in the grammatical system. It is not

\footnotetext{
31 Troupeau, Lexique-index, 129.

32 Ibn Ya'ǐš, Šarh al-Mufașșal, 4, 210.

33 Carter, Muḍāric, 8.

34 Sībawayhi, Kitāb, 1, 406 (apud Carter).
} 
easy to demarcate the specific meaning of each; however, some suggestions have been made by Carter as to the functional difference between mudāra'a or mud̄āric and other concepts, such as qiyās and mušabbah. According to Carter, mud̄āra'a is a 'descriptive' term, referring to 'empirical resemblances in the data', while qiyās is a 'systematic' term, denoting 'abstract regularities in the system, ${ }^{35}$ Following the same line of reasoning, Carter maintains that the active participle mud̄āric is associated with 'inherent' resemblance, whereas the passive participle mušabbah stands for 'similarity that has been imposed on the word by speakers.' ${ }^{36}$ In what follows, I wish to further examine these observations, and explore in greater detail the term al-mudāric and the nature of the resemblance which it serves to indicate. For this purpose I will go back to the locus classicus where the mudāric is discussed in the Kitāb.

The term al-mudāric is first introduced in chapter two of the Kitāb. Sībawayhi uses this term to refer to the prefixed verbal pattern $y$-af' $a$-V which, like nouns, exhibits final vowel/morpheme change, due to the effect of a certain grammatical operator. Sībawayhi explains this fact by saying: wa-'innamā d̦āra'at 'asmä'a l-fä ìīna 'anna-ka taqūlu 'inna 'abda llāhi la-yaf'alu fa-yuwāfiqu qawlaka la-fāilun ḥattā ka’anna-ka qulta 'inna zaydan la-fāilun fìmā turìdu min-a l-ma'na 'And [yaf'alu forms] resembled the agent nouns [for] you say 'inna 'abda llāhi la-yaf'alu "Indeed 'Abdallāh does" and it corresponds your saying la-fácilun so much as if you were saying 'inna zaydan la-fácilun "Indeed Zayd is doing" in the [same] meaning you intend'. ${ }^{37}$ Shortly after that, Sībawayhi

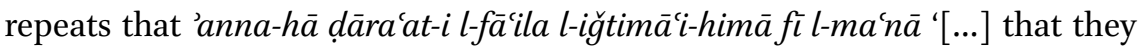
(i.e. yaf'alu forms) resembled the agent noun since both converge (lit. 'come together') in meaning.38 Sibawayhi thus contends that the resemblance of the verbal pattern yaf'alu to the agent noun fã i ilun is due to their common meaning. In order to fully understand what is meant by ma'na in this context, we turn to al-Mubarrad who makes it plain that 'inna-mā qüla la-hā mud̄aricatun li-'anna-hä taqa'u mawāqi'a l'asmä'ifí l-ma'nā 'They were termed [the] resembling [forms] because they take the same position of the [agent] nouns in [conveying the same] meaning. ${ }^{39}$ In a similar manner, Ibn Ya î̌s states that yaf'alu forms resemble the agent noun because they yaqa'u mawāqi'a l-'asmä $\vec{i}$ wa-yu'addìma'āniya-hā 'occupy the place of the nouns and convey their mean-

35 Carter, Muḍāric', 5.

36 Ibid., 6 .

37 Sībawayhi, Kitā b, 1, 2.

38 Ibid.

39 al-Mubarrad, Muqtadab, 2, 1. 
ings.' ${ }^{40}$ Putting it in modern terms, we may say that the mudāara'a of yaf'alu to the agent noun is semantic and paradigmatic in nature: it stems from the fact that yaf'alu, occupying the same position as fäilun in the clause, conveys the same meaning.

Sībawayhi mentions two other features by which the mudàra'a of yaf'alu to the agent noun is established. The first is the compatibility (illustrated in the examples above) of the 'emphasizing' la- with both yaf'alu and fãilun, a compatibility not attested with fa'ala. The second is the prefixation of the 'future' particle sawfa/sa- to yaf'alu, compared to the prefixation of the definite article to the noun. ${ }^{41}$ This latter feature is explained by Sībawayhi's commentator, al-Sīrāfì, as follows: the plain verb yaf'alu, which indicates either a present or a future time, resembles a mubham 'indefinite' noun such as rağulun, which does not refer to a specific man. The adding of the definite article to rağul makes its reference to a certain man specific, the same as the adding of sawfa/sato yaf'alu marks its specific reference to future time. ${ }^{42}$ The semantic vagueness ('ibhām) or polysemy (ihtiläfal-ma'ānī) of yaf'alu is further compared to that of a noun like 'ayn, which (depending on the collocation) may be used to indicate such diverse meanings as 'eye' ('ayn al-insān), 'well' ('ayn al-mā'), 'direction of prayer' ('ayn al-qibla), and the 'cavity of the knee' ('ayn al-rukba). ${ }^{43}$ Some grammarians after Sibawayhi took up all these (as well as other) features and composed lists of wuğūh 'aspects' in respect to which yaf'alu resembles the agent noun. ${ }^{44}$ It is important to keep in mind, however, that these additional features of resemblance, i.e., the compatibility with $l a$ - and the concretization through a prefixed modifier, are only secondary to the more fundamental feature of common meaning. As al-Suyūṭi comments, la- and sawfa/sa-are added ba'da stihqāqi l-'irāabi after the declension was rightly claimed [by the resemblance]. ${ }^{45}$ In other words, the resemblance of yaf'alu to fã ilun is not preconditioned by the presence of these features, but only corroborated by them.

An obvious though often overlooked fact is that the resemblance of the verbal pattern yaf'al-V to the agent noun is discussed only in relation to the form ending in raf' $(u)$, namely, al-mudāaic al-marfüc . This stands to reason, since the features of resemblance mentioned above apply only to yaf'alu. The

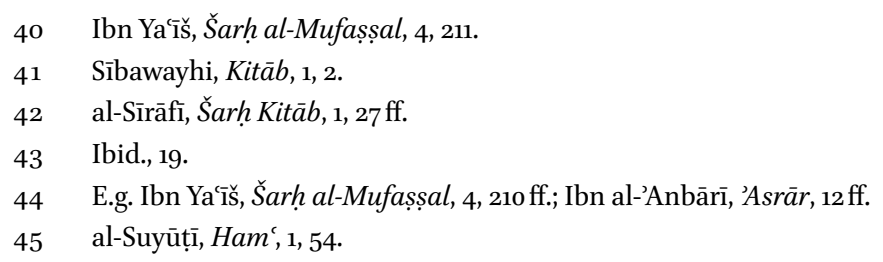


two other forms ending in nașb and ğazm, viz. yaf'ala and yaf'al, are called mudāric only by extension: they share the same morphological pattern with yaf'alu, but they do not occupy the position of a noun in the clause or convey its meaning. Moreover, al-mud̄āri al-marfü is distinct from al-mud̄āric al-manșūb and al-muḍāi' al-mağzūm in being affected by an 'abstract operator' ('āmil ma'nawiyy) rather than a 'literal operator' ('ämil lafziyy), such as the negative particles lan or lam, preceding yaf'ala and yaf'al, respectively. ${ }^{46}$ According to Sibawayhi, the form yaf'alu is assigned the raf' due to the fact that it occurs in the clause in a position where a noun could occur (not necessarily an agent noun!). Thus yaf'alu is found in the position of the subject, predicate, second object or circumstantial, or in the position of an adjective, in apposition or in a genitive construction. ${ }^{47}$ Sibawayhi admits that the substitution of yaf'alu and fä́ilun is limited: in some positions the occurrence of yaf'alu is precluded, e.g., the subject position after 'inna, while in other positions the agent noun is not featured, e.g., the predicative position after the verb $k \bar{a} d a{ }^{48}$ This is explained by the fact that, however similar, yaf'alu is not a noun but ultimately a verbal form.

So far I have discussed the resemblance of the verbal form yaf'alu to the agent noun, however, the similarity between the two forms also works in the opposite direction. Sïbawayhi attributes the ability of the agent noun to govern an indefinite noun in the accusative to the fact that it is similar to yaf'alu in both its grammatical effect ('amal) and meaning (ma'nāa).$^{49}$ Thus, in a clause such as hā $\bar{d} \bar{a}$ da aribun Zaydan gadan 'This one is going to hit Zayd tomorrow', the agent noun dāribun governs the object Zaydan since it has the same meaning and grammatical effect that yadribu has in the clause hād $\bar{a}$ yadribu Zaydan gadan 'This one will hit Zayd tomorrow'. If the agent noun does not indicate the same meaning as yaf'alu but refers to a past occurrence, it will not govern an accusative object but a genitive complement, e.g., hā $d \bar{a}$ d̦âribu Zaydin 'This one has hit Zayd'. In the Sībawayhian terminology, the verb is mudāric 'resembling' the agent noun and thus entitled to 'i'rāb 'declension', while the agent noun ğarā mağră 'follows the course' of the verb and is thus entitled to 'amal 'grammatical effect'. In both cases, the similarity is motivated by the common meaning of both forms.

46 For a general discussion of the theory of 'amal and the distinction between both types of 'awāmil, see Levin, Amal.

48 Sībawayhi, Kitāb, 1, 3, 364-365.

49 Sībawayhi, Kitāa $, 1,70$. 
The similarity between yaf'alu and the agent noun is not strictly reciprocal or of equal status, as one could argue. ${ }^{50}$ Careful attention to the terminology used by Sïbawayhi is revealing of the different nature he ascribes to the similarity in each case: the agent noun is not muḍāric, but ğarā mağrā al-fic al-mud̦aric ${ }^{51}$ This brings us back to the question of the meaning of mudāra'a against other terms indicating analogy and similarity. Sībawayhi does not interchange between mud̄āric and ğarā mağrā; however, he substitutes the latter term with 'ašbaha or šubbiha 'to be or be made similar'. Sïbawayhi argues that the agent noun was made similar (šbbiha) to the verb that resembled it (dâara'a-hü), the same way that the verb was made similar (šubbiha) to the agent noun in declension. ${ }^{52}$ It is evident that subbiha refers to the 'gains' of the resemblance: the grammatical effect in the case of the agent noun, and the declension in the case of the verb. We recall that the agent noun is not similar in all circumstances to the verb whereas the resemblance of the verb to the agent noun is built-in. This accords well with Carter's insight that mud̄āra'a indicates inherent resemblance. We can refine Carter's observation by saying that dāra'a refers to the acquiring of an inherent property through resemblance whereas ğarā mağrā, 'ašbaha, or šubbiha refer to a conditioned behavior brought about by similarity.

Later grammarians are not as careful as Sïbawayhi in maintaining the distinction between $\operatorname{ca}_{\bar{r}} \mathrm{a}^{\prime} a$ and other terms indicating analogy. Thus Ibn al-Sarrāğ draws an equation between yaf'alu and fä'ilun saying that the first 'a'raba limudāara'ati l-ismi 'declined due to resemblance to the noun' while the latter 'a'mala bi-mudāra'ati l-fili 'governed [the object] by virtue of resemblance to the verb'. ${ }^{53}$ Ibn Ya'ǐš, too, freely interchanges between mud̄arra'a and mušābaha, conceived by him as two synonymous terms, thus saying that l-mušābahatu 'awğabat la-hü l-'irrāba 'the resemblance granted it [i.e. the verb] the declension.' ${ }^{54}$ However, also in these formulations, it is clear that the syntactic resemblance is what brings about (or results in) morphological similarity. In other words: the mudāra'a (or mušābaha) is the cause and the 'írāb is the effect.

5o Carter, Mudāric, 6-7, argues that the resemblance between the imperfect verb and the agent noun is not only reciprocal but also circular. It is true that the mechanism of resemblance can work in both directions; however, it is not simply bi-directional: the nature of the resemblance is different in each case and resides in distinct domains. See Sībawayhi, Kitāb, 1, 70 ff.: šubbiha bimā ḍāra'a-hū min-a l-fili kamā šubbiha bi-hī fì li'rābi.

52 Ibid., 73 .

53 Ibn al-Sarrāğ, 'Ușūl, 1, 123 .

54 Ibn Yac̄ǐš, Šarh al-Mufașṣal, 4, 210. 
Apparently, this causal relation was not wholly understood or maintained in the writings of some modern scholars. Brockelmann, for instance, translates mudāric as '(dem Nomen in der Annahme der Kasusendungen) ähnelndes. ${ }^{55}$ More explicitly, Ryding argues that the term mudāaric 'was adopted because of the fact that the present tense mood markers on the verb [...] resemble the case markers on nouns', so that the present tense '"resembles" a noun in this ability to change its desinence. ${ }^{56}$ Evidently, Ryding describes an inverse relation between mudāra'a and 'írāb, so that the similarity in declension is the underlying reason for the resemblance. Also Versteegh explains that, apart from resemblance in the 'syntactic function', the mudāari' is so designated 'since the verbal forms of the imperfect have almost the same endings as the nouns.' ${ }^{57}$ Even Carter's insightful article on the term mudāric in the Kitāb of Sībawayhi falls short when classifying the resemblance of the 'imperfect verb' to the agent noun as morphological (while the resemblance of the agent noun to the verb is classified as syntactical). ${ }^{58}$ To be sure, the resemblance of yaf'alu to the agent noun has morphological exponents. Yet, according to the Arab grammarians' view, these are but the surface expressions of the resemblance at the deeper semantic and syntactic levels.

\subsection{Summary}

In this chapter, I have presented the Arab grammarians views as to the semantological nature of the verb and its distinctive grammatical features. The verb, as generally accepted, is designed to express events in time. According to Sībawayhi, the verbal system consists of three types of verbs corresponding to the three physical times: fa'ala, yaf'alu, and if'al. According to later grammarians, the tripartite division of the timeline is matched with a bipartite tense system in Arabic, by establishing a certain hierarchy between the present and future, both marked by yaf'alu. While fa'ala, the mādī 'past', and if'al, the 'amr 'imperative', were termed after their semantic meanings, the term for yaf'alu, al-mudâric 'the [verb] resembling [the agent noun]', originated in the grammatical analysis of the verb. The resemblance of yaf'alu to the agent noun is semantic and paradigmatic in nature: taking the same place of the agent noun in the clause and conveying the same meaning, yaf'alu resembles the agent

\footnotetext{
55 Brockelmann, Grundriss, 2, 145.

56 Ryding, Modern Standard Arabic, 442, no. 7 .

57 Versteegh, Greek Elements, 78.

$5^{8}$ Carter, Muḍāric, 10-11.
} 
noun and thus assumes final word declension. The agent noun, when conveying the same meaning as yaf'alu, may also follow its course and govern an indefinite accusative noun. However, the resemblance of yaf'alu to the agent noun is inherent in the verbal form whereas the similarity of the agent noun to yaf'alu arises only in certain defined occasions.

It appears that the Arab grammarians maintained a rather profound view of the verbal system in Arabic, more profound than the one accredited to them by some modern scholars. ${ }^{59}$ It is a striking fact that of the two basic tenses fa'ala and yaf'alu, the second is defined in comparison to a nominal form. Indeed, as their terminology suggests, the Arab grammarians considered the semantic and syntactic resemblance of the verb yaf'alu to the agent noun as its most prominent characteristic. This view of yaf'alu is doubtless original and, as will be further shown in this work, may be corroborated by ample data from Classical Arabic prose. ${ }^{60}$

59 Brockelmann, Grundriss, 2, 145, points out the seeming negligence of the Arab grammarians in giving the verbal forms names that are not of the same logical order, see also below chapter 3 .

6o Versteegh, Greek Elements, 79, argues that the comparison of the verb to the noun is 'not as original as it appears to be at first sight'. As evidence, he points at the Greek doctrine, according to which a finite verb such as loúei 'He washes' is equivalent to the periphrastic form estì loúûn 'He is washing'. It is clear, however, that the Greeks had something else in mind when posing this equivalence: they referred to the complex structure of the finite verb, whose constitutive elements are transparent in the periphrastic participial structure (cf. Goldenberg, Verbal Structure, $153 \mathrm{ff}$.), and not to its syntagmatic and paradigmatic relations with the participle. 


\section{The Verb in Arabistic Literature}

\section{1} The Verbal System in Arabic and Semitic

Unlike the Arab grammarians, whose grammatical description of the Arabiyya was for the most part self-contained, betraying no interest in parallels found in the sister languages, Western scholars in the past two centuries have studied Classical Arabic as an exemplar-albeit prominent—of the overall Semitic bundle of languages. Consequently, their analysis of Arabic data usually involved some comparison, active or latent, to data found in other Semitic languages, as well as some assumptions as to the evolution of the Semitic system in general. As native speakers of modern European languages, also well-versed in the Greco-Latin tradition, Western scholars had a different set of categories and questions in mind than their Arab predecessors. We shall see below how all this shaped their view of the tense system, contributing to its becoming what Goldenberg has described as the 'weakest point in the Semitic verbal grammar.'

For Western scholars, the problem of the tenses in Semitic languages, and specifically in Arabic, has been essentially a problem of translation. As many of them admitted, even a partial correspondence between the tenses in Semitic and in Indo-European languages is hard to identify. ${ }^{2}$ This lack of correspondence resides first of all in the compactness of the Semitic system, which consists of a relatively small number of verbal forms. ${ }^{3}$ However, more acute is the problem of defining the meaning of these forms. As Reckendorf puts it: Wir sollen Verba finita begreifen, die zeitlos sind und zumal unsere Perfekta und Imperfekta zur Übersetzung verwenden, ohne dabei etwas Praeteritales zu denken. ${ }^{4}$ Obviously, the view that the verbal forms in Arabic are 'timeless' is radically different from the one held by the Arab grammarians (see above 2.2), and presents a genuine rethinking of the subject matter. This new view of the verbal system was affected by the Classical and European background of these scholars, as well as by the introduction of the historical-comparative method into Semitic linguistics in the nineteenth century.

1 Goldenberg, Amharic Tense System, 88.

2 E.g. Cohen, Système verbal, 14.

3 E.g. Brockelmann, Grundriss, 2, 144.

4 Reckendorf, Syntaktischen Verhältnisse, 1, $5^{2}$.

(C) MICHAL MARMORSTEIN, 2016 | DOI: 10.1163/9789004310483_004

This is an open access chapter distributed under the terms of the Creative Commons

Attribution-Noncommercial-Non-Derivative 3.0 Unported (CC-BY-NC-ND) License 
In his comparative grammar, Brockelmann approaches the problem of the tenses in Semitic languages by going back to its (pre-)historical roots. Following Bauer, he suggests that Proto-Semitic had only one verbal form, the prefixed $y$ aqtul, indifferent of time distinctions. Later on, a second form developed from the nominal clause, namely, the suffixed qatal-, which has come to indicate the 'present' in East-Semitic and the 'perfect' in West-Semitic. ${ }^{5}$ Indeed, this theory may explain the temporal indefiniteness characteristic to $y$-aqtul or the traces of a stative meaning of qatal- in various Semitic languages. However, a more significant point in this reconstruction is the idea that the verbal system in West-Semitic languages is built upon the opposition between two simple forms only: a prefixed one and a suffixed one.

As a matter of fact, the idea that the Semitic verbal system is based on a binary opposition was established long before Brockelmann. In Arabic linguistics, one can go back as far as de Sacy's grammar, who described two simple tenses in Arabic, a 'preterit' and an 'aorist'. ${ }^{6}$ A systematic analysis of the verbal system identifying a binary opposition between the suffixed and the prefixed verbal patterns was first presented by Ewald. In his textbook of Biblical Hebrew from 1870, Ewald explains the logic underlying his analysis in the following words: '[...] no language, when it introduces distinctions, can start from anything threefold; antithesis is almost always merely simple and thoroughgoing, because elicited by its [counter] thesis [...] Thus, both in thought and language, every distinction is at first drawn between no more than two things. ${ }^{7}$ According to this view - which has become a basic tenet in subsequent literature-an opposition between two forms (or sets of forms) is inherent to the Semitic verbal system. However, the attempts to define this semantic opposition have generated a long dispute among scholars, a dispute which by now 'fills a whole library'. In the following section, I will shortly review the various opinions as to the ultimate meaning of the verbal forms in Classical Arabic, specifically whether this meaning is regarded as primarily temporal or aspectual.

5 Brockelmann, Grundriss, 2, 145-146.

6 de Sacy, Grammaire arabe, 1, 148.

7 Ewald, Hebrew Syntax, 2. For a detailed discussion of the development of the terms 'perfect' and 'imperfect' in Semitic linguistics, see Goldenberg, Amharic Tense System, 88-94.

8 Sasse, Theory of Aspect, 210. 
In a rather simplified fashion, one could say that the dispute among Western scholars revolves around the question of whether the verbal system is basically tense-oriented or aspect-oriented. Indeed, most scholars do not preclude any of these (and other) semantic notions when listing the various uses of the verbal forms. Rather, it is the identification of the grundbedeutung, the underlying meaning from which all of these uses are derived, which spurs on the controversy.

While the concept of external or relative time was commonly employed by the Arab grammarians (see above 2.2), the concept of the internal time of the verbal situation penetrated Arabic linguistics only in the nineteenth century. ${ }^{9}$ In his Arabic grammar, Ewald was the first to introduce the pair of terms perfectum and imperfectum to account for the semantic distinction marked by the suffixed and the prefixed verbal patterns. ${ }^{10}$ In doing so, Ewald 'set right' the confusing terminology of the Arab grammarians who, according to Brockelmann, 'gave up logical correctness' by naming one pattern after its use (i.e. $m \bar{a} a \underline{d} \bar{\imath}$ 'past') and another after its form (i.e. muḍ̄aric 'resembling'). ${ }^{11}$ Rather than a temporal value, Ewald ascribed to the verbs meanings which would later on be referred to as aspectual. The terms perfect and imperfect became the conventional terms in the Western tradition for the two verbal patterns. It is noteworthy that a further distinction between these two patterns pointed out by Ewald, namely, the modal distinction between certum and incertum, was not maintained in the subsequent literature.

The category of aspect, as was generally defined in regard to Arabic (and Semitic in general), refers to the grammaticalized expression of the distinction between a completed situation and an incomplete situation, signified by the perfect-imperfect pair. Fleischer, for example, argued that a temporal definition of the verbal forms, such as suggested by de Sacy, obscures the 'real essence' of the two verbs, which mark the opposition between 'completion' and 'incompletion'.12 Reckendorf, too, described an opposition between a 'realized' situation and a situation 'in the process of realization' signaled by the Perfekt and Imperfekt. However, unlike Fleischer, Reckendorf does not regard

Although Sībawayhi speaks of a verbal situation which lamyanqați 'has not ceased' (Kitāb 1, 1), and of a situation which qad waqa'a wa-nqața'a 'has happened and ceased' (Kitāb 1, 73), these occasional comments hardly amount to a systematic theory of aspect.

10 Ewald, Grammatica critica, $112 \mathrm{ff}$.

11 Brockelmann, Grundriss, 2, 145.

12 Fleischer, Kleinere Schriften, 1, $95 \mathrm{ff}$. 
aspect as a pure concept: he recognizes the correlation between completion and anteriority as expressed by the perfect, and (like Ewald before) points out the relation between the aspectual meaning of both forms and their modal and textual functions. The perfect, accordingly, marks 'certainty' and is used to make statements; the imperfect refers to a non-realized situation and is used for descriptions. ${ }^{13}$ Such semantic relations are also identified by other scholars such as Wright, who lists the various temporal uses of the perfect and imperfect, ${ }^{14}$ or Brocklemann, who stresses the contrast between the 'stating' function of the perfect and the 'describing' function of the imperfect. ${ }^{15}$ Nonetheless, it is still the 'opposing aspects inherent in the perfect and the imperfect' which are considered to be fundamental to the verbal system as a whole. ${ }^{16}$

The theory of aspect in Semitic, and particularly in Arabic, was further developed by French scholars. In his monograph on the Semitic verbal system, Marcel Cohen presented a comprehensive analysis of the phenomenon of aspect in Semitic languages and its peculiar traits (compared to Greek or Slavic). ${ }^{17}$ Cohen's theory had great influence on later French Arabists, who endorsed the view that the accompli and the inaccompli in Arabic do not signify a subjective 'situated time', but have an objective aspectual value, such that correlates with certain temporal and modal distinctions. Thus, according to Gaudefroy-Demombynes and Blachère, when not affected by the context, the accompli and the inaccompli have an 'absolute' temporal value: the former is psychologically related to the idea of past, while the latter bears an analogy to the notion of the present or the future. ${ }^{18}$ David Cohen, in his study on the general category of verbal aspect, also identifies a fundamental oppostion of aspect between the two verbal forms in Classical Arabic. However, he defines (after Benveniste) two 'temporalizing' contexts, i.e., narrative and dialogue, in which the accompli and inaccompli acquire a specific temporal value. ${ }^{19}$ Fleisch, too, maintains that the opposition between the accompli and the inaccompli is

\footnotetext{
13 Reckendorf, Syntaktischen Verhältnisse, 1, $53 \mathrm{ff}$.

14 Wright, Grammar, 2, $1 \mathrm{ff}$.

15 Brockelmann, Arabische Grammatik, 118. Elsewhere, the functional distinction between 'stating' (konstatieren) and 'describing' (schildern) is regarded as a grammatical distinction between a 'constative' and a 'cursive' aspect, cf. Brockelmann, "Tempora", $139 \mathrm{ff}$. The latter terms were borrowed by Rundgren, in his studies of the Semitic aspect, and later on by Reuschel, in his study of tense and aspect in the Qurān (see Aspekt und Tempus, 24).

16 Fischer, Classical Arabic Grammar, 102.

17 Cohen, Système verbal.

18 Gaudefroy-Demombynes and Blachère, Grammaire de l'arabe, 246.

19 Cohen, L'aspect verbal, 84-85.
} 
in principle aspectual. However, he admits (like Reckendorf before) that while the accompli can indicate time in itself, when serving as the narrative tense, the inaccompli is never capable of indicating time in itself. ${ }^{20}$

The conclusion that the perfect, as opposed to the imperfect, embodies a temporal component, was arrived at in the Arabistic literature several times. Beeston, for instance, argues that the semantic opposition between the two verbal patterns lies in the value of their 'predicate element', which may be either dynamic or static. This opposition - though not strictly grammatical, but also lexical—is also defined by him as 'aspectual.'. ${ }^{21}$ According to Beeston, 'the only definitely time-marked verb [...] is the suffix set verb in cases where it has dynamic aspect, being then explicitly past'.22 Keeping with the same general idea, Götz, too, contends that a form like kataba, signaling 'retrospective', is marked for time-perspective, whereas a form like yaktubu has no temporal value, its 'relevance' lies solely in its lexeme. ${ }^{23}$

Although the theory of aspect became prevalent in the majority of grammatical descriptions, the tense-oriented approach was not discarded by all. Some one hundred and fifty years after de Sacy, it was Aartun who advocated anew the analysis of qatal-and yaqtul- as plain tense forms, the first marking 'preterit' the second marking 'non-preterit', 'present'. ${ }^{24} \mathrm{~A}$ more sophisticated analysis of the system, following the so-called 'noetic' model, was proposed by Denz. In this model, the verbal forms fit into a grid whose main coordinates are temporal; aspectual distinctions do not exist by themselves, but are logically entailed by the temporal ones. ${ }^{25} \mathrm{~A}$ similar analysis was advanced by Kuryłowicz, who determined a hierarchy of functions of the binary pair qatala-yaqtulu. The primary function of the first, which is the positive member in the opposition, is to indicate anteriority, while the primary function of the latter, which is the neuter-negative member, is to indicate non-anterior or simultaneous action. ${ }^{26}$ In a more recent study, Bahloul, too, employs the tool of markedness to account for the semantic opposition indicated by the perfect and imperfect. According to his analysis, the perfect embodies the positive features of '+anteriority' and

\footnotetext{
$20 \quad$ Fleisch, Verbe arabe, 177.

21 Beeston, Arabic Language, 76.

22 Ibid., 79.

23 Götz, Tempora, 96.

24 Aartun, Altarabischer Tempora.

25 Denz, Verbalsyntax, presents the noetic model in the introduction to his description of the dialect of Kwayriš. A short theoretical outline of this model is also presented in Denz, Tempus und Aspekt?.

26 Kuryłowicz, Studies in Semitic, 8 off.
} 
'+dimensionalization', whereas the imperfect embodies either the negative (-) or the neuter $( \pm)$ values of these features. ${ }^{27}$

The question as to the basic meaning of the suffixed and prefixed patterns in Classical Arabic continues to intrigue modern scholars. Most of them agree that both patterns indicate temporal and non-temporal meanings, however, the exact definition of these is yet a matter of dispute. ${ }^{28}$ It is noteworthy that Comrie's paragraph-long description of the tenses in Classical Arabic has gained currency is recent years, even among Arabists. Comrie cuts to the point by stating that, in addition to their aspectual values, the perfect and the imperfect also embody a component of relative time reference. ${ }^{29}$ Appealing as it is, such a compact analysis can hardly capture the complexity of the system. In fact, one may rightly doubt whether an abstraction at such level reflects at all a linguistic reality, thus whether it brings us any closer to understand the mechanism found in practice in Classical Arabic.

\subsection{Summary}

In this chapter, I have reviewed the ongoing dispute over the semantic opposition marked by the two basic verbal forms fa'ala and yaf'alu in the Arabistic literature. While the binary structure of the verbal system has been commonly accepted (and, in fact, regarded as self-evident), the scholars have been divided as to the basic semantic opposition marked by fa'ala and yaf'alu. We have seen that most scholars, while aiming at compact and clear-cut definitions, come to admit the differences between fa'ala and yaf'alu with respect to their having a temporal value. When applied to these forms, the terms 'perfect' and 'imperfect' turn thus to be misleading in more than one sense: not only do they stand for different meanings than those generally associated with them (considering

27 Bahloul, Arabic Verb, $140 \mathrm{ff}$.

28 Bubenik, Hewson, and Omari, Tense, Aspect and Aktionsart, outline a general model for the tense system of Arabic or better, the Arabic 'type' (Arabic, in this article, stands for all forms of the written and spoken language). The authors contend that 'the familiar morphological opposition katab-a versus $y a-k t u b$ - $u$ is best described by double temporo-aspectual labels past/Performative versus non-past/Imperfective' (45). Although the authors introduce some innovations, specifically the analysis of fa'ala as Performative rather than Perfective (the first fits into the cognitive scheme of 'ascending time', the latter into the scheme of 'descending time'), their study follows by and large the same basic conception of the verbal system as binary and non-symmetrical.

29 Comrie, Tense, 63. 
either the Slavic perfective and imperfective, or the perfect and imperfect in Romance languages), but also, they do not indicate a single functional opposition. While fa'ala is generally described as the complete-anterior form, most scholars have difficulty to capture the content of yaf'alu in positive terms, thus coming full circle to the 'illogical' asymmetry suggested by the Arab grammarians in the first place.

The ongoing controversy over the basic meaning of fa'ala and yaf'alu leads one to think that, while there are certain obvious tendencies, there is no one, basic, category that could crack the logic of the Arabic verbal system. The pursuit of a neat formal definition which will fit all the cases is bound to fail. At the synchronic level, the uses of both forms are too many and diverse; also from a historical perspective, it is hard (if not impossible) to trace the development of the verbs from a primitive state of simple oppositions. Rather, we can only approach a functional definition of the verbal forms by giving due consideration to the particular, concrete, contexts in which they are used. The following chapters are dedicated to a discussion of the structure of context and a close examination of the functions of the verbal forms in different contexts. 


\section{The Structure of Context}

\subsection{The Conceptualization of Context}

Linguistics in the twentieth century has been largely concerned with the fundamental question of defining language as an object of scientific observation in and of itself. This endeavor proceeded in two divergent paths, often referred to by contrasting pairs of terms such as: 'sentence-centered' vs. 'text-centered' theories, ' 'micro-linguistics' vs. 'sociolinguistics' or 'stylistics', 'a priori grammar attitude' vs. 'emergence of grammar attitude,' ${ }^{3}$ or simply 'formal linguistics' vs. 'functional linguistics.' Recalling the Saussurean program, we may say that the contrast reflected in this terminology lies in different understandings of the langue-parole dichotomy. ${ }^{5}$ However diverse (and even contradicting) general theories of language may be, ${ }^{6}$ it appears that all pursue the same basic question: what constitutes the linguistic system and to what degree should it be abstracted away from its actual instances? Put differently, to which extent should the contextualization or de-contextualization of linguistic data be carried out?

Context, as a pre-theoretical notion, is readily understood as the particular situation of communication in which a certain spoken or written text is produced. However, as far as its linguistic analysis is concerned, context is rightly

1 Petöfi, Beyond the Sentence.

2 Lyons, Semantics, 2, $585 \mathrm{ff}$.

3 Hopper, Emergent Grammar.

4 Dik, Functional Grammar, 2-3.

5 De Beaugrande, Text Linguistics, 168, neatly summarizes this problem in twentieth century linguistic theory: 'the toughest problems have stemmed from the assumption that a "language" has a quite different mode of organization than does "actual speech" (or texts), and from the corresponding aspiration to describe language independently of actual speech'.

6 Two radically different approaches are outlined, for instance, in the works of Chomsky and Firth. Chomsky, Aspects, 3-4, sets forth a clear-cut distinction between 'competence' and 'performance', of which only the first, in its 'perfect' and 'ideal' manifestation, is considered as a valid object for linguistic investigation. In contrast, Firth, Technique, presents a theory of language based entirely on the notion of context. As is often the case with extreme ideas, both theories (influential as they were) were severely challenged in the attempt to render them to actual practice.

(C) MICHAL MARMORSTEIN, 2016 | DOI: 10.1163/9789004310483_005

This is an open access chapter distributed under the terms of the Creative Commons

Attribution-Noncommercial-Non-Derivative 3.o Unported (CC-BY-NC-ND) License 
viewed as a 'lumpen mass' that is extremely hard to disentangle. ${ }^{7}$ Lyons provides a general definition of context as 'a theoretical construct, in the postulation of which the linguist abstracts from the actual situation and establishes as contextual all the factors which, by virtue of their influence upon the participants in the language-event, systematically determine the form, the appropriateness or the meaning of the utterances'. ${ }^{8}$ The point to be stressed in this definition, as Lyons himself admits, is that of systematicity. Indeed, the challenge in the analysis of context is to identify what Hymes (after Pike) has referred to as the 'emic' features, ${ }^{9}$ i.e., those features which are relevant to the production and interpretation of a specific instance of communication and which are further generalizable to a set of such communications. In other words, in defining context the linguist is confronted with the question of what are the discursive, textual, social, and cultural variables which correlate with the grammatical forms in a systematic and predictable manner and what are the local or contingent elements which defy any formalization so as to fit a generally valid linguistic account.

Both theoretical and descriptive linguists have always made ample use of context as an explanatory device, to refer to the cognitive, social, and textual background which affects the interpretation of a certain stretch of discourse. The cognitive and social aspects of context (context as 'knowledge' and 'situation', respectively) have been of interest to linguists working in the fields of pragmatics and sociolinguistics; some (notably conversation analysts) have regarded the sequential progression of interaction, i.e., the textual sequence, as essential to the notion of context. ${ }^{10}$ However, not many attempts have been made to accommodate context into the structure of the linguistic system. One comprehensive model of context as a linguistic construct was proposed by Halliday, in a number of works, and Hasan. ${ }^{11}$ Their model (in the various forms it assumed over the years) attempts to incorporate the 'interpersonal' or 'situational' and 'textual' components into the semantological and grammatical system of the language. Fleischman, too, proposed a multi-layered model of the linguistic system, in which the meanings of a grammatical form reside in the referential ('propositional'), pragmatic ('textual' and 'expressive') and 'metalin-

\footnotetext{
7 Cf. Brown and Yule, Discourse Analysis, $5^{0 .}$

8 Lyons, Semantics, 2, 572.

9 Hymes, Foundations, 11.

10 For a detailed review of the various approaches to context as 'knowledge', 'situation', and 'text', see Schiffrin, Approaches, $365-378$.

11 Halliday, Text as Semantic Choice; Halliday and Hasan, Cohesion, 26 ff.; Hasan, SystemicFunctional Model.
} 
guistic' levels. ${ }^{12}$ In a similar manner, Waugh presents a hierarchy of 'contextual meanings', which are categorized as 'pragmatic', 'textual', 'modal', 'discursive', 'expressive' and 'referential'.13 Both Fleischman and Waugh employ the tool of markedness in order to unpack the cluster of functions associated with the grammatical form, and to establish the correlation between form and function in a given situation of communication. Another comprehensive approach to language in context, stemming from the analysis of everyday conversations, was proposed by Schiffrin..$^{14}$ According to Schiffrin's model of discourse (or 'coherence in talk'), language as used comprises interactional and social dimensions such as 'exchange,' 'action' and 'participation', alongside 'ideational' and 'informational' dimensions. These dimensions are not autonomous, but rather interrelated components which come into play in each instance of discourse.

Naturally, every theory of con-text has at its background a certain text. ${ }^{15} \mathrm{~A}$ general model of context structure is to be viewed, therefore, as a grid or an elastic mold which can accommodate various kinds of texts. This grid may vary to a great extent with respect to the medium, style, and register in which a certain text is produced. Modern spoken texts allow for a delicate inspection, both at the phonetic or prosodic level and at the situational or interpersonal level, an inspection to which an ancient written document cannot be submitted. The themes and goals, as well as the discursive conventions and strategies, also differ to a great deal among such kinds of texts. Nevertheless, the postulation of a definable contextual matrix, within which semantogrammatical elements assume a certain function, appears to be universally valid for all texts.

The present work is concerned with classical written texts. Contextualization in this case is bound to have a more limited potential, especially as far as the (extra-linguistic) interactional dimensions are concerned. Yet, at the textual level, the overall contour will prove to be more solidly definable, due to the inherently structured nature of classical literary texts. Since context has a highly complex structure, its unpacking (as the above mentioned models suggest) can only be reached through a multi-layered analysis. In this work I will deal with some features of the discursive situation, mainly the deictic context,

\footnotetext{
12 Fleischman, Theory of Tense-Aspect.

13 Waugh, Tense-Aspect, 241-242.

14 Schiffrin, Discourse Markers, $24 \mathrm{ff}$.

15 Cf. Schiffrin, Approaches, 362 , commenting that 'contextual information is always information that is identified in relation to something else that is the primary focus of our attention $[\ldots]$ the identity of that "something else" (and what kind of sense we are trying to make of it) influences our decisions about what counts as context [...]'.
} 
as well as the structure of text, at the macro- and micro-syntactic levels. Lexical input will also be considered in this analysis, as one of the main factors which affect the distribution and interpretation of the verbal forms. In the succeeding sections, this cluster of features will be treated under the following five headings:
(a) Deictic reference
(b) Text types
(c) Interdependency
(d) Clause types
(e) Lexical classes

\subsection{Deictic Reference}

Reference, as intended here, is the relation between a linguistic expression and its referent, established with respect to the deictic center of discourse. The act of referring relates the linguistic sign to the personal sphere, i.e., it anchors it in the situation of the speaking/narrating subject. ${ }^{16}$

The deictic center determines the coordinates in relation to which the entire discourse is organized. It is sometimes regarded as the objective situation of speech, whereby the present moment and spot, as well as the roles of the speaker and hearer, are determined. ${ }^{17}$ However, the (typical) deictic center is better conceived of as the subjective situation of the speaker/narrator, located in a certain time and space, being in a certain mental disposition, and concerned with a certain topic. Tense, aspect (as distinct from Aktionsart or lexical aspect), and modality, as well as other subjective indices, are accordingly refer-

16 It is precisely the anchoring of the expression in the situation of the speaking (or narrating) subject which distinguishes reference from mere denotation. Cf. the definition of reference given by Lyons, Semantics, 1, 174, as 'the relationship which holds between an expression and what that expression stands for on particular occasions of its utterance'.

17 By 'objective' it is meant that the speech situation rather than the speaker's situation is considered to be the reference point. Comrie, Tense, 14, defines the most typical 'reference point' as the 'speech situation', which equally determines the time, space, and persons involved in it; the category of tense refers accordingly to the 'present moment' of speech. As a matter of fact, the orientational (time, space) as well as the mental (or modal) categories are not established in respect to the situation, as an objective locus, but in respect to the subjective position of the speaker. 
ential or deictic grammatical categories. The notions of 'absolute' and 'relative' tenses are therefore somewhat misleading: the former do not refer to an objective time-layer, but indicate a certain relation to the subjective situation of the speaking/narrating subject; the latter are referential to the first. The same tense form can refer either directly or indirectly to the deictic center. The type of reference is entailed by the form's syntactic status, i.e., by its being syntactically independent or dependent, as will be discussed in 4.4.

The deictic center changes according to the type of discourse or text. One can define three possible reference points: (a) the first person speaker or narrator, (b) the third person narrator, and (c) the third non-personal or generic person.

The first person is the pivot on which the entire situation of speech revolves. It is the deictic center, in respect to which temporal, spatial, and modal relationships are defined. The first person also determines inter-subjective relationships, in projecting its epistemic and affective stance on the second and third persons. The first person may also serve as the deictic center of narratives. Such personal experience narratives converge to some extent with personal reports that are embedded in dialogues. The problem of distinguishing between these two text types is addressed below in 4.3 .

The third person narrator is different from the third person in direct speech, since its identity is not determined in respect to the first person. The third person narrator marks a self-contained, self-anchored world, detached from the deictic situation of narration itself. The detachment from the concrete ('real') situation in which the story is told may provide the narrator with an omniscient epistemological position. ${ }^{18}$

The third non-personal or generic person is distinct from both the third person in direct speech and the third person narrator, as it is not anchored in any situation, either of speech or of narrative. As far as reference is concerned, the generic person has a privative value, i.e., it is non-referential. Being a deictic 'signal', the generic person has thus a unique function: it does not

18 According to Hamburger, Logic, 73-74, the definition of epic fiction rests upon the fact that 'it contains no real I-Origo, and secondly in that it therefore must contain fictive I-Origines, i.e., reference or orientational systems which epistemologically, and hence temporally, have nothing to do with a real I who experiences fiction in any way-in other words with the author or the reader'. 
relate linguistic 'symbols' to a particular situation of communication, but rather denies their relation to such one. ${ }^{19}$

Subjective anchoring, in the sense of reference to the speaking/narrating subject or its privation, as was discussed above, is not overlapping with the general notion of subjectivity. Subjectivity is omnipresent in language, whatever the referential point may be. ${ }^{20}$ The difference between discourse types in this regard lies in the extent and explicitness in which subjectivity comes into play. Direct speech is naturally imbued with subjectivity, traceable in nearly every segment. Subjectivity is also discerned in third person narratives ('epicfiction'), when the presence of the narrating subject, whom we are usually unconscious about, may become apparent through artful means. ${ }^{21}$ Subjectivity is sometimes expressed in generic utterances, albeit in an implicit and restricted fashion. Due to the inherently non-anchored nature of generic utterances, markers of subjectivity (e.g. focus particles) which otherwise indicate a specific relation to the situation of discourse (e.g., to the speaker's stance), are somewhat fossilized, as part of the 'fixation' of the utterance as a whole (see also below 11.3). The following table summarizes the discussion on the three reference points:

TABLE 4.1 Three reference points

Deictic center Type of reference

first person speaker/narrator

explicit subjectivity, personal, external to text third person narrator implicit subjectivity, personal, internal to text third generic person implicit subjectivity, non-personal

19 Bühler, Theory of Language, introduced the distinction between 'symbols' and 'signals' to account for the distinction between linguistic signs whose function is to 'represent' and linguistic signs which are used to 'appeal', the latter are compared with traffic signs.

20 In his much-quoted article on this topic, Benveniste, Subjectivity, 225, says: 'Language is possible only because each speaker sets himself up as a subject by referring to himself as $I$ in his discourse'. His further observation is even more firmly stated: 'Language is marked so deeply by the expression of subjectivity that one might ask if it could still function and be called language if it were constructed otherwise'.

21 This includes both explicit intrusions of the narrator in the stream of narration, such as by addressing his audience, or implicit intrusions, using, for instance, the 'free indirect style'. I agree with Hamburger, Logic, $155^{-156}$, that such intrusions do not disrupt the illusion of fiction, by reflecting real genuine direct speech, rather, they are poetic devices by which 'narrative function [is] turned upon itself'. 


\subsection{Text Types}

The notion of text, as worked out by linguists, has emerged by contradistinction to the notion of the sentence. ${ }^{22} \mathrm{~A}$ text is not just a sentence cluster but, as Halliday and Hasan define it, 'a unit of language in use' which forms a meaningful 'unified whole. ${ }^{23}$ The text is that through which language is produced and that through which it is made accessible to observation. The text is a 'communicative process': it gains meaning only in a particular context of communication. ${ }^{24}$ Thus, in a more technical way, the text is defined as 'a unit of situational-semantic organization: a continuum of meaning-in-context, constructed around the semantic relation of cohesion. ${ }^{25}$

The text is realized through structural units such as paragraphs, complex sentences, and simple clauses, which constitute its hierarchical structure. These are not self-contained units, but rather segments which are interlocked in one another by many and diverse grammatical and semantic devices, e.g.: connectives and focus particles, pronouns and pro-verbs, agreement and consecutive markers, introduction and closure expressions, etc. The discourse strategies of ellipsis and repetition are also means to indicate the cohesiveness of units in the text. At a higher level, a particular thematic or argumentative organization of a text segment marks its internal structural unity, its 'uniform orientation', and gives rise to the specific identity of the text as a whole. ${ }^{26}$ Even the simplest clause in a text betrays its inclusion in a higher level of the overall structure, by virtue of these cohesive elements. A simple clause within a text, a 'text-sentence' in Lyon's terminology, presents therefore a different structure than that of a simple decontextualized or idealized 'system-sentence'. This is not to say that a simple clause cannot constitute a complete text in itself. In real language use, to be distinguished from abstractions made by linguists, clause units which constitute coherent text units do exist, for instance, in the form of generic propositions.

The typology of texts which will be outlined here is based on two parameters: (a) the reference point and (b) the overall cohesive structure of the text.

22 linguistic unit of text relative to that of the sentence.

23

24

25

26 Halliday and Hasan, Cohesion, 1-2.

Oomen, Texts and Sentences, 272.

Halliday and Hasan, Cohesion, 25.

Cf. the many contributions in Petöfi, Text vs. Sentence, dedicated to the definition of the

Hinds (following Grimes, Thread of Discourse, $102 \mathrm{ff}$.) defines paragraph as 'a unit of speech or writing that maintains a uniform orientation', Organizational Patterns, 136. This uniformity may be of space, time, theme, or participants. 
Each type of text is associated with a certain reference point and is realized through a certain 'organizational pattern'. ${ }^{27}$ The basic distinction is drawn here between the dialogue, the narrative, and the generic utterance. Obviously, this distinction is far from being exhaustive; it rises from the analysis of the particular body of texts studied in the present work. This taxonomy corresponds in part to the one of reference outlined above; the difference lies in the fact that the first person is not exclusive to a single text type, but has a double association with both the dialogue and the narrative.

The reference point determines the distribution of an array of syntactic features by which a text type is structurally defined. ${ }^{28}$ Perhaps the most prominent of these features, that has been discussed at length by linguists, is the different distribution and function of verbal forms in the dialogue and the narrative. ${ }^{29}$ The dialogue is the domain of forms marked for 'current relevance' (e.g. perfect) whereas the epic narrative is the domain of the 'historical' forms (e.g. simple past). This distinction is entailed by the direct involvement of the speaking subject in the first case and by its total detachment from the latter. In the same vein, markers of subjectivity abound in dialogues while in third person narratives, and even more so in generic utterances, they are expressed only implicitly.

Besides their reference point, text types are distinct from each other in their overall cohesive structure or texture. Without delving into the enormous literature on narratives and dialogues, we can yet point at some significant structural differences between these two text types:

27 Hinds, Organizational Patterns, demonstrates how various discourse types, e.g., 'procedural', 'expository' or 'conversational', assume their particular identity through a different linear and hierarchical organization of their constitutive segments.

28 Cf. Cohen, Tense-Aspect, for the characterization of the dialogue and the narrative textemes in the Old Babylonian epic, in view of a cluster of syntactic features, e.g.: personal sphere, modality, the information structure of the clause, and forms of verbal and nonverbal predication.

29 In the attempt to explain 'otherwise puzzling gaps and asymmetries' (Lyons, Deixis and Subjectivity, 117) in the tense system of European languages, linguists such as Benveniste, Weinrich, and Lyons have all resorted to a basic distinction between two essentially different discourse types or modes: 'history' and 'discourse' (Benveniste, Correlations of Tense), Erzählen and Beschprechen (Weinrich, Tempus) or 'historic' and 'experiental' mode of description (Lyons, Semantics, 2, 688; Lyons, Deixis and Subjectivity). One should note, however, that the overall approach of each of these writers to the problem is considerably different. 
(a) The dialogue is structured as an exchange of relatively short and segmented stretches of discourse. The narrative, by contrast, exhibits an organized, relatively longer, sequence of interrelated events.

(b) The dialogue is co-constructed by a speaker and an addressee. The narrative is transmitted through a single channel (even if polyphonic) at a time. ${ }^{30}$

(c) The dynamics of dialogues is that of stimulus-and-response. ${ }^{31}$ The dialogue proceeds in exchange pairs, some of which are intrinsically related, e.g., adjacency pairs such as: greeting-greeting, question-answer, offeracceptance/refusal, etc. ${ }^{32}$ Narratives, on the other hand, are the medium by which situations and experiences are (chrono)logically shaped so as to be comprehended and further communicated.

(d) The dialogue is strongly anchored in the here-and-now of the interlocutors, while the narrative is characterized by being spatiotemporally distant from the situation of narration. ${ }^{33}$

(e) The dialogue reflects the information transmitted while the narrative describes it. ${ }^{34}$

Not only from a literary but also from a linguistic point of view, the category of narratives is notoriously hard to define. For one thing, narratives display a complex structure, consisting of (at least) two subunits or modes: the 'evolution mode', through which the plot is unfolded, and the 'comment mode', through which descriptions, evaluations, and other amplifications of the plot are transmitted. ${ }^{35}$ Another intricate issue concerns the discursive sphere to which the narrative belongs. It appears that such a restriction of the narrative either to the 'fictive' or 'unreal' sphere or to the 'factual' or 'historical' sphere is unten-

30 In literary works, a common device by which polyphony is expressed is through 'free indirect style'. Polyphony, however, is most pervasive in ordinary conversations. In her study of conversational discourse, Tannen, Talking Voices, $99 \mathrm{ff}$., follows Voloshinov and Bakhtin in arguing that in dialogues the speech of others is not merely reported; rather, it is (re-)constructed in a new context while keeping the traces of the prior text from which it is derived.

31 Shisha-Halevy, Topics, $138 \mathrm{ff}$., defines this dynamics more specifically as the alternation of two subsystems: the 'allocutive' and the 'responsive'.

32 Cf. Schegloff and Sacks, Opening up Closings, $295 \mathrm{ff}$.

33 Toolan, Narrative, 1.

34 Ibid. 3 .

35 For the distinction between the 'evolution mode' and the 'comment mode' in the narrative see Shisha-Halevy, Topics, $34 \mathrm{ff}$. 
able. ${ }^{36}$ The narrative is a linguistic device that may be exploited in various ways. The important factor is the position assumed by the narrator, and more specifically, to what extent he is involved in the narrative. As is well known, stories are not only related by an impersonal narrator, but quite often by a personal 'I', whether imaginary or real. From a grammatical point of view, it seems best to keep with the distinction between first person narratives and third person narratives: the first are characterized by an internal narrating voice and an external reference point (which results in a double point of view), while the latter are inversely characterized by an external narrating voice and an internal reference point. Thus, the first person narrator has a privileged position: he is not just an observer, but an actor and evaluator of the dramatic events. In contrast, the third person narrator is not agentive but only instrumental. Not only the stream of events, but also the characters' evaluations and reflections are channeled through him.

The major distinction between dialogues and narratives can be further refined if one considers other textual structures which assume an intermediate position between these two types. One such subtype is the report. Similar to the narrative, the report has a linear organization and it proceeds as an account of interrelated events. Unlike the narrative, the report is strictly informative and does not have an evaluative function. ${ }^{37}$ It lacks (or makes only minor use of) dramatic or fictionalizing devices which characterize the narrative, e.g.: suspensions, repetitions, shifts in focalization and voice, etc. Moreover, the report has current relevance: it is anchored in the here-and-now of the reporter and presents a topic in a more economic and straightforward fashion than one would expect to find in a proper narrative. Formally, the distinction between narratives and reports may be approached by the examination of the relative frequency and syntactic distribution of grammatical indices of either 'dramaticity' (e.g. presentative particles) or 'actuality' (e.g. perfect forms).

Besides the dialogue and the narrative there exists a third type of text which is sometimes subsumed under the more general type of expository discourse. Here this type of text is referred to as the generic utterance, with the

36 A rather restrictive view of the narrative is proposed by Hamburger, Logic, who identifies proper fiction with the third person and the 'fictive', non-historical time only. Benveniste, Correlations of Tense, 206, on the other hand, defines the 'historical' utterance as the 'narration of past events'. Genette, Fictional/Factual, in examining the question of whether there exists a genuine difference between factual and fictional narrative, arrives at the conclusion that both types of narrative can approach one another by means of fictionalizing or de-fictionalizing, respectively.

In the words of Fleischman, Tense and Narrativity, 103, the report does not 'make a point'. 
intention to emphasize that property which is viewed as its hallmark, namely, the reference to the generic person, or inversely put, the non-referentiality to the personal sphere. The generic utterance is not anchored in the situation in which it is pronounced, nor does it mark internal deixis like the third person narrator. The generic utterance is not bound to a certain context of situation, therefore it can be infinitely reproduced without any change or adaptation. Generic utterances are usually self-contained propositions, often taking the form of topicalized clauses (see below 4.5).

It is important to stress the distinction (which is not always carried out) between text types as structural units, and speech situations as the communicative events in which they are put to use. In an ordinary conversation, a public address, or a literary work, dialogues, narratives, and generic utterances are not isolated from each other but constantly interwoven in one another. Literary dialogues may be conceived of as yet another mode of narrative transmitting ('narrative' in the sense of the pre-shaped story material). ${ }^{38}$ Everyday conversations naturally abound with storytelling sequences. Narratives may be embedded in expository texts, explicating and illustrating a certain topic, while generic utterances are often introduced into dialogues to support and reinforce a particular statement. It is important to keep in mind, however, that as far as their structural identity is concerned, these text types are nevertheless distinct from each another: each is associated with a different reference point and each exhibits a particular organizational pattern. The table below summarizes the discussion of the three text types:

TABLE 4.2 Three text types

Text type Reference point Cohesive structure

dialogue first person speaker exchange pairs, short and segmented

narrative

first person narrator

third person narrator

chains, sequences of events

generic utterance third generic person self-contained propositions

38 Thus, according to Hamburger, Logic, 179: 'the narrative act is a formative, shaping function, of which one can just as well say that it is set beside other shaping functions such as dialogue, monologue, and erlebte Rede, as one can also say-indeed, more preciselythat, fluctuating, it assumes now this, now that form'. For the distinction between the 'narrative text' and the 'story' levels, see Bal, Narratology. 


\subsection{Interdependency}

Within a text, clauses are interdependent in various degrees and forms. Interdependency is a syntactic phenomenon correlating with a set of semantological relations, which construct the hierarchical structure of the text. ${ }^{39}$ The typical patterns in which interdependency is realized endow the text with a particular 'juncture contour', thus differentiating between narration, commentary, direct speech, exposition, and subtypes or modes thereof. ${ }^{40}$

The traditional dichotomy between coordination and subordination has been reckoned by many modern linguists as insufficient in accounting for all the configurations subsumed under the notion of clause linkage. Two main issues were given the most attention in this regard: (a) the definition of subordination and (b) the correlation between syntactic dependency and the functional distinction between foreground or background. The first issue was dealt with in the frame of universal typologies of clause linkage. The second issue was discussed in relation to narrative discourse and the functional or cognitive aspects of the text.

General linguists have rejected in the last decades the dichotomous model of coordination versus subordination. Rather than mapping clauses into one of these categories, a set of grammatical parameters has been proposed, in respect to which the grade or 'strength' of the linkage between two clauses can be determined. The models that have been proposed are either combinatory or scalar. Van Valin derives his typology from the primitive features which define linkage relations, i.e., embeddedness and dependency. Thus, besides coordination and subordination there exists a third intermediate configuration, 'cosubordination', which realizes the features '-embedded' '+dependent'. ${ }^{41} \mathrm{Hai}$ man and Thompson also propose a set of formal properties or processes by which the distinction between coordination and subordination can be defined, e.g.: identity of subject, tense or mood, reduction, incorporation, intonational

39 Halliday, Functional Grammar, 216 ff., discusses two dimensions of inter-clausal relations, i.e., a 'syntactic' one and a 'logico-semantic' one; Matthiessen and Thompson, Discourse and Subordination, discuss the correlation between clause combining and the rhetorical organization of texts.

40 The notion of 'juncture contour' is defined by Shisha-Halevy, Topics, 478 , as 'distinctive linkage and delimitation profile over boundaries inside a specific domain frame'. Juncture, according to this view, is a much broader phenomenon than that of clause-linkage; it is reflected 'from the graphemic level to longer stretches of text'.

41 Van Valin, Syntactic Relations. 
linking, order of clauses, and identity of speech act perspective. ${ }^{42}$ Lehmann, in a comprehensive study on clause linkage in the languages of the world, bases his typology on a number of continua, all extending 'from a pole of maximal elaboration to a pole of maximal compression (or condensation) of lexical and grammatical information. ${ }^{43}$ Lehmann's continua refer to the syntactic level and sententiality of the subordinate clause, the grammaticalization of the main predicate, the interlacing of actants and the explicitness of the linkage between the two clauses. In a similar manner, Raible's monograph (drawing on Seiler's universal theory of language dimensions) outlines a scale of 'junction', ranging between the two ends of 'aggregation' and 'integration'. According to Raible, a fundamental aspect of the distinction between parataxis and hypotaxis resides in the locus of assertion: in the first case, two states of affairs are separately asserted, while in the latter case it is the relation between them that is asserted. ${ }^{44}$ Raible also accounts for the distinction between junction patterns at the pragmatic level. Thus, aggregation is characterized as more open and complex while integration is less open and more simple to interpret. $^{45}$

All these models attempt to redefine the concept of subordination by drawing a distinction between what was previously conceived of as two overlapping notions, namely, hypotaxis and embedding. Hypotaxis is accordingly understood as 'subordination of a clause in the narrow sense', or as the non-symmetrical relation between two clauses of unequal status (as opposed to parataxis). ${ }^{46}$ Embedding, on the other hand, refers to the mechanism by which a clause comes to function as a constituent within another clause. ${ }^{47}$ Thus, hypotaxis is a type of subordination which involves dependency while embedding is a type of subordination which results in constituency. Subordinate clauses which are not considered to form part of the predicative core of the clause, e.g. adverbial clauses, are accordingly described as hypotactic, while other types of clauses, such as substantival or adjectival clauses which occupy the position of a core argument (the subject or the object), are described as embedded.

Recent treatments of the topic of adverbial, and particularly, circumstantial clauses in Classical Arabic have addressed the problem of the syntactic status

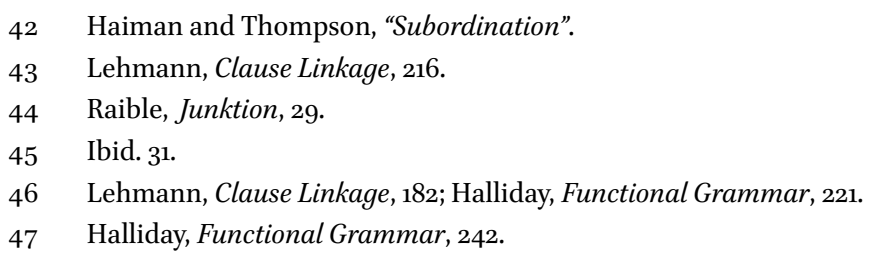


of the clause. Some writers, like Isaksson, adopt the distinction outlined above between hypotaxis and embedding, viewing circumstantial clauses as dependent but not embedded. ${ }^{48}$ Isaksson's approach follows from both formal and semantic considerations, however the latter appear to play a more significant role: following Halliday, Isaksson correlates between the 'enhancing' function of the clause and its syntactic status. Other writers, like Waltisberg, do not maintain the same distinction between hypotaxis and embedding. Considering a set of formal criteria, Waltisberg outlines a scale according to which the degree of dependency of the clause (e.g. 'weak', 'clear', 'strong') can be qualified. ${ }^{49}$ The main criterion which determines the scalar ordering is the linking device of the clause, specifically whether it is explicit, i.e. syndetic, or implicit, i.e. asyndetic.

Waltisberg refers to a fairly large number of clause patterns in his 'integration scale'. Though one may argue against the relative ordering of some of these patterns, the general principle still seems correct. ${ }^{50}$ Rather than forcing a binary distinction on all clause patterns, which is often simply derived from an a-priori taxonomy of coordinating and subordinating conjunctions, one can arrive at a more accurate characterization by examining a set of formal features through which the grade of interdependency is reflected. The following are the features considered in this work:

(a) Juncture contour. As stated above, text types are different in their juncture contour: narratives are constructed as sequenced and complex chains of units, while dialogic utterances are characterized by what Givón has described as 'paratactic strategies of clause juxtaposition', resulting in a segmented and often fragmented structure of discrete units. ${ }^{51}$

(b) Position of the clause in the chain. In Classical Arabic, main clauses occur in the initial position of a chain whereas dependent clauses occur in subsequent positions. One exception to this rule is the case of bipartite constructions (e.g. conditionals), whereby a seemingly dependent clause precedes its main clause. As a matter of fact, in such cases the inverted order is used to indicate a special type of interdependency, a mutual

\footnotetext{
48 Isaksson, Circumstantial Qualifiers, 2-4.

49 Waltisberg, Satzkomplex, 69-81.

$50 \quad$ Marmorstein, Review of Waltisberg, 370-372.

51 Givón, Syntax, 2, 218. The characterization as segmented and fragmented applies to the structure of single propositions; it does not apply to the dialogue exchange itself, which proceeds in a systematic sequence of 'turns', 'pairs' or 'allocutions and responses', see above 4.3 .
} 
dependency between two parts of one and the same construction (see also below 8.4).52

(c) Symmetry of the verbal syntagm. The syntactic relation between an initial and a subsequent slot in the chain may be either symmetrical or non-symmetrical. Symmetrical relations are marked by the repetition of the same verbal syntagm or by the introduction of a syntagm that has the same syntactic status. By 'verbal syntagm' I mean the clause type, the linking device preceding it, and the verbal form realized in it. Symmetrical relations are exhibited, for instance, in a narrative chain, where the clause type ('verbal clause'), the paradigm of linking devices ('connective particles'), and the verbal form ( fa'ala) are reproduced in each link..$^{53}$ The symmetrical relation is maintained as long as the same verbal syntagm is repeated. Symmetry is broken once the chain presents a switch to another verbal syntagm. Asymmetrical relations are harder to discern when the verbal form is repeated but not the linking device, as in the sequence \#yaf'alu $\varnothing$-yaf'alu (\#, representing initiality, belongs to a different class of devices than $\varnothing$, representing asyndesis, see below 6.1.2).

(d) Substitution class of the verbal form. As Goldenberg defines it, 'embedding' refers to the operation whereby a sentence occupies 'the position of a part of another sentence' in such way that it 'assumes the status of some linguistic form, thus syntactically equivalent of some morphological category'54 Such an understanding of syntactic subordination goes back to the Arabic grammatical tradition, in which embedded clauses are conceived as 'paraphrases' of the simple nouns whose position in the clause they occupy. ${ }^{55}$ Embedding is thus strongly connected with the structural notion of paradigm, i.e., the set of grammatical patterns which forms a substitution class in a given syntactic environment (see above 1.3.1).

According to Waltisberg, Satzkomplex, 75-77, such structures exhibit a lower grade of integration between a 'fronted' dependent clause and the following matrix clause. In my view, it is not a matter of grade but of kind of interdependency: this order shows that the construction is exocentric: neither clause is a modification of the other and neither can be reduced without giving up the meaning of the entire construction.

I use the term 'symmetrical relations' to refer to the equal syntactic status of two successive clauses; it is not to be inferred that, within a given sequence, the order of these clauses is reversible.

Goldenberg, Contribution of Semitic Languages, 2.

Ibid. 
Some modern linguists, such as Matthiessen and Thompson, have argued against substitution as a test by which embedding of certain clauses can be demonstrated. The fact that adverbial clauses (e.g. 'before leaving') can be replaced by nominalizations (e.g. 'before his departure'), but not by ordinary nouns, shows that the substitution (or paraphrase) in this case is only a 'metaphor.' ${ }^{6}$ Substitution is also not as pertinent in scalar models of clause linkage, whose main focus is the particularities of each clause (which determine its relative position on the scale) and not the paradigmatic relations between different types of clauses.

It appears, however, that a comprehensive account of dependency relations cannot dispense with the dimension of paradigmatics. It is correct that different clause types show different grades of syntagmatic interdependency. For instance, the predicative participle is more integrated with its main clause than a finite verb such as yaf'alu, due to its degradation in finiteness. Yet, the participle commutes with yaf'alu in the same syntactic environments (see below chapter 8). Commutation is understood here as a syntactic operation rather than a semantic process of paraphrasing. Naturally, a certain amount of information is lost when replacing a more finite form with a less finite form, yet the same syntactic relation with the matrix clause is maintained in both cases. The important thing in this regard is that both forms (whether finite or degraded) are associated with the same syntactic configurations and occupy the same functional slot.

\subsection{Clause Types}

Moving one further step down in the hierarchical structure of the text, the simple clause is the immediate frame in which the verbal form is realized. The verbal form is a minimal clause in itself, consisting of a verbal lexeme, a pronominal theme, and the predicative relation between them. ${ }^{57}$ The simple clause is an extended pattern, including also a slot for the explicit (overt) nominal theme or topic. The relation between the verb and its explicit theme is marked by the position of the latter relative to the verb, and its agreement with it.

Classical Arabic distinguishes between two basic clause types in which the predicate is (or may be) verbal: the so-called ğumla filiyya 'verbal clause' and

$56 \quad$ Matthiessen and Thompson, Discourse and Subordination, 280.

57 Goldenberg, Verbal Structure, 173 . 
the grumla ismiyya 'nominal clause'. The distinction between these two types of clauses was first defined by the Arab grammarians. The verbal clause consists of a $f_{i} l$ 'verb' followed by a $f a \bar{c}$ il 'agent'. The initial verb (in the third person) does not agree in number and possibly in gender with its agent. The nominal clause consists of a mubtada' 'subject' and a habar 'predicate', which may be either nominal, adverbial, or verbal. The verbal predicate agrees in number as in gender with its subject. The Arab grammarians distinguished between the nominal theme of the verbal clause, which they perceived as merely 'indexal' ('alamma) and the nominal theme of the nominal clause, which they perceived as pronominal (ism).58

The formal distinction in the relative order of the verb and its theme and in their agreement marks a functional distinction between the two clause types. The verbal clause may be described as a 'block predication', centered on the event expressed by the verb. The nominal clause, consisting of a topical nounphrase to which a verbal predicate is assigned, may be described as 'entityoriented. 59

The choice of a clause type correlates on the one hand with the verbal form realized in it, and on the other, with the text type or mode in which the clause is realized. In verbal clauses expressing narrative events facala forms prevail, while yaf'alu forms are more common in nominal clauses, which are characteristic of expository or descriptive texts. ${ }^{60}$ Khan regards the aspect of the verb as the 'operative factor' behind this distribution. ${ }^{61}$ However, his use of the terms 'perfect' and 'imperfect' seems not to imply what is generally meant by this terminological pair in Arabic linguistics, namely, the opposition between 'complete' and 'incomplete', but it refers to the distinction between 'dynamic' and 'static' modes of depicting a situation, as suggested, e.g., by Beeston. ${ }^{62}$ The table below summarizes the outlined distinctions between the verbal clause and the nominal clause:

$5^{8} \quad$ For a detailed account of the distinction between the verbal clause and the nominal clause according to the Arabic grammatical tradition, see Levin, Nominal and Verbal Sentences.

59 Cf. Goldenberg, Verbal Agreement, for the functional distinction between verb-initial sentences and topicalizations in Arabic, and Holes, Modern Arabic, 251-253, for a similar distinction between 'event-oriented' and 'entity-oriented' clauses.

6o This observation is outlined by Khan, Studies, $30-31$, and further elaborated by Holes, Modern Arabic, 251-253.

61 Khan, Studies, 30-31.

62 Beeston, Arabic Language, 76-79. 
TABLE 4.3 The verbal clause vs. the nominal clause

Clause type Formal structure Verbal form Text type/mode

\begin{tabular}{llll}
\hline verbal & {$[$ verb+theme $]$} & fáala & narrative \\
nominal & {$[$ topic $]+[$ verb $]$} & yaf'alu & expository, descriptive \\
\hline
\end{tabular}

\subsection{Lexical Classes}

A verbal lexeme represents a certain conceptualization of an experience or a state of affairs in the real world. The semantic nature and structure of this conceptualization are both described in the literature as 'aspectual'. The aspectual nature of a verbal lexeme (referred to by many names, among which Aktionsart is still very common) is not conceived by modern linguists as necessarily ontological or categorial, but as a potential set of properties (or constraints) which allows for a certain construal of a specific verb, and which distinguishes classes of verbs in general. ${ }^{63}$

The traditional distinction which underlies the study of aspect is drawn between grammatical aspect, encoded by morphological inflection and indicating the subjective viewpoint of the speaker regarding the verbal situation, and lexical aspect, expressed by lexical derivation and reflecting intrinsic properties of the verbal lexeme. This dichotomy has given rise to an enormous body of literature in the past decades, in which the semantic essence and the grammatical scope of that which has been neutrally termed 'ASPECT' is constantly debated and redefined. ${ }^{64}$ However, as Sasse points out, a major point of consensus among linguists is that any theory of aspect is fundamentally concerned with 'the modeling of the linguistic encoding of situations with respect to their boundaries'.65 Indeed, such semantic features as durativity and telicity, stativity and dynamicity, as well as inception, progression,

63 Cf. Dahl, Tense and Aspect, 26-27; Rothstein, Structuring Events, 4, argues that lexical classes are 'sets of constraints on how the grammar allows us to individuate events'; Croft, Verbs, § 2.2.1, argues against Vendler's use of the term 'senses' to refer to what are in fact alternative 'aspectual types or construals' which a certain verb may possess.

64 In his extensive review of the current literature on the subject of aspect, Sasse, Theory of Aspect, uses the notations ASPECT ${ }_{1}$ and ASPECT 2 to refer to the two dimensions of grammatical and lexical aspect, respectively.

65 Ibid., 201. 
and completion, refer all to some kind of boundary defining. The distinction between perfectivity and imperfectivity, which has originated in Classical and Slavic linguistics, also relates to the notion of external and internal bounding, as corresponding to a certain morphological—rather than lexical or syntacticmarking system.

The fact that there exist some clear correlations between grammatical and lexical aspects (e.g.: perfective and telic, imperfective and atelic), alongside the absence of explicit morphological marking of grammatical aspect in many languages (e.g. Germanic, and notably English), has led some theoretical and general linguists to question and, in fact, dispense with the distinction between grammatical and lexical aspect altogether, proposing instead a unidimensional approach to aspect. ${ }^{66}$ Rather than a property of the verbal form or lexeme, aspect is viewed as a global property of the clause, brought about by a delicate interplay between the verb, its arguments, and complements. Such an approach to aspect has indeed much more to it. However, there is one level of analysis, namely, the text level, at which the distinction between grammatical and lexical aspect appears to be yet relevant and evident. Distinct text types have a different effect on situation types, so that a possible construal of the verb in one form of discourse may become irrelevant in another. For instance, the distinction between 'states' and 'activities' which, depending on the grammatical form of the verb, entails various temporal and modal nuances in direct speech, is by and large neutralized in a narrative chain, in which events or scenes are framed (bounded) and placed in a sequence, regardless of their inherent semantic constituency. Such observations and others have long been made by linguists stressing the inherent relation between discourse structure or 'taxis' (i.e., the cohesive ordering of two chronologically-related events) and the grammatical aspect of the verb (i.e., perfective vs. imperfective), even going on to suggest that the former is the ultimate signifié of the latter. ${ }^{67}$

Another dimension of lexical classes, which for some reason is fairly marginal in discussions of verbal aspect (though quite central in the literature on clause linkage) has to do with the informativity of the verbal lexeme. Naturally, every verb in the lexicon imparts knowledge about a certain experience, or bet-

\footnotetext{
66 Sasse, Theory of Aspect.

67 According to Jakobson, Shifters, 135, the category of taxis 'characterizes the narrated event in relation to another narrated event and without reference to the speech event'. Tactic relations such as simultaneity, anteriority, interruption, etc. are indicated by a particular combination of perfective and imperfective forms in the narrative. Hopper, Aspect and Foregrounding, 239, suggests that grounding may well explain the existence of elaborate tense-aspect systems in some languages.
} 
ter, apprehension of experience, in the world. However, not all verbs are equal in terms of the extent of their 'informational load'. Informativity is inherently related to the transitivity of the verb-phrase. Transitivity, as defined by Hopper and Thompson, is a complex phenomenon, involving a number of semantic and grammatical properties of the verb-phrase which correlate so as to express a higher or lower degree of 'effectiveness' with which the action is carried over from one participant to the other. ${ }^{68}$ The higher the verb is on the scale of transitivity, the more informative it is; that is, it provides a more specific and elaborated depiction of the situation. At the discourse level, verbs with a higher informative value are likely to form the pivot of the communicated message, while verbs with a lower informative value often fulfill the function of amplifiers or modifiers. The lexicon often comprises a class of descriptive or 'phase' verbs (e.g.: 'to start', 'to continue', 'to stop') whose dedicated function is to modify other events. Other groups of verbs, though higher on the scale of transitivity and informativity, may also assume a modifying function. Such groups include, e.g., motion and setting verbs and speech verbs (see below chapter 8).

\subsection{Summary}

In this chapter, I have proposed a model of context structure which includes the relevant discursive, syntactic, and lexical features that interact in a systematic and predictable manner with the verbal form. The proposed contextual structure comprises five components: deictic reference, text and texture, macro-syntax (clause linkage), micro-syntax (clause type), and lexical classes. In the subsequent chapters, the interaction between the contextual structure and the verbal forms in Classical Arabic will be examined in greater detail.

68 Hopper and Thompson, Transitivity. 


\section{The Verbal Inventory}

\subsection{Inventory of Forms}

The verbal system of Classical Arabic comprises a small number of simple verbal forms. The simple forms can be further augmented by modifiers or expanded by the auxiliary verb kāna. The morphological classification to simple, modified, and compound verbs does not reflect a functional hierarchy of more fundamental and more marginal forms; in a given syntactic environment, a modified or a compound form may prevail.

The opposition between a simple form and a modified or compound form can be either (a) functional, so that a semantic distinction is expressed by the simple and the non-simple form or (b) structural, so that the simple form is unmarked or ambiguous vis-à-vis the modified or compound form. The interpretation of the verbal form is sometimes imposed by the syntactic construction in which it is realized. In such case, the contrast between the simple and the non-simple form has to do with a certain (c) accentuation: the non-simple form provides an explicit expression to the meaning implied by the syntactic construction. Comparing, for instance, the simple yaf'alu and the modified $s a$ yaf'alu, we encounter these three possibilities (see also below 5.2.2.3):

$\begin{array}{llll}\text { a. yasma'u } & \text { He hears } & \text { sa-yasmáu } & \text { He will hear } \\ \text { b. yaqūlu } & \text { He says/will say } & \text { sa-yaqūlu } & \text { He will say } \\ \text { c. 'in dahala fa-yarāā } & \text { If he goes in he will see } & \text { 'in dahalafa-sa-yarāa } & \text { If he goes in he will see }\end{array}$

The verbal system of Classical Arabic presents a distinction in the desinence of the prefixed forms which is often captured under the label of 'mood' (see below 5.2.1). The moods, however, do not signal the semantic contrast between realis and irrealis. ${ }^{1}$ Rather, the forms belonging to the indicative system are modally unmarked and can express a wide range of meanings including desire,

1 Palmer, Mood and Modality, 4, defines mood-systems as 'basically ("prototypically") binary', marking the distinction between 'realis' and 'irrealis'. In Classical Arabic, however, this semantic distinction does not correlate with two separate sets of grammatical forms.

(C) MICHAL MARMORSTEIN, 2016 | DOI: 10.1163/9789004310483_006

This is an open access chapter distributed under the terms of the Creative Commons 
possibility, and non-factuality. The modal forms, on the other hand, are much more limited in their semantic scope, and are used to indicate meanings which relate to the notion of volition. Modality, in particular the deontic type, can thus be conveyed by a marked or explicit form, such as the imperative or the energetic, or by an unmarked or implicit form, such as yaf'alu (see also below $5 \cdot 3)$ :

\begin{tabular}{lllll}
\hline tadhulu & You will/shall go in & udhul & Go in & (directive) \\
'adhulu & I will/shall go in & la-'adhulanna & I shall go in & (commisive)
\end{tabular}

Verbal negation in Classical Arabic cannot be regarded as a form of modification of the simple forms. For one thing, negation particles have a different distribution than verbal modifiers, e.g., they are compatible with interrogatives. For another, negation particles may trigger the use of a verbal form otherwise not occurring as an affirmative form in the same circumstances. Negation particles may also call for a certain interpretation of the verbal form which is uncommon with the affirmative form (see also below 5.4).

In the subsequent sections a survey of the inventory of the verbal forms in Classical Arabic is presented. First, the affirmative indicative forms are surveyed, then the modal and the negated forms are presented.

\subsection{Indicative Verbal Forms}

The verbal forms presented in this section are modally unmarked. They may be simple, modified, or expanded by the auxiliary verb kāna. Syntactically, they have a wide distribution and may figure in both independent and dependent clauses.

\subsubsection{Simple Forms}

There are two simple finite verbal forms: fa'ala and yaf'alu. The formal distinction between them lies in the position of their pronominal theme: facala has a suffixed pronoun, hence it is labeled the suffix conjugation; yaf'alu has a prefixed pronominal index, hence it is labeled the prefix conjugation. ${ }^{2}$ In fact, in

2 The prefixed pronoun exhibits a greater morphological degradation than the suffixed pronoun. For its description as indexical by the Arab grammarians, see above 4.5. 
the second and third person, a morpheme distinguishing gender and number is suffixed to the form. For this reason, yaf'alu is also labeled the circumfix conjugation:

TABLE 5.1 Suffix and prefix conjugations

\begin{tabular}{|c|c|c|c|c|c|c|c|}
\hline \multicolumn{4}{|c|}{ Suffix conjugation } & \multicolumn{4}{|c|}{ Prefix (circumfix) conjugation } \\
\hline \multicolumn{2}{|c|}{ sg. } & \multicolumn{2}{|c|}{ pl. } & \multicolumn{2}{|c|}{ sg. } & \multicolumn{2}{|c|}{ pl. } \\
\hline masc. & fem. & masc. & fem. & masc. & fem. & masc. & fem. \\
\hline \multicolumn{2}{|c|}{ fa'al-tu } & \multicolumn{2}{|c|}{ fáal-nā } & \multicolumn{2}{|c|}{ '-af'al-u } & \multicolumn{2}{|c|}{$n-a f^{\prime} a l-u$} \\
\hline fa'al-ta & fáal-ti & facal-tum & fa'al-tunna & $t-a f^{\prime} a l-u$ & $t-a f^{\prime} a l-\bar{\imath}-n a$ & $t-a f^{\prime} a l-\bar{u}-n a$ & $t-a f^{\prime} a l-n a$ \\
\hline fa'al-a & fa'al-at & fáal- $\bar{u}$ & fa'al-na & $y-a f^{\prime} a l-u$ & $t-a f^{\prime} a l-u$ & $y-a f^{\prime} a l-\bar{u}-n a$ & $y-a f^{\prime} a l-n a$ \\
\hline \multicolumn{4}{|c|}{ du. } & \multicolumn{4}{|c|}{ du. } \\
\hline \multicolumn{2}{|c|}{ masc. } & \multicolumn{2}{|c|}{ fem. } & \multicolumn{2}{|c|}{ masc. } & \multicolumn{2}{|c|}{ fem. } \\
\hline \multicolumn{4}{|c|}{ fáal-tumā } & \multicolumn{4}{|c|}{$t-a f^{\prime} a l-\bar{a}-n i$} \\
\hline \multicolumn{2}{|c|}{ fáal-ā } & \multicolumn{2}{|c|}{ fáal-atā } & \multicolumn{2}{|c|}{$y-a f^{\prime} a l-\bar{a}-n i$} & \multicolumn{2}{|c|}{$t-a f^{\prime} a l-\bar{a}-n i$} \\
\hline
\end{tabular}

The prefix conjugation consists of a set of forms, distinguished from each other in the quality of their final short vowel and in the presence of a final morpheme $-n$ or $-n n$ (with several allomorphs). These endings signal the moods of the verb. The indicative forms whose base ends with a consonant are signaled by the vowel $-u$; forms ending with a long vowel (the gender/number morpheme) are signaled by the -na/-ni ending. The feminine plural shows a different pattern, as it does not have a distinctive mood morpheme: 
TABLE 5.2 The moods

\begin{tabular}{|c|c|c|c|}
\hline Moods & sg. & pl. & du. \\
\hline$u$-form (indicative) & $y a f^{\prime} a l-u$ & $y a f^{\prime} a l-\bar{u}-n a$ & $y a f^{\prime} a l-\bar{a}-n i$ \\
\hline$a$-form (subjunctive) & yaf'al-a & yaf'al-ū & $y a f^{\prime} a l-\bar{a}$ \\
\hline$\varnothing$-form (jussive) & yaf'al & yaf'al-ū & $y a f^{\prime} a l-\bar{a}$ \\
\hline$n$-form (energetic) & yaf'al-a-n(na) & yaf'al-u-u-n(na) & yaf'al-a-a-n(ni) \\
\hline
\end{tabular}

Besides the two finite forms fa'ala and yaf'alu, the participle is another simple form pertaining to the verbal system. The participle is an adjectival pattern of the verb. It is non-finite in the sense that it does not embody a pronominal theme, but only gender and number markers. Syntactically, it behaves in principle like a nominal: (a) it takes case endings, (b) it is determined by the article or the tanwin, or (c) is bounded by a genitive complement. On the other hand, the participle, like finite verbs, may take an accusative complement.

As a predicative form with a verbal lexeme, the participle may enter the system of oppositions with the finite verbal forms. In such case, the participle does not serve a classificatory function: it does not assign a certain property to the theme, but it expresses its incidental state or disposition. ${ }^{3}$ Formally, the two functions are not always easy to distinguish unless the participle is determined by the article, a fact which precludes its verbal reading. ${ }^{4}$ Other adjectival patterns, such as facil and facil, derived mostly from stative verbs, can also enter the system of oppositions with the finite verbal forms (see below [8.14]). The participle and the 'participle-like' adjectives may be assigned either the nominative or the accusative case. As primary predicates, they take the nominative; as secondary predicates, they take the accusative.

\subsubsection{Modified Forms}

The modifiers are elements (perhaps of verbal origin) which co-occur with the simple verbal forms. The modifiers are: $q a d$, la-, and sawfa/sa-. They are

3 Beeston, Arabic Language, 66, defines 'classificatory predicates' as those 'assigning the theme to membership of a category'. Reckendorf, Zum Gebrauch des Partizips, 256-258, correctly observes that the participle is not inherently stative, but it indicates a state or disposition with respect to the theme.

4 A definite predicative participle has, according to Beeston's classification, an 'identificatory function', cf. Arabic Language, $66 \mathrm{ff}$. The participle assumes a verbal reading when it has deictic anchoring, i.e., when it is personally (hence spatiotemporally) bounded. 
distinct from clausal operators such as 'inna or 'anna (see below 6.2.2) in that they have only the verbal form, rather than the entire clause, in their scope. Verbal modifiers are generally incompatible with either negation or interrogation particles and pronouns. They have an affirmative function, yet it is hard to define their precise semantic meaning. $q a d$, la-, and sawfa/sa-operate in the domain of propositional modality: they express a degree of certainty or commitment with regard to the validity of the contents expressed by the verb. ${ }^{5}$ The interaction of $q a d$, la-, and sawfa/sa- with the simple verbal forms may result in the expression of certain temporal or aspectual meanings, although in most cases, these meanings are yet fraught with modal nuances. ${ }^{6}$ The use of some modified forms is restricted to specific syntactic structures, while the use of others is highly subjective and opened to a variety of syntactic environments.

The modifiers $q a d$, la-, and sawfa/sa- do not combine freely with all the verbal forms: the form yaf'alu is the only one compatible with all three modifiers. However, the co-occurrence of $q a d$ with facala is far more frequent (or far less constrained) than its co-occurrence with yaf'alu, as summarized in table 5.3:

TABLE 5.3 The verbal modifiers

\section{Modifiers fáala yaf'alu fäilun}

\begin{tabular}{llll}
\hline qad & + & + & - \\
la- & - & + & + \\
sawfa/sa- & - & + & - \\
\hline
\end{tabular}

\subsubsection{The Modifier qad}

The use of qad fa'ala is far more extensive than that of qad yaf'alu. In fact, rather than being a sheer modification of the simple fáala, qad fa'ala has acquired

5 Palmer, Mood and Modality, 68-69, discusses cases in which markers of modality combine with declaratives so as to indicate strong assertion or various degrees thereof. Lyons, Deixis and Subjectivity, 110, mentions the modal particles of German as an example for a nonobligatory albeit very common device to express 'the speaker's attitude or degree of commitment', in clauses that are unmodalized or declarative.

6 The assumption that the modifiers had originally a modal (assertive) function is corroborated by the fact that some modified forms, e.g., la-yaf'alu and qad yaf'alu, are not found in dependent clauses. The opposite also holds true: when a modified form occurs in a dependent clause, it loses much of its modal force in favor of the expression of temporal and aspectual nuances. 
the status of a verbal form in its own right. This can be established in view of its relationship with the simple fa'ala and by comparison to the modified qad yaf'alu.

The syntactic distribution of fa'ala is distinct from that of qad fa'ala. Both forms belong to the same substitution class in affirmative independent clauses and in substantival and adjectival clauses. However, adverbial and predicative clauses (see below chapter 8), show a strong tendency to favor either facala or qad fa'ala, or feature only one of them (we recall that qad fa'ala almost never occurs in interrogative and negative clauses, for exceptions see [9.76], [9.83]). In these clauses, facala and qad facala partake in different systems of oppositions, so that (synchronically speaking) the second cannot be regarded as a further extension or specification of the first.

Not only in terms of frequency, but also as far as syntactic and lexical features are concerned, qad fa'ala has a far larger scope of application than qad yaf'alu. The modified form qadyaf'alu, as opposed to qadfa'ala, does not occur, in principle, in dependent clauses. It is not used with every lexeme. In dialogues, qad $y$ af'alu is occasionally found with the verbs ra'ä 'to see/comprehend', 'alima and 'arafa 'to know' (see below [9.16]); otherwise, it is mostly used in generic utterances (see below [11.5]). Furthermore, the syntactic juncture of qad and yaf'alu is less tight than that of qad and fa'ala: in kāna-compounds, qad precedes as a rule the auxiliary with $y a f^{\prime} a l u$ (the same as it precedes the auxiliary with the participle), whereas it is often interposed between the auxiliary and fa'ala (see below 8.2.1):

TABLE 5.4 qad fa'ala $v$ s. qad yaf'alu

\begin{tabular}{lll}
\hline & qadfáala & qadyaf'alu \\
\hline Frequency & high & low \\
Dependency & independent/dependent cl. & independent cl. \\
Lexical class & not limited & limited \\
Juncture in compounds & $\begin{array}{l}\text { kāna qadfáala } \\
\text { qad kānafáala }\end{array}$ & qad kāna yaf'alu \\
\hline
\end{tabular}




\subsubsection{The Modifier la-}

The modifier la-co-occurs with either yaf'alu or the participle in clauses introduced by the operator 'inna (see below 6.2.2.2). Clauses introduced by inna are either independent or enclosed in larger syntactic frames, following the conjunction hattā or the circumstantial $w a$-. The operator 'inna may also head a mutually dependent construction (see below 8.4). Only in very rare cases, yaf'alu preceded by la- occurs outside the frame of an 'inna-clause.

The verbal form fa'ala may also be preceded by an element la-in the apodosis of a conditional construction or in the content clause of an oath. Although formally identical, this $l a$ - has a different distribution than the verbal modifier $l a$-. The $l a$ - of ğawāb 'apodosis' introduces the second part of a conditional construction initiated by the particle law (or lawlā), or it may precede a protasis introduced by 'in. The apodotic la- may also introduce the content of an oath. This is explained by the fact that the oath and its content are structurally similar to a condition, having two interconnected parts. ${ }^{7}$ The apodotic $l a$ - is prefixed to facala or to the energetic. It has in its scope the second clause of a bipartite construction. In contrast, the verbal modifier la-, known as the la- of tawkid 'emphasis', is prefixed either to yaf'alu or to the participle (see below 9.2.3), ${ }^{8}$ and has in its scope the predicate of a single clause. That the apodotic $l a$ - and the emphasizing $l a$ - are functionally distinct is corroborated by the fact that the first can precede the negated form $m \bar{a}$ fa'ala (law fa'ala ... lā-mā fa'ala ...), while the latter is incompatible with negation. ${ }^{9}$

Modifiers can be accumulated: $l a$ - may be preposed to the modified form qad fa'ala or to the modified compound form qad kāna+V. The fact that la-may be preposed to qad fa'ala evidences the tight juncture of qad and fa'ala that allows the construction to be put as a single unit in the scope of another verbal modifier..$^{10}$ la-qad facala occurs in various syntactic structures, among which

Sadan, $\breve{G} a w \bar{a} b$, reviewing the use of the technical term $\check{g} a w a \bar{a} b$ in the Arabic lexicographical and grammatical tradition, renders it as 'an utterance following another utterance'. The adduced examples show, however, that a ğawāb is not just a consecutive clause, but has an intrinsic semantic relation to the preceding clause (or part of clause). The meaning of ğawāb should be therefore understood in a stricter sense, as a consecutive clause in a bipartite construction.

$8 \quad l a$-is not limited to verbal or adjectival forms only. It can also precede prepositions.

9 For a detailed survey of the various taxonomies of the occurrences of $l a$ - proposed by the Arab grammarians, see Testen, Asseverative la-, $1-56$.

10 Wright, Grammar, 2, 19, quotes one example of the modifier la-preposed to sawfa. Such cases were not found in my corpus. 
are the apodosis of $l a w$-conditionals and oath expressions. In the latter case, la-qad fa'ala is far more common than la-fa'ala. ${ }^{11}$

\subsubsection{The Modifier sawfa/sa-}

The modifier sawfa, or its shorter and more common form sa-, is only compatible with yaf'alu. The modified form sawfa/sa-yaf'alu can occur in independent clauses (see below [9.17]), in substantival clauses linked by 'anna (see below [7.5]), and in raising constructions (see below [8.73]). It is also quite common in apodotic or comment clauses introduced by $f a$ - The modified form sawfa/sayaf'alu refers to a posterior event. The posterior meaning of sawfa/sa-yaf'alu arises most clearly with stative verbs, which would otherwise have a concurrent reading with the simple $y a f^{\prime} a l u .{ }^{12}$ In other cases, e.g., in the apodosis of a conditional construction or in a comment clause, the modifier sawfa/sa- does not contribute to a temporal disambiguation or specification of $y a f^{\prime} a l u$, since the meaning of posteriority is already imposed by the syntactic structure. In such cases, the modifier sawfa/sa- may be said to serve as a heavier means by which the meaning of posteriority is expressed.

\subsubsection{Compound Forms}

A compound verbal form consists of the auxiliary verb kāna and the simple verbal forms fa'ala, yaf'alu, the participle (assigned the accusative), or the modified form qad fáala. ${ }^{13}$ The auxiliary kāna, as opposed to the verbal modifiers, has in its scope a full clause, either nominal or verbal, and even an entire paragraph. It may immediately precede its predicate or it may initiate a long chain of predications, without being repeated. Thus, the realization of kāna-clauses, or more specifically of kāna-compounds, often takes place at the text level, as the 'minimal' clausal structure is extended to a multi-clausal stretch.

The auxiliary verb kāna operates as a temporal or a modal adapter: it adjusts the predicate to the deictic point of reference (see above 4.2), so that the predicate is left to indicate aspectual distinctions. One can distinguish between four

11 It appears that the preference of either la-fa'ala or la-qadfa'ala is in part lexeme-sensitive, cf. Kinberg, Qad.

12 The technical use of the term 'concurrent' in this work is explained below, see 7.2.

13 Modifying verbs other than kāna combine with simple verbs and form verbal complexes. However, these verbs are distinguished from kāna in that: (a) they impart an additional overlay of meaning to the temporal or modal meaning conveyed by kāna; (b) they are rather constrained in their possible combinations with a content verb, often combined only with yaf'alu. 
manifestations of the auxiliary: the 'anterior' kāna, the 'posterior' yakūnu, the 'subjunctive' 'an yakūna and the 'conditional' 'in yakun/käna. As far as their function is concerned, the latter two manifestations should have been presented together with the other modal forms. However, as the current discussion focuses on formal aspects of the verbal inventory, they will be subsumed under this section as well.14

The anterior kāna locates its predicate in a point previous to some other reference point. It can precede all the simple forms and the modified qad fa'ala (see below 8.2.1). Anteriority can also be syntactically marked, by the asymmetrical juxtaposition of a matrix clause and a dependent clause (see below 6.1.2). Occasionally, the morphological and the syntactical markers converge, i.e., when a kāna-compound occurs in a dependent clause (see below [7.13], [7.14], [7.31], [7.33], [7.52]-[7.54], [7.77], [7.78], [7.80]).

The posterior yakūnu is far less common than the anterior kāna. Interestingly, it is not attested with the simple forms fa'ala and yaf'alu. It does precede the participle and the modified form qad facala.

The subjunctive yakunna and the conditionals yakun/kāna accommodate the simple verbal forms into a fixed clausal pattern, triggered by operators such as 'an or 'in. The subjunctive 'anyaküna is constructed with fa'ala, the participle, and qad fa'ala. Interestingly, in my corpus, 'an yakūna fa'ala stems from the Ta'rīh and Majāazi texts, while 'an yakūna qad fa'ala is mostly found in the Buhalä text.

The conditional yakun/käna form compounds with all the simple forms and the modified form qad fa'ala. ${ }^{15}$ The verb kanna can also precede the conditional particle. In such cases, its scope is extended to the entire conditional construction. Like the subjunctive, yakun/kāna allow forms which otherwise do not follow directly the conditional particle, viz., yaf'alu, the participle, and qad fa'ala, to occur in the clause. ${ }^{16}$ The use of fáala after kāna brings about

14 The relatively uncommon mā kāna li-yaf'ala, involving the so-called lāmal-ğuhūd 'the lām of denial', will not be discussed in this section.

15 The term conditional does not refer here to the semantological notion of conditionality ('possible and non-necessary') but to a formal structure which is common to both hypothetical conditional constructions and non-hypothetical or temporal constructions. All these constructions exhibit the bipartite pattern fa'ala fa'ala, which is introduced by particles such as 'in, law, 'i $\underline{d} \bar{a}$, and lammāa, and such pronouns as man, $m \bar{a}$, kullamā, etc. Proper conditional constructions introduced by 'in, or one of the pronouns embodying 'the meaning of 'in', exhibit also yaf'al forms.

16 The conditional particle law appears to be less restrictive than 'in, allowing qad fa'ala and yaf'alu (with certain lexemes) to follow it directly. 
the opposition between the simple fa'ala and its compound counterpart kāna fa'ala. Within a conditional clause, this pair of forms does not mark the temporal opposition 'past': 'anterior past', but serves to indicate other oppositions. For instance, in 'id $\underline{a}$-constructions, fa'ala may depict an habitual occurrence which is temporally unbounded, while kāna fáala depicts a past habitual occurrence. In conditionals introduced by 'in, the same pair indicates the modal distinction between hypothetic-yet-realizable events (with an implied future time reference) and impossible or unrealizable events (with an implied past time reference). In conditionals introduced by law, the simple fa'ala and the compound kāna fa'ala can be said to be distinct only in terms of markedness, since law dictates as a rule the impossible or unrealizable reading of the clause.

The anterior kāna and the conditional kāna may appear in a reductive analysis as one and the same thing: in both cases, kanna locates the verbal situation in a previous, actual or hypothetical, point in time. However, one can adduce a number of arguments against this analysis: (a) the conditional kāna forms a substitution class with the apocopate yakun and not with yakūnu, as elsewhere in the system; (b) the hypothetical sense of kāna arises not only in conditional clauses, but also in other types of clauses, where it forms compounds with yaf'alu and the participle (see below [7.76], [7.81]); and (c) the conditional kāna does not indicate a step back in time, neither in 'in nor in law-conditionals: 'in kāna yaf'alu/ fã ilan has an implied non-past reference while law kāna fáala has the same past time reference as law fáala. Table 5.5 below summarizes the above discussion on compound kāna forms:

TABLE 5.5 Compound kāna forms

\begin{tabular}{lcccc}
\hline Auxiliary & fáala & yaf'alu & fä́ilan & qadfáala \\
\hline 'anterior' kāna & + & + & + & + \\
'posterior' yakūnu & - & - & + & + \\
'subjunctive' 'an yakūna & + & - & + & + \\
'conditional' 'in/'í⿴囗十a/law yakun/kāna & + & + & + & + \\
\hline
\end{tabular}




\subsection{Modal Verbal Forms}

In a broad definition, the term modality refers to the expression of 'certain attitudes of the mind of the speaker towards the contents of the sentence.'. ${ }^{17}$ Modality, in this sense, converges to a large extent with the notion of subjectivity, and thus may be considered as omnipresent in language. ${ }^{18}$ In a more restrictive view, modality is regarded as the semantic domain corresponding to the grammatical category of mood (or some other formally defined category) ${ }^{19}$ The category of modality covers thus only a certain part in the realm of subjectivity; the other, more elusive (and far less studied) part, is occasionally referred to as expressivity. In the traditional view, modal forms are classified into two basic types: epistemic and deontic. ${ }^{20}$ According to more recent diachronic and typological studies of modality, four types of modality can be distinguished: agent-oriented, speaker-oriented, epistemic, and subordinating. ${ }^{21}$

In Classical Arabic, modality is often expressed through the verbal forms. ${ }^{22}$ The verbal system consists of indicative and non-indicative moods. The indicative forms have a broad grammatical and semantic scope of application: (a) they are realized in both independent and dependent clauses, and (b) they are modally unmarked, so that they may be used to express both assertive and non-assertive meanings. Deontic modal forms are found only in independent clauses. The subjunctive, on the other hand, is never found in independent

17 Jespersen, Philosophy, 313 .

18 Lyons, Deixis and Subjectivity, 102, defines subjectivity in a very similar way as 'the way in which natural languages, in their structure and their normal manner of operation, provide for the locutionary agent's expression of himself and of his attitudes and beliefs'.

19 Narrog, (Inter)subjectification, 392-393, argues against the definition of modality in terms of 'speakers' attitudes and subjectivity', since 'the means of expression of the speakers' attitudes are far too varied to be subsumed under one category label'.

20 Palmer, Mood and Modality, refines this classification by drawing a basic distinction between 'propositional' and 'event' modality, which in a modal system are further divided into 'epistemic' and 'evidential', 'deontic' and 'dynamic', respectively.

21 Bybee, Perkins, and Pagliuca, Evolution, $177 \mathrm{ff}$. The authors comment that agent-oriented modality, though part of the propositional content of the clause, is still included in their study, since 'these modal senses are the diachronic sources of most senses that Do qualify as modality in other studies'. Narrog, (Inter)subjectification, proposes yet another model of modality, consisting of two dimensions: a dimension of 'volitivity' and a dimension of 'speaker-orientation'.

22 Although modality is often expressed by verbs, it can also be indicated by other grammatical means such as the modal particles layta and lacalla, which are used to express wish and possibility, respectively. 
clauses. Its use is not determined by semantic or pragmatic considerations, but by the syntactic structure of the clause.

The modal forms indicating deontic modality are the imperative if $a l$, the jussive li-yaf'al, and the energetic la-yaf'alanna. The imperative has the same base form as the apocopate form $y a f^{\prime} a l$, without the prefixes. It is inflected for the second person only. The jussive is one manifestation of the apocopate form $y a f^{\prime} a l$, preceded by the conjunction $l i-.^{23}$ The apocopate $y a f^{\prime} a l$ has yet another modal use: it functions as a conditional form (see also below). ${ }^{24}$ In fact, yaf'al may be described as the non-assertive form par-excellence: it occurs only in the frame of 'mands' (command, request, etc.), conditions, or negations. ${ }^{25}$ The energetic has the same base form as the subjunctive yaf'ala, with the addition of the 'energic' suffix $-n(n a)$. The energetic, often following expressions of oath or serving as the apodosis of law and la-in conditionals, is preceded as a rule by the 'apodotic' la-.

The subjunctive yaf'ala occurs in dependent and embedded clauses. As such it differs to a great deal from the deontic forms, which occur as a rule in main clauses. As a dependent form, the subjunctive is merely propositional and therefore deprived of subjective illocutionary force. It is triggered by a set of operators and its use is determined by the overall syntactic structure of the clause. ${ }^{26}$ The subjunctive occurs in complement clauses of mental verbs or in consecutive and final clauses introduced by hattāa, 'anna, and li- (and complex forms thereof). However, the subjunctive may also occur in a clause conveying an entailed, sequential, or responsive meaning. In these cases the subjunctive follows particles such as the sababiyya 'causal' $f a$ - or 'idan and marks modal congruence with the first part of the construction, which indicates a non-assertive (imperative, hortative, negative, interrogative) meaning (see also below 10.2.3).

23 In accordance with the traditional view (cf. Wright, Grammar, 1, 291), li- preceding the mağzūm and the manșūb forms is viewed here as different from the preposition li- preceding nouns. One formal difference between the two is the elision of the vowel $i$ when $l i$-, prefixed to the mağzumm, is preceded by $f a$ - or $w a$ - (e.g.: $\left.f a-l-y a f^{\prime} a l\right)$. li-can be prefixed to the verbal form or it can be adapted to it by another conjunction, such as 'an and kay.

24 The conditional $y a f^{\prime} a l$ is distinct from the jussive $y a f^{\prime} a l$ both grammatically and semantically: (a) it is not conjoined with $l i-;$ (b) it participates in a mutually dependent construction (conditional construction); and (c) it does not indicate deontic modality.

25 Giolfo, Yaqum vs. Qāma, 156-158, proposes an overall analysis of the verbal system in Classical Arabic, based on the contrast between 'certainty' and 'uncertainty'. In this analysis, $y a f^{\prime} a l$ is the least 'certain' form, pertaining to the domain of 'virtual uncertainty'.

26 For a comprehensive discussion of the subjunctive in Classical Arabic, see Sadan, Subjunctive Mood. 
The indicative forms, though generally not marked for modality, may have in certain cases a specific modal function. This function is not viewed here as secondary to the main indicative or assertive function, but as yet another application of the same grammatical form. facala expressing optative meaning is a case in point. Optative clauses are characterized by a distinct syntactic pattern (see below 9.4). In these clauses, fáala expresses a kind of volition (a personal wish projected on God) that is never conveyed by the modal forms. Another case where facala has a modal function is in conditional constructions. ${ }^{27}$ The paradigm of facala and the apocopate $y a f^{\prime} a l$ is used in both the protasis and the apodosis of the basic 'modally interdependent' conditional structure: 'in yaf'al/fa'ala yaf'al/ fa'ala. ${ }^{28}$ Table 5.6 below summarizes the above discussion on the modal forms:

TABLE 5.6 The modal forms

\begin{tabular}{lll}
\hline Deontic & $\begin{array}{l}\text { imperative } \\
\text { jussive } \\
\text { energetic } \\
\text { optative }\end{array}$ & $\begin{array}{l}\text { if'al } \\
\text { li-yaf'al } \\
\text { li-yaf'alanna } \\
\text { fáala }\end{array}$ \\
Neutral & subjunctive & yaf'ala \\
Epistemic & conditional & yaf'al; fáala \\
\hline
\end{tabular}

\subsection{Negated Verbal Forms}

Negation in Classical Arabic cannot be simply regarded as a modification of the simple or compound verbal forms. Certain negation particles may trigger the use of a verbal form not having an affirmative counterpart used in the same circumstances. Or, they may impart to the verb a temporal or a modal sense that

27 For an analysis of the semantic opposition between facala and yafal in conditional constructions, see Giolfo, Yaqum vs. Qāma.

28 Peled, Conditional Structures, 9, describes the relationship between a fa'cala / yaf'al protasis and a fa'ala/yaf'al apodosis as 'modal interdependence': each part induces the conditional sense of the other. Modal interdependence is contrasted with 'modal split', where each part of the construction indicates different modality. 
is not indicated by the affirmative form. For these reasons, the negated forms are better viewed as a system of their own (see below 9.2.4).

The negation particles attested in the corpus are la , māa, laysa, lam, lan and $\dot{g}$ ayr. The most basic particle $l \bar{a}$ is detectable in other more complex negation particles (e.g.: * la-'aysa, *la-ma, * $\left.l a-{ }^{\prime} a n\right)$. Also in its distribution, la is the most common negation particle, in both main negations and secondary or double negations ('neither ... nor ...'), where it functions as the default negation particle, regardless of the form which the first negation assumes.

Some negation particles, such as $l \bar{a}, m \bar{a}$, and laysa, are compatible with more than one verbal form. $l \bar{a}$ can negate the indicative forms fa'ala, yaf'alu, and (rarely) the participle, as well as the modal forms yaf'al and yaf'alanna. mā negates all the indicative forms while laysa can only negate yaf'alu and the participle. Other negation particles are form-specific: lam is compatible only with yaf'al, lan with yaf'ala, and gayr with the participle (as with other nominal forms). The combination of a certain negation particle and a verbal form marks various kinds of negations. Thus, lam+yaf'al indicates past negation while $l \bar{a}+y a f^{\prime} a l$ functions as prohibitive. The particle lan negates yaf'ala in main clauses, whereas in dependent clauses yaf'ala is negated by $l \bar{a}$.

The negation of the participle is often doubly marked: besides the negation particle $m \bar{a}$ or laysa, the participle can be preceded by the preposition $b i$-, assigning it the genitive case. This structure is designed to express a strong negation of both the 'nominal' and the 'verbal' participle: in the first case, it indicates the dissociation of a certain property and the theme; in the latter, it emphasizes the negation of a certain state or disposition of the theme (both readings may conflate, see below [9.52]). Table 5.7 below summarizes the above discussion on verbal negation:

TABLE 5.7 Negated verbal forms

fáala yaf'alu fã́ilVn yaf'al yaf'ala yaf'alanna

\begin{tabular}{lllcccc}
\hline la & + & + & $(+)$ & + & {$[$ 'an cl. $]$} & + \\
ma & + & + & $+[b i-]$ & - & - & - \\
laysa & - & + & $+[b i-]$ & - & - & - \\
lam & - & - & - & + & - & - \\
lan & - & - & - & - & + & - \\
gayr & - & - & + & - & - & - \\
\hline
\end{tabular}


A compound form is negated once: either the auxiliary verb or the content verb is negated. The following negation patterns are attested in the corpus:

TABLE 5.8 Negated compound forms

\begin{tabular}{|c|c|c|}
\hline Negation & Auxiliary & Content \\
\hline lam & yakun & $\begin{array}{l}\text { fa'ala } \\
\text { yaf'alu } \\
\text { fácilan }\end{array}$ \\
\hline$m \bar{a}$ & kāna & $\begin{array}{l}\text { yaf'alu } \\
\text { fāiilan }\end{array}$ \\
\hline Auxiliary & Negation & Content \\
\hline kāna & $l \bar{a}$ & $\begin{array}{l}\text { yaf'alu } \\
\text { fāilan }\end{array}$ \\
\hline kāna & $\dot{g} a y r$ & fāiilin \\
\hline
\end{tabular}

\subsection{Summary}

In this chapter, I have presented the inventory of the verbal forms in Classical Arabic. The classification of the forms was based mainly on their morphosyntactic properties, although some semantic features were also taken into consideration. The forms were accordingly characterized with respect to their being: (a) affirmative or negated, (b) indicative (modally unmarked) or modal, (c) simple, modified, or compound. In the subsequent chapters, the formal and the functional properties of the verbal forms, specifically those constituting the indicative paradigm, will be further discussed and illustrated. 


\section{The Syntagmatic Structure of the Clause}

The verbal form, a minimal clause in itself, is part of the larger syntagm of the simple clause (4.5). The simple clause is defined with respect to (a) its internal constituency, the intra-clausal syntagm, and (b) its external relations with the adjacent clauses in the text, the inter-clausal syntagm. In this chapter, I will proceed from the larger configuration to the smaller. I will discuss first the dependency status of the clause and the linking devices introducing it into the textual sequence, then I will move on to discuss word order and the operators within the simple clause.

\subsection{The Inter-clausal Syntagm}

\subsubsection{Dependency Status}

Interdependency, as discussed above (4.4), is a scalar phenomenon. The dependency status of a clause is determined by a combination of features: the overall juncture contour and the position of the clause in the sequence, the linking device, the clause type (nominal or verbal), the verbal form realized in it, and its substitution class. In analyzing the dependency status of a clause, the general juncture contour should be considered first. Independency and dependency may figure in very different ways in the narrative, proceeding in a continual flow of concatenated clauses, and in direct speech, proceeding in a staccato pace of short segments. Evidently, more complex configurations of interdependency are found in the narrative chain. Within a chain, the relation between two adjacent clauses is marked as symmetrical by the repetition of the same type (or class) of linking devices, clausal structure, and verbal form. In such case, the clauses are defined as main or independent. By contrast, a clause is regarded as dependent to some degree when it exhibits a certain structural asymmetry relative to the preceding clause.

In a fine analysis, taking into account each formal and semantic feature of the complex clause, one can identify as many degrees of dependency as the number of the clause structures he can distinguish. Such an analysis was carried out by Waltisberg, who attempted to establish a detailed scale of clause linkage in Classical Arabic. ${ }^{1}$ In the present work I will settle for a less delicate

1 Waltisberg, Satzkomplex, $70 \mathrm{ff}$.

(C) MICHAL MARMORSTEIN, 2016 | DOI: 10.1163/9789004310483_007

This is an open access chapter distributed under the terms of the Creative Commons

Attribution-Noncommercial-Non-Derivative 3.0 Unported (CC-BY-NC-ND) License 
slicing of the continuum, as my aim is not only to examine the distinct features of each clause, but also to identify those which are shared by a group of clauses and which make them a unified category. For the latter purpose, I will thus distinguish between four levels of clausal interdependency:

(a) Main clauses (see below chapter 9, 10.2.1, 10.3.1, chapter 11)

(b) Bidirectional or mutually dependent clauses (see below 8.4, 10.4)

(c) Unidirectional dependent clauses (see below 8.3, 10.2.3, 10.3.1)

(d) Embedded clauses (see below chapter 7, 8.2)

In a succinct account, we can capture this division of four levels by considering the following three variables: (a) the position of the clause, specifically, whether it can occupy the initial position in the chain; (b) the symmetrical relations with respect to the adjacent clause in the chain; and (c) the substitution with a simple morphological constituent. Table 6.1 presents the way in which these variables apply to each level:

TABLE 6.1 Four levels of interdependency

\section{Initiality Symmetry Substitution}

\begin{tabular}{llll}
\hline main clause & + & + & - \\
mutually dependent clause & + & - & - \\
dependent clause & - & - & - \\
embedded clause & - & - & + \\
\hline
\end{tabular}

Clauses distinct in their dependency status belong to different strata in the hierarchical structure of the text. Consequently, the level of analysis of a given clause in the text varies with respect to its dependency status. Main clauses, which contain indicators of the text's reference point and its overall cohesive structure, can be fully analyzed only at the text level. Dependent and embedded clauses, on the other hand, which only indirectly relate to the text's reference point (via their matrix clause), are analyzed at the lower level of the (complex-)clause. However, there are some dependent and mutually dependent clauses which are only found in some text types. These clauses participate in the construction of the text's overall cohesive structure and thus should also be treated at the text level (see below 8.4 and 10.4). 


\subsubsection{Linking Devices}

There are implicit and explicit exponents of linkage. The implicit exponents mark two different types of syntactic relations: initiality, symbolized as \#, and asyndesis, symbolized as $\varnothing$. In Classical Arabic, a clause positioned in the absolute beginning of a text or in a resuming position is syntactically independent. Oftentimes it is not introduced by an explicit linking device:

\section{(6.1) dahaltu yawman 'alà 'isḥāqi bni 'ibrāhìma l-mawșiliyyi I came one day to 'Isḥāq b. 'Ibrāhīm al-Mawṣilī. (Riwāyāt 1, 65)}

However, a clause in a subsequent position, that is dependent on the preceding clause, may also be introduced by implicit means. In such cases, the syntactic relation is marked by asyndesis. ${ }^{2}$ A weak dependency is manifested in [6.2], in which an asyndetic fa'ala follows an initial fa'ala, thus the verbal form is repeated but not the same linking device. The pattern fa'ala $\varnothing$-fa'ala is distinct from the pattern fácla conN-fa'ala (see below 10.2.1) in that it does not mark chronological sequence but a relation of specification. The second $\varnothing$-fáala, referring to the same state of affairs as the first fa'ala (often even repeating the same verbal lexeme), further specifies the identity of the actors or the particular form in which the action was carried out: ${ }^{3}$

\section{'atā-hu habaru 'abi-hi 'atā-hu bi-hì rağulun min 'iğlin}

The news on his father came to him, a man from 'Iğl brought it to him. (Reckendorf, Arabische Syntax, 307)

Asyndesis may indicate a closer juncture between clauses and even embedding. Embedding is an inter-clausal relation inasmuch as it refers to the relation between two clauses within a complex clause. Embedded clauses are defined in respect to the simple morphological constituent in the matrix clause whose position they occupy (see above 4.4). Embedded adjectival and adverbial clauses may be asyndetically linked. The grammatical nucleus of an asyndetic adjectival clause, sifa in traditional terms, is an indefinite nounphrase:

2 I draw the distinction between initiality and asyndesis in order to account for two essentially different junction patterns; namely, the outset of speech or 'anapocrisis', and the leaning of the clause on the previous speech or its being 'apocritic', cf. Goldenberg, Amharic Tense System, 3 .

3 Cf. Reckendorf, Syntaktischen Verhältnisse, 2, 445-446. 


\section{(6.3) wa-'amara la-hum bi-hädimin yahdimu-hum}

He ordered [to provide] them [with] a servant that would serve them. (Riwāyāt 1, 7)

The grammatical nucleus of an adverbial, and specifically an adverbial-predicative clause, is a verb-phrase or some other form of nexus. What is subsumed here under the category of adverbial-predicative clauses is referred to by a number of terms in the Arabic grammatical tradition, namely, hăl 'circumstantial', maf' $\bar{u} l(\underline{t} \bar{a} \bar{n} i)$ '(second) object' and habar 'predicative'. The fact that the first two terms ( $h \bar{a} l$ and $\left.m a f^{\prime} u \bar{l} t \underline{a} \bar{n} n i\right)$ may be used interchangeably with the latter term (habar) is revealing of the special status ascribed to this category of clauses which, unlike other adverbial expansions, is considered as an essential component of the clause (see also below 8.2). ${ }^{4}$ Since predicativity is viewed here as the distinctive feature of this type of clauses, I will henceforth refer to it simply as the predicative clause. Examples [6.4] and [6.5] illustrate predicative clauses in a verbal complex and a presentative clause, respectively:

\section{(6.4) fa-harağnā nas'alu 'an rasūli llāhi}

We went out to seek the Messenger of God. (Sirra 1, 294)

(6.5) Kunnā ğulūsan 'inda șanamin [...] naharnā ğazūran fa-iḍā șāìhun yașịhu

We were sitting near an idol [...] we slaughtered a camel when suddenly someone was shouting. (Ta'rīh 3, 1145-1146)

It should be noted that the distinction between an attributive and a predicative asyndetic clause is not always clear-cut. In many cases where the nominal antecedent (the mawșūf or $\underline{d} \bar{u} a l-h \bar{a} l$ ) is indefinite, it seems that both interpretations are equally plausible. Waltisberg suggests that the distinction be based on the content of the matrix verb, so that if it belongs to the group of 'translocal' verbs (i.e., verbs of motion or caused motion), the following clause is to be interpreted as 'modal' or 'final' rather than attributive. ${ }^{5}$ To be sure, an attributive or a predicative reading of the clause is strongly affected by the matrix verb. However, suggesting that only a predetermined group of verbs may be followed

4 See Sībawayhi, Kitāa , 2, chapter 12, discussing the class of verbs whose second maf' $\bar{u} l$ cannot be omitted due to its being the habar of the first maf'ül, and chapter 117, discussing presentative clauses in which the hăl constituent functions as the habar of the (definite) presented entity.

5 Waltisberg, Satzkomplex, 9o-91, 317 ff. 
by adverbial or predicative clauses, or that asyndetic clauses following other verbs cannot be interpreted as such, is evidently circular. In [6.6] and [6.7] both readings of the asyndetic clause are possible. In the first case the matrix verb is marra 'to pass by', a typical motion verb; in the latter it is istașhaba 'to take as companion', a verb which does not pertain to the core of 'translocal' verbs (though it may imply movement):

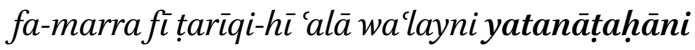

He passed in his way by two goats butting/that were butting one another. (Kalīla wa-Dimna, 78 )

(6.7) wa-stașhaba ma'a-hū rağulan yadullu-hū 'alā l-țarìqi

He took as companion a man, to show/that would show him the way. (Riwāyāt 2, 26)

Explicit syndesis is commonly marked by the connective particles wa- and $f a$ - The connective $w a$ - is more basic than $f a$-: it indicates a general additive relation between two or more simple or complex terms. The connective $f a$-, by contrast, embodies a vectorial component: it marks a connection that has an internal (chrono)logical order (tartīb). Both $w a$ - and $f a$ - introduce main clauses, in initial or subsequent positions, or dependent clauses. When introducing main clauses, $w a$ - and $f a$-are paradigmatic with the implicit initiality marker; when introducing dependent clauses, they are paradigmatic with asyndesis. Consider the following examples:

(6.8) wa-'aqbala 'abū sufyāna bi-l-î́ri wa-hāaū hawfan šadìdan hìna danaw min-a l-madinati

'Abū Sufyān came with the caravan and they feared a lot when they approached Medina. (Maj̄āzì, 39)

(6.9) qadima ḍamḍamu fa-șāḥa bi-l-nafiri

Damḍam came and shouted at the troop. (Maj $\bar{a} z \bar{z}, 34)$

(6.10) wa-țala'at qurayšun wa-rasūlu llāhiyașuffu-hum

Qurayš appeared while the Messenger of God was aligning them (i.e. his companions). (Mag $\left.\bar{a} z \bar{\imath}, 5^{6}\right)$

In [6.8], both the initial and the subsequent clause are linked by $w a-$ and present the same clause type and verbal form, thus the sequence features two interconnected main clauses. In [6.9], the linking device is switched; however, 
since both \# and $f a$ - belong to the same paradigm of linking devices, and the same clause type and verbal form are repeated, symmetry is maintained. In [6.10], though the same exponent of linkage is used (wa-), the clause type and verbal form of the second clause are altered (verbal-to-nominal, fa'ala-toyaf'alu). Thus, the relation between the second clause and the first clause is one of syntactic dependency.

Other less common means of explicit syndesis are tumma 'then(after)' and hatta ' 'until'. These particles have a special function in the narrative chain: tumma indicates the elapse of an interval of time between two succeeding events, while hattā introduces the final event in a series of events (hattā may also introduce consecutive dependent clauses, in which it also serves to indicate the $\dot{g} \bar{a} y a$ 'final destination' or 'endpoint' of the main event):

(6.11) fa-șallā l-nabiyyu l-išăàa țumma ğăàa 'ilà manzili-hī

The Prophet prayed the evening prayer and then he came to his house. (Șahịh 1, 42)

\section{(6.12) fa-rağa ū 'alā ḥāmiyati-him ḥattā qadimū al-madīnata}

They went back to their garrison until they [finally] arrived at Medina. (Riwāyāt 2, 8)

Implicit and explicit linking devices are distinguished from operators at the intra-clausal level in that they do not affect the internal structure of the clause. In fact, they often co-occur with clausal operators. Table 6.2 presents the paradigms of implicit and explicit linking devices in a chain:

TABLE 6.2 Implicit and explicit linking devices

\begin{tabular}{|c|c|c|c|c|}
\hline \multirow{2}{*}{ Chain } & \multicolumn{2}{|c|}{ main clause + main clause } & \multirow{2}{*}{\multicolumn{2}{|c|}{ main clause + dependent clause }} \\
\hline & initial & subsequent & & \\
\hline implicit linking & \# & & \# & $\varnothing$ \\
\hline explicit linking & $\begin{array}{c}w a- \\
f a- \\
\text { tumma }\end{array}$ & $\begin{array}{c}\text { wa- } \\
\text { fa- } \\
\text { tumma } \\
\text { hattā }\end{array}$ & $\begin{array}{c}\text { wa- } \\
\text { fa- } \\
\text { tumma } \\
\text { hattā }\end{array}$ & $\begin{array}{c}w a- \\
f a-\end{array}$ \\
\hline
\end{tabular}

6 In the initial position of a chain, tumma is nearly always followed by the introductory 'inna. 


\subsection{The Intra-clausal Syntagm}

The syntagmatic structure of the simple clause is determined by both (a) the word order and grammatical agreement between the subject/agent and the predicate, and (b) the clausal operators.

\subsubsection{Word Order and Agreement}

As already discussed (4.5), there are two basic clause types in Classical Arabic: verb-initial clauses and topicalization structures. In accordance with the Arabic grammatical tradition, these are referred to as the verbal clause and the nominal clause, respectively. The two clause types are distinct in the relative order of their subject/agent and verbal predicate, and in the grammatical agreement between them. In a verbal clause, the verbal predicate does not agree in number and possibly in gender with the following nominal theme. In a nominal clause, by contrast, the verbal form agrees in both number and gender with the preceding nominal theme.

This formal difference in agreement is evidently manifested in the third person only. The third person verbal clause incorporates what may be defined as a dummy pronoun; the nominal entity which follows the verb is newly introduced into discourse. Once introduced, this entity is referred to by means of full agreement in the subsequent clauses. Thus, the category of verbal clauses breaks down into ones which present new topics, in which agreement is not manifested, and ones which exhibit topic continuance, and hence show agreement. The transition from one pattern of agreement to the other may be carried out between two succeeding clauses, as in [6.13], or within the same verbal complex, as in [6.14]:

\section{(6.13) wa-'aqbala l-mušrikūna fa-staqbalū l-šamsa}

The polytheists came forward and faced the sun. (Majā $z \bar{\imath}, 56)$

(6.14) wa-ğa'ala 'aṣhāâu rasūli llāhi yaqdamūna

The companions of the Messenger of God started to arrive. (Maj̇̄zi, 371)

As far as their function is concerned, both subtypes of the verbal clause focus on the verbal event, rather than on the subject entity. Though the subject entity may provide 'given' information (in cases of topic continuance), the clause as a whole is not 'about' that entity. ${ }^{7}$ The nominal clause, by contrast, has a

7 For the distinction between these two properties of the topic, i.e., 'givenness' and 'aboutness', see Halliday, Transitivity, 212; Schiffrin, Conditionals as Topics. 
markedly different structure and function. In the nominal clause, a definite subject entity - a topic - precedes the verb. The topic is made definite by virtue of anaphoric reference to the third person, exophoric reference to the first and second persons, or by indicating a proper name. Rather than focusing on the verbal event, the structure of extraposition calls attention to the topic, thereby indicating the boundaries of a discourse span. ${ }^{8}$ In some cases, this attention involves a comparison and even contrast between two topics:

(6.15) fa-naḥnu na'budu l-malāikata wa-l-yahūdu ta'budu 'uzayran We worship the angels while the Jews worship 'Uzayr. (Sira 1, 236)

Objects and adverbial complements usually follow the verb. When positioned before the verb, especially at the head of the clause, they are put in focus:

(6.16) qāla 'ayna turìdu qāla 'iyyā-ka ǧitu li-'ūmina bi-ka

He said: 'where are you heading?' He replied: 'To you I came to believe in you.' (Majīāzi, 406)

(6.17) yā sayyid-ī l-sāata wallāhi tahruğu rūḥ-ī

My lord, now, by God, my spirit flies away. (Riwāyāt 1, 249)

As already noticed by Khan (see above 4.5), there is a strong correlation between the clause type and the verbal form realized in it: facala forms are more common in verbal clauses whereas yaf'alu forms are characteristic of nominal clauses. A nominal clause featuring a facala form is thus highly marked in terms of distribution; it usually serves to lay emphasis on the preposed nominal theme:

(6.18) fa-qāla 'abū bakrin 'a-lā tarā mā yașna'u hādāa l-safihu qãla 'anta fáalta hā $\underline{d} a \bar{b}$ bi-nafsi-ka

'Abū Bakr said: 'Don't you see what this fool does?' He replied: 'You did it yourself.' (Sira 1, 246-247)

\subsubsection{Clausal Operators}

Clausal operators form a heterogenic class of exponents, comprising both nominals and particles. The common denominator of these exponents can be defined negatively, by contrast to both verbal modifiers (5.2.2) and linking

8 See Khan, Studies, ${ }_{31} \mathrm{ff}$. 
devices (6.1.2). Clausal operators have in their scope not only the verbal form but the entire clause. They do not mark inter-clausal order or sequence but affect the internal organization of the clause and the predicative relation. Clausal operators may head embedded clauses or non-embedded, main, mutually dependent, or dependent clauses. In embedded clauses, the operator serves as the grammatical nucleus, marking the substantival, adjectival, or adverbial identity of the clause. In non-embedded clauses, the operator serves as a modifier of the nexal relation, or it marks the internal segmentation of the clause. The semantic effect of these operators is not only confined to the simple clause, but may bear on the surrounding textual unit as well. In the following, I will briefly present the group of operators in embedded clauses and then the operators in non-embedded clauses.

\subsubsection{Operators of Embedded Clauses}

Embedded clauses exhibit the tightest form of junction on the interdependency scale. Embedding implies the substitution of a finite clause with a simple non-finite morphological constituent of a clause or a phrase. We have already seen that embedded clauses can be simply juxtaposed to their grammatical nucleus, thus introduced into the inter-clausal sequence by means of asyndesis. Other embedded clauses incorporate their grammatical nucleus in the form of a pronoun or a particle, which are here simply referred to as operators. The term 'operator' or 'embedding operator' is preferred to the traditional term, 'subordinating conjunction', since the latter often implies a dichotomous conception of dependency, dividing the entire spectrum of clause linkage between subordination and coordination. As a matter of fact, subordinating conjunctions and coordinating conjunctions are syntactic exponents of different order and can therefore co-occur in the same sequence, the latter preposed to the first (e.g. $f a-m \bar{a})$. Moreover, coordinating conjunctions do not necessarily introduce independent clauses (e.g. wāw al-hâal).

The embedding operators may be classified into those heading substantive (content or mas dar) clauses, adjective (relative or attributive) clauses, and adverbial clauses. Some operators may head more than one clause type. For instance, the operator $m \bar{a}$ may head both content clauses and relative clauses. ${ }^{9}$ Table 6.3 presents a partial list of embedding operators; it contains the operators which head the type of clauses that were studied in the present work:

9 For a detailed account of the discussion in both medieval and modern literature regarding the conjunctional or pronominal nature of exponents such as $m \bar{a}$ and lla $\underline{a} \bar{i}$, which may introduce either a substantival or an adjectival clause, see Goldenberg, Alladī al-Mașdariyyah. 
TABLE 6.3 Operators of embedded clauses

\begin{tabular}{|c|c|c|}
\hline Embedded clause & Operator & Remarks \\
\hline substantival/content clause & 'anna & $\begin{array}{l}\text { 'anna occurs independently or preceded } \\
\text { by a preposition, e.g: li-'anna. In the latter } \\
\text { case, the embedded clause functions } \\
\text { as the genitive complement of the } \\
\text { preposition. 'anna together with mā, can } \\
\text { constitute a compound operator 'annamā. } \\
\text { The clause introduced by 'anna exhibits } \\
\text { the order of the nominal clause; the } \\
\text { subject is assigned the accusative case. }\end{array}$ \\
\hline
\end{tabular}

adjectival/relative clause lla $\underline{d} \bar{\imath} \quad$ The pronoun llad $\bar{\imath}$ is inflected for number and gender, and, in the dual, also for case. The pronoun lladi and its conjoined clause are related by apposition, as clearly observable with the plural form lladina.

$m \bar{a} / m a n \quad$ The pronouns $m \bar{a} / m a n$ occur independently or preceded by a preposition, e.g. bi-mā, mim-man. In the latter case, the embedded clause functions as the genitive complement of the preposition. $m \bar{a}$ and man may introduce the protasis of a conditional construction; $m \bar{a}$ may also introduce content clauses (the so-called $m \bar{a}$ al-mașdariyya) and temporal clauses (the so-called mà al-daymūma). These cases will not be treated in the present work.

adverbial clause

hìna The operator hina is a nominal form in the construct state. Its conjoined clause has thus the status of a genitive complement. 


\subsubsection{Operators of Non-embedded Clauses}

Non-embedded clauses include main clauses, mutually dependent clauses, and dependent clauses. Operators of non-embedded clauses consist of pronouns and particles whose function is to: (a) modify in some way the plain unmarked assertion, and sometimes (b) specify the semantic relation with the adjacent clause; (c) mark the internal segmentation of the clause, and sometimes (d) indicate the relation of the clause to the overall argumentative structure of the text. The operators can be divided into two large groups, according to their modificatory (a-b) or organizational (c-d) function. The list presented in table 6.4 is not exhaustive; it contains the operators that head the type of clauses which were studied in the present work. Notice that some operators assume both functions and thus reoccur in both groups:

TABLE 6.4 Operators ofnon-embedded clauses

\begin{tabular}{|c|c|c|c|}
\hline Group & Sub-group & Operator & Remarks \\
\hline \multirow[t]{2}{*}{ Modificatory } & $\begin{array}{l}\text { Introductory } \\
\text { Modal } \\
\text { Focus }\end{array}$ & $\begin{array}{l}\text { 'inna [la- }] \text {, } \\
\text { lākinna, la'alla, } \\
\text { layta }\end{array}$ & $\begin{array}{l}\text { Clauses headed by 'inna and its 'sisters' } \\
\text { exhibit the order of the nominal clause. The } \\
\text { nominal subject is assigned the accusative } \\
\text { case. 'inna has a number of functions: it } \\
\text { introduces exposition and explication } \\
\text { clauses; often when co-occurring with la-, it } \\
\text { indicates asseveration. lākinna denotes } \\
\text { contrast between clauses. la'alla and layta } \\
\text { denote the modal meanings of possibility } \\
\text { and wish, respectively. }\end{array}$ \\
\hline & & 'innamā & $\begin{array}{l}\text { The compound restrictive particle 'inna-mā } \\
\text { marks the second part of the clause as } \\
\text { focused; the part which follows it directly is } \\
\text { thematic (or, in the case of verbal forms, } \\
\text { made thematic by means of } m \bar{a} \text {, the } \\
\text { embedding operator or nominalizer). }\end{array}$ \\
\hline
\end{tabular}




\begin{tabular}{|c|c|c|c|}
\hline Group & Sub-group & Operator & Remarks \\
\hline & \multirow[t]{3}{*}{ Interrogative } & 'a, hal & 'a, hal introduce yes-no questions. \\
\hline & & $\begin{array}{l}m \bar{a}(\underline{d} \bar{a}), \text { man, } \\
\text { 'ayy }\end{array}$ & \multirow{2}{*}{$\begin{array}{l}\text { The pronominal interrogatives } m \bar{a}(\underline{d} \bar{a}) \text {, } \\
m a n \text {, 'ayy, and the adverbial interrogatives } \\
\text { kayfa, 'ayna, matā, introduce wH-questions. }\end{array}$} \\
\hline & & $\begin{array}{l}\text { kayfa, 'ayna, } \\
\text { matā }\end{array}$ & \\
\hline & Presentative & 'id $\underline{a}$ & $\begin{array}{l}\text { The particle 'id } \underline{a} \text { functions as a presentative } \\
\text { in the narrative. The presentative clause } \\
\text { consists of a nexus, i.e., a nominal entity } \\
\text { and a predicative expansion. 'id } \underline{d} \bar{a} \text {-clauses } \\
\text { are in complementary distribution with } \\
\text { 'id-clauses, in which a verbal form follows } \\
\text { the presentative. }\end{array}$ \\
\hline
\end{tabular}

Organizational Topic 'amma $\bar{a}[\mathrm{fa}-\mathrm{C}$ The particle 'ammā introduces the (nominal
or other) topic and $f a$ - the comment of a main clause.

\begin{tabular}{ll} 
Setting $[$ la $]$ & $\begin{array}{l}\text { The particle 'inna heads the first clause in a } \\
\text { mutually dependent, setting-presentative } \\
\text { construction in the narrative. The setting } \\
\text { clause exhibits the nominal clause } \\
\text { order; 'inna precedes the subject (in the } \\
\text { accusative) and la- the predicate. }\end{array}$ \\
\hline bayna $(m \bar{a})$ & $\begin{array}{l}\text { baynā/baynamā head the first clause in a } \\
\text { mutually dependent, setting-presentative } \\
\text { construction in the narrative. The setting } \\
\text { clause exhibits the nominal clause order. }\end{array}$
\end{tabular}


Clauses introduced by different operators may be nested in each other, as in the following example:

(6.19) fa-'ammā mā qāla bnu 'isḥāqa fì dālika fa-'inna-hü 'innamā stadalla biza'mi-hì 'alā 'anna d̄ālika ka-d̄àlika li-’anna llāha 'azza dikru-hū faraja min halqi ğamīi halqi-hī yawma l-ğum'ati

And as for what Ibn 'Ishạa said about that, he claimed to have found evidence that this was indeed so (i.e., that the creation of the world had begun on Saturday) because God had finished creating His entire creation on Friday. (Tarihh 1, 42)

The initial clause is introduced by the topicalizer 'ammā. The comment, introduced by $f a$-, takes the form of an 'inna-clause with a 'dummy' pronominal theme (damir al-ša'n), whose predicate clause is headed by the focus particle

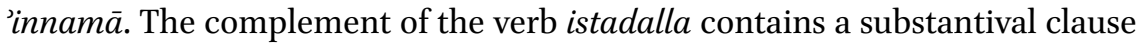
introduced by 'anna. The first three operators, 'ammā, 'inna and 'innamā, introduce main clauses: either a 'high-rank' topicalization ( ğumla kubrā) or a 'lowrank' comment clause ( ̌́umla șugrāa); the last operator, 'anna, introduces an embedded clause, the genitive complement of the preposition 'alā.

\subsection{Summary}

In this chapter, I have presented the exponents of the inter-clausal syntagm, specifically, the implicit and explicit linking devices which introduce the clause into the textual sequence, and the exponents of the intra-clausal syntagm. The latter were divided into two components: word order and subject-predicate agreement patterns, and clausal operators. Operators which head embedded clauses function as the grammatical nucleus of the clause. They mark the substantival, adjectival, or adverbial identity of the clause. Operators which head non-embedded clauses have either a modificatory or an organizational function. Their effect often exceeds the boundaries of the clause and bears on the surrounding textual unit as well. A detailed discussion will follow in the next chapters, devoted to the analysis of verbal patterns at the (complex-)clause level and at the text level. 


\section{The Verbal Paradigm in Embedded Clauses}

In this chapter, a selection of substantival, adjectival, and adverbial clauses is discussed. The discussion is centered on the functional oppositions marked by the verbal forms in these clauses. Each section starts with the analysis of the simple and modified forms, then the compound and the negated forms are discussed. Limited distribution or special uses of a form are specifically noted. Given that some observations are relevant for more than one type of clauses - sometimes even for all - a certain amount of repetition is inevitable. Some semantic notions and other relevant concepts are mentioned only in brief, awaiting further elaboration in the following chapters.

\subsection{Preliminaries}

In the hierarchical structure of the text, embedded clauses constitute the lowest stratum. Embedded clauses are constituents of complex clauses: they occupy the syntactic position of a noun-phrase or an adverbial. In most cases, they do not refer directly to the deictic center of the text (see above 4.2), but relate to it via their matrix clause (for an exception, see [7.72] below). Since embedded clauses do not refer directly to the situation of the speaking/narrating subject, the expression of certain modal meanings, in particular volition, is less salient in them. In general, indicators of subjective involvement are more limited in embedded clauses, though not entirely absent from them. Embedded generic clauses, like all generic clauses, have a privative referential value. However, within the generic domain, one verbal situation may refer to another, thus being assigned a location in time which is relative to it.

The verbal paradigm in embedded clauses consists of indicative forms: simple, modified, and compound. With simple forms, the non-symmetrical configuration of [main clause + embedded clause] is syntactically marked, by the embedding operator and the syntagmatic sequence; with modified and compound forms, it is also morphologically marked, by the modifier or the auxiliary (against the use of a simple form in the main clause).

An important feature which affects the interpretation of the verbal form is the nature of the verbal lexeme or verb-phrase. There are two pertinent semantic distinctions in this regard: the first, between potentially bounded (telic) and unbounded (a-telic) situations, and the second, between situations

(C) MICHAL MARMORSTEIN, 2016 | DOI: 10.1163/9789004310483_008

This is an open access chapter distributed under the terms of the Creative Commons

Attribution-Noncommercial-Non-Derivative 3.o Unported (CC-BY-NC-ND) License 
analyzable into phases, i.e. (dynamic) activities, and ones which are not, i.e. (static) states. ${ }^{1}$

The verbal forms may be sorted into two groups: the first comprises the simple forms yaf'alu, fa'ala, and the active participle, which do not mark the verbal situation as necessarily bounded; the second group comprises the modified forms sa-yaf'alu, qad fa'ala, and the passive participle, which impose an initial or terminal bounding of the verbal situation.

\subsection{Substantival (Content) 'anna-clauses}

The operator 'anna introduces content clauses of verbs of knowledge and acquisition of knowledge (including perception). Rarely, they also follow desiderative verbs. Clauses introduced by 'anna may function as object complements of verbs or as genitive complements of prepositions, e.g.: li-'anna, ka-'anna, ma' 'anna. The operator 'anna heads a nominal clause whose nominal theme is assigned the accusative case.

Given their high frequency in the corpus, substantival 'anna-clauses provide a good starting point for the exploration of the verbal paradigm in embedded clauses. The observations made henceforth regarding the semantic oppositions marked by the verbal forms are for the most part also pertinent in adjectival and adverbial clauses.

The contour of a verbal situation, including its temporal value, is largely determined by the interaction between the verbal lexeme and the verbal form, or to be more precise, between the internal and the external boundary-marking of the verbal situation. Modal nuances are more context dependent than aspectual and temporal meanings, thus not as easily predictable. The time reference of the verbal form is relative to the one established in the main clause. We observe that:

- Both yaf'alu and $f \bar{a}^{c} i l V n$ indicate concurrence with unbounded (including stative) lexemes and posteriority with bounded ones. ${ }^{2}$ The difference is that

1 Though correlating to a large extent, the distinction between these two sets of semantic oppositions should be kept, as the verbal forms interact differently with each of them. Cf. Rothstein, Structuring Events, 12 ff., for a classification of events according to the 'two aspectual properties' defined as [ \pm stage] and [ \pm telic].

2 I use the term 'concurrence' to refer to the temporal relation between two (or more) events which co-occur at the same time frame, though not necessarily at the very same instant. I use the term 'simultaneity' to refer to exact synchronicity. 
yaf'alu marks the dynamic unfolding of the situation while $f \bar{c} i l V n$ marks it as static. Futurity expressed by yaf'alu nearly always involves a modal flavor, whereas with $f \bar{c} i l V n$, a modal meaning does not surface as much. ${ }^{3}$

- sa-yaf'alu indicates that the situation is yet to occur and thus has a posterior time reference with all lexemes, regardless of their being bounded or unbounded, dynamic or static.

- fa'ala indicates persistence ('existing state') with stative lexemes and anteriority with dynamic, either bounded or unbounded, lexemes. ${ }^{4}$

- Both qad fáala and maf'ülVn indicate a bounded verbal situation. The difference is that qad facala depicts a state resulting from a previous process, thus it is analyzable into phases, ${ }^{5}$ while $m a f^{\prime} \bar{u} l V n$ refers to the resultant state alone.

Table 7.1 summarizes the aspectual and temporal distinctions marked by the verbal forms in 'anna-clauses. The examples which follow illustrate each case referred to in the table. Notice that with sa-yaf'alu, maf'ülVn and qad fa'ala only examples with potentially unbounded lexemes are adduced, to show the bounding force of the verbal form:

\section{TABLE 7.1 Temporal-aspectual distinctions in 'anna-clauses}

Time reference

Verbal form

Bounded lexeme Unbounded lexeme

\begin{tabular}{l|l|l}
\hline yaf'alu & posteriority [7.1] & concurrence-dynamic [7.2] \\
\hline$f a ̈ c i l V n$ & posteriority [7.3] & concurrence-static [7.4] \\
\hline sa-yaf'alu & \multicolumn{2}{|c}{ posteriority [7.5] } \\
\hline
\end{tabular}

3 For a more detailed discussion of futurity as expressed by yaf'alu, see below 9.2.1.

4 The meaning paraphrased as 'present state exists' emerges from the interaction of 'anteriors' and stative predicates; see Bybee, Perkins, and Pagliuca, Evolution, 74.

5 I hold a different view than Beeston, Arabic Language, 78, who ascribes to qad a 'conversive force', by which the dynamic aspect of the 'suffix-set' is transformed into a static one. In fact, the modified form qad fa'ala embodies two phases: the (dynamic) process and its (static) result. 
TABLE 7.1 Temporal-aspectual distinctions in 'anna-clauses (cont.)

\section{Time reference}

Verbal form

Bounded lexeme Unbounded lexeme

\begin{tabular}{l|l|l}
\hline fa'ala & anteriority [7.6] & persistence [7.7] (stative lexemes) \\
\hline maf'ūlVn $^{\prime}$ & \multicolumn{2}{|c}{ resultativity-static [7.8] } \\
\hline qadfáala & \multicolumn{2}{|c}{ resultativity-dynamic [7.9] } \\
\hline
\end{tabular}

(7.1) fa-'alima l-qawmu'anna-hum yulāqūna l-qitāla

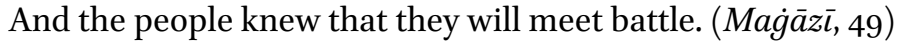

(7.2) fa-'Tam 'anna-hū yurïdu qatla-ka

Then know that he wants to kill you! (Kalila wa-Dimna, 109)

(7.3) 'alim-hum 'annī sǟirun 'ilay-him

Make them know that I am going to them! (Riwāyāt 2, 11)

(7.4) fa-lammā ra'ā l-rağulu 'anna l-diba qạșidun naḥwa-hū

And when the man saw that the wolf was proceeding toward him ... (Kalïla wa-Dimna, 63)

(7.5) wa-'arafa 'anna-hū qad 'awqa'a fì nafsi-hì mà țalaba wa-'anna l-'asada sa-yahdaru l-țawra wa-yatahayya'u la-hū

And he knew that he had planted in his mind what he wished, and that the lion will be wary of the ox, and will get prepared for him. (Kalïla waDimna, 95)

(7.6) 'uhbira 'anna 'amra bna sālimin wa-'aṣhāaba-hū rāḥu 'amsi

He was informed that 'Amr b. Sālim and his companions had gone yesterday. (Maj̄̄āi, 205)

6 The verb sāra may have either a bounded or an unbounded reading (i.e., 'to go away, depart': 'to go'). In [7.3], sẫiran is followed by the complement 'ilay-hi which specifies the destination of the going, thus the participle is interpreted as bounded. 
(7.7) 'innā nahšā yā rasūla llāhi 'an yazunna 'aduwwu-nā 'annā karihnā lhurūğa 'ilay-him ğubnan 'an liqāì-him

We fear, O Messenger of God, that our enemy will think that we did not want to come out to them out of fear of encountering them. (Magia żi, 210)

(7.8) fa-'awwalu mā 'awqa'a fì rü'-'̄'anna māl-ì mahfüzun 'alay-ya The first thing that struck my mind is that the preservation of my wealth is incumbent upon me (lit. 'that my wealth is preserved upon me'). (Buhalä', 78$)$

(7.9) ğìtu'uhbiru-ka'annì qad 'àmantu bi-llāhiwa-bi-rasūli-hīmuhammadin I came to inform you that I have become a believer (lit. 'that I have believed') in God and in his Messenger Muhammad. (Sira 1, 230)

The meaning of the verbal form is not only affected by the lexico-grammatical features described above. Quite often, the surrounding context or other pragmatic features are involved in its interpretation. For instance, repetition or presupposition seem to explain cases in which yaf'alu forms, instead of indicating posteriority with bounded lexemes, indicate concurrence. In these cases, yaf'alu refers to a situation whose 'actual referential concern' is extended over a period of time including the one indicated in the main clause. ${ }^{7}$ What calls for the 'still actual or relevant' interpretation of yaf'alu is its being conceived or presented as given or backgrounded. Consider, for instance, the following example:

(7.10) wa-sa'altu 'an-i l-muġannīna 'ayna yağtami'ūna [...] wa-qad balaġa-n̄̄ 'anna l-qawma yağtamiüna inda-ka

And I asked about the singers, where do they gather [...] I came to know that the people gather at your [place]. (Riwāyāt 1, 17)

The verb yağtami'üna in the substantival clause repeats the same information that was already mentioned in the question 'where do they meet', and whose abiding actuality and relevance are in fact presupposed by it. It indicates a frequentative situation taking place within the time frame indicated by qad

7 Janssen, Preterit as Definite, 168-169, explains the use of the present tense in such cases where the event 'does not coincide temporally with the time the sentence is spoken', as indicating 'actual referential concern to the speaker from his vantage point'. See also below 9.2.1. 
balaga-nī. The same frequentative meaning of yaf'alu with bounded lexemes is also observed in generic 'anna-clauses, which by definition refer to information that is presented as common ground shared by all:

(7.11) yā 'ağaban man ra'ā 'aw sami'a 'anna l-buzāta tahtațifu l-g̈ilmāna O how astonishing! Who [ever] saw or heard that falcons snatch children. (Kalïla wa-Dimna, 119)

As opposed to the frequentative yaf'alu, a generic participial form, whether active or passive, yields a static meaning of the verbal situation, due to the nonphasal contour marked by this grammatical form:

\section{(7.12) kāna bi-yaqūnin ma'lūman 'anna l-zamāna muḥdațun It was surely known that time is created. (Ta'rih 1,18$)$}

Substantival 'anna-clauses also feature compound forms with the anterior kāna. The situation expressed by kāna yaf'alu is located within a time span previous to the one indicated in the main clause; the situation expressed by kāna facala is located at a point in time previous to the one indicated in the main clause. Thus, kāna fáala carries a double marking of anteriority: it accentuates the anterior meaning already indicated by the simple fa'ala (see above 5.1):

(7.13) i'lam 'annìmundu yawmi waladtu-hā [...] kuntu'arfa'u min daqìqi kulli 'ağinatin hafnatan

Know, ever since I gave birth to her [...] I used to take a handful of flour from every piece of dough. (Buhalä, 55)

(7.14) fa-'ahbara-nā 'anna muhammadan kāna 'arada li-'iri-nā fì bad'ati-nā And he informed us that Muhammad had been observing our caravan since we started our [journey]. (Maj̄àzí, 28)

In my corpus, the negated forms lā yaf'alu, mā fa'ala, and lam yaf'al were attested in 'anna-clauses. The negative particles do not seem to have special bearing on the temporal interpretation of the verbal form: with bounded lexemes, lā yaf'alu has a posterior time reference, whereas with unbounded or stative lexemes, it has a concurrent meaning:

(7.15) wa-waqa'a fìnafsi-hĩ ’anna-hū là yarğíu 'ilā makkata It occurred to him that he is not going back to Mecca. (Mag் $\bar{a} z \bar{l}, 36)$ 
(7.16) ma'a 'annì là 'āmanu 'an takūna l-dāiratu 'alay-kum Along with that, I am not sure that you will have any success. (Maġāzi, 63)

The negated forms $m \bar{a}$ fa'ala and lam yaf'al were both found to be used in the same syntactic environment. A functional distinction between the two, as the one found in main clauses (see below 9.2.4), could not be observed in embedded clauses introduced by 'anna:

(7.17) fal-ya'lam 'anna-hū lam yu'ta fì dālika min qibali-nā wa-'innamā 'utiya min qibali ba'di nāqilī-hi 'ilay-nā

[The reader] should know that he was not given this [information] by us, but rather it was brought by some of its transmitters to us. (Ta'rih 1 , 7)

(7.18) wa-kāna man tahallafa lam yulam li-'anna-hum mā ḩarağù 'alà qitālin wa-'innamā harağù li-l-ìri

Whoever stayed behind was not scolded because they did not go out for a battle, but rather they set out for the caravan. (Maj $\bar{a} z \bar{\imath}, 21)$

On very rare occasions, 'anna-clauses follow desiderative verbs. In my corpus, such examples were only encountered in the Sahịh text, where 'annaclauses followed the verb wadda 'to wish', featuring both yaf'alu and fa'ala. Given the scarce evidence, it is hard to tell the exact functional distinction between both forms. However, the particular contexts in which the examples are found suggest that yaf'alu is used to refer to a hypothetic yet possible state of affairs, while fa'ala is used to refer to a counterfactual one (see also above $5 \cdot 3 \cdot 2)$ :

(7.19) wa-la-wadidtu 'annī uqtalu fí sabïli llāhi

I wish that I would be killed for the cause of God. (Șahịh, 17)

(7.20) la-wadidtu 'anna-ka dakkarta-nā kullayawmin

I wish that you had reminded us every day. (Șahịh, 29)

In [7.19], 'uqtalu conveys the wish of the Prophet, which, at the time when pronounced, is still realizable. In [7.20], on the other hand, the wish dakkarta-na is answered with an explanation as to why the desired action is not feasible. 
Adjectival clauses may be adjoined directly to their nominal antecedent by means of juxtaposition, or they may join it via a mawșūl 'conjunctive pronoun', semantically representing the nominal antecedent and syntactically appositive to it. The mawșūl, here referred to by the general term 'operator', functions as the grammatical nucleus of the clause. In adjectival clauses where no such operator is explicitly present, one may assume, on the basis of paradigmatic opposition, that an implicit conjunctive pronoun occupies this slot. ${ }^{8}$ Another way of analyzing this construction is to view the close syntagmatic contact between the clause and its antecedent as the marker of the adjectival relation. ${ }^{9}$ Indeed, asyndetic adjectival clauses must immediately follow their nominal antecedent, and cannot be freely positioned in the text, unlike adjectival clauses which are headed by an operator (i.e., which incorporate their grammatical nucleus).

The pronominal operators which introduce adjectival (or, more generally, relative clauses) may be classified into two sets: (a) lladī and its inflection and (b) mā, man. The first set marks the grammatical categories of number, gender, definiteness, and sometimes case; the second set marks the distinction between persons and non-persons. The lladit-set often follows its nominal antecedent while the $m \bar{a} / m a n$-set seldom follows an explicit noun-phrase. Both types of adjectival clauses can occupy any syntactic position in a complex clause or in a nominal phrase in which a simple noun can occur.

The verbal paradigm in adjectival clauses consists of the same set of indicative forms found in substantival 'anna-clauses. The (implicit and explicit) operators introducing adjectival clauses do not impose a certain word order on the clause. I exclude from the present discussion conditional constructions headed by the operators $m \bar{a}$ and man: the overall configuration of these bipartite constructions, as well as their verbal paradigm (comprising, besides fáala, the apocopate $\left.y a f^{\prime} a l\right)$, are clearly distinct from the ones found in adjectival clauses.

\subsection{1 llad̄ì-clauses}

The pronominal operator lladī heads adjectival clauses whose antecedent is determined. It marks the categories of number and gender in the singular

8 Cf. Goldenberg, Allad̄īal-Mașdariyyah, 252.

9 For such a view of 'contact clauses' in English (e.g.: 'this is the boy we spoke of') see Jespersen, Modern English, 3, 81ff. 
and plural and, in addition, the category of case in the dual. The nominal antecedent of lladit-clauses may be either particular and specific or generic.

The verbal paradigm in lladi-clauses consists of simple, modified, and compound indicative forms. In principle, the same observations outlined above with respect to 'anna-clauses are pertinent also in lladit-clauses. There are, however, some modal nuances which appear to be more salient in this type of adjectival clauses.

The form yaf'alu indicates concurrence with unbounded lexemes:

(7.21) fa-taqaddama bi-hã 'ilā mawdịi-hà llad̄i yurìdu rasūlu llāhi 'an yaḍa'a$h \bar{a} f i-h i$

And he proceeded with it to the place where the Messenger of God wanted him to place it. $\left(\right.$ Mag $\left.\bar{a} z \bar{\imath}, 5^{6}\right)$

Repetition or presupposition may bring about a concurrent reading of yaf'alu with bounded lexemes:

\section{(7.22) man hādā l-rağulu llậì yadribu 'alay-ki bāba-ki kulla laylatin}

Who is this man that knocks at your door every night? (Sira 1, 335)

In [7.22], yadribu repeats the same piece of information that was already recounted in the previous narrative: fa-ra'aytu 'insānan ya'ti-hā min ğawfi llayli fa-yadribu 'alay-hā bāba-hā 'And I saw a man coming to her in the middle of the night and knocking on her door'. The adverbial phrase kulla laylatin makes it plain that the situation expressed by yadribu is frequentative. ${ }^{10}$ The same frequentative meaning of yaf'alu is also observed in lladit-clauses whose antecedent is generic:

\section{(7.23) wa-l-lāzibu huwa llad̄i yaltaziqu ba'ḍ-hū bi-ba'ḍin}

And the sticking [substance] is that which sticks to something else. (Ta'rīh 1, 88)

The difference between yadribu in [7.22] and yaltaziqu in [7.23] resides in the bounded or unbounded time span in which the frequentative repetition takes place, a span determined by the reference to a particular thus bounded

10 The presence of the adverb kulla laylatin is by no means a necessary condition for the habitual interpretation of $y$ af'alu. It provides an additional, explicit marking of this meaning. 
subject-entity ('this man') or to a generic thus unbounded subject-entity ('the sticking substance').

It is rather uncommon that yaf'alu within a lladit-clause indicates plain futurity. Consider the following example:

(7.24) 'andiğ hubz-ì llad̄ìyūdáu bayna yaday-ya

Prepare well my bread that is served to (lit. 'put in front of') me! (Buhalä', 84)

It is the imperative 'andig in the main clause that sets a future time reference for the situation in its entirety, while $y \bar{u} d a^{\prime} u$ retains a frequentative meaning. Rather than asserting a future occurrence, yaf'alu often conveys the meanings of possibility and ability:

(7.25) wa-man-i llad̄i yuhriğu-nā min-hu 'a-lasnā 'a'azza l-arabi wa-'aktarahum mälan wa-silăhan

Who will [be able to] take us out of it? Aren't we the strongest and most wealthy and armed among the Arabs?! (Riwāyāt 2, 36)

The simple form fa'ala has anterior meaning with dynamic lexemes. With stative lexemes it indicates persistence:

(7.26) naḥnu nu'ți-ka llad̄ì sa’alta

We will give you that which you asked for. (Mag்āzī, 373)

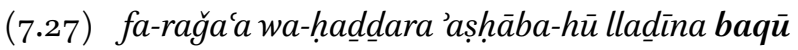

And he came back and warned his friends who stayed [there]. (Riwāyāt $2,14)$

While anteriority is doubly marked by the compound form kāna fa'ala (see [7.33] below), the modified qad fa'ala emphasizes the complete realization of the verbal situation, as shown in [7.28]. We recall that both these meanings, i.e., anteriority and completion, may be conveyed by fa'ala, although facala is not explicitly marked for any of them:

\section{(7.28) 'aštahì l-lạ̣ma lladì qad taharra'a}

I crave for the meat that has been overcooked. (Buhalä', 91)

Participial forms, both active and passive, are not very common in lladit-clauses. In my corpus, there were only examples in which the participle could be interpreted as concurrent, with both unbounded and bounded lexemes: 
(7.29) 'a-ra'ayta law qultu fì-ka ġayra llad̄ì 'anta la-hū mustaḥiqqun min-a lbāțili

Look at that, if I would have composed false poems about you, which you are not worthy of ... (Riwāya $\bar{a} t 1,7)$

(7.30) fa-mā llad̄ì anta fi-hi l-'āna muğmíun

What is it that you are decided about now? (Kalìla wa-Dimna, 67)

In cases when the time reference indicated in the main clause is (concrete or fictional) past, the distinction between yaf'alu and kāna yaf'alu in the adjectival clause is subtle: the compound form reproduces the expression of past time reference, whereas the simple form is temporally unspecified, indicating only a frequentative repetition:

(7.31) fa-harağat min madhali l-māì lladì kāna yahruğu min-a l-ġadìri And it came out from the mouth of the water that would flow out from the pond. (Kalïla wa-Dimna, 9o)

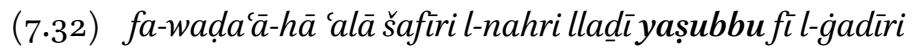
And they both laid it on the edge of the river that flows to the pond. (Kalïla wa-Dimna, 91)

Just as in 'anna-clauses, in lladit-clauses, the use of the compound form kāna fa'ala accentuates the anterior meaning indicated already by the simple form (see above 5.1):

\section{(7.33) wa-'ayna lladì kunta habbarta-nī bi-hì}

Where is that which you have told me about? (Riwāyāt 2, 193)

In my corpus, I have encountered very few examples of negated forms in llad $\bar{\imath}^{-}$ clauses. The attested negated forms are là yaf'alu and lam yaf'al, referring to future time and past time, respectively:

\section{(7.34) al-ḥamdu li-llāhi llậī là yubramu mā naqada}

Praise be to God; what He has destroyed will never be re-established. (Ta'inh 6, 3286) 
(7·35) wa-kāna qad balaġa fìl-buhliwa-l-takdiyati wa-fì katrati l-māli l-mabāli-

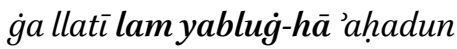

He has attained, through his greed and mendicancy and [his] great wealth, sums of money that no one has ever attained [before]. (Buhalä, $71-72)$

In [7.34], due to the divine nature of the antecedent, lāyaf'alu is interpreted as a certain prediction. In [7.35], due to the presence of a generic referee ('ahadun '[no]one'), lam yaf'al is interpreted as a sweeping negation of the past (see below 11.3). In both cases, the verbal form does not negate the occurrence of a specific future or past event, but rather affirms the validity of a general truth.

\subsubsection{Asyndetic Adjectival Clauses}

Asyndetic adjectival clauses, șifa 'descriptive' in the Arabic grammatical tradition, are not introduced by an explicit operator. Rather, they follow directly after their nominal antecedent, which may be analyzed as the nucleus of the clause (see above 7.3). The nominal antecedent in asyndetic adjectival clauses is not determined. It may be either particular and non specific or generic.

The verbal paradigm in asyndetic adjectival clauses consists of the same forms found in lladit-clauses. In general, the aspectual and temporal distinctions that were specified above with regard to 'anna-clauses are also observed in asyndetic adjectival clauses. Yet, this type of clauses features some particularities which deserve a discussion of their own.

With stative lexemes, yaf'alu indicates concurrence with the situation expressed in the main clause, whether the overall temporal frame is past or nonpast:

(7.36) wa-ğa'alū kullamā hāğa-hum 'ahadun min-a l-awsi wa-l-hazraği bišay'in yakrahūna-hū lam yamši ba'du-hum 'ilā ba'din

Whenever someone from 'Aws or Hazrağ provoked them with something they hated, they stopped (lit. 'began not') going to one another [for help]. (Riwāyāt 2, 14)

(7.37) ib'aț maī rağulan min țiqāti-ka yafhamu bi-l-'arabiyyati

Send with me one of your trustworthy men who understands Arabic! (Riwāyāt 2, 192)

The same concurrent meaning of yaf'alu is also evident with dynamic, unbounded lexemes: 


\section{(7.38) fa-laqiya mrảatan taḥmilu ța'āman}

And he came across a woman carrying food. (Sira 1, 320)

Rather than mere futurity, it is often the case that $y$ af'alu with bounded lexemes conveys the modal meanings of ability or possibility:

(7-39) 'arā fì hādihi l-ağamati samakan kațīran nașìdu-hū li-muddatin I see in this swamp many fish that we could fish for a while. (Kalila wa-Dimna, 84)

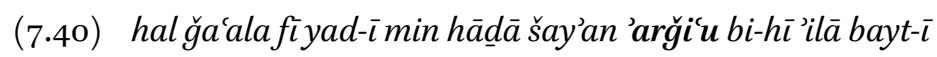

Did he thereby put anything in my hand I could take back to my home? (Buhalä) 49)

In certain cases the exact modal nuance expressed by yaf'alu is not easy to demarcate. Thus, the meaning of ability appears sometimes to be fraught with that of obligation. This is the case in [7.41]-[7.42], where people are appointed to some duty, specified in the adjectival clause:

(7.41) wa-sta'mala rasūlu llāhi 'alà l-ḥarasi muḥammada bna maslamata fì hamsina rağulan yațüfüna bi-l-'askari

The Messenger of God appointed Muhammad b. Maslama as the head of the guard of fifty men, who would go around the army [camp]. (Maḡāzi, 217)

(7.42) wa-'amara la-hum bi-hādimin yahdimu-hum wa-'abdin yasqī-him l$m \bar{a} a$

He ordered [to provide] them [with] a servant that would serve them and a slave that would provide them water. (Riwāyāt 1, 7)

In all the above examples, the interpretation of $y a f^{\prime} a l u$ as expressing plain futurity, devoid of modal nuances, does not seem to be supported by the context. However, the following example presents us with a different case:

(7.43) wa-'in lam taf'alū kāna la-hü fi-kum dabhun țumma bu'ițtum min ba'di mawti-kum fa-ğu'ilat la-kum nārun tuḥraqūna fi-hā

But if you do not act [as he calls you to] he will have you slaughtered; then you will be raised from the dead and put in fire, in which you will be burned. (Sir $a 1,326)$ 
Although not directly uttered by the Prophet, this is a prophecy stating the general divine plan. In this context, the statement is granted the status of an absolute truth and, consequently, conveys the utmost certainty regarding its future execution (cf. [7.34] above). Thus, compared with the other examples, we may say that tuhraqūna indeed functions as an assertion of future event.

Just as in substantival 'anna-clauses and adjectival llad̄it-clauses, in asyndetic adjectival clauses, fa'ala with stative lexemes indicates persistence, whereas with dynamic lexemes it indicates anteriority relative to the time frame established in the main clause:

(7.44) su'ila l-nabiyyu 'an 'ašyāà kariha-hä The Prophet was asked about things he detested. (Sahịh, 36)

(7.45) 'utiya hiraqlu bi-rağulin 'arsala bi-hì maliku ġassāna Heraclius was brought a man, whom the king of Gassān had sent. (Sạịh, 9)

The modified form qad facala, due to the bounding force of $q a d$, indicates anteriority with both stative and dynamic lexemes, relative to the time frame established in the main clause:

(7.46) ințaliq bi-nā 'ilā 'adnā mã̄i l-qawmi [...] bi-hā qalïbun qad 'araftu 'udūbata $m \bar{a} \bar{i}-h \bar{a}$

Let us reach the nearest point to the water of the people $[\ldots]$ in it there is a well, whose sweet water I have already come to know. (Majāzi, 53)

(7.47) fa-ğalasatā 'alā sarīin qad wuḍi'a la-humā

They both sat on a bedstead that had been put down for them. (Riwāyāt 1, 24)

We observe a special use of fa'ala and qad fa'ala in asyndetic adjectival clauses whose nominal antecedent functions as an internal object, derived from the same root as the main verb (either in the form of a verbal noun or a nomen vicis). In these cases, fa'ala and qad fa'ala do not refer to an anterior situation, but to the immediate consequence of the preceding event. The nominal antecedent does not refer to a particular entity but to an outstanding exemplar of a certain type or kind ('such a $\mathrm{x}$ that'): 
(7.48) fa-șāḥa șayhatan sami'a-hā rahțu-hū

He shouted [such] a shout that it reached his troop (lit. 'that his troop heard it'). (Riwāayāt 2, 24)

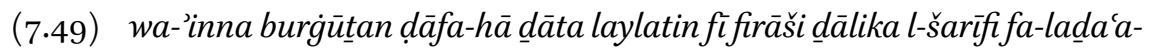
hü lad'atan 'ayqazat-hu

And a flea was her (i.e., the ant's) guest one night, in the bed of that distinguished man, and he stung him [such] a sting that it awakened him. (Kalïla wa-Dimna, 93)

(7.50) fa-'inna-hū qad 'afrața fí 'amri l-țawri 'ifrātan qad hağğana ra'ya-hū For he had exaggerated in the matter of the ox [such] an exaggeration that made him (lit. 'his mind') scorned. (Kalïla wa-Dimna, 81)

In my corpus, the participle occurred only in very few cases as the predicate of an asyndetic adjectival clause. With bounded lexemes, active participial forms were found to indicate posteriority relative to the time frame established in the main clause. Compared to yaf'alu, the participle seems to not be imbued with the modal nuances of possibility and obligation; rather, a straightforward reference to the immediate or expected future is expressed by the participle:11

(7.51) wa-qad ruwiya 'an rasūli llāhi [...] 'axbārun 'anā dِākirun min-hā ba'da mā hadara-nī

There have been reports transmitted on the authority of the Messenger of God [...] of which I shall mention some that have reached me. (Ta'rin $1,61)$

Asyndetic adjectival clauses also exhibit compound forms. As elsewhere, kāna indicates an anterior point of reference (relative to the main clause), while the predicative forms fa'ala and yaf'alu are left to indicate the aspectual opposition between bounded/incidental and unbounded/habitual situations. The compound kāna fáala accentuates the meaning of anteriority whereas kāna qad facala marks both the anteriority and completion of the verbal situation:

11 For the notions of 'immediate future' or 'expected future', referring to 'events which are expected to occur in the near future, or to those which have been prearranged', see Bybee, Perkins, and Pagliuca, Evolution, $249 \mathrm{ff}$. It may be that with immediate future one is not concerned with the expression of predictions in the strict sense, but with 'assertions announcing the imminence of an event' (273), see also below 9.2.1. 
(7.52) hādihi riwāyatu l-kalbiyyifí qașāida kațīratin kāna yaqūlu-hā fi-hi This is al-Kalbì's version as to many poems he used to compose with regard to him. (Riwāyāt 2, 187)

(7.53) fa-stahrağa sayfan kāna la-hū wa-dir'a hạadìdin kānā dufinā fì nāhiyati l-mazraiati

And he drew out a sword he had and an iron armor that had been buried at the corner of the field. (Mag்äzi, 208)

(7.54) fa-lammā stațqala nawman 'amadat 'ilā sammin kānat qad hayya'athu

And when he fell into heavy sleep, she took up a poison that she had fixed. (Kalīla wa-Dimna, 78 )

In my corpus, asyndetic adjectival clauses featured the negation of yaf'alu with either $l \bar{a}$ or $m \bar{a}$. As is the case in main clauses, māyaf'alu was mostly used with stative and unbounded lexemes, thus indicating concurrence with the main clause (see also below 9.2.4):

(7.55) la-qad-i staqbalta-nì bi-’amrin mā 'arā-ka qulta-hū li-'ahadi raciyati-ka mundu walayta

Indeed, you have welcomed me with something I don't think you have said to anyone of your citizens (lit. 'herd') since you became the ruler. (Ta'rīh 3, 1145)

As already illustrated above, the negative lāyaf'alu, like the affirmative yaf'alu, may convey various degrees of certainty. The interpretation of the form as expressing a lower or a higher degree of certainty is determined, inter alia, by the particular or generic context in which the clause is situated. Consider the following examples:

(7.56) hattā habasa-hüfìmaḥbasin là yadhuulu 'alay-hi fi-hi'ahadun To the point that he put him in prison in which no one would/could come to [visit] him. (Riwāyāt 2, 187)

(7.57) 'inna min-a l-šağari šağaratan lā yasquṭu waraqu-hā There is a kind of tree (lit. 'a tree among the trees') whose leaves never fall. (S. Sặh 1, 25) 
In the narrative from which [7.56] is extracted, the characterization of the prison as such that 'no one would/could visit' is invalidated later in the story when someone in fact visits the person in prison. By contrast, the generic statement in [7.57] conveys a fact which cannot be invalidated.

The same consequential meaning indicated by fa'ala and qad fa'ala following an internal object was also attested with the negated form mä fa'ala. The negated form lam yaf'al, also when following an internal object, was used to indicate past negation:

(7.58) wa-qad fuğíat nafs-ì bi-fağı̌áatin māa 'așabtu min-hā 'iwadan My soul was afflicted by [such] a disaster, for which I could not find consolation. (Kalïla wa-Dimna, 120)

(7.59) wallāhi la-'in 'ištu la-ka la-'aqtulanna-ka qitlatan lam yuqtal-hä 'arabiyyun qattu

By God, If I outlive you[r plot], I will kill you in a way by which no other Arab has ever been killed yet. (Riwāyāt 2, 195)

\subsection{3 mā-clauses}

The pronominal operator $m \bar{a}$ represents non-persons. The thing or matter indicated by $m \bar{a}$ may have either particular or generic, specific or non-specific reference. The clause headed by $m \bar{a}$ rarely follows an explicit nominal antecedent. However, it is often the case that the clause is preceded or followed by a prepositional min-phrase, which serves to specify the lexical content represented by the grammatical nucleus $m \bar{a}$ (see [7.63] and [7.72] below). ${ }^{2}$ Clauses headed by $m \bar{a}$ may occur independently or as genitive complements of prepositions or nouns in the construct state. ${ }^{13}$

The verbal paradigm in relative $m \bar{a}$-clauses comprises simple, modified, and compound indicative forms. In the following, the semantic oppositions between these will be discussed.

With unbounded (including stative) lexemes, yaf'alu indicates concurrence, whether the temporal frame established in the main clause is past or nonpast:

12 The degree or kind of specificity indicated by a min l-bayān phrase vis-à-vis the definite article and the tanwin is a subject well worthy of study.

13 Though relative $m \bar{a}$-clauses may be paraphrased by substantives, they are distinct from other substantival $m \bar{a}$-clauses, in that they do not express content ( $m \bar{a}=$ 'that') but refer to an entity $(m \bar{a}=$ 'what'). 
(7.6o) kāna rasūlu llāhi 'id 'amara-hum 'amara-hum bi-mā yuṭīqūna Whenever the Messenger of God ordered them, he ordered them to do what they were able to bear. (Șahịh, 13)

(7.61) fa-qad yahḍuru țáāma-kum l-šayhu llad̄i qad dahaba famu-hū wa-lșabìyu llad̄i lam yunbat famu-hū wa-'aț 'imū-hum mà ya'rifüna For the old man whose teeth (lit. 'mouth') are already gone, and the boy whose teeth haven't come out yet, may well attend your meal, so provide them with what they are accustomed to! (Buhalä, 105)

Also with bounded lexemes, yaf'alu may indicate concurrence. In such cases, the content expressed by yaf'alu is presupposed or backgrounded, as in the following example:

(7.62) fa-lam ya'rid 'alay-hi l-ța'āma wa-nahnnu na’kulu [...] fa-qultu subḥana llăhi law danawta wa-'așabta ma'a-nā mim-mā na'kulu

He did not offer him anything to eat while we were eating [...] so I said: 'God forbid! If you could draw near us and have some of what we are eating.' (Buhalä', 38)

The speaker refers to a state of affairs that was previously mentioned, and that is presented as still abiding at the time of the utterance. The concurrent reading of yaf'alu is occasionally corroborated by adverbs referring to the present situation of speech:

(7.63) wa-'innamā kānat ǐšat-ì 'ilā l-yawmi mim-māa 'așīdu hāhunā min-a lsamaki

For my living until today was [based] on those fish I catch here. (Kalïla wa-Dimna, 83)

It is interesting to compare [7.62] and [7.64], where the same lexical content, i.e. 'to eat', is expressed by yaf'alu:

\section{(7.64) 'innī qad taraktu la-ka mā ta'kulu-hū 'in hafazta-hū}

I have left you what you could eat (i.e. live from) if you are careful of it. (Buhalä', 73)

In [7.64], as is usually the case with bounded lexemes, yaf'alu indicates posteriority. The meaning of futurity is nevertheless coupled with that of possibility: the certainty of the prediction expressed by ta'kulu-hū is not only limited by the 
subjective epistemological position of the predictor, but also by the following conditional. A somewhat different position for making predictions is assumed by the first person, when committing himself to doing something. In this case, the prediction is inevitably tinted with the subjective intention of the executer (see also below 9.2.1):

(7.65) yāa 'àla 'awsin qātilū 'alā l-'aḥsābi wa-șna'ū mițla mā 'aṣna'u O people of 'Aws, fight for honor (lit. 'for the noble descents') and do as I will do! (Maj̇̄̄zí, 224)

When generically interpreted, yaf'alu is not located in a time relative to the temporal frame established in the main clause. The generic yaf'alu indicates a concurrent meaning, inasmuch as it conveys a general truth that is valid for all times (see below 11.3). This temporal relation is observed with both bounded and unbounded lexemes, the difference is that the first have a (dynamic) frequentative reading while the latter have a static one:

(7.66) māta ka-mā yamūtu l-nāsu

He died [the same way] as people die. (Riwāyāt 2, 21)

(7.67) lammā qadima 'alā l-nu'māni șādafa-hū lā māla inda-hū wa-lā 'atẫta wa-lā mā yaṣluḥu li-malikin

When he arrived to Nu'mān he found him with neither money nor property or whatever is appropriate for a king. (Riwāyāt 2, 187)

To see the difference between particular and generic reference, it is interesting to compare [7.75] below and [7.66]. In the first case, the characterization of the particular l-nāsu as 'those who used to stand at the door' is limited in time, while in the latter case the characterization of the generic l-nāsu as 'those who die' is an a-temporal fact.

The simple form fa'ala indicates with stative lexemes a persisting situation, as shown in [7.68]. With dynamic lexemes, fa'ala indicates anteriority relative to the time frame established in the main clause, whether that be past or nonpast, as shown in [7.69]:

(7.68) naf'alu yā 'abā l-qāsimi mà 'ạ̣babta

O ’Abū Qāsim, we will do what you want. (Maġāzì, 364) 
(7.69) 'a-là tahmusu mā 'aṣabta min banì l-nadìri ka-mā hamasta mā 'aṣabta min badrin

Will you not take one fifth of what you have taken [as booty] from Banū Nadiir, the same as you took one fifth of what you had taken [as booty] from Badr? (Majīāzī, 377)

As elsewhere, also in $m \bar{a}$-clauses the modified form qad facala, with both bounded and unbounded (stative or dynamic) lexemes, depicts a static situation resulting from a dynamic process:

(7.70) 'așāba-nā min-a l'amri mà qad 'alimta

The matter that you know (lit. 'you have come to know') of has befallen us. (Maj̇̄zzì, 411)

(7.71) wa-'innā nahšā 'alay-ka wa-'alà qawmi-ka mā qad dahala 'alay-nā We fear for you and your people [that you will face] that which has befallen us. (Sïra 1, 252)

The example below illustrates a special case: the modified form qad mada does not refer to a point in time previous to the narrative time indicated by qāla; rather, it indicates anteriority relative to the time of reporting itself:

(7.72) fa-qāla bnu 'isḥāqa mā qad maḍa dikru-hū Ibn 'Isḥāq said what has already been mentioned. (Ta'rīh 1, 192)

Just as yaf'alu, the active participle fácilun may indicate either concurrence with unbounded lexemes or posteriority with bounded ones. The differences are that: (a) fácilun indicates a static rather than a frequentative situation, and (b) the future indicated by fä ilun is not fraught with modal nuances such as ability and obligation. Rather, this form indicates imminence or an expected future (see also [7.51] above):

(7.73) wa-'in zafirtum lam nanam 'an-i l-țalabi [...] wa-yašg̉al-kum min šảninā mà 'antum-u l-āna min-hu hà̃ūuna

If you overcome [us], we will not rest [from] looking for revenge [...] and you will be troubled by our matter which you are now free of [concern]. (Riwāyāt 2, 40) 
(7.74) wa-qad ġadat qurayšun fa-ğalasū fì 'andiyati-him yantazirūna mà 'abū ğahlin fã iilun

Qurayš had already had breakfast and sat in their assemblies to watch what 'Abū Ğahl was about to do. (Sira 1, 190)

In $m \bar{a}$-clauses the compound form känayaf'alu is primarily used to refer to an unbounded or recurring situation, extending over a period of time previous to the one indicated in the main clause:

\section{(7-75) fa-waqafa 'alā mā kāna yaqifu l-nāsu 'alay-hifíl-qadìmi}

And he stood [at the door] in the same way people used to stand in old times. (Riwāyāt 1, 252)

We observe a less common use of the compounds kāna yaf'alu and kāna fāilan in $m \bar{a}$-clauses, where kāna serves to indicate a hypothetic meaning. In these cases, the $m \bar{a}$-clause functions as the topic of a complex clause, whose following comment is preceded by $f a$-. This structure, similar to topicalizations marked by 'ammā $f a-$, is reminiscent of conditional constructions. The resemblance, however, is syntactic rather than semantic, since the meaning of implication clearly does not emerge in these structures:

(7.76) fa-mā kuntum turīdūna 'an taṣna'ū yawman min-a l-dahri fa-min-a l'āni

And that which you would have liked to do some day—now is the time [to do it]. (Mag் $\bar{z} z \bar{\imath}, 364)$

Anteriority is doubly marked with the compound form kāna fa'ala. The compound kāna fáala is not only used in the narrative, relative to the past or the fictional time indicated by fa'ala, but also in the dialogue, relative to the present time of speech:

(7.77) wa-salaba-hū mā kāna 'àtā-hu min mulki l-samā̉i l-dunyā wa-l-'arḍi He deprived him of the rule that he had (lit. 'had come to him') over the lower heaven and the earth. (Ta'rin 1, 101)

(7.78) qad 'alimta haqqa-ka 'alay-ya wa-widda mā bayn-īwa-bayna-ka wa-mā kuntu ğa'altu la-ka min nafs-ī wa-dimmat-ì ayyāma ’arsala-nì 'ilay-ka l'asadu

You know my duty to you, and the affection between us, and my devotion (lit. 'soul') and responsibility for you in the days when the lion sent me to you. (Kalïla wa-Dimna, 96) 
The contrast between a dynamic aspect marked by yaf'alu and a static aspect marked by the participle is most evident in kāna-compounds, comparing, for instance, [7.75] above and [7.79] below:

(7.79) tabayyana la-hum mā kāna 'an-hum mustatiran

They became aware of what had been concealed from them. (Ta'ring 1 , 94)

The static (or non-phasal) structure of the verbal situation is indicated by both the active and passive participles with the anterior kāna. In [7.80], the topical $m \bar{a}$-clause refers to a situation (kāna mulattahan) which came about prior to the past event indicated in the comment (dulika):

(7.80) fa-mā kāna min-hā mulațahan dulika d̄ālika dalkan šadìdan

And that part of it (i.e., of the thick bread) that had been smeared - this was rubbed well. (Buhalä', 85)

Topical $m \bar{a}$-clauses exhibit the hypothetic use of kāna also with the participle (see [7.76] above). In [7.81], the imperative $f a-s ̦ n a-h u$ in the comment clause establishes a future time frame, in which the situation indicated by kunta șānican could be realized:

\section{(7.81) fa-mā kunta șāni'an 'id ā hallū bi-ka fa-ṣnac-hu}

Then do what you would do when they stay with you! (Magia żi, 204)

Clauses headed by $m \bar{a}$ feature the negation of yaf'alu with $l \bar{a}$ (the negation with $m \bar{a}$ is apparently precluded in order to avoid homonymy). With both bounded and unbounded lexemes lāyaf'alu was found to indicate the meaning of impossibility:

(7.82) 'inna hādā l-'a'mà l-mulhida l-zindīqa qad hağā-ka fa-qāla bi-'ayyi šay'in fa-qāla bi-mā là yanțuqu bi-hì lisān-ì wa-là yatawahhamu-hü fikr-ì This blind, unbelieving infidel has lampooned you [in verse]! He said: 'By saying what?' He replied: 'By [saying] what my tongue cannot utter and my mind (lit. 'thought') cannot imagine.' (Riwāyāt 1, 261)

Past negation in $m \bar{a}$-clauses is indicated by the negated form lam yaf'al. Here, again, one can assume that the use of the negative particle $m \bar{a}$ is precluded since it is homonymic with the pronominal operator $m \bar{a}$ : 


\section{(7.83) li-'anna-humā qarawiyāniyasîfāni mā lam yarayā}

Because they both are countrymen, describing what they have not seen. (Riwāayāt 2, 176)

\subsection{4 man-clauses}

The pronominal operator man represents persons. The person referred to by man is either particular or generic, specific or non-specific. Clauses headed by man rarely follow an explicit nominal antecedent (for an exception see [7.87] below). The identity of the person represented by man is often specified by a prepositional min al-bayān phrase (see [7.85] and [7.97] below). Adjectival man-clauses occur independently or as genitive complements of prepositions or nouns in the construct state.

The verbal paradigm in adjectival man-clauses consists of simple, modified, and compound indicative forms. The verbal forms in man-clauses present some deviations from the temporal-aspectual distinctions observed in other embedded clauses. These, as well as the common uses, will be henceforth discussed.

With unbounded (including stative) lexemes, yaf'alu indicates concurrence with the time frame established in the main clause:

\section{(7.84) iğtama'a nāsun fì l-masğidi mimman yantahilu l-iqtișāda fì l-nafaqati} In the mosque, there gathered people who profess the economy of expenditure. (Buhalä, 53 )

With bounded lexemes, yaf'alu is normally interpreted as having a posterior time reference. As noticed above, the future meaning of $y a f^{\prime} a l u$ is fraught with modal nuances, ranging from ability, possibility, or obligation - that is, lower certainty - to absolute validity or certainty as to the execution of the verbal event. The degree of certainty is affected by the epistemological position or authority of the predictor/executer, allowing him to make more or less 'objective' predictions. The following examples illustrate the difference between prediction made by a particular person, whose knowledge and ability to foresee the future is limited, and prediction made by a predictor who holds an absolute knowledge as to future happenings:

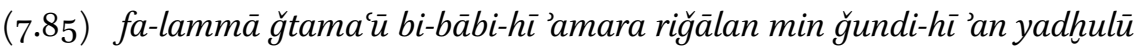
l-ḥäira llad̄i banā tumma yaqtulū kulla man yadḩulu 'alay-him min-a l-yahüdi

And after they gathered at his door, he ordered men from among his soldiers to go into the cistern that he had built, and then kill all the Jews who will/may enter upon them. (Riwāyāt 2, 11-12) 
(7.86) wa-la-'amr-ì la-'in kāna muhammadun kādiban 'inna fíl-'arabi la-man yakfi-nā-hu

By my life, if Muhammad is a liar there are among the Arabs those who will/can save us from him. (Mag் $\bar{a} z \bar{\imath}, 42-43)$

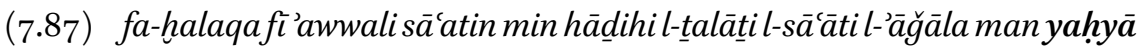
wa-man yamūtu

And in the first one of these three hours he created the [fixed] terms, who will live and who will die. (Tarih 1,20$)$

The pronoun man often represents a generic entity. In such cases yaf'alu does not refer to a point in time relative to the one established in the main clause, but to a situation which is temporally unbounded, and which therefore appears as concomitant with any other point in time:

(7.88) fa-daqqa 'alay-hi l-bāba daqqa wātiqin wa-daqqa mudillin wa-daqqa man yahăäu 'an yudrika-hū l-'asasu

He knocked on his door [with] the knock of a confident person, and the knock of a presumptuous person, and the knock of someone afraid that the night guard would catch him. (Buhalä, 66)

The use of the form fáala in man-clauses deviates to some extent from its use in other types of embedded clauses. With stative lexemes, facala indicates a persisting situation. The same meaning is also indicated by the negated form lamyaf'al:

(7.89) 'ayyu l-islāmi hayrun qāla tuțimu l-ța'āma wa-taqrảu l-salāma 'alā man 'arafta wa-man lam ta'rif

Which [way of practicing] Islam is best? He said: 'Serve food and greet with "Peace [be upon you]" those whom you know and those whom you don't know.' (Șahịh, 11)

With dynamic lexemes, fáala may refer not only to anterior situations but also to posterior situations:

(7.9o) wa-'ašära 'ilay-hi man hạạ̣ara-hū wa-qālū uskut fa-sakata Those who brought him in signaled to him and said: 'Shut up!' So he became silent. (Riwāàāt 1, 254) 
(7.91) fa-lammā nazala fì l-nahri kāda yaġraqu fa-ra’ā-hu qawmun min 'ahli l-qaryatifa-'arsalū 'ilay-hi man-i stahrağa-hū

And when he went down in the river he almost drowned. Then, some people from the village saw him and sent to him someone who pulled him out. (Kalïla wa-Dimna, 63-64)

In [7.91], the event of 'pulling out' clearly follows the event of 'sending'. Notice that the syntagmatic order of the clauses conforms with the chronological order of the events: the embedded man-clause follows the main verb and depicts the next event in the narrative chain.

In generically interpreted man-clauses, fa'ala is also used to indicate persistence. In this case, however, persistence does not coincide with a particular period of time, but is interpreted as an ever-enduring state:

(7.92) al-muslimu man salima l-muslimūna min lisāni-hīwa-yadi-hì

The Muslim is one who the Muslims are safe from [the harm of] his tongue and hand. (Șahịh, 11)

Since facala in generic man-clauses does not indicate a temporally bounded event, one may encounter such cases where it interchanges with yaf'alu, the typical form in generic clauses:

(7.93) țalātun man kunna fi-hi wağada ḥalāwata l-imāni [...] wa-man yakrahu 'an ya'ūda fì l-kufri ba'da 'ị 'anqada-hū llāhu ka-mā yakrahu 'an yulqā fì l-nāri: (in the title) bābu man kariha 'an ya'ūda fíl-kufri

There are three [traits] that whoever has them in him finds the sweetness of belief [...] and [the third of which is] one who hates to revert to infidelity after God has saved him, the same way as he hates to be thrown into the fire [of hell]:: The chapter on he who hates to revert to infidelity (Șahịh, 13)

Adjectival man-clauses often follow the elative 'awwal '(the) first' as genitive complements. ${ }^{14}$ In these cases, too, fa'ala is not used to indicate anteriority (unless the genitive construction is preceded by kāna):

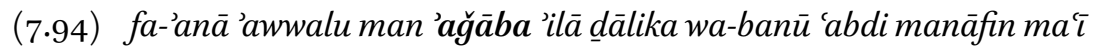
Then I am the first to agree to it and Banū 'Abd Manāf are with me. (Maḡāzī 1, 200)

14 Cf. Reckendorf, Syntaktischen Verhältnisse, 2, 605. 
Another special use of fáala in man-clauses is observed in 'tautological' constructions such as illustrated in the next example:

(7.95) 'anta 'arsalta 'ilā qurayšin 'an tarǧi'a fa-rağa'a man rağa'a wa-maḍā man maḍa

You have instructed (lit. 'sent to') Qurayš to come back, so some came back (lit. 'he who came back came back') and some went on (lit. 'he who went on went on'). (Maj̇̄ā̄i 1, 45)

It appears that man is used in these cases to mark the underspecification of a class of referents, relative to other markers of nominal determination: man rağa'a is both indefinite (as opposed to al-rāăíu), and not quantified (as opposed to rāğíun/rāğíūna). ${ }^{15}$

I could not find a single example in my corpus in which qad fa'ala was employed in a man-clause. ${ }^{16}$

In my corpus, there were very few examples in which the participle was attested in man-clauses. In the following example, the participle, with a bounded lexeme, is employed to indicate an immediate future (see [7.51] and [7.74] above):

(7.96) maqrūnan dikru kulli man 'anā dākiru-hū min-hum fì kitāb-ì hādā bi-

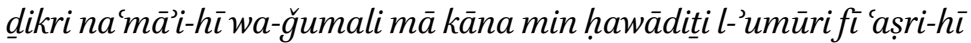

To the account on everyone whom I mention in this book of mine, an account on his graces and a summary of the events which took place at his time is added. (Ta'rih 1,5$)$

The compound forms are employed in man-clauses as elsewhere: kāna yaf'alu indicates an unbounded, recurring or ongoing, situation, which extends over a period of time previous to the one indicated in the main clause. With dynamic lexemes, kāna fa'ala depicts an event that has occurred prior to the time frame established in the main clause, and with stative lexemes, a situation that still persists at that time:

15 Cf. Fischer, Classical Arabic Grammar, 218, who describes the 'uncertainty' expressed by man in these cases.

16 Reckendorf, Arabische Syntax, 432, adduces one example of qad fa'ala within a manclause: 'inna 'awsan man qad 'arafta 'Aws ist einer, den du kennst'. 
(7.97) fa-bnu'ubayyin lā yanșuru ḥulafẳa-hū wa-man kāna yamna'u-hū mina l-nāsi kulli-him

Ibn 'Ubayy would not help his allies and those who used to protect him

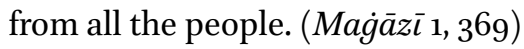

(7.98) wa-ma'a rasūli llāhi 'ammu-hū ḥamzatu bnu 'abdi l-muțtalibi wa-'abū bakri bni abì quhāafata l-șiddīqu wa-'aliyyu bnu 'abì țālibin fì riğāli min-a l-muslimina mimman kāna 'aqāma ma'a rasūli llāhi bi-makkata

And with the Messenger of God were his uncle Hamza b. 'Abd alMuțtalib, 'Abū Bakr b. 'Abī Quhạâa the righteous, and 'Alī b. 'Abī Ṭālib, from among the Muslims who stayed with the Messenger of God in Mecca. (Sira 1, 225)

The same as the affirmative yaf'alu (see [7.88] above), the negated là yaf'alu also indicates a temporally unbounded situation in generically interpreted man-clauses:

\section{(7.99) wa-lā rảya li-man lāyuțāu}

There is no [significance to the] opinion of one who is not obeyed. $\left(\right.$ Maḡā $\left.z \bar{\imath}, 5^{2}\right)$

\subsection{Adverbial hịna-clauses}

The operator hina 'at the time when' heads a temporal clause. Like other timedenoting nouns with adverbial function, hina is in the construct state. The clause that follows it functions as its genitive complement.

Adverbial hina-clauses follow the main clause as a rule. ${ }^{17}$ The temporal relation expressed by hina is that of coincidence or immediate adjacency between two events: the event in the main clause and the event in the embedded hinaclause are presented as realized within a common time frame, whether in reality they precede, follow, or overlap each other. ${ }^{18}$ The verbal forms occurring

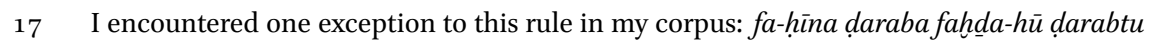
ra'sa-hū bi-sayfin (Riwāyāt 2, 23) - And right after he hit his thigh, I hit his head with a sword.'

18 Declerck, When-clauses, defines the semantics of when as that by which a 'common frame' or 'coreferentiality' between two intervals of time is established. When, accordingly, does not express strict overlapping, but rather, 'all that is required is that the two [situations] should be conceived as falling within the same interval' (245). 
in hina-clauses are fa'ala and yaf'alu, nearly always in the affirmative. ${ }^{19}$ While hina facala indicates recentness with respect to the event in the main clause, hina yaf'alu indicates simultaneity, with both bounded and unbounded lexemes:

(7.100) fa-nțalaqa hịna 'atā-hu kitābu-hū

And he left as soon as his letter had reached him. (Riwāyāt 2, 193)

(7.101) law nazarta 'ilay-hi hịna yadhulu 'alay-ka

If you look at him, when he enters upon you ... (Kalïla wa-Dimna, 95)

(7.102) 'in ra'ayta l-'asada hīna yanzuru 'ilay-ka

If you see the lion, when he looks at you ... (Kalïla wa-Dimna, 109)

The distinction between hina and other time-denoting operators, such as lam$m \bar{a}$ 'after' and baynā/baynamā 'while', is described in the grammatical literature mostly in semantic terms. According to Reckendorf, lammā and hìna are different in that the first indicates the Zeitpunkt in which the event occurs, thereby marking a clear boundary between two succeeding events, whereas the latter indicates a short or long Zeitraum in which the event occurs. ${ }^{20}$ Beeston defines the functional contrast between lammā and hina as that between the marking of 'past time' (with stative aspect) and the marking of 'actual simultaneity'.21 Though not incorrect, these descriptions overlook two important syntactic facts: (a) lammā co-occurs only with fáala, while hìna co-occurs with both fa'ala and yaf'alu; and (b) lammā-clauses come first in the chain while hina-clauses nearly always follow their matrix clause. In fact, from a syntactic point of view, lammā-clauses are better compared with baynā/baynamāclauses, since both types of clauses partake in structures of mutual dependency as setting or background units (see below 8.4 and 10.4). Clauses headed by hina, on the other hand, are embedded in the main clause and function as local adverbial expansions. Also from a semantic point of view, the definition of the

19 Reckendorf, Syntaktischen Verhältnisse, 2, 662, adduces one example in which hìna is followed by a negated form: numsiku l-hayla [...] hịna lā yumsiku-hā 'illā l-șuburu 'We hold the horses $[\ldots]$ as only the patient hold them'. In this case, it is not negation but restriction that is marked by the $l \bar{a}$ 'illā structure.

20 Reckendorf, Syntaktischen Verhältnisse, 2, 662.

21 Beeston, Arabic Language, 99. Beeston ascribes to lammā the same 'conversive force' he ascribes to the modifier $q a d$, transforming the dynamic aspect of the 'suffix-set' verb into a static one. 
contrast can be refined: while lammā marks the transition from one interval to another ('after'), and baynā/baynamā the inclusion of one interval in another ('while'), hina indicates a temporal adjacency which may extend from a single point of contact (with fa'ala) to total overlapping (with yaf'alu). These observations are summarized in the table below:

TABLE 7.2 The contrast between hịna, lammā, and baynā/baynamā

\begin{tabular}{|c|c|c|c|}
\hline & ḥina & lammā & baynāa/baynamā \\
\hline Verbal form & fa'ala, yaf'alu & fáala & yaf'alu \\
\hline Position & subsequent & initial & initial \\
\hline Dependency status & embedded & mutually dependent & mutually dependent \\
\hline Semantic relation & $\begin{array}{l}\text { immediate adjacency } \\
\text { ('upon', 'when') }\end{array}$ & succession ('after') & inclusion ('while') \\
\hline
\end{tabular}

\section{$7 \cdot 5$ Summary}

In this chapter, I have discussed the semantic oppositions marked by the verbal forms in a selection of embedded clauses. I have tried to demonstrate how the interaction between the lexical content and the grammatical form defines the internal structure of the verbal situation and determines its relative time reference. Some aspectual and temporal properties of the verbal forms were observed in all types of embedded clauses. Other contextual features which were found to be pertinent across the board are: repetition and presupposition, deixis, specifically the distinction between particular and generic reference, and the epistemic position of the speaker/agent, which allows him to make more or less valid or confident predictions.

Special uses of the verbal forms were encountered in specific types of clauses. Thus, a consequential meaning of fa'ala and qad fa'ala was observed in asyndetic adjectival clauses whose antecedent is an internal object. In manclauses, fa'ala displayed what may be described as loose temporality, allowing for both anterior and non-anterior readings of the form. Moreover, some operators were found to have greater bearing on the interpretation of the verbal forms than others. Adverbial hina-clauses, for instance, express the meaning of 'sloppy simultaneity' with both fa'ala and yaf'alu, ${ }^{22}$ regardless of the nature

22 For the concept of 'sloppy simultaneity' see Declerck, When-clauses, 231, 244-248. 
of the verbal lexeme. The exclusion of qad facala from this type of clauses may also be attributed to the semantics of the operator hina. In contrast, the operators of substantival and adjectival clauses do not have such an effect on the temporal interpretation of the verbal forms. Rather, one may even discern in certain adjectival clauses the lack of temporal specificity or the preference of modal meanings over a strict temporal one. 


\section{The Predicative Paradigm}

In this chapter, a variety of embedded, dependent, and mutually dependent clauses is discussed. In the grammatical literature, these clauses are treated separately, as distinct types of verbal complexes or subordinate structures. Nevertheless, these clauses have a common trait which justifies their analysis under a single heading: they all present the same set of verbal forms which function as second predicates in complex predications. I shall therefore apply the term the predicative paradigm to this set of forms. The following discussion will focus on the paradigmatic regularity, which can be shown to cross-cut diverse syntactic levels, and the functional oppositions marked by the predicative forms in each clause type.

\subsection{Preliminaries}

The term predicative has a long history in general linguistics. It is traditionally associated with a nominal—usually adjectival—form, which completes the content of the primary verbal (mostly copular) predicate. The predicative is sometimes distinguished from other related categories, such as the 'converb' and the 'co-predicative', both referring to an adverbial constituent (whether verb-derived or not) which 'expands' or 'restricts' the content expressed by the primary verb. ${ }^{1}$ However, the borderline between these categories is not clearly demarcated in every language. Moreover, there is no general consent as to their scope of application. ${ }^{2}$ I prefer, therefore, the term predicative for being general enough, i.e., for not being necessarily connected with a specific word-class (e.g., verb or noun), or a grammatical realization thereof (e.g., nonfinite or accusative). I use the term predicative to refer to the syntactic position assumed by a predicate whose function is to complete the content expressed by another predicate, so as to form a complex predication.

1 For a detailed discussion of these categories and some relevant literature, see Premper, "Zustandssätze", 304-321.

2 The term 'converb' would have been quite proper for the description of the predicative forms in Arabic, if not typically associated with non-finite verbs, see Haspelmath's definition of a converb as 'a nonfinite verb form whose main function is to mark adverbial subordination' (Converb, 3).

(C) MICHAL MARMORSTEIN, 2016 | DOI: 10.1163/9789004310483_009

This is an open access chapter distributed under the terms of the Creative Commons 
Complex predications consist of (at least) two predicates, often referred to as 'primary' and 'secondary'. The primary predicate is the grammatical nucleus of the complex predication, whereas the secondary predicate is usually the semantically salient constituent. Rather than an hierarchy of predicates, it seems thus more correct to speak of integration or combination of predicates or clauses. Integration - as opposed to the traditional dichotomy of coordination and subordination-is regarded as a scalar phenomenon, accommodating various degrees and forms of predicate or clause-combining. ${ }^{3}$ The extent to which both predicates are integrated follows from the amount of grammatical and lexical material shared by them. Whether the construction presents a high degree of 'elaboration' or a high degree of 'compression', to use Lehmann's terms, ${ }^{4}$ integration entails that: (a) both predicates or clauses are not selfcontained syntactic units, and (b) they depict one common occasion.

In Classical Arabic the predicative paradigm consists of three forms: yaf'alu, the participle, and qadfa'ala. In this well-defined syntactic slot, one may speak of a basic aspectual meaning of the forms, yaf'alu marking a dynamic-progressive situation, the participle marking a static state, and qad fa'ala marking a state resulting from a previous process. As for their temporal value, the predicative forms are essentially co-temporal, indicating either simultaneity (total overlap) or coincidence (partial overlap) with the time frame established in the main clause:

TABLE 8.1 The predicative paradigm

\begin{tabular}{lll} 
Predicative form & Aspect & Temporal value \\
\hline yaf'alu & dynamic-progressive & simultaneous, coincidental (terminal) \\
${\text { fácil } V n / m a f^{\prime} u ̈ l V n}^{\prime}$ & static & simultaneous \\
qadfáala & resultative & coincidental (initial)
\end{tabular}

The triad of yaf'alu, the participle, and qad fa'ala constitutes the core of the predicative paradigm. The form facala seldom functions as a predicative. This may be explained by the fact that fáala is used to indicate self-contained events

3 See Van Valin, Syntactic Relations; Haiman and Thompson, "Subordination"; Halliday, Functional Grammar, $216 \mathrm{ff}$.; Lehmann, Clause Linkage; Matthiessen and Thompson, Discourse and Subordination; Raible, Junktion. In Arabic linguistics, see Isaksson, Circumstantial Qualifiers; most notably Waltisberg, Satzkomplex.

4 Lehmann, Clause Linkage, especially 216. 
(hence its use as the narrative form), not coinciding with other events. The same goes for sa-yaf'alu, which rarely participates in complex predications (see below 8.2.4). Quite often, when fa'ala and sa-yaf'alu are used, the predication involves a certain abstraction at the semantic level, thus calling for some extension of the notion of common occasion.

A wide definition of complex predications, as such realizing a certain degree of syntactic and semantic integration between (at least) two predicates, covers a large and quite heterogenic group of structures. These extend from simple morphological constituents-closely-integrated with their matrix clause-to textual units, where integration is rather loose. ${ }^{5}$ In the following sections, I start by discussing closely integrated complexes in which the predicative form is embedded. Then, one type of dependent clauses, the syndetic circumstantial clause, is discussed, and finally, mutually dependent, setting and presentative clauses are presented. The common denominator of all these constructions is the presence of the predicative paradigm.

\subsection{Verbal Complexes}

The term verbal complex covers various manifestations of [main verb + embedded verb]. These range from closely integrated structures, involving auxiliaries and modifying verbs, to lexically and grammatically looser ones, where the main verb retains its full semantics. ${ }^{6}$ The main verb is the grammatical nucleus of the complex in that it marks the syntactic status of the entire complex; the embedded verb is usually the lexical pivot of the complex. Nonetheless, it should be stressed that both verbs convey some amount of grammatical and lexical information: the main verb is never entirely depleted (even the auxiliary kāna may be said to convey the notion of 'being'), while the predicative form marks such categories as number, gender, diathesis, and aspect.

In both medieval and modern grammars of Classical Arabic, the structures which are here subsumed under the title of verbal complexes are treated as separate categories. Despite their formal identity, a distinction is drawn between structures initiated by the auxiliary kāna and the mental di-transitive verbs ('af'äl l-qulüb), in which the predicative is deemed as kernel, and structures

5 Most structures exhibit the iconic relation pointed out by Givón, Syntax, 2, 328, between semantic and syntactic integration: The greater is the semantic connectivity between two events the stronger will be the syntactic dependency between the clauses indicating them.

6 The same verb can have a double realization, either as a lexically 'full' verb (tämm) or as a lexically 'deficient' verb (nāqiș), which is thus followed by a predicative form. 
initiated by intransitive and mono-transitive verbs, in which the predicative is considered peripheral. The Arab grammarians designate the first type of predicative habar 'rheme' (paired-off with ism 'theme'), whereas the latter is termed hăal 'circumstantial' (defined in contrast to a proper maf'ūl 'object complement'). ${ }^{7}$ This distinction follows from a categorical semantic approach, classifying verbs into distinct 'families', and a strict formal view of the clause, dividing it into an essential part ('umda) and a redundant part ( fad la). However, the distinction between $h \bar{a} l$ and habar is not always kept, and the fact that the two terms are sometimes used interchangeably is in itself quite telling: it discloses the special identity of this syntactic constituent, which at the same time is both predicative (in its essence) and adverbial (in its position). ${ }^{8}$ From a diachronic point of view as well, adverbial-circumstantial and predicative clauses may be regarded as akin to each other: the latter, more inherently integrated with their matrix clause, reflect a further grammaticalization of the former. ${ }^{9}$

Verbal complexes present the same syntactic structure, whatever the lexical class of the main verb is: the predicative-a verb(-derived) form in adverbial position-is juxtaposed to the main verb; ${ }^{10}$ both verbs exhibit subject-identity (in that we include inalienable entities, see below [8.46]). The adverbial status of the predicative obtains a formal mark when the predicative is realized as a nominal (verb-derived) form, i.e., as the accusative participle. The finite forms yaf'alu and qad fa'ala occupy the same syntactic position as the participle and thus acquire — by virtue of their paradigmatic interrelation — an adverbial status.

The following discussion of verbal complexes is divided into five sections according to the class of the main verb. I will proceed from kāna-compounds, located on one end of the integration scale, toward less integrated complexes,

8 Levin, Kāna, 192-196, discusses the correspondence between the categories termed habar, $h \bar{a} l$, and maf'ūl țāni in Sībawayhi's Kitāb. It is worth quoting in this regard Ibn Ya īšš Šarh al-Mufașșal, 2, 7, who explicitly states that al-hâalu ziyādatun fi l-fäidati wa-l-habari 'The circumstantial expression is an addition to the informativity [of the clause] and to its predicate'. He explains that in a clause like marartu bi-l-farazdaqi qā̇iman 'I passed by al-Farazdaq [while] standing' the predication ('ihbār) of 'passing by' is added another predicate (habar 'ähar); the only difference is that the first is obligatory ('alä sabili lluzūmi), whereas the latter is additional and can thus be renounced (ziyādatan yağ $\bar{u} z u$ l-istigināu 'an-hā).

10 On the internal structure of compound verb forms and the adverbial status of the predicative complement see Goldenberg, Compound Verbs. 
initiated by modifying verbs, motion and state verbs, perception and permission verbs, and speech verbs. Complexes initiated by full action verbs (which present the same syntactic structure) are not dealt with. Nearly all the examples illustrate verbal complexes in main clauses (see but [8.16] and [8.18]). For kāna-compounds in dependent clauses, see chapter 7 above.

\subsection{1 kāna-compounds}

Compound kāna forms present the highest degree of integration within a verbal complex. The auxiliary verb kanna expresses either a temporal or a modal meaning (see above 5.2.3). In this section, however, I will only discuss compounds initiated by the anterior kāna. The predicative form indicates the content of the verbal situation as well as its internal unfolding. The opposition between the predicative forms operates therefore at the lexical as well as the grammatical levels.

The compound form kāna yaf'alu was thoroughly studied by Nebes, who applied a semantological method of categorization to his Classical Arabic material. ${ }^{11}$ The form kāna yaf'alu, according to Nebes, is an imperfect whose marked time reference is past. This meaning of kāna yaf'alu stands in opposition to the marked perfectivity of facala, on the one hand, and the unmarked time reference of $y a f^{\prime} a l u$, on the other. ${ }^{12}$

The present discussion in not concerned with the general function of kāna yaf'alu. Rather, the opposition between yaf'alu and the other verbal forms which co-occur with kāna is in focus. As mentioned, this opposition resides in two domains: (a) the lexical domain, to which the issues of lexical compatibility and the valence of the verb-phrase belong, and (b) the grammatical domain, in which the aspect marked by the verbal form comes into play.

The verbal form yaf'alu is the least lexeme-sensitive of all verbal forms: it may convey all types of verbal situations, both static and dynamic, telic and atelic, and be realized in both intransitive (active and passive) and transitive verb-phrases. Intransitive and transitive are used here in a strict syntactic sense, to refer to the grammatical relation between a verbal situation and its accusative complement(s). ${ }^{13}$ As for its grammatical aspect, yaf'alu depicts an unbounded situation: either one that continues throughout the period of time indicated by kāna, or one that constantly repeats itself. The repetition is frequentative in nature, i.e., it is not a mere iteration of the verbal situation, but

\footnotetext{
11 Nebes, Kāna Yaf'alu, especially chapter 2, in which his analytical method is presented.

12 Ibid., especially chapter 7 .

13 As a semantic concept, transitivity is obviously multi-faceted and scalar, cf. Hopper and Thompson, Transitivity.
} 
a regular and predictable recurring which is valid through the entire period of time indicated by kāna. ${ }^{14}$ In the following, the various manifestations of kāna yaf'alu will be illustrated and explained.

With both stative and dynamic lexemes, kāna yaf'alu occurs in transitive verb-phrases. Transitivity may code a different semantic relation in each case:

(8.1) wa-kāna rasūlu llāhi yuḥibbu l-fa’la wa-yakrahu l-țìrata

The Messenger of God used to love the good omen and hate the evil omen. (Maj̇̄̄zī, 218)

(8.2) 'ayyu-hā l-maliku kunna qawman 'ahla ğāhiliyyatin na'budu l-'așnāma wa-na'kulu l-maytata wa-na'tī l-fawāḥiša wa-naqța'u l-'arhāma wanusìu l-ğiwāra

O king! We were people of the Ğăhiliyya, worshiping the idols, eating the carrion, committing abominations, violating the rules of consanguinity, and harming those who sought our protection. (Sira 1, 219)

(8.3) wa-kāna mra’an tanașșara fì l-ḡāhiliyyati wa-kāna yaktubu l-kitāba l'ibrāniyya fa-yaktubu min-a l-'inǧlli bi-l-ibrāniyyati mā šăà llāhu 'an yaktuba

And he was a man [who] became Christian in the Ğăhiliyya. He used to write in the Hebrew script and would write in Hebrew whatever God wished him to write from the Gospel. (Șahịh, 5)

Also in intransitive verb-phrases kāna yaf'alu is used. Example [8.4] below exhibits the passive form of 'arafa 'to know':

(8.4) fa-'ahrağa qawsa-hū wa-ğu'bata-hū wa-sayfa-hū wa-kāna yu'rafu bi-lšă̌ă'ati

And he took out his bow and his quiver and sword; and he was known for [his] bravery. (Mag் $\bar{a} z \bar{\imath}, 223$ )

Within kāna-compounds, certain lexemes are not encountered with the participle but only with yaf'alu. These pertain to various classes of verbs, including mental states, ${ }^{15}$ perception, or action:

14 For a discussion of the semantic nature of frequentative repetition, see below 11.3.

15 The verb yurìdu is another prominent case where yaf'alu is preferred to the participle, see also Waltisberg, Satzkomplex, 293. 
(8.5) wa-kuntu 'arğū 'an 'arudda-hū 'alà qurayšin fa-'ăhuda l-miata nāqatin And I was hoping to bring him back to Qurayš and to get [as a reward] the one hundred she-camels. (Sira 1, 331)

(8.6) fa-kuntu 'arā min-a l-nāsi wa-l-hayli mā lā 'așifu min-a l-katrati And I saw people and horses which I cannot describe due to their great numbers. (Mag் $\bar{a} z \bar{\imath}, 408)$

(8.7) wa-kāna 'abū'aḥmada rağulan darīra l-bașariwa-kāna yațūfu makkata

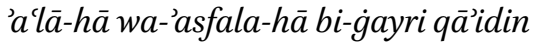

'Abū 'Ahmad was a blind man and he used to walk around Mecca, [from] its highest [to] its lowest parts, without anyone to lead [him the way]. (Sir $a 1,316)$

The compound kānayaf'alu often co-occurs with adverbs and adverbial clauses which specify the frequentative nature of the verbal situation:

(8.8) wa-kāna 'idā rakiba yab'atú 'ilay-himà bi-ba'îrayni yarkabāni ma'a-hü And whenever he rode, he used to send to both of them camels so that they would ride with him. (Riwāyāt $\left.1,5^{8}\right)$

(8.9) wa-kāna 'abū bakrin kațīran mā yasta'dinu rasūla llāhi fì l-hiğrati 'Abū Bakr kept asking the Messenger of God for permission to [set out] on the Hiğra. (Sira 1, 323)

In some cases, kānayaf'alu co-occurs with the modifiers qad and la-qad, which precede the compound form as a rule. The modifier qad expresses both anteriority (already indicated by kāna) and completion:

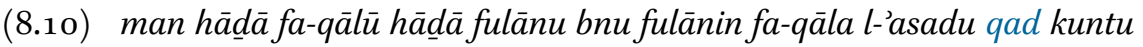
'a'rifu' abā-hu

Who is this? They said: 'This is so-and-so, son of so-and-so.' So the lion said: 'I had known his father.' (Kalïla wa-Dimna, 70)

In [8.10] the 'knowing' of the father, who is already deceased by the time the clause is uttered, is marked as 'cut-off' by qad. The modifier la-qad, unlike the plain qad, embodies an explicit mark of asseveration. Thus, in [8.11] the speaker asserts the unusual sight he has seen by means of la-qad: 
(8.11) la-qad kunnā narā riǧālan bịdan 'alā ḩaylin bulqin mā kunnā narā-hum qablu wa-là ba'du

Indeed, we saw white men on piebald horses. We never saw them before or after. (Maḡāzi, 409)

Following kāna, the predicative yaf'alu is always negated with $l \bar{a}$ :

(8.12) fa-harağnā nas'alu 'an rasüli llāhi wa-kunnā lā na'rifu-hū lam nara-hū qabla d̄àlika

We went out to ask the Messenger of God, and we did not know him, nor had we seen him before that. (Sira 1, 294)

The compound form kāna fäilan/maf'ülan shows a clear contrast to kāna yaf'alu, at both the lexical and the grammatical levels. The predicative participle is found almost exclusively in intransitive configurations. It serves to indicate a static situation which is viewed in its entirety, i.e., which does not break down into internal phases or recurrent instances.

The predicative participle is used with stative lexemes:

(8.13) wa-kullu-hum kāna lè muḥibban wa-ilay-ya mä̉ilan wa-lì muṭīan And everyone loved me and was favorably inclined to me and was obedient to me. (Riwāāāt 1,35)

Notice that muhibban is connected with its object by means of the preposition $l-16$ whereas yuhibbu in [8.1] has a direct object. Derived from verbs of mental state and disposition, the adjectival patterns facil, facil, and faclän often serve as predicative forms side by side with the participle:

(8.14) wa-našảa l-nağāāìyu ma'a 'ammi-hī wa-kāna labïban ḥāziman min-a l-riğāli

The Negus grew up with his uncle, and he was wise and resolute from among the men. (Sira 1, 222)

16 The Arab grammarians consider this $l$ - as al-läm li-taqwìyat al-ämil 'the lām which strengthens the regent', cf. Wright, Grammar, 2, $61 \mathrm{ff}$. Being a nominal form, the participle has less 'power' to govern an object complement; the lām thus serves as an explicit exponent of this grammatical relation. 
The participle is very common with verbs of state and motion. With motion verbs, the participle indicates the situation of being in a move, rather than actual kinesis or progression:

(8.15) wa-kāna 'adiyyu bnu zaydin wāqifan bayna yaday-hi 'Adī b. Zayd was standing in front of him. (Riwāyāt 2, 184)

(8.16) hattā 'idāa kunnā bi-l-mușallā rāğíína min badrin baraka 'alay-nā Until [the time] when we were near al-Muṣallā, coming back from Badr, it (i.e. the camel) fell on its knees (lit. 'kneeled down to us'). (Maj̇āzī, 25)

Besides indicating the mental state of a subject, the participle is also found with stative lexemes depicing a physical state:

(8.17) wa-kāna dāri'an wa-'alay-hi miğfarun lā rafrafa la-hū fa-kānat ḥanğaratu-hū bädiyatan

And he was wearing armor and a helmet with no visor, so his neck was exposed (lit. 'visible'). (Maḡāzī, 227)

The participle rarely occurs with transitive lexemes. When it does, it is often realized in the passive form, so that the verb-phrase is intransitive:

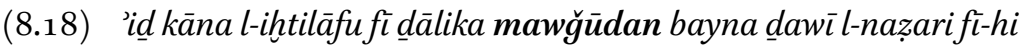
As the controversy about that [matter] exists between those holding a view about that. (Ta'rih 1,86$)$

The participle may also be realized in the active form. However, in these cases transitivity is not exercised, since the verb occurs without an explicit object complement:

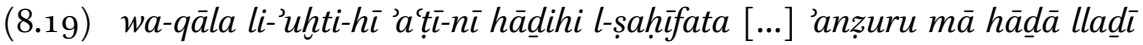
ğăa bi-hì muhammadun wa-kāna 'umaru kätiban

And he said to his sister: 'Give me this leaf [of book ...] so that I may take a look at that which Muhammad has brought,' for 'Umar was literate (lit. 'writer'). (Sira 1, 226)

Comparing the participle in [8.19] and yaf'alu in [8.3], we observe two points of contrast: (a) the participle kătiban has no object complement, and (b) rather than indicating recurring instances of writing like yaktubu, it expresses a state 
so stable that has reached the status of a skill. This stands to reason, as the participle is an adjectival form which inherently indicates an attributive relation. Whether the attribute is accidental (temporary) or inherent is not specified by the participial form, but only by the context. ${ }^{17}$

The compound kāna fä 'ilan/maf'ülan is occasionally preceded by the modifiers qad and la-qad. As elsewhere, qad imparts both the meanings of anteriority and completion, thus it sets limits to the static situation indicated by kāna fäilan/maf'ülan; la-qad stresses the veracity of the verbal situation:

(8.20) qad kuntu 'anā ğâhilan mițla-ka hattā waffaqa-nì llāhu 'ilā mā huwa 'aršadu

I used to be ignorant like you until God made me successful in achieving the right way. (Buhalä, 40)

(8.21) la-qad kāna 'ilay-nā muhssinan wa-la-nā mukarriman Indeed, he was good to us and honoring us. (Kalïla wa-Dimna, 103)

Within kāna-compounds, the predicative participle is negated as a rule by gayr: ${ }^{18}$

(8.22) wa-kānat-i l-am'äu muttașilatan ġayra mutabāyanatin

The intestines were intertwined [and] not separated from each other. (Buhalä, 99)

The compound form kāna qad fa'ala or qad kāna fa'ala can be analyzed in two ways: as the modified form qad fa'ala expanded by kāna, or as the compound form kāna fáala modified by qad. Examples of both orders are found in the corpus, although kāna qad fáala is by far more common:

(8.23) wa-kānū qad 'uțū basțatan fíl-ḩalqi

They were given a large stature. (Ta'rihh 1, 167)

17 Cf. Reckendorf, Zum Gebrauch des Partizips, 256. There are languages in which the distinction between an accidental and an inherent attribute is marked on the (inflected) adjectival form, see Goldenberg, Predicative Adjectives.

18 I have encountered one case in which the predicative participle was negated by $l \bar{a}$ in a conditional clause: fa-'in kunta lā 'ākilan šay'an sakattu 'anā wasakatta 'anta (Buhalä', 47) - 'And if you were not eating anything, I would have been silent and you would have been silent.' This example is unusual in two points: the participle is negated by $l \bar{a}$ and realized in a transitive verb-phrase. 


\section{(8.24) wa-qad kāna 'uṭiya fatā’a l-sinni}

He was given youth (lit. 'the youth of age'). (Riwāyāt 1, 19)

The compound kāna qad fa'ala embodies the meanings of anteriority and completion. Anteriority is doubly marked by both the modifier and the auxiliary. Similarly to kāna fáala (to be discussed below), kāna qad fáala is mostly used as a background form in the narrative. However, kāna qad fa'ala is more frequent and has a wider distribution than kāna fáala. It is found with nearly all classes of verbal lexemes; the only class of verbs which does not occur with kāna qad fa'ala is that of state verbs such as 'aqāma 'to dwell'. This may be explained by the fact that kāna qad fa' ala — due to the effect of qad-indicates a temporally framed situation which is incompatible with stative background descriptions. Indeed, we often encounter kāna qad fáala in contexts where temporality, or to be more precise, the successive order of the events, is salient to the narrative:

(8.25) fa-lammā rağa'a ba'da ḥinin țalaba ḥadìda-hū wa-kāna l-rağulu qad $\boldsymbol{b} \bar{a} \boldsymbol{a}-\boldsymbol{h} \bar{u}$

And after a while, when he came back, he asked for his iron, [but] the man had already sold it. (Kalìla wa-Dimna, 119)

(8.26) wa-kāna 'abū 'àmirin-il-fāsiqu qad haarağa fì hamsīna rağulan min'awsi llāhi ḥattā qadima bi-him makkata hịna qadima l-nabiyyu l-madīnata 'Abū 'Āmir, the sinner, had already gone out with fifty men from 'Aws Allāh until he arrived with them in Mecca, at the time when the Prophet arrived in Medina. (Maḡā $z \bar{l}, 205$ )

(8.27) fa-'in kāna d̄ālika ka-d̄ālika fa-qad kāna l-mā̉u wa-l-rịhu huliqā qabla l-'arši

If this is so, then the water and the wind were created before the throne. (Ta'īh 1, 37)

The compound form käna fáala is less frequently used than kāna qad fáala. It gains preference in cases where the lexical input is incompatible with the meaning of bounding marked by qad, or when the relative order of the events is not considered as important as the assertion of their actual occurrence. Example [8.28], for instance, presents a case where käna fáala occurs with the state verb makata 'to stay': 
(8.28) kāna nūḥun makata fíqawmi-hì alfa sanatin 'illā ḩamsīna āman yad'ūhum 'ilä llāhi

Noah had stayed among his people for $95^{\circ}$ years (lit. 'thousand years minus fifty years'), calling upon them to [worship] God. (Ta'rihh 1, 186)

In narratives, kāna fa'ala is used when the temporal sequence is not deemed as important as the assertion of the actual occurrence of the events. Notice the difference between [8.25] and [8.29], extracted from the same story: in the first case, the temporal sequence is crucial to the point of the narrative (the man claims back his iron after the iron has already been sold); in the latter case, the events themselves (that are reported in direct speech) are given the most focus:

(8.29) kuntu waḍatu hadìda-ka fì nähiyatin min-a l-bayti fa-'akala-hü l-ğurd̄ānu (Kalīla wa-Dimna, 119)

I had placed your iron at a corner of the house and the rats ate it.

Although the temporal sequence is not in focus, kāna fa'ala may co-occur with temporal adverbs:

(8.30) wa-kāna ğabalun harağa laylan min mawdii in kāna fi-hi

Ğabal had gone out at night from the place where he had been. (Buhalä, 65)

In [8.30] the adverb laylan 'at night' indicates the temporal setting of the situation. However, this setting is not presented as relative to some other point. The compound kāna fa'ala also occurs with the focus particle 'innamā, which stresses the veracity of the situation expressed in the clause. In this case, too, it is not the relative position of the event within the narrative sequence that is being asserted, but the fact that it has actually taken place:

(8.31) 'innamā kāna qatala l-qātilu min-humā 'ahā-hu 'anna llāha 'azza wağalla 'amara-humā bi-taqrïbi qurbānin

The fact of the matter is that one of them killed his brother because God ordered them to offer a sacrifice. (Ta'rih 1, 142)

As it does not carry a specific marking of temporal framing, kāna fáala is also compatible with an adverb such as rubbam $\bar{a}$, which indicates an unbounded iteration: 
(8.32) wa-kānū rubba-mā hasșsu-hu fa-waḍa'ū bayna yaday-hi l-durrāğata lsaminata

They often endowed him with special honor and put in front of him a plump francolin. (Buhalä', 85)

The predicative qad facala is generally incompatible with negation. The predicative fa'ala is also not negated. Instead, lam yaf'al is used:

\section{(8.33) kānayahrusu rasūla llāhi lam yufāriq-hu}

He used to guard the Messenger of God; he would not leave him. (Maj̄̄āi, 217)

\subsubsection{Modifying Verbs}

Modifying verbs, 'ahawāt kāna 'kāna's sisters' in the Arabic grammatical tradition, serve to describe a certain phase or aspect of the verbal situation, which is expressed by the predicative form. In Classical Arabic, modifying verbs comprise several lexical classes; ${ }^{19}$ however, the main semantic distinction can be drawn between two groups of verbs: those which indicate the initial phase of the verbal situation and those indicating its continuation or duration. There are no modifying verbs referring to the terminal phase of the verbal situation or to its accomplishment, hence this group of verbs is incompatible with the resultative meaning of qad facala.

The predicative form $y a f^{\prime} a l u$ is compatible with both groups of modifying verbs. The most common representative of the first is ğa'ala 'to start'. ${ }^{20}$ The verbal complex ğa'ala yaf'alu is found with all classes of verbs, in affirmative and negative forms:

(8.34) fa-ğáala yamšı̀ wa-yaq'udu wa-yanzuru 'ilà l-țarīqi hattā rufía la-hū dimnatu muqbilan

And he started to walk and sit and look at the road until Dimna, [while] approaching, came into his sight. (Kalìla wa-Dimna, 75)

19 Modifying verbs, the same as kāna, can also be used as full verbs. Cf. Waltisberg, Satzkomplex, 198-199, for some ambiguous examples, where the verbal form may be interpreted either as a modifying or a full verb.

20 Waltisberg, Satzkomplex, 348, reports that verbs indicating ingressivity formed $72 \%$ of the modifying verbs attested in his corpus; the verb ğa'ala had by far the greatest number of tokens. 
(8.35) fa-ğa'alū ya ̣ribūna-hum ḥattā nuqiḍat șufüfu-hum And they started to hit them until their lines were destroyed. (Mag் $\bar{a} z \bar{l}$, 226)

(8.36) fa-ğa'alū lā yatrabūna la-humā wa-lā yư̌ğabūna bi-himā kamā kānū yatrabūna

And they stopped (lit. 'started not') being moved and delighted by them the way they used to be. (Riwāyant 1, 57)

With cognitive verbs which are, by their nature, static, ğa'ala indicates the entrance into a state or a disposition, thus the meaning of becoming ('starting to be'):

(8.37) wa-ğa'ala ’abū ğahlin yusarru bi-mā șana'a l-mušrikūna bi-'utbata And 'Abū Ğahl became delighted by what the polytheists did with

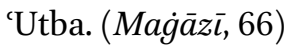

Besides ğa'ala, there are other verbs which indicate inchoative meaning. These originate from diverse lexical classes, e.g.: 'așbaha 'to be [in] day time', 'ahada 'to take', indafa'a 'to rush off'. The modifying verb șāra, illustrated in [8.38], also functions as a motion verb indicating the arrival at a certain place or destination (e.g. șāra 'ilā fulānin 'He came to such a one'):

(8.38) fa-iḍa șirtu ka-d̄ālika fa-qad ḍahaba kasb-ī min māli ġayr-ī wa-șāra gayr-ì yaksibu min-nī

If I become like that, my earnings from someone else's money will disappear and someone else will start earning from me. (Buhalä’ 93)

To the same group of inchoative verbs also belong verbs indicating imminence or intention. These verbs do not refer to the actual outset of the verbal situation but to the phase immediately preceding it, either in the physical or in the mental world of the agent: ${ }^{21}$

(8.39) fa-lammā ntahā 'ilā l-nahri lam yağid 'alay-hi qanțaratan li-yaqța'a-hū wa-l-dibu kāda yudriku-hū

21 In the Arabic grammatical tradition, 'af'āl al-šurū' 'the verbs of beginning' and 'af'āl almuquaraba 'the verbs of approximation' are lumped together, cf. Wright, Grammar, 2, 106109 . 
And when he got to the river he did not find a bridge to cross it over, while the wolf was about to reach him. (Kalïla wa-Dimna, 63)

The predicative yaf'alu often co-occurs with the second group of modifying verbs, indicating the continuation or duration of the verbal situation. Among these verbs, lam yazal 'to not cease' is by far the most frequently encountered. Notice in [8.41] the opposition between the predicative participle and yaf'alu, the first indicates a static situation while the latter indicates a dynamic one:22

(8.40) wa-naḥnu lam nazal naḍribu-hū bi-suyūfi-nā ma'a l-awsi fì ḥarbi-him kulli-hā

And we continued to fight him with our swords, together with 'Aws, throughout their war. (Magi $\bar{a} z \bar{\imath}, 369)$

(8.41) wa-qüla 'anna-hū lam yazal muqìman bi-makkata yahuğğg wa-ya'tamiru

It was reported that he continued to stay in Mecca, performing the pilgrimages of the Hajj and the 'Umra. (Ta'rîh 1, 164)

The predicative participle is seldom found with the first group of modifying verbs indicating an inchoative meaning. This may be explained by the nonphasal nature of the participle, which rules out the reference to its internal phase. However, with stative lexemes, the participle may co-occur with modifying verbs conveying the meaning of becoming, i.e., the entrance into a new state. In such cases, the verbal situation is not broken down into its internal phases but the entire situation ('non-being $\mathrm{x}^{\prime}$ ) is transformed to another ('being $\left.\mathrm{x}^{\prime}\right)$ :

(8.42) wa-qad wallāhi yā rasūla llāhi 'aṣbaḥtu muštāqan 'ilā murāfaqati-hī fì l-ğannati

By God, O Messenger of God, I have come to yearn to accompany him in Heaven. (Ma $\dot{a} \bar{z} z \bar{\imath}, 213)$

The participle is quite common with the second group of modifying verbs indicating the continuation or duration of the verbal situation. As with kāna, the predicative participle mostly occurs in intransitive verb-phrases:

22 Tarīh 3, 1150, provides a parallel example, in which yaf'alu specifies, by negation, the dynamic aspects of 'standing still': fa-mā ziltu wāqifan mā 'ataqaddamu 'amām-ī wa-lā 'arği $u$ wară'-ī 'And I kept standing, I did not proceed forward or returned back.' 
(8.43) wa-lam 'azal li-d̄âlika l-sammi min lisāni-ka hăàifan mušfiqan 'an ya'urra-n̄̄ bi-šay'in kārihan li-qurbi-ka d̄ākiran li-maw'izati l-'uqalā'ifi ğtinābi muqārabati 'ahli l-fuğūri

And because of your poisonous tongue, I kept being afraid and worried that I would be ashamed of something, [and I kept] hating your closeness [while] remembering the lesson of the wise men: to avoid being close to immoral men. (Kalïla wa-Dimna, 118)

Besides typical modifying verbs such as lam yazal or mā dāma, there are other verbs which serve to indicate continuation or duration. These are often motion and state verbs, such as madā 'to pass' and labita 'to abide', which in some contexts undergo semantic bleaching:

(8.44) fa-labita l-’awsu wa-l-hazrağu mutaḥāribìna 'išrìna sanatan fì 'amri sumayrin

'Aws and Hazrağ kept fighting for twenty years because of the matter of Sumayr. (Riwāyāt 2, 19)

As mentioned above, modifying verbs expressing either inchoative or durative meaning are incompatible with qad fa'ala. Also the simple fa'ala is rarely found with modifying verbs; the few existing examples stem mostly from poetry. ${ }^{23}$ In my corpus, I have encountered one example in which the form 'arāda 'he wanted' co-occurred with the modifying verb 'as ā 'it might be'. The compatibility of 'arāda and 'asā may be explained by the fact that, as opposed to qad fa'ala, fa'ala does not indicate the complete and concrete realization of the verbal situation:

\section{(8.45) fa-'asā-hu 'arāda l-tafộla fì l-qismati}

Perhaps he wanted [to be given] preference in the allotment [of the gifts]? (Buhalä', 91)

\subsubsection{Motion and State Verbs}

Verbs expressing a movement towards a destination or a certain position or location in space are very common in complex predications. Such verbs indicate the outset or setting of the verbal situation which is specified by the following predicative form. With this group of verbs we find the predicative triad yaf'alu, fä'ilan/maf'ülan, and qad fa'ala, marking the opposition between a

23 Cf. Reckendorf, Arabische Syntax, 297, for poetry quotes such as 'așbahat 'ad dalatnī. 
progressive, a static, and a resultative aspect, respectively. As both the main verb and predicative verb refer to the same situation and are co-temporal, fa'ala-being neither simultaneous nor coincidental-is excluded from the predicative paradigm.

In both traditional and modern grammatical literature, verbal complexes initiated by motion and state verbs provide the most typical example of circumstantial constructions. While the Arab grammarians were mostly concerned with the grammatical properties of the hăl 'circumstantial expression', and the syntactic relation with its (pro)nominal antecedent, i.e. $\underline{d} \bar{u}$ al-ḥal 'the circumstantial expression's referee', modern studies of circumstantial clauses focus on the semantics of the main verb and its effect on the interpretation of the predicative form. The following discussion is concerned with the semantic compatibility between the main verb and the predicative verb, as well as the functional opposition between the predicative forms.

In the Arabic grammatical tradition, the predicative form yaf'alu is considered to have two manifestations: (a) as hăal muqārin 'simultaneous circumstantial', or as (b) hạlmuqaddar 'intended circumstantial.' ${ }^{24}$ Modern grammars maintain the same distinction between yaf'alu forms which are 'simultaneous with or following the action expressed by the governing verb. ${ }^{25}$ In his short article, Abboud diverts attention from yaf'alu to the semantics of the main verb: since $y$ af'alu co-occurs with 'event-completion' verbs, it may refer either to the event or to its 'eventual completion'. According to Abboud, such an explanation 'obviates the need for a hăl muqaddar'. ${ }^{26}$ A somewhat different view is presented in Waltisberg's work on circumstantial clauses. Although he, too, maintains that the semantics of the main verb affects the interpretation of yaf'alu, Waltisberg suggests a neat separation between a 'modal' (simultaneous) and a 'final' (posterior) function of yaf'alu, which are then paired off with syndetic circumstantial clauses and final clauses, respectively. ${ }^{27}$

A detailed examination of all the possible combinations shows that the temporal value of $y a f^{\prime} a l u$ is not solely determined by the content of the main verb, nor by that of the predicative verb, but by the interaction of both. We observe a general rule: if (at least) one of the verbal lexemes is potentially unbounded (a-telic), then yaf'alu is interpreted as simultaneous (totally overlapping); if neither is unbounded, then yaf'alu is interpreted as coincidental (partially

24 Cf. Wright, Grammar, 2, 19-20.

25 Fischer, Classical Arabic Grammar, 220.

26 Abboud, Hāl Construction, 195.

27 See Waltisberg, Satzkomplex, $§ 5.2$ and $§ 5.6$; Cf. Marmorstein, Review on Waltisberg, 381382 . 
overlapping), i.e., the situation expressed by yaf'alu proceeds from the one expressed by the main verb. The coincidental relation should not be analyzed as simple succession, since both the main verb and yaf'alu refer to the same situation, the first depicting its outset or setting, the latter its destination.

The rule outlined above is demonstrated in the following set of examples, where the main verb indicates: (a) movement towards a destination, i.e., motion and goal; (b) movement in space with no goal; or (c) static position in space. In [8.46]-[8.47] the main verb belongs to the first group of motion verbs while the predicative verb indicates an unbounded situation; yaf'alu is thus interpreted as simultaneous:

(8.46) fa-rağa'a bi-hā rasūlu llāhi yarğufu fu'ādu-hū

And the Messenger of God returned with them (i.e. the verses) his heart shivering. (Șahīh, 5)

(8.47) fa-labisa dir'a-hū wa-'ahada sayfa-hū fa-harağa ya'dū

He wore his armor, took his sword and went out running. (Majīa zì, 370)

In [8.48] the main verb belongs to the first group of motion verbs while the predicative verb indicates a bounded situation; yaf'alu is thus interpreted as coincidental:

\section{(8.48) fa-harağù yaṭlubūna-humā fi kulliwağhin}

They went out looking for both of them in all directions. (Riwāyāt 2, 24)

In [8.49] the main verb belongs to the second group of motion verbs; yaf'alu is thus interpreted as simultaneous:

(8.49) wa-marrū yaḍibūna bi-l-dufüfi wa-yazmirūna bi-l-mazāmìri They marched striking tambourines and playing the pipes. ${ }^{28}$ (Maj $\bar{a} z \bar{\imath}$, 375)

In [8.50]-[8.51], where the main verb belongs to the third group of state verbs, yaf'alu, whether unbounded or bounded, is interpreted as simultaneous:

28 The verb marra can be interpreted as either bounded ('to pass by') or unbounded ('to march'). In the latter case, no limitation or destination of the movement is indicated, as in [8.49]. 
(8.50) fa-bāta yabkì

He spent the night crying. (Riwāyāt 2, 32)

(8.51) fa-bātū yaṭlubūna-hū ḥattā ya’isū min-hu

They spent the night looking for him until they gave up all hope of [finding] him. (Riwāyāt 2, 178)

Not only with verbs of (vectorial) motion, but also with verbs of caused motion, yaf'alu indicates the goal of the event launched by the main verb:

(8.52) fa-'arsala 'ilay-hi yad' 'u-hu

And he sent to him [a messenger] inviting him [to come]. (Riwāyāt 2, 29)

In these cases, too, yaf'alu is not strictly successive, nor does it indicate finality; rather, it indicates the terminal stage of the verbal situation. That the two notions, i.e., final and terminal, are not simply overlapping can be demonstrated, inter alia, by the fact that proper final clauses, such that are introduced by an explicit operator (e.g. li- 'for'), are external to the verbal situation and hence can be negated, whereas the terminal yaf'alu-being an internal and inseparable part of the verbal situation - is never negated.

While coincidental or terminal yaf'alu forms cannot be negated, yaf'alu indicating simultaneity does exhibit negation with $l \bar{a}$. Quite often, $l \bar{a}$ yaf'alu paraphrases the content expressed by the preceding (affirmative) predicative form:

(8.53) wa-bātat șāhilatan haylu-hum là tahda'u

Their horses stayed up the night neighing; they would not calm down. (Maj̄äzì, 217)

(8.54) wabaqütu mabhūtan lā 'astațīu l-kalāma wa-lā l-ğawāba wa-lā l-harakata li-mā hālața qalb-ī

I remained speechless; I could not talk nor respond or move for what had befallen me. (Riwāààt 1, 46)

The predicative participle depicts a static situation. It may indicate: (a) the outcome of a previous process in the passive form; (b) the persistence in a certain state with dynamic lexemes; or (c) the endurance of a state with stative lexemes. These three options are illustrated in the examples below. Notice that in [8.56] the participle, as elsewhere (see [8.17] above), is used to describe 
physical appearance, dressing, and specifically, the girding of a sword (other parallel examples are Riwāyāt 2, 185: mutaqallidan; Sìra 1, 225: mutawǎšsihan); Example [8.57] demonstrates the functional opposition between the participle and yaf'alu with regard to transitivity: the first is used in intransitive verbphrases whereas the latter takes an object complement:

(8.55) fa-makata mumallakan 'alay-hā 'ašhuran

He remained its king (lit. 'enthroned') for several months. (Riwāyāt 2, 184)

(8.56) fa-'aqbala muṣlitan sayfa-hū fìnafarin min-a l-yahūdi He approached unsheathing his sword amid a group of Jews. (Maj̇̄zi, 372)

(8.57) fa-ḩarağnā huäifìna nahăfu l-rașada

We set out afraid; we were fearing an ambush. (Mag் $\bar{a} z \bar{\imath}, 28)$

The last example illustrates a general principle of complex predications. We may refer to it as the principle of increased specificity: each predicative is added to the previous one, thereby depicting the given situation in greater detail. The increased specificity is obtained by the accumulation of predicates, and not by their internal order. Consider, for instance, [8.58]-[8.59] in which rakiba 'to ride' functions either as the main (specified) verb or as the predicative (specifying) form:

(8.58) lam 'arkab hațatan dِāhiban wa-là rāğían

I did not ride a single step either going or coming. (Mag் $\bar{a} z \bar{\imath}, 26)$

(8.59) 'aqbaltu rākiban 'alā ḥimārin 'atānin

I came close, riding on a she-ass. (Șahịh, 31)

Quite often, the lexemes of both the main verb and the predicative form pertain to the same class of motion verbs. According to Waltisberg, in such cases the participle serves to mark 'situation-identity' between both verbal forms. ${ }^{29}$ It appears, however, that the notion of situation-identity fails to capture the specifying function of the participle and its semantic contribution to the verbal complex. To be sure, there are cases where the content of both verbs is very

29 Waltisberg, Satzkomplex, 286-291. 
similar. However, even in these, the predicative is not simply tautological, but serves to elaborate the content of the main verb, often by indicating the point of departure or the direction of the motion:

(8.6o) wa-'aqbala 'abū ğubaylata sä̀iran min-a l-šāmi And 'Abū Ğubayla came proceeding from al-Šām. (Riwāyāt 2, 11)

\section{(8.61) hattā qumtu fì qiblati-hī mustaqbila-hū}

Until I stood in his direction of praying facing him. (Sira 1, 228)

Unlike yaf'alu, the participle is rarely interpreted as indicating the terminal stage or destination of the verbal situation. Example [8.62] is one case that may be interpreted as such:

\section{(8.62) ğìtu-ka ‘äidan bi-ka}

I came to you asking for your protection. (Riwāàa $t$ 1, 55)

In other cases where the main verb indicates vectorial motion, what one usually finds is the participle indicating an appointment or assignment, rather than the destination or goal. As an adjectival form, the participle is most suited to the expression of such attributes, whether these have a temporary or a permanent validity. Example [8.63] provides a good illustration to the distinction between the participle, indicating an appointment, i.e., an (assigned) attribute, and yaf'alu, which breaks down this attribute into its actual instances. The Qur'ānic quote in [8.64], which has a parallel in the Sira, is yet another case where the participle, like non-derived adjectives, is used to indicate an appointment ('being sent as') rather than a goal ('being sent to');

(8.63) fa-ba'ața llāhu 'iblīsa qādìyan yaqụ̂ bayna-hum

God sent 'Iblīs as a judge to judge among them. (Ta'rīh 1,85$)$

(8.64) fa-ba'ața llāhu l-nabiyyīna mubašširìna wa-mundirìna / wa-lākinna llāha ba'ata-nī bašìran wa-nadīran

God sent the prophets as bringers of glad tidings and warners. (Q 2:213; Ta'rīh 1, 184) / But God sent me as a bringer of glad tidings and a warner. (Sira 1, 189)

As already mentioned above, a predicative facala is incompatible with motion verbs, due to its self-contained temporal framing (this is not to be confused with the notion of boundedness: facala, with stative lexemes, may well indi- 
cate unbounded persisting situations). The modified qad fa'ala, on the other hand, does co-occur with motion verbs, indicating a process whose result is coincidental with the situation expressed by the main verb. As opposed to the coincidental yaf'alu, the tangent point of qad fa'ala and the main verb is not the terminal stage of the latter but its initial one:

(8.65) fa-ğăàa 'a rābiyyun qad 'aqbala min tihàmata

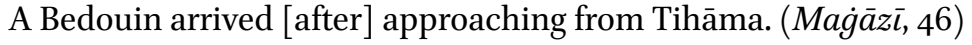

(8.66) wa-’aqbala l-mušrikūna qad șaffü șufüfa-hum

The polytheists approached [being] already arranged in lines. (Maj̇ $z \bar{a} \bar{l}$, 220)

\subsubsection{Perception and Permission Verbs}

Perception verbs and verbs indicating permission form a sub-group of complement-taking verbs in Classical Arabic. Both these classes of verbs head raising constructions. The term 'raising' refers to the syntactic fusion of two clauses, a complement-taking verb and its propositional complement, whereby the subject of the second clause is fronted to the object position of the first. The raised element is in fact shared by both clauses, and thus cannot by analyzed as an exclusive member of either. ${ }^{30}$

The mechanism of raising allows for two interpretations of perception verbs: either as indicators of concrete perception of an object and its condition (e.g., 'I saw him doing'), or as indicators of notional perception of a whole situation or fact (e.g., 'I saw that he was doing'). The latter use may trigger a further shift or abstraction of the meaning of the verb, from physical perception to mental comprehension (e.g., 'I realized that he was doing'). ${ }^{31}$

30 Discussing such examples as 'I found her gone', Jespersen, Philosophy, 122, suggests regarding the entire combination ('nexus') her gone as the object of the main verb. According to Givón, Syntax, 2, 272, such cases exhibit the process of raising, whereby an argument of the subordinate clause is converted to an argument of the main clause. By contrast, Waltisberg, Satzkomplex, 322-323, views the raised element as still belonging to the embedded clause. As a matter of fact, this question cannot be decided, for the raised element is formally marked (through its case and agreement) as relating to both clauses at the same time.

31 According to Arabic grammatical tradition, when ra’ā and wağada are not intended in their physical denotation (i.e., in the sense of ru'yat al-'ayn 'the seeing of the eye' or wiğdān al-dālla 'the finding of the lost beast'), but rather in their mental denotation, their second object is indispensable to the clause, serving as the predicate of the first object, see Sībawayhi, Kitāb, 1, 13 . 
The distinction between the patterns of concrete and notional perception is not only semantic, but it also has syntactic correlates: (a) complement clauses introduced by the operator 'anna are not free variants of raising constructions, but mostly interchange with the pattern of notional perception; ${ }^{32}$ and (b) the paradigm of predicative forms which is compatible with the expression of notional perception is wider and also includes verbs not indicating cotemporality with the main verb. Thus, while the pattern of concrete perception involves only the predicative triad, yaf'alu, qad fa'ala, and the participle, the pattern of notional perception also includes fa'ala and sa-yaf'alu, both referring to events which are not envisaged as co-occurring with the situation of perception.

The predicative form yaf'alu occurs with both patterns of concrete and notional perception. With the first pattern, yaf'alu depicts an ongoing situation, simultaneous with the moment of seeing, hearing, or finding:

\section{(8.67) fa-ra'ā-nì 'atawaḍ̂’u min kūzin hazafin}

He saw me performing the ablution using a pottery jug. (Buhalä, 37)

(8.68) 'a-mā wallāhi la-samitu muhammadan yaqūlu

Verily, by God, I heard Muḥammad saying. (Majḡazzi, 35)

(8.69) wa-'tabir 'ayḍan d̄ālika bi-l-milhi llad̄ì yūḍa'u taḥta l-misrağati wa-lnuhālati llatī tūdáu hunāka li-taswiyati-hā wa-tașwībi-hā kayfa tağiduhumā yan'așirāni duhnan

Consider that too, along with the salt that is put under the lamp, and the bran that is put there to level it and tilt it, how much oil you will find them (i.e., the salt and bran) to exude. (Buhalä', 41)

In the negative form as well, la $y$ yaf'alu functions as predicative in raising constructions. Example [8.70] is ambiguous in that the syntactic relation between the indefinite object qawman and the following lāyurìdüna can be analyzed as either predicative or attributive (see above 6.1.3):

(8.70) wa-lākinnì wallāhi ra'aytu qawman là yurìdūna 'an ya'ūbù 'ilā 'ahlì-him But, by God, I saw people not willing to return to their families. ( $M a-$ $\dot{g} \bar{a} z \bar{l}, 62)$ 
The predicative yaf'alu is also compatible with $r a^{3} \bar{a}$, when this indicatesrather than concrete ocular perception - the seeing of a certain scene in a dream or the envisioning of a scene:

(8.71) 'innī qad ra'aytu ru'yan [...] wa-'arā bn-ì yațlubu-nì țalaban hațītan I dreamt (lit. 'I saw a dream') [...] and I see my son looking for me anxiously. (Sira 1, 254)

With the second pattern of notional perception or comprehension, yaf'alu expresses a prediction, a situation that is not concomitant but posterior to that indicated by the main verb. As the moment of comprehension does not coincide with the comprehended fact, the posterior sa-yaf'alu may also be used:

(8.72) fa-tarā muhammadan yaḥșiru-nā sanatan

Do you think that Muhammad will besiege us for a year? (Mag $\left.\bar{a} z \bar{\imath},{ }_{3} 68\right)$

(8.73) wa-'ammā talabu bn-ì 'iyyā-ya tumma ḥabsu-hū 'ann-ī fa-innī 'arā-hu sa-yağhadu 'an yușība-hū mā 'așāba-nì

And as for my son's looking for me and being withheld from me, I see it [as if] he will strive so that what happened to me will happen to him [too]. (Sira 1, 254)

As with verbs of motion and caused motion, when yaf'alu co-occurs with permission verbs it may be coincidental, referring to the terminal stage of the complex situation:

(8.74) fa-qad 'amara-nā 'an lā nada'a-ka tastaqirru 'alà l-'ardi

He has instructed us to not let you stick to the ground. (Riwāyāt 1, 248)

The predicative participle is compatible with the expression of concrete as well as notional perception. In both cases it depicts a static situation, one that exists or persists at the moment of perception:

(8.75) țumma ğàat-i mra’atu l-hağğāmi ba'da sāatin li-musāmarati șadìqatihā mra’ati l-iskājifa-wağadat-hā marbūṭatan

Then the wife of the cupper came after one hour to have an evening chat with her friend, the wife of the shoemaker, and she found her tied up. (Kalïla wa-Dimna, 79) 


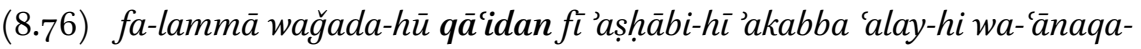
$h \bar{u}$

When he found him sitting among his friends, he bent down over him and embraced him. (Buhalä, 43)

(8.77) fa-qultu yā rasūla llāhi mā la-ka 'an fulānin fa-wallāhi 'innī la-'arā-hu mu'minan

So I said: 'O Messenger of God, what do you have [in mind] about soand-so, for by God, I think he is a believer.' (Șahịh, 15)

With verbs indicating permission, the predicative participle also depicts a static situation. Notice that in [8.78] the participle, as elsewhere, is intransitive, whereas the following yaf'alu has an object complement:

(8.78) fa-'ahbara-nā 'anna muḥammadan kāna 'araḍa li-'iri-nā fì bad'ati-nā wa-'anna-hū taraka-hū muqìman yantaziru rağ'ata-nā

And he informed us that Muhammad was observing our caravan since we started our [journey], and that he had left him to stay [there] and watch for our return. (Mag் $\bar{a} z \bar{\imath}, 28)$

The predicative form qad facala, in both patterns of concrete and notional perception, is used to indicate a process whose resultant state coincides with the time of perception itself:

(8.79) 'asma'u l-șawta qad-i rtafa'a fì 'a là qawrā

I hear the voice already risen at the top of Qawrā. (Riwāyāt 2, 47)

(8.80) 'innī'arā qurayšan qad 'azma'at 'alā l-ḩurūği

Indeed, I think that Qurayš have already decided to go out. (Majīaz $\bar{\imath}$, 36)

As is usually the case, qad fa'ala is preferred to fa'ala when the chronological order of the events is deemed salient to the narrative. Thus in [8.81], the fact that 'Adī was already dead when the messenger found him, and not just the mere fact of his death, has great bearing on the later development of the narrative:

(8.81) 'innì wağadtu 'adiyyan qad mäta qabla 'an 'adhula 'alay-hi I had found 'Adī already dead before I entered upon him. (Riwāyāt 2, 191) 
In some cases, the perceived situation consists of a number of scenes, either overlapping or following each other in time. Example [8.82] is a good illustration of the predicative triad. We observe that the order of the forms-first the participle, then yaf'alu, and qad fa'ala - is a fixed one, regardless of the nature of the matrix clause. This order may be viewed as iconic, reflecting the decreasing degree of integration of the predicative form with the main verb: ${ }^{33}$

(8.82) wa-la-ka-'annī ’anzuru 'ilay-kum zāininina yataḍāga șibyānu-kum qad taraktum dūra-kum hulüfan wa-’amwāla-kum

It is as if I look at you departing, your children crying out, [after] you have left your homes and possessions neglected. (Mag் $\bar{a} z \bar{\imath}, 365)$

In my corpus, a predicative fa'ala was not found in raising constructions very often. Unlike the temporally bounded, coincidental qad fa'ala, fa'ala refers to a self-contained period of time. With concrete perception, fa'ala is found with lexemes indicating an enduring state. Notice in [8.83] the indefinite time frame indicated by the adverb zamānan 'for a while':

(8.83) 'innī qad ra'aytu l-malika 'aqāma bi-makāni-hì hādāa zamānan lā yabrahu min-hu

Indeed I have seen [that] the king remained in this place of his for a while, not moving from it. (Kalìla wa-Dimna, 73)

The predicative fa'ala is more likely to occur when perception is not intended in its physical sense, but in its mental sense. Thus, fa'ala is used in visions and dreams, or in the expression of realizations and conclusions:

(8.84) ra'aytu rākiban 'aqbala 'alā ba'îri-hī [...] fa-'arā l-nāsa ğtama'ū 'ilay-hi I saw [in a dream] a rider [that] approached on his camel [...] and I saw [that] the people gathered to him. (Mag் $\bar{a} z \bar{l}, 29)$

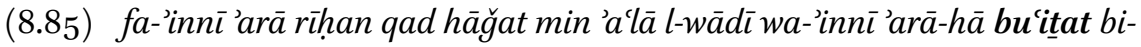
nașri-ka

I see a wind has risen from above the valley and I think it has been sent to help you. (Maj̄̄āi, 29) 
As is the case elsewhere, the predicative fa'ala is not encountered in the negative form; instead, lam yaf'al is used:

(8.86) inhaḍ-i l-sā'ata 'ilā l-faḍli bni yahyā fa-'inna-ka taǧidu-hū lam ya’dan li'ahadin ba'du

Get up [and go] now to al-Fạ̣l b. Yahyā; you will find him not allowing anyone [in] yet. (Riwāyāt 1, 30)

\subsubsection{Speech Verbs}

Another defined class of verbs which initiate verbal complexes are speech verbs. The predicative forms which co-occur with speech verbs are yaf'alu and the participle. These forms increase the specificity of the verbal situation by referring either to the content expressed or to the vocal quality of speech itself. Notice that [8.88] exhibits an unusual case where the participle is followed by an object complement:

(8.87) qāla l-’â̌s̄à yamdaḥu l-samaw'ala

Al-’A‘̌sā said praising al-Samaw’al. (Riwāyāt 2, 27)

(8.88) qāla l-walìdu rāfían șawta-hū

Al-Walīd said raising his voice. (Buxalä, 65)

\subsection{Circumstantial Clauses}

Not only in verbal complexes, i.e., in embedded clauses, but also at higher syntactic levels, the predicative paradigm is found. In this section I will discuss one type of dependent clause, the circumstantial clause, in which the predicative triad is used. The aspectual oppositions between the forms are the same as those described above: yaf'alu indicates an ongoing situation or process, the participle indicates a static state, and qad fa'ala indicates a result.

The category of al-ğumla al-hâliyya 'the circumstantial clause' was described by the Arab grammarians as a complex ('periphrastic') manifestation of the $h \bar{a} l$ category. However, modern research has demonstrated that the asyndetic hâal constituent and the syndetic ğumla hạliyya do not interchange freely with each other. ${ }^{34}$ In fact, there are a number of formal and functional distinctions between them:

34 Cf. Premper, "Zustandssätze”; Isaksson et al., Circumstantial Qualifiers; Waltisberg, Satzkomplex. 
(a) The subject of the syndetic circumstantial clause is not necessarily coreferential with the subject of the main clause, thus both clauses do not necessarily refer to the same verbal event. It should be noted, however, that the subject of the circumstantial clause is not entirely new, but can be retrieved from the previous context. ${ }^{35}$

(b) The syndetic circumstantial clause is not lexeme-sensitive: it does not cooccur with specific classes of verbs in the matrix clause.

(c) Syndetic circumstantial clauses are backgrounded whereas their asyndetic counterparts are foregrounded. The latter distinction is often correlated with the temporal relation marked by the syndetic and asyndetic clause, to wit, simultaneity vs. sequentiality (or chaining). ${ }^{36}$ Although generally correct, this correlation is too sweeping. As was already discussed, the predicative forms refer to situations which overlap with the situation indicated by the main verb, or which precede or proceed from that situation.

The formal and functional distinctions outlined above reflect different degrees of integration of asyndetic and syndetic circumstantial clauses and their matrix clause. The asyndetic predicative forms, occupying the position of an adverbial (accusative) complement, show a higher degree of integration than syndetic circumstantial clauses, connected to their matrix clause as self-standing clause units (we recall that the participle in syndetic circumstantial clauses takes the nominative case!). Also from a functional point of view, asyndetic predicative forms serve to single out a certain aspect, feature, or stage of the complex situation. Syndetic circumstantial clauses, on the other hand, are comments elaborating on a certain entity, depicting in greater detail the situation indicated in the main clause, or describing the setting in which the latter takes place.

Except for some minor cases in which $f a$ - is used, the circumstantial clause is connected as a rule with $w a-{ }^{37}$ The connective $w a$ - is a general connective particle: it simply indicates the adjoining of two or more elements or clauses. The particular semantic relation between the adjoined clauses, whether it

35 It is rather unusual that the subject of the circumstantial clause is newly introduced into the text. As the following example shows, the subject may be indefinite, though still strongly associated with other topics and hence presupposed (like inalienabilia): kuntu 'inda šayhin min 'ahli marwa wa-șabiyyun la-hū șaj̇irun yal'abu bayna yaday-hi (Buhalä' 38)-'I was at [a place of] a sheikh from the people of Marw, and a young boy of his was playing in front of him'.

36 Cf. Premper, "Zustandssätze", 275.

37 For circumstantial clauses introduced by fa-, see Nebes, Satzschema. 
be chronological, causal, contrastive, or other, is not indicated by $w a$ - but determined by the given context. ${ }^{38}$

$w \bar{a} w$ al-hâal 'the circumstantial $w a-$ ' may introduce either a nominal or a verbal clause (see above 4.5). When the predicate is yaf'alu or the participle, the nominal clause pattern is mandatory; with qad facala, the pattern of the verbal clause is preferred, although there are a few examples where the subject is fronted. In the following, I will illustrate and discuss circumstantial clauses with each of the verbal forms.

Circumstantial clauses whose verbal predicate is yaf'alu may refer to a situation concomitant with the one indicated in the matrix clause. The concomitant relation is sometimes interpreted as contrastive, especially when the subject of the circumstantial clause is not only different, but in fact confronted to the subject of the main clause:

(8.89) fa-ğa'altu 'amš̀̃ ruwaydan wa-rasūlu llāhi qã̉imun yușallì yaqra’u lqur'āna

I started to walk slowly while the Messenger of God was standing, praying, [and] reciting the Qur’ān. (Sìra 1, 228)

(8.9o) fa-dahala 'alay-hi rağulun kāna la-hū ğāran wa-kāna lì șadīqan fa-lam ya'riḍ 'alay-hi l-ta'āma wa-nahnu na'kulu

When in came a man, a neighbor of his and a friend of mine, and he did not offer him food, though we were eating. $($ Buhalä, 38$)$

Like the asyndetic yaf'alu, the circumstantial yaf'alu-being co-referential with the subject of the main verb-may refer to the same verbal event as the latter. Thus, in [8.91]-[8.93], the same verb qāla is followed each time by a circumstantial clause, specifying either the manner of speech, its location, or the content expressed:

(8.91) fa-lammā qāla surāqatu mā qāla wa-huwa yanțiqu bi-lisāni 'iblīsa šağu'a l-qawmu

And when Surāqa said what he said, and he was speaking with the tongue of 'Iblīs, the people were encouraged. (Majā $z \bar{\imath}, 39)$

38 For a different view of syndetic circumstantial clauses, as such indicating a 'catalogue' of semantic relations, see Waltisberg, Satzkomplex, 358. König, Converb Constructions, provides a general account of the controversy over the polysemous or vague nature of adverbial verb forms. 
(8.92) samitu 'aliyyan yaqūlu wa-huwa yahṭubu bi-l-küfati

I heard 'Alī saying while he was delivering a sermon in Kufa. (Mag்äzi, 57)

(8.93) [...] qāla wa-huwa yuḥaddițu 'an fatrati l-wahyi

He said, while delivering a hadit on the period of pause in revelation. (Șaḥịh 1, 6)

In circumstantial clauses yaf'alu is negated by lā. Quite often, lā yaf'alu occurs with verbs of knowledge, depicting a situation where one subject is ignorant about the activity of the other:

(8.94) fa-marrat-i l-hayyatu 'alā l-hazanati wa-hum là ya'lamūna The snake passed by the keepers [and entered] while they did not know. (Ta'rih 1,104$)$

Circumstantial clauses whose predicate is the participle are either co-referential with the situation depicted by the main verb, or refer to a concomitant situation. We observe that the participle in [8.95] follows a non-derived adjectival form which indicates the mental state of the subject (see [8.14] above). In [8.96], the participle refers to the physical appearance of the subject, specifically to his girding for battle (another example is Mag $\bar{a} \bar{a} z \bar{\imath}$ 1, 39: wa-huwa mutawaššịun bi-sayfi-hī; see also [8.17] and [8.56] above):

(8.95) fa-ğàà-nī wa-huwa hazizinun munkasirun He came to me sad and [heart] broken. (Buhalä', 9o)

(8.96) wa-'ahada l-nabiyyu l-qawsa wa-'ahada qanātan bi-yadi-hī [...] wa-lmuslimūna mutalabbisūna l-silāha

The Prophet took the bow and he took the spear in his hand [...] while the Muslims were putting on their weapons. (Maj̇̄ zī, 215)

The same as the asyndetic participle, the circumstantial participle occurs as a rule in intransitive verb-phrases, either with intransitive lexemes or, with transitive lexemes, in the passive form:

(8.97) Laqiya-hū safihun min sufahāi qurayšin wa-huwa 'ämidun 'ilā l-ka'bati One of the Qurayš fools came across him while he was heading towards the Ka'ba. (Sira 1, 246) 
(8.98) li-’anna-hū lā šay’a yatawahhamu-hū mutawahhimun fì qawli qā̉ili dâlika 'illā wa-huwa mawğūdun fí qawli qã̀ilin

Because there is nothing which one may presume [to be implied] in this statement without existing in a statement such as ... (Tarinh 1,58$)$

On rare occasions the participle takes an object complement. We observe, however, that the object in such cases is not a prototypical one, i.e., an individualized affected entity, but in fact, forms a collocation with the verbal form:

(8.99) wa-kayfa yastațīu dِālika wa-huwa 'àkilun 'ušban

How is he able to do that while being a grass-eater? (Kalïla wa-Dimna, 92)

Circumstantial clauses whose predicate is qad fa'ala exhibit mainly the pattern of the verbal clause, although one may encounter a few cases in which the subject is fronted:

(8.100) wa-rağa'a l-nağǎšiyyu wa-qad 'ahlaka llāhu 'aduwwa-hū

The Negus came back [after] God had already destroyed his enemy. (Sira 1, 221)

(8.101) wa-harağa l-ḩabaru 'ilā l-nāsi wa-riğălu bañ̄ l-mușțaliqi qad-i qtusimū wa-mulikū

The news went out to the people, while the men of the Banū Muștaliq had already been divided [among their captors] and become [their]

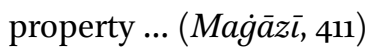

A plausible explanation to the different clausal pattern of wa-qad facala visà-vis wa-huwa yaf'alu/wa-huwa fä'ilun may be that the latter nominal patterns are indeed plot-external descriptions, sometimes even generic or encyclopedic comments, centered on a certain entity, while wa-qad fa'ala, though deviating from the main facala-plotline and depicting an anterior event, is not purely descriptive, but rather incorporated in the stream of events (see also below 10.3.2).

Circumstantial clauses sometimes present the inna la-clausal pattern. The operator 'inna introduces the entire clause whereas the modifier la-precedes the predicate. When the predicate is verbal, la- may be prefixed to either yaf'alu or the participle. The structure wa-inna la- has an emphasizing function: it indicates that the content expressed in the clause stands against a certain expectation, explicit or implicit in the surrounding context, and that it is there- 
fore remarkable. There is an important functional distinction between ordinary circumstantial clauses and wa-inna la-clauses: unlike the first, wa-inna la-clauses are not merely descriptive or orientational (if at all), but they present the personal evaluation of the narrator regarding the narrated situation. Consider, for instance, the examples below:

(8.102) wa-la-qad rảaytu-hū yanzilu 'alay-hi l-wahyu fì l-yawmi l-šadìdi l-bardi fa-yufșimu 'an-hu wa-inna ğabina-hü la-yatafașșadu 'araqan And I saw him [when] the revelation came upon him, on a very cold day; then it departed from him, while his forehead was dripping with sweat. (Sahịh, 6)

(8.103) fa-la-qad luddat maymūnatu wa-'inna-hā la-șāìmatun

And Maymūna was given the medicine while she was fasting. (Sìra 2, 1007)

In [8.102], 'A'iša says that it was an extremely cold day when the revelation came upon the Prophet, but nevertheless she saw that he was sweating. In [8.103], Maymūna is reported to be given medicine, despite the fact that she was fasting.

Being unusual in the nominal clause pattern, qad facala is also not found in the 'inna la- pattern. Nevertheless, qad fa'ala is compatible with the emphasizing la-which precedes the modified form. The same as wa-inna-hü layaf'alu/wa-'inna-hü la-fácilun, also wa-la-qad fa'ala has an evaluative function: it imparts the impression of the narrator regarding the related event:

(8.104) la-qad ḥaddata-nī 'abdu llāhi bni 'abbāsin 'anna 'ādama nazala ḥina nazala bi-l-hindi wa-la-qad hặğa min-hā 'arba'ina hiğğatan 'alā riğlay-hi ${ }^{39}$

'Abdallāh b. 'Abbās told me that when Adam came down it was in India; from there he had performed the pilgrimage to Mecca on foot forty times. (Ta'ihh 1, 124)

39 Interestingly, wa-la-qad hağğa does not refer to an anterior event relative to the preceding nazala. It may be that la-qad fa'ala, as opposed to qad fa'ala, serves mainly an expressive goal and is not used for the purpose of grounding. This suggestion awaits further research. 


\subsection{Mutually Dependent Clauses}

Mutually dependent constructions are exocentric, that is, neither their first nor their second part may be said to function as the main constituent or nucleus to which the other is subordinate. As already discussed above (6.1.2), mutual dependency is marked as distinct from other types of interdependency by inverting the usual order of the conjoined dependent clause, from subsequent position to initial. The global meaning of a mutually dependent construction is gathered from the contents of both its parts, so that neither one can be omitted without giving up much of the sense of the entire construction.

Conditional sentences are perhaps the best known example of mutually dependent constructions. The conditional meaning is obtained by the juxtaposition of a protasis and an apodosis. ${ }^{40}$ Conditional clauses may be introduced by the same conjunction as modifying adverbial clauses, e.g.: 'in 'if', 'id $\underline{d} \bar{a}$ 'when/if'. However, the relative position of the clause determines its interpretation. When the clause takes the initial position it is a conditional, when it is postposed it is an adverbial expansion of the main clause. ${ }^{41}$ The seemingly inverted order of the conditional construction marks the relation of mutual dependency, whereby both clauses have an equal syntactic status. ${ }^{42}$ Not only the syntagmatic order, but also the paradigmatic constitution of the verbal forms is different in conditionals and in modifying adverbial clauses. Prototypical conditional sentences present a limited range of possibilities, the verbal form in the protasis-fa'ala or yaf'al-triggers off the verbal form in the apodosis-fa'ala or yaf'al, and both forms assume a hypothetical meaning. ${ }^{43}$

40 Cohen, Conditionals, 15, views the syntactic relationship between both parts of the conditional construction as mutual dependency. As far as their semantic interrelation is concerned, 'ordinary conditionals' are defined by him as 'structures containing two domains of events or state of affairs' of which 'neither domain can be confirmed or denied at the time of the utterance, and the likelihood of one domain (the apodosis) to take place depends directly on the realization of the other domain (the protasis)'.

That the protasis and apodosis cannot be inverted while maintaining their function was already observed by the Arab grammarians. The Arabic terminology also reflects the distinction between a proper conditional, termed šart, and a postposed modifying conditional, termed zarf; cf. Peled, Conditional Structures, 139-140.

42 A conditional clause is not just less integrated with its matrix clause, compared to postposed dependent clauses (Waltisberg, Satzkomplex, 75-77); rather, it exhibits a different kind of interdependency, a mutual dependency.

43 Besides the prototypical construction there are other types of conditional sentences in which the apodosis is not selected by the protasis but, following the conjunction $f a$-, is free 
By contrast, modifying adverbial clauses are free to follow a wide variety of clause patterns, ${ }^{44}$ and the temporal or modal meaning of their verb, as is generally the case in dependent clauses, is relative to the point of reference of the main clause.

Apart from conditional sentences, there are other types of mutually dependent constructions. The present discussion focuses on those in which the predicative paradigm is employed. These constructions can be divided into two interrelated kinds: (a) setting clauses and (b) presentative clauses. Although the predicative paradigm is common to all of them, there is an important difference between verbal complexes and circumstantial clauses, on the one hand, and setting and presentative clauses, on the other. The former operate at the syntactic level of the complex-clause, and thus may be found in any type of discourse, e.g., dialogues, narratives, expositions, etc.; the latter operate at the text level and can only be found in narratives. They are, in fact, marked patterns of narration (for a detailed discussion, see below 10.4).

\subsubsection{Setting Clauses}

Setting clauses are introduced by the operator ( $f a-)$ baynā/baynamā 'while'. They take the first position in the complex construction (like conditional clauses), followed by a presentative clause. Clauses headed by baynā/baynamā exhibit the pattern of the nominal clause, where the nominal theme precedes an adverbial (prepositional) or a verbal predicate. In cases where the predicate is verbal, it is realized as either yaf'alu or the participle, always in the affirmative. Here, as well, we observe the opposition between the dynamicprogressive-transitive yaf'alu and the static-intransitive participle:

\section{(8.105) baynā 'anā 'amšı 'id sami'tu șawtan min-a l-samāi}

As I was walking, I suddenly heard a voice from heaven. (Șaḥih, 6)

(8.106) fa-baynamā humā wāqifāni bayna yaday-hi 'id saqața țāirāni 'alāl-sūri And while they were standing in front of him, suddenly two birds landed on the wall. (Riwāyāt 2, 180)

The modified form qad fa'ala, incompatible with the durative (unbounded) meaning of baynā/baynamā, is not attested in this clause type. However, qad

to comprise verbal and nominal patterns other than fa'ala or yaf'al; cf. Peled's category of 'modally split conditional sentences' (Conditional Structures, chapter 4). 
fa'ala may be incorporated into the setting in the form of a circumstantial clause. Notice that in [8.107] the subject of the circumstantial is fronted, so as to match the order of the baynā/baynamā clause:

\section{(8.107) fa-baynā ’anā fìmağlis-īwa-l-hadamu qad haffü bīwa-ğawāriy-yayata- raddadna bayna yaday-ya 'idā 'anā bi-šayhin} And while I was in my living room, the servants had already surrounded me and my maids were coming and going in front of me, all of a sudden there was an old man with me. (Riwāaya 1 1,45)

Setting clauses may also take the form of the 'inna la-pattern. The same as in baynā/baynamā-clauses, yaf'alu and the participle function as verbal predicates. The distinction between setting clauses introduced by baynāalbaynamā and those introduced by 'inna is not a syntactic one:45 both types of clauses exhibit a mutually dependent construction with the same verbal paradigm. Rather, the distinction resides in the domain of expressivity. Setting clauses introduced by inna signal the presence and stance of an internally involved, 'homodiegetic' narrator, telling the story from his own first-hand experience: ${ }^{46}$

45 I hold a different view than Nebes, Inzidenzschema, who draws a syntactic distinction between a setting clause introduced by baynā/baynamā and one introduced by 'inna. The first is labeled 'the dependent clause-main clause construction', whereas the latter is labeled 'the "emphatic" main clause-main clause construction'. According to Nebes, the past time reference of yaf'alu (the imperfect) in the baynā/baynamā-clause is obtained due to its being dependent upon and concomitant with fa'ala (the perfect) in the following superordinate clause. In 'inna-clauses, by contrast, yaf'alu does not assume its past meaning relative to fa'ala, but is interpreted as 'historic present': its temporal value is endowed by the speaker/narrator, who envisions past events as if currently unfolding in front of his eyes. In my view, both clauses exhibit the same syntagmatic relations and paradigmatic structure: $y a f^{\prime} a l u$ and the participle in both cases mark the same aspectual distinctions, while the temporal frame of reference is established by the eventive-narrative fa' ala. Moreover, the general qualification of 'inna as 'emphatic' can be further specified. To be sure, 'inna does not indicate a contrastive focus; it does not assert the content of the clause against the explicit or implicit preceding context. On the contrary, 'inna (like baynā /baynamā) presents cataphoric background: it frames the narrative scene in which the dramatic development is about to take place.

46 For the notion of 'homodiegetic', see Genette, Narrative Discourse, 245. In my corpus I could find only one example in which a setting clause introduced by 'inna did not stem from a first-person narrative. In this example the predicate is not verbal but a prepositional phrase, thus the following presentative is introduced by 'idā: fa-inna 'abda l-hakami yawman la-fí l-masğidi l-harāmi 'ị̂a fatan dāhilun (Riwāyāt 1, 64)—'One day while 'Abd al-Hakam was in the holy mosque, there came in a young man'. 
(8.108) fa-wallāhi 'innī la-'amšì naḥwa-hū [...] 'ị harağa naḥwa bābi banī sah$\min$

By God, I was walking toward him [...] when suddenly he went out toward the gate of Banū Sahm. (Mag் $\bar{a} z \bar{\imath}, 31)$

(8.109) fa-wallāhi 'innī la-qā 'idun fì 'ahl-ì 'ị nazartu 'ilā za ìnatin By God, I was sitting among my people when suddenly I noticed a woman in a camel-borne sedan. (Sïra, 2, 948)

\subsubsection{Presentative Clauses}

Presentative clauses take the second position in the complex construction. Presentative clauses which involve the predicative paradigm are introduced by the particle 'id $\bar{a}$ and exhibit the pattern [nominal-phrase + predicative form] ${ }^{47}$ The predicative paradigm comprises the triad of $y a f^{\prime} a l u$, the participle, and qad fáala. Interestingly, the participle in 'id $\bar{a}$-clauses-rather than taking the accusative case (as in verbal complexes) - assumes, as a rule, the nominative case: 48

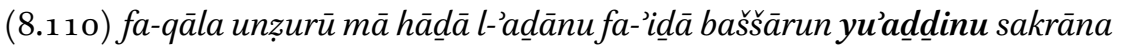
And he said: 'Look what is this call!' And there was Baššār calling for prayer while drunk. (Riwāayàt 1, 261)

47 The nominal presentee after 'i $\underline{d} \bar{a}$ may be definite or indefinite. It either takes the nominative case or is realized as the genitive complement of the preposition bi- 'with'. However, when followed by a predicative form, the nominal presentee is nearly always attested in the nominative.

48 In my corpus, as well as in the major grammars of Classical Arabic, there are no examples of ' $i \underline{d} \bar{a}$-presentatives in which the participle is attested in the accusative case. On the other hand, there are quite a few examples of presentatives introduced by $h \bar{a} \underline{d} \bar{a}$ in direct speech, in which the participle takes the accusative, e.g.: fa-qāla yā rasūla llāhi hāâā 'umaru bnu l-hațtāb mutawaššihan l-sayfa (Sīra 1, 227) —'And he said: O Messenger of God, [out] there is 'Umar b. al-Hațtāb girding the sword'. This double manifestation of the participle is explained by Bloch, Presentative Structures, as a semantogrammatical development of presentatives in Arabic, from 'amplified' constructions, in which the participle (or some other form) is adverbial (i.e. accusative), to 'proclitic' constructions, in which it is predicative (nominative). In a synchronic view, however, the fact that a fluctuation between both manifestations exists is by itself instructive: it reflects the adverbial-yetkernel status of this 'amplifying' term, which, unlike other adverbials (e.g., temporal or locative), forms part of the predicative core of the clause, see above 8.2. 
(8.111) fa-ǧìtu 'ilā ìbrāhìma l-mawșiliyyi fa-'idà l-bābu maftūḥun wa-l-dihlīzu qad kunisa wa-l-bawwābu qāidun

I came to 'Ibrāhīm al-Mawșilī, and behold, the door was opened, the hall was already swept, and the door-keeper was sitting. (Riwāyant 1, 28)

(8.112) fa-fataha-hā la-hū fa-'idāa fi-hā șūratu 'àdama wa-durriyyati-hī kulli-him fa-'idà kullu rağulin maktūbun 'inda-hū 'ağalu-hū wa-'id̄a 'àdamu qad kutiba la-hü 'umru'alfi sanatin

He opened it (i.e. His hand) for him, and behold, in it there was the picture of Adam and all his progeny, and there was the [life] term of each man written down with Him, and there was Adam, a term of

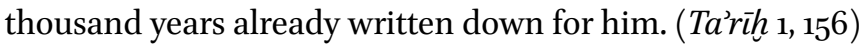

\subsection{Summary}

In this chapter, I have discussed a paradigm of verbal forms which function as predicatives in complex predications. This paradigm consists of yaf'alu, the participle, and qad fa'ala, marking an ongoing situation, a state, and an outcome, respectively. All three forms are co-temporal, either simultaneous (totally overlapping) or coincidental (partially overlapping) with the time frame established in the main clause. The predicative paradigm cross-cuts different syntactic levels: it is used in verbal complexes and circumstantial clauses at the (complex-)clause level, and in mutually dependent constructions at the text level, as summarized in table 8.2 below:

TABLE 8.2 The predicative paradigm across the board

\begin{tabular}{lll}
\hline & The predicative triad & Other verbal forms \\
\hline verbal complexes & $\begin{array}{l}\text { yaf'alu } \\
\text { fä́ilan/maf'ülan } \\
\text { qadfáala }\end{array}$ & $\begin{array}{l}\text { fáala (auxiliary, perception) } \\
\text { sa-yaf'alu (perception) }\end{array}$ \\
\hline circumstantial clauses & $\begin{array}{l}\text { wa-huwa yaf'alu } \\
\text { wa-huwafä́ilun/maf'ülun } \\
\text { wa-qadfáala }\end{array}$ & \\
\hline
\end{tabular}


TABLE 8.2 The predicative paradigm across the board (cont.)

\begin{tabular}{|c|c|c|}
\hline & The predicative triad & Other verbal forms \\
\hline setting clauses & $\begin{array}{l}\text { baynā/baynamā huwa yaf'alu } \\
\text { baynā/baynamā huwa fā'ilun } \\
\text { *qad fa'ala not adjacent to } \\
\text { baynā/baynamā }\end{array}$ & \\
\hline presentative clauses & $\begin{array}{l}\text { ¿idā huwa yaf'alu } \\
\text { 'id̄ā huwa fāilun/maf'ūlun } \\
\text { 'id̄ā huwa qad fa'ala }\end{array}$ & \\
\hline
\end{tabular}

The identification of the predicative paradigm leads to some interesting observations with regard to the Classical Arabic verbal system in general. Firstly, by contrast to the general opinion (see above chapter 3), fa'cala and yaf'alu do not function as a binary pair. As a predicative form, fa'ala is quite marginal vis-àvis the dominant role played by yaf'alu and its counterparts, the participle and qad fa'ala. Secondly, despite their close syntactic mud̄ära'a 'resemblance' (see above 2.3.2), yaf'alu and the participle are distinct at several semantic levels, as presented in table 8.3 below:

TABLE 8.3 yaf'alu $v$ s. the participle

yaf'alu Participle

Grammatical aspect dynamic-progressive static

Verbal attribute habit / goal property / appointment

Transitivity (mostly) transitive intransitive

Lexical informativity higher lower

Thirdly, it is clear that qad fa'ala is not simply an extension of fa'ala, at both the syntactic and semantic levels: (a) qad facala is far more frequent as a predicative, whereas fa'ala usually functions as the main verb; and (b) qad fa'ala indicates a temporally bounded situation, whereas fa'ala indicates a selfcontained event. These distinctions are summarized in table 8.4 below: 
TABLE 8.4 qad fa'ala $v s$. fa'ala

qadfáala fáala

Favored syntactic position predicative main

Grammatical aspect resultative perfective-eventive

Temporal reference coincidental self-contained 


\section{The Verbal Paradigm in the Dialogue}

The last two chapters were dedicated to the analysis of the verbal paradigm at the (complex-)clause level: the function of the verbal forms in embedded, dependent, and mutually dependent clauses was examined. In this and in the following two chapters, I will move on to discuss the verbal paradigms at the text level. I draw a basic distinction between three text types: the dialogue, the narrative, and the generic utterance. This distinction is based on two parameters: (a) the reference point and (b) the overall cohesive structure of the text (see above 4.3). In the present chapter, the distribution and function of the verbal forms in the dialogue will be examined. Specifically, the effect of the context of situation on the interpretation of the verbal forms will be discussed.

\subsection{Preliminaries}

Dialogue, in non-technical language, is often taken to be synonymous with conversation. In this capacity, dialogue is the form in which the most basic and ordinary language —indeed, the form which human language was primarily designed for-manifests itself.' In yet a broader sense, dialogue is conceived of as not only the most basic form of language use, but as an inextricable component thereof, for language is interactional in its very nature, a joint production' of a speaker and an addressee. ${ }^{2}$

When used in a technical fashion, however, it is important to keep the two concepts of dialogue and conversation apart: while conversation refers to a type of communicative situation, dialogue refers to a type of textual structure.

1 This idea has been expressed time and again in the literature: see Lyons, Semantics, 2, 637638 , arguing that 'there is much in the structure of languages that can only be explained on the assumption that they have developed for communication in face-to-face interaction'; also in similar wording, Levinson, Pragmatics, 54.

2 Tannen, Talking Voices, 12. In discussing the interactional nature of conversations, Tannen contends that a conversation in not simply 'a matter of two (or more) people alternately taking the role of speaker and listener', since both 'speaking and listening include elements and traces of the other'.

(C) MICHAL MARMORSTEIN, 2016 | DOI: 10.1163/9789004310483_010

This is an open access chapter distributed under the terms of the Creative Commons

Attribution-Noncommercial-Non-Derivative 3.0 Unported (CC-BY-NC-ND) License 
An ordinary conversation is the most common situation in which a dialogue is realized, although other types of textual structures, such as narratives and generic utterances, may well be embedded in conversations. A literary work is another communicative situation in which dialogues are found. In this case, the dialogue may be viewed as yet another channel of story transmission, alternating with that of the narrative. Consider, for example, the following excerpt, in which the king's desire, presented in the form of direct speech, functions as a link within the sequence of events:

\section{(9.1) țumma qāla li-l-yahūdi 'inna l-malika yurīdu zìyārata-kum fa-’a'iddū nuzlan fa-'a'addü-hu}

Then he said to the Jews: 'The king wants to visit you - so prepare the food [offered to the guest]!' So they prepared it. (Riwāyāt 2, 11)

Literary or represented dialogues are considerably different from ordinary dialogues in everyday conversation. For one thing, in literary dialogues the phatic component, or references to the 'mechanical requirements of talk', are far less encountered and sometimes even completely absent. ${ }^{3}$ Secondly, in (nonperformed) literary dialogues, certain features which make up what Tannen calls 'the poetics of conversational discourse' are missing, especially those marked by prosodic means. ${ }^{4}$ Furthermore, ordinary and literary dialogues are different in their non-referential (or informative) functions. In ordinary dialogues, the social function (i.e., the establishing of the relationships among the participants) appears to exhaust much of the efforts of the interlocutors, and may be considered in some cases to constitute the ultimate goal of the conversation. Thus, one may encounter many features in ordinary conversation whose presence cannot be explained in any (better) way than the marking of involvement and rapport. ${ }^{5}$ Literary dialogues, by contrast, serve primarily an expressive function: besides transmitting information, the dialogue contributes to the

3 In her multi-dimensional model of discourse, Schiffrin, Discourse Markers, 24-25, refers to that aspect as the 'exchange structure' of discourse.

4 Tannen, Talking Voices, presents an extensive study of the features which contribute to the poetics or aesthetics of conversational discourse. These often manifest themselves through phonic or prosodic means. One could argue that punctuation marks in literary works serve a similar function. However, (original) punctuation is entirely absent from the classical works I have examined.

5 Tannen, Talking Voices, 13, argues that 'coherence and involvement are the goal—and, in frequent happy occurrences, the result—when discourse succeeds in creating meaning through familiar strategies'. 
characterization of the dramatis personae and to the overall dramatic impact of the composition. ${ }^{6}$

Dialogues, then, may vary to a great deal depending on the communicative situation is which they are realized. However, there appear to be two essential properties of dialogue which characterize this type of textual structure, regardless of the particular - spoken or written, ordinary or literary-form it assumes. The first is related to the deictic nature of the dialogue; the latter to its cohesive structure. The dialogue is egocentric: the identity of the persons involved, as well as the spatiotemporal coordinates, are all determined with respect to the speaking subject. Every utterance in a dialogue is revealing of a certain 'self', situated in a specific social and cultural context, holding a certain stance, and viewing reality from a particular vantage point. The dialogue is also interactional: it always consists of an exchange between (at least) two involved and active parties. Being egocentric and interactional, the dialogue is distinct, on the one hand, from generic utterances, which are devoid of particular reference, and on the other, from narratives (or other monologic structures), in which only one party actively contributes to discourse. These two properties largely determine (and, from the analyst's perspective, explain) the bulk of syntactic structures that are found in dialogues and the meanings they are designed to convey.

Although often taken to be the most basic form of discourse, dialogues present a tremendous structural complexity and variability. This may be explained by the fact that a dialogue is embedded in a social activity whose purpose is not simply informative, but also (and even to a greater extent) expressive and persuasive. The interactional component is therefore fundamental in analyzing the structure of dialogues. It is not without reason that speech-act theories, and pragmatics in general, were primarily oriented to dialogic utterances, since in dialogues structure and meaning are always integrated with the component of action. As Schiffrin points out, cohesion in discourse ('discourse' implying, for the most part, conversation) is achieved through a (successful) integration of these three components, i.e. structure, meaning, and action, which come into play at several dimensions: syntactic, semantic, and pragmatic. In her words: 'Local coherence in discourse is thus defined as the outcome of joint efforts from interactants to integrate knowing, meaning, saying, and doing.7

6 In literary works, the use of the same strategies that are found in ordinary conversations is never there for its own sake, but always as part of the artistic or mimetic act.

7 Schiffrin, Discourse Markers, 29. 
The structure of dialogues, then, can be approached from several angles. In the present study, the structure of dialogues in Classical Arabic prose is not explored in its entirety, but rather the discussion focuses on the verbal paradigms which operate in them. Specifically, I will examine the indicative affirmative forms occurring in main clauses, although, for the sake of coherence, a short review of the negated forms will also be presented. It should be noted that the following discussion of dialogue clauses does not fit strictly with either the standard classification of sentence-types (i.e., declarative, imperative, interrogative) or with a certain typology of speech-acts; rather, it follows from the analysis of the verbal paradigms which were found to be used in different types of clauses, thus the classification may be said to reflect both syntactic and pragmatic aspects of the examined clauses.

\subsection{Declarative Clauses}

Declarative clauses are considered to be unmarked with respect to other sentence-types (or moods). They are the most frequently occurring type of clauses and, quite often, they do not include any positive marker of their 'declarative' meaning. ${ }^{8}$ As for their use, declarative clauses are employed in the dialogue for a great number of speech-acts. The fact that they are commonly associated with a descriptive or representative function is not so much suggested by authentic linguistic evidence, as by the history of language study (or better, its philosophical sources). Proper declaratives, so to speak, which serve a purely descriptive function, are usually of generic nature (see below chapter 11). As particular clauses, declaratives in the dialogue come close to having a descriptive function when they serve to express a mental state or perception, that is, when they are used as external verbalizations of internal states or processes (see below 9.2.1). Otherwise, declaratives are often used to state a certain position or offer support to this position, that is, to express an argument. We shall see below (9.2.2) that, although no explicit marker of the declarative meaning exists, Classical Arabic does have an exponent for the argumentative function of a clause, namely, the introductory 'inna.

As mentioned above (9.1), dialogue is considered to be the most basic form of language use. For this reason, grammars usually quote examples from dialogue in order to illustrate the typical meaning of a verbal form. A clause such as presented in [9.2] could have served well the discussion of the tense-aspect opposi-

8 Cf. König and Siemund, Speech Act, $284 \mathrm{ff}$. 
tion marked by fa'ala and yaf'alu, the first indicating past perfective meaning, the latter indicating non-past (or present-future) imperfective meaning:

(9.2) wayla-kum qataltum 'abā-hu bi-l-'amsi wa-'aqtulu-hü l-yawma Woe unto you! You killed his father yesterday and am I to kill him today?! (Sira 1, 222)

There are two basic problems with such an analysis of the meanings of fa'ala and yaf'alu. Firstly, this analysis is usually generalized by the grammarians so as to account for all the cases which exist in the language (see above chapter 3 ). Secondly, it reduces the functional complexity of the verbal forms to pure, clear-cut temporal or aspectual notions. Clearly, in [9.2], as suggested by the translation, 'aqtulu-hū cannot be simply understood as an assertion of future event. Rather, this form involves the modal sense of obligation, refuted by an implied tone of reproach. But not only the interference of modal nuances in the temporal interpretation of the verbal forms challenges the neat tense-aspect opposition mentioned above. The precise meanings of tense and aspect, too, are not as self-evident as often taken to be in the frame of a dialogue. Consider, for instance, the following examples:

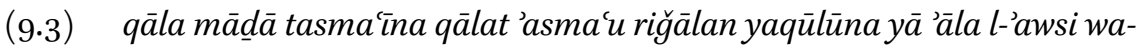
riğālan yaqūlūna yā 'āla l-hazraği qāla l-āna hamiya l-qitālu He said: 'What do you hear?' She said: 'I hear men saying "O people of 'Aws [come to battle]" and men saying "O people of Hazrağ [come to battle].' He said: 'Now the battle is fierce.' (Riwāyāt 2, 47)

(9.4) qāla buraydatu 'arkabu l-'āna fa-'ātî-kum bi-ğam'in kațīfin min qawm-ī Burayda said: 'I will ride now and come [back] to you with a group of tough men from my people.' (Mag்āzī, 405)

In both examples the adverb l'äna 'now' is used to signal the current relevance, presence, or actuality of the events from the point of view of the speaker. Thus, in [9.3], it is hard to claim that the fa'ala form hamiya refers to a past complete event. Even if we interpret it as 'to become fierce', the impression of this process still abides at the time when the clause is uttered. The same applies to [9.4], in which the yaf'alu forms 'arkabu and 'ātī cannot be said to refer to an unapproached future, for the intention to act is already present at the time when the clause is uttered. That the speaker's 'now' coincides with both impressions (or outcomes) and intentions raises a question as to the reality of a rigidly sliced time line (at least) in the sphere of the dialogue. 
All this should not be taken to mean that tense and aspect distinctions do not exist in the dialogue, but only that they do not exist in a pure, absolute fashion. In the dialogue, temporal and aspectual meanings are always conflated with other meanings, modal or, at yet a higher level, pragmatic, which stem from the egocentricity (or subjectivity) of the dialogue and from its interactional nature.

The following discussion of declarative clauses is divided into four sections. First, plain declaratives are examined. Second, clauses introduced by the argumentative 'inna are discussed and, thereafter, asseverations taking the form of the inna la-pattern. Last, declaratives in which negative forms are used are shortly reviewed.

\subsubsection{Plain Declaratives}

Plain declarative clauses exhibit the pattern of either the verbal clause or the nominal clause, not initiated by an introductory or a modificatory operator (see above 6.2.2.2). As discussed above (4.5), there is a certain correlation between the verbal form and the clausal pattern in which it occurs, so that yaf'alu forms are more prone to occur in nominal clauses than fa'ala forms. In general, extrapositions are more common with the first person than with the second and third persons. This, too, can be explained by the egocentric nature of dialogues, in which the extensive mention of ' $\mathrm{I}$ ' is not motivated by special conditions (e.g., by contrast to another person), but serves to re-activate the most natural and accessible topic of discourse. The participle, in itself a nonfinite form, always occurs in the nominal clause pattern.

Plain declarative clauses provide a good syntactic environment to examine the interaction between the verbal lexeme (the lexical aspect) and the verbal form (the grammatical aspect). As noted above (7.2), the verbal lexeme may be characterized according to two semantic distinctions, namely, boundedness and analyzabilty into internal phases. As for the verbal forms, the distinction is drawn between forms which do not impose a certain bounding of the situation, i.e., yaf'alu, fa'ala, and fã ilun, and those which impose such bounding, i.e., sawfa/sa-yaf'alu, qad fa'ala, and maf'ülun.

The temporal value of verbs in the dialogue is determined relative to the zero-time of the dialogue. Far from its graphic representations, the zero-time of the dialogue is not simply a medial point on a logically constructed time axis. Rather, it converges with the subjective vantage-point of the speaker, with respect to which not only temporal but also aspectual and modal meanings, as well as pragmatic motivations, are determined. It will therefore be more accurate to define the reference point of the dialogue using a comprehensive term such as 'the situation of the speaker' (see above 4.2). In the following, I will 
attempt to outline the way by which the semantic and grammatical properties of the verbal form interact with the specific situation of the speaker so as to produce the set of meanings found in dialogues. I shall use relative terms such as posterior and anterior to refer to the time reference of the form, saving the absolute terms, e.g., future and past, to indicate the corresponding logical notions.

The verbal form yaf'alu, with unbounded lexemes denoting activities or states, is normally interpreted as concurrent with the zero-time of the dialogue. In [9.5]-[9.7], yaf'alu occurs with cognitive verbs, indicating perception or mental states. Although the examples exhibit all three persons, with this type of verbs, $y a f^{\prime} a l u$ is by far more attested in the first person. This may be explained by the fact that one is more inclined to make assertions about his internal state than about the mental states of others:

(9.5) 'asma'u riǧālan yaqūlūna yā 'àla l-awsi wa-riǧălan yaqūlūna yā 'àla lhazraği

I hear men saying 'O people of 'Aws [come to battle]' and men saying 'O people of Huazrağ [come to battle].' (Riwāyāt 2, 47)

(9.6) tålamu wallāhimā bi-makkata min qurašiyyin wa-lā qurašiyyatin la-hū naššun fa-șāiidan [...] 'illā wa-qad ba'ața bi-hì ma'a-nā You know, by God, there is not a man or a women in Mecca who has one našš or more [...] but he has sent it with us. (Mag்äzi, 41)

(9.7) al-hূiwānu hìwānu-hü fa-huwa yurìdu 'an yudassima-hü The table belongs to him and he wants to grease it. (Buhalä, 45)

With verbs denoting a continuous or recurring activity, such as 'abada 'to worship', yaf'alu also has a concurrent meaning:

(9.8) fa-nahnnu na'budu l-malāikata wa-l-yahūdu ta'budu 'uzayran We worship the angels while the Jews worship 'Uzayr. (Sira 1, 236)

With bounded lexemes, the verbal form yaf'alu is interpreted as having a posterior time reference relative to the zero-time of the dialogue. However, futurity expressed by yaf'alu appears to involve in most cases a modal nuance, especially in the first and second persons:

(9.9) qālā nahruğu fa-nuqātilu-hū fa-bakā wa-qāla lā tahruğā fa-wallāhi 'inna-hü la-nabiyyun 
They both said: 'We will go out and fight him.' He cried and said: 'Don't go out, for, by God, he is a prophet!' (Majāa $z \bar{\imath}, 33$ )

In [9.9] nahruğu fa-nuqātilu-hū do not express a pure prediction, but in fact, a statement about the speakers' intention to act. In such cases, intention is conflated with prediction to such an extent that one cannot regard the latter as the 'focal use' of yaf'alu..$^{9}$ Motion and action verbs such as represented by nahruğu and nuqätilu consist of both the components of intention and prediction. While intention is experienced by the speaker at the present moment of speech, prediction is less certain and always hinges upon the limited epistemological position of a particular subject (in generic clauses, by contrast, no such limits exist). Cognitive verbs, such as those illustrated above, are different from motion and action verbs in their semantic structure. In these verbs, intention and action are not so easily separable, at least in the case of feelings and sensations of which our mind is only receptive and which we normally have no control over (unless we take a deliberate, strongly intended action). However, it is not impossible (even if rare) to find yaf'alu forms which predict a certain mental state. In such cases, the reference to future time is imposed by the surrounding context. This is the case in [9.10], where the future interpretation of wa-yakrahüna 'they will hate' is entailed by the prophetic context of the clause:

\section{(9.10) wa-hādā l-baladu mawlidu-hū wa-mab'aț-hū tumma yuhriǧu-hū qaw- mu-hü min-hā wa-yakrahūna mā ğăa bi-hì}

This country is his birthplace and place of mission; then his people will expel him from there and despise what he has come with (i.e., the new faith). (Tarih 3, 1144)

9 Bybee, Perkins, and Pagliuca, Evolution, 280, argue that 'the future is less a temporal category and more a category resembling agent-oriented and epistemic modality'. Also Lyons, Semantics, $2,815-816$, states that 'we are seldom in a position to lay claim to knowledge of the future $[\ldots]$ ', thus the future tense 'is rarely, if ever, used solely for making statements or prediction, or posing and asking factual questions about the future. It is also used in a wider or narrower range of non-factive utterances, involving supposition, inference, wish, intention and desire'. While I agree that a pure assertion of future events is possible only for those who hold a privileged epistemological position, e.g. prophets, I do think that the component of intention or desire in a future utterance, by contrast to prediction, is very much 'factive'. For this reason, I have described [9.9] as a 'statement of intention'. Cf. also Fleischman, Future, 30, reviewing the discussion of the notion of future as a 'projection of the subjective, experiential present'. The modal value of the future is, accordingly, a projection of 'modalized notions', such as volition and obligation, which are 'rooted in the present'. 
Explicit reference to future time in the context induces a posterior reading of static verbs, whereas explicit reference to present time may induce a concurrent reading of dynamic verbs. The present time does not necessarily coincide with the exact moment of speech, but it can also be a longer span of time which forms part of the speaker's 'actual referential concern.' ${ }^{10}$ As Janssen articulately points out, 'it is the actual referential concern to the speaker that permits the event at issue to be situated, with regard to the time of the utterance, within a broad temporal region in positions that vary significantly'" Such an understanding of the meaning of the present tense, as the form marking an actual, focal, and relevant situation, obviates the otherwise puzzling questions as to the generality or semantic indefiniteness of the present tense. Thus, concurrent yaf'alu forms may equally report on momentary activities overlapping with the speech time, or on habitual activities characteristic of the present situation of the speaker:

(9.11) yā sayyid-ì l-sāata wallāhi tahruğu rūḥ-ī

My lord, now, by God, my spirit flies away. (Riwāyāt 1, 249)

(9.12) fa-qāla yā rasūla llāhi kayfa ya'ti-ka l-wahyu fa-qāla rasūlu llāhi 'ahyānan ya'tī-nì mițla șalșalati l-ğarasi

He said: 'O Messenger of God, how does the revelation come upon you?' The Messenger of God said: 'Sometimes it comes upon me like the ringing of a bell ...' (Sahịh, 4)

There are two other cases in which yaf'alu, occurring with bounded dynamic lexemes, is nonetheless interpreted as having a concurrent meaning. In these, no explicit reference to the present situation is made. In the first case, yaf'alu serves to externalize or verbalize an internal observation:

(9.13) wayla-ka tuharribu-nī ka-'annì mațlūbun

Woe to you! you force me to flee as if I were a wanted man. (Buhalä), 69)

(9.14) țumma ğa'ala ya'malu safinatan fa-yamurrūna fa-yas'alūna-hü fa-yaqūlu 'a'malu-hā safinatan fa-yasharūna min-hu wa-yaqūlūna ta'malu safinatan fì l-barrifa-kayfa tağrì

10 Janssen, Preterit as Definite, 169.

11 Ibid. 
Then he started to build an ark and they passed by and asked [what was he doing] so he said: 'I am building an ark from it.' They made fun of him and said: 'You are building an ark on land, how could it float?!' (Tärih 1, 186)

In [9.13] the speaker notices that he is forced to flee, and in [9.14] the speaker (echoed later by his addressees), explains the sight about which he is asked. These examples resemble those in which perception verbs are involved (see [5] above), only in this case the clause does not communicate direct perception but an observation involving further cognitive calculation.

The second case in which dynamic yaf'alu forms may assume a concurrent reading is with speech verbs, specifically with qāla 'to say'. The saying reported by yaqülu is understood as still abiding at the time of speech. Such an interpretation of the verbal form suggests that it is not the event of saying that is being referred to, but the content of the saying:

\section{(9.15) fa-qāla lì yaqūlu la-ka 'amìru l-mu’miniña 'ağğil 'ilay-ya}

He said to me: "The Commander of the Faithful tells you: "Hurry up [and come] to me."' (Riwāyāt 1, 65)

To recapitulate the hitherto discussion of the meaning of yaf'alu in the dialogue: with unbounded, static and dynamic lexemes, yaf'alu refers to a concurrent ongoing situation; with bounded lexemes, yaf'alu is interpreted as referring to an intended posterior situation. Deviations from these general tendencies are triggered by a specific context, either one carrying an explicit reference to the future (e.g. prophecy) or one carrying an explicit reference to the present moment or situation. External verbalizations of observed situations are also concurrent with the dialogue time.

The verbal form yaf'alu can be preceded by the modifiers la-, qad, and sawfa/sa- (see above 5.2.2). The form la-yaf'alu will be discussed below in section 9.2.3. The modified qad yaf'alu is scarcely found in dialogue clauses; it is usually used in generic clauses (see below 11.3). In the dialogue, qad yaf'alu is attested with the verbs ra'a 'to see' and 'arafa 'to know', mostly in the first person. It appears that in such cases, as suggested by [9.16], qad has an assertory function: it serves to stress the validity of the assertion expressed by the plain yaf'alu:

(9.16) qum 'ilay-hi fa-qad 'arā llāha 'atā-ka bi-mā yuhzi-ka

Get up [and go] to him, for I see that God brought you something that will humiliate you. (Riwāyāt 1, 247) 
The modified form sa-yaf'alu, and to a lesser extent, sawfa yaf'alu, are more frequently attested in the dialogue. sawfa/sa-yaf'alu serve to refer to posterior occurrences, with either bounded or unbounded lexemes. With the latter types of lexemes, one can observe a neat opposition between the concurrent yaf'alu (see [6] above) and the posterior sawfa/sa-yaf'alu, as illustrated below:

(9.17) țumma ğa'ala ya'malu safinatan fa-yamurrūna fa-yas'alūna-hü fa-yaqūlu 'a'malu-hā safinatan fa-yasharūna min-hu wa-yaqūlüna ta'malu safinatan fì l-barrifa-kayfa tağrì fa-yaqūlu sawfa ta lamūna

Then he started to build an ark and they passed by and asked [what was he doing] so he said: 'I am building an ark from it.' They made fun of him and said: 'You are building an ark on land, how could it float?! So he said: 'You will know.' (Ta'rīh 1, 186)

The verbal form facala refers either to anterior occurrences, with dynamic lexemes, or to persistent situations, with stative lexemes:

(9.18) fa-qāla 'umaru yā rasūla llāhi ğìtu-ka li-ūmina bi-llāhi wa-bi-rasūli-hı̄ wa-bi-mā ğàa min-a llāhi

'Umar said: 'O Messenger of God, I came to you to express my belief in God and in His Messenger and in what he has brought from God.' (Sira 1, 227)

(9.19) fa-qāla l-rağulu 'àmantu bi-mā ğìta bi-hì

The man said: 'I believe in what you have brought.' (Șahịh, 26)

The persistent meaning of static fa'ala forms is explained by the fact that fa'cala, by contrast to qad fa'ala, does not mark the verbal situation as necessarily bounded. Thus, 'ämantu in [9.19] depicts an event whose imprints, its relevance and actuality, extend to the dialogue time. Note that the distinction between anteriority and persistence marked by fa'ala exists only in the dialogue. In the narrative, the chain structure imposes a perfective-eventive reading of facala, regardless of the type of the verbal lexeme (see below 10.2.1).

Interestingly, there is a small group of stative lexemes with which fa'ala is not used to indicate persistence but rather concurrence. Two such lexemes are șadaqa 'to tell the truth' and kadaba 'to tell lies'. When directed to the addressee, sadaqa and kadaba do not report on anterior events, but judge one's words as either true or false. To some extent, șadaqa and kadaba resemble verbs such as 'to name' or 'to appoint' in having a similar performative force (see below 
9.3). The (semi-)performativity of șadaqa and kadaba may explain their concurrent reading:

\section{(9.20) șadaqtumā wa-kaḍaba man qāla ġayra d̄ālika}

You are both right and anyone who says otherwise lies. (Sira 1, 248)

Other stative lexemes which indicate concurrence with fa'ala are šăa 'to want' and 'ahabba 'to like', when referring to a current desire of the speaker:

\section{(9.21) [...] wa-qad kabirat sinn-īwa-raqqa 'azm-ì wa-'aḥbabtu liqāa rabb-ī \\ [...] I have grown old, my bones have become tender, and I desire to meet my Lord. (Maj̇̄ zī, 213)}

In cases such as [9.21], the speaker uses fa'ala in order to mark politeness and humbleness. Such examples are particularly challenging to the common temporal-aspectual analysis of fa'ala, since it is not the past-perfective meaning of fa'ala, but its association with remoteness and indirectness, which makes this form suitable for polite requests.

In contrast to fa'ala, the verbal form qad fa'ala, with both static and dynamic lexemes, marks a bounded situation. With stative lexemes, qad facala indicates the completion of the transition from one state to another (e.g., 'not knowing' $\rightarrow$ 'knowing'):

(9.22) qad 'araftu maqālata-ka fa-rāği' 'aqla-ka wa-'Lam 'anna li-kulli' insānin manzilatan wa-qadran

I already know your position, but, reconsider the matter! Know that every man has an [assigned] status and rank! (Kalïla wa-Dimna, 66)

Resultativity, while very characteristic of qad fa'ala, is not the only meaning expressed by this form. In the sphere of the dialogue, qad fa'ala displays a complex semantic structure, consisting of a cluster of temporal, aspectual, and modal meanings. The present discussion is not aimed to determine which of these meanings is the original meaning of qad facala. ${ }^{12}$ Rather, the goal is to

12 In the Arabistic literature, one finds several attempts to explain the multiplicity of functions fulfilled by $q a d$. Testen, Asseverative la-, $85 \mathrm{ff}$., argues that the original role of $\mathrm{qad}$, from which its other meanings are derived, is the marking of perfective aspect. A different view is presented in Bahloul, Arabic Verb, chapter 5, who contends that the invariant meaning of $q a d$, underlying all of its uses, is assertorial. In my view, the existing data does not provide us with enough evidence to reach a decisive conclusion. Nevertheless, the fact 
examine the interaction of qad facala and the surrounding context in order to understand the conditions in which a certain meaning suggests itself more strongly than others.

We shall first look at a case where the temporal and aspectual meanings of qad fa'ala surface:

\section{(9.23) là tantazirū-nì bi-l-'akli fa-qad 'akaltu}

Don't wait for me with the food, for I have already eaten. (Riwāyāt 1, 40)

In [9.23] it is clear that qad 'akaltu 'I have already eaten' refers to a complete event of eating, and hence to the resultant state of satiation, which explains the speaker's request not to postpone the meal time on his behalf. In [9.24], by contrast, the emphasis lies not on the fact that the event is already completed, but on the fact that it was indeed carried out:

(9.24) wayha-ka 'a-hādā ši'ru-ka llad̄ì 'anšadta-hū l-farazdaqa qultu na'am faqāla qad wallāhi 'aṣabta wallāhi la-'in kāna hādā l-farzadaqu šăciran la-qad hasada-ka

Woe unto you, is this your poem that you sang to al-Farazdaq? I said: 'Yes.' He said: 'By God, you surely did [it] well! If this al-Farazdaq is a singer then he must envy you.' (Riwāyāt 1, 13)

The response qad 'asabta 'you did well', corroborated by the oath expression wallāhi 'by God', has an assertorial function: it stresses the fact that the event of singing exceeded the expectations of the speaker and that it is therefore remarkable.

It is interesting to notice the different uses of qad fa'ala in the dialogue vis-àvis the narrative. First of all, qad fa' ala in the dialogue may occur in main clauses whereas in the narrative it only occurs in dependent circumstantial clauses (when not embedded, see below 10.3.1). Secondly, in the dialogue, qad fa'ala is mostly used to present the background or offer an explanation to a certain position, the same as argumentative 'inna-clauses. This causal meaning of $q a d$ fa'ala is evidently related to its anterior meaning. In the narrative, on the other hand, the anterior meaning seems to predominate. Consider, for instance, the following excerpt in which the same event, viz. qad 'ahlaka, is mentioned twice, first in the dialogue and then in the narrative:

that qad fa'ala is generally incompatible with negation may be taken as evidence for the proposal that its core meaning is assertorial. 
(9.25) 'a-la 'abširū fa-qad zahara l-nağāšìyu wa-qad 'ahlaka llāhu 'aduwwahū [...] wa-rağa'a l-nağǎšiyyu wa-qad 'ahlaka llāhu 'aduwwa-hū

Rejoice, for the Negus has conquered and God has destroyed his enemy [...]; and the Negus came back after God had destroyed his enemy. (Sïra $1,221)$

In the dialogue, qad 'ahlaka clearly serves to explain the request expressed by the imperative 'abširü. In the narrative, qad 'ahlaka is part of the chronological transmission of the story. In both cases, neither the temporal nor the causal meaning can be ruled out; yet, in each of them, due to the different text type, a chronological or a logical interpretation of qad fáala suggests itself more strongly.

The active participle fä ilun, in the dialogue as elsewhere (see above 7.2), does not impose a certain bounding of the verbal situation. In contrast, the passive participle maf'ülun depicts a terminally bounded situation. With unbounded lexemes, fäilun refers to a situation concurrent with the zero-time of the dialogue. As opposed to yaf'alu, fä́ilun does not indicate an ongoing or recurring situation, but a static one:

(9.26) qad samitunna sūi raddi-hı̀ alay-kunna wa-'anā hẳifun mițla-hū minhu

You have heard his offensive reply to you and I fear of [getting] the same [reply] from him. (Riwāyāt 1, 11)

With bounded lexemes, fấilun is interpreted as having a posterior time reference relative to the zero-time of the dialogue. In many of these cases, $f a^{-}$ilun serves to express an immediate future. ${ }^{13}$ In contrast to $y a f^{\prime} a l u$, which states the speaker's intention to take action (and, hence, predicts the occurrence of that action), fäilun states the readiness of the speaker to take action. As illustrated in [9.27], the act of going out is that settled in the speaker's mind, so as to initiate the process in effect:

\section{(9.27) fa-qāla 'utbatu lā šay'a 'anā ḩāriğun}

'Utba said: 'Nothing. I am leaving!' (Mag் $\bar{a} z \bar{\imath}, 38)$

13 Immediate future forms, according to Bybee, Perkins, and Pagliuca, Evolution, 244ff., are 'restricted to events which are imminent or about to occur in the immediate future'. As a matter of fact, immediate futures may be regarded as not futures at all, since rather than predictions, these forms amount more to 'assertions announcing the imminence of an event' (273). 
The subjective opposition between intention and readiness marked by yaf'alu and fãilun should not be simply reduced to the objective opposition between far and near future. In the dialogue, the temporal location of the events appears less important and, in fact, derives from the speaker's subjective evaluation as to the feasibility or probability of the events to take place.

The passive participle, with both bounded and unbounded lexemes, depicts a resultant state, concurrent with the zero-time of the dialogue:

(9.28) yā rasūla llāhi l-qawmu mad'ürūna faziūuna

O Messenger of God, the people are scared and frightened. (Majīzi, 54)

Table 9.1 below summarizes the discussion of the functions of the verbal forms in declarative clauses:

TABLE 9.1 The verbal forms in declarative clauses

\section{Verbal lexeme}

Verbal form

bounded

unbounded

Context/lexeme-specific

\begin{tabular}{|c|c|c|c|}
\hline yaf'alu & $\begin{array}{l}\text { concurrent } \\
\text { ongoing situation }\end{array}$ & $\begin{array}{l}\text { posterior } \\
\text { intention }\end{array}$ & $\begin{array}{l}\text { concurrent } \\
\text { explicit present }\left(l-s \bar{a}^{c} a t a\right) \\
\text { observations, sayings (yaqūlu) } \\
\text { posterior } \\
\text { explicit future (prophecy) }\end{array}$ \\
\hline$s a(w f a)-y a f^{\prime} a l u$ & \multicolumn{2}{|c|}{ posterior } & \\
\hline qadyaf'alu & & & $\begin{array}{l}\text { concurrent-assertive } \\
\text { 'arā, 'a'rifu }\end{array}$ \\
\hline fáala & persistent & anterior & $\begin{array}{l}\text { concurrent-indirect/remote } \\
s ̌ \bar{a} a, \text { 'ahabba } \\
\text { concurrent-'performative' } \\
\text { șadaqa, kaḍaba }\end{array}$ \\
\hline qad fáala & \multicolumn{2}{|c|}{ anterior-complete-causal-assertive } & \\
\hline
\end{tabular}




\section{Verbal lexeme}

Verbal form

unbounded

Context/lexeme-specific

\begin{tabular}{l|l|l|l}
\multicolumn{2}{c}{ unbounded } & \\
\hline$f a \bar{c}$ bilun & concurrent state & $\begin{array}{l}\text { posterior } \\
\text { readiness }\end{array}$ & \\
\hline maf'ūlun & \multicolumn{2}{c}{ concurrent result } & \\
\hline
\end{tabular}

\subsubsection{Argumentative 'inna-clauses}

The display of arguments constitutes a great part of any dialogue exchange. An argument, as Schiffrin defines it, is 'discourse through which speakers support disputable positions. ${ }^{14}$ It comprises, accordingly, three parts: position, dispute, and support. An argumentative clause, i.e., a clause which contributes to the construction of an argument, can be used to convey any of these parts. Quite often, clauses which express support or dispute do not follow the explicit mention of a position, but implicitly, by endorsing or rejecting a certain position, they also make plain what its content is about.

Positions, i.e., assertions about situations and events, beliefs and ideas, are often expressed by plain declaratives. However, they can also take the marked form of 'inna-clauses. The operator 'inna is used for a number of functions. ${ }^{15}$ One of its major roles is to introduce what may be described as 'expository' clauses, i.e., clauses which outline a certain position. Expository 'inna-clauses do not occur freely in the dialogue, but are found adjacent to clauses expressing commands, demands, requests or questions, whether these are directly addressed or only inferred. Expository 'inna-clauses initiate thus bipartite structures, in which the first part, the expository unit, implies the second part, the unit addressing the second party.

The verbal paradigm in expository 'inna-clauses consist of yaf'alu, fa'ala, qad fa'ala, and the participle. As far as their temporal, aspectual, and modal meanings are concerned, these forms exhibit the same distinctions as the ones observed in plain declaratives, as illustrated below:

\footnotetext{
14 Schiffrin, Discourse Markers, 18.

15 The syntactic distribution and discourse functions of 'inna were thoroughly studied in Marmorstein, 'Inna-Sentences.
} 
(9.29) 'inna-nì 'asmuru l-laylata ma'a 'amìri l-mu'minina fa-hal tuhsinu 'an tahduwa

I will spend the night chatting with the Commander of the Faithfulare you good in singing the songs which urge the camels? (Riwāaya $t$ 1, 25)

(9.3o) 'inna rağulan min 'așhābi-ka qatala rağulayni min qawm-īwa-la-humā min-ka 'amānun wa-'ahdun fa-b'aț bi-diyati-himā 'ilay-nā

A man from your companions killed two men of my people, while they had your protection and agreement, so send us their blood money! (Maḡa $\bar{a} \bar{\imath}, 364)$

(9.31) 'innī qad ğìtu bi-irsāli-ka fa-mā inda-ka

I have come with your release, what do you have at your [disposal]? (Riwāyāt 2, 190)

(9.32) yā ma šara l-'ușāti 'innì mufțirun fa-'afțirū

O people of disobedience, I am breaking my fast, so break your fast! (Majā zī, 47)

Argumentative 'inna-clauses are not only used to display a position but also to explicate a certain position or appeal to the addressee. In such cases, the bipartite structure shows an inverted order, in which the 'inna-clause follows a (direct or indirect) command, request or question. The position which explicative 'inna-clauses serve to support is often not explicitly stated, but implicit in the content of the 'inna-clause itself. The explicative 'inna thus encodes both sides of the argument (i.e., the position and the reaction to this position), thereby encapsulating its dialogic nature. ${ }^{16}$

Explicative 'inna-clauses feature the verbal forms yaf'alu, fa'ala, qad fa'ala, and the participle, and to a smaller extent, sa-yaf'alu, as illustrated in the following set of examples:

(9.33) iḥmū la-nā zuhūra-nā fa-innā nahăfu 'an nu'tā min warāì-nā Shield our backs, for we fear that we will be approached from behind us! (Maj̇̄ażi, 224)

16 According to Schiffrin, Discourse Markers, 18, arguments incorporate both monologic and dialogic properties, the latter have to do with 'the interactional organization of dispute'. The rhetoric of dispute is sometimes captured in the most compact lexical items, e.g.: Arabic's 'inna, Hebrew's harei, or car in French (for the latter, see Larcher, Le 'segmentateur', 6o). 
(9.34) 'anā 'abdu-kayā 'amīra l-mu'minīna fa-qul mā šìta siwā baššārin fa-inn̄̄ halaftu fì amri-hī bi-yaminin ġamūsin

I am your servant, O Commander of the Faithful; ask whatever you want but Baššār, for I took the gamūs-oath in his case. (Riwāyāt 1, 258)

(9.35) fa-tanahhhā nāhiyatan wa-l-samā̉u tumțiru 'alay-hiyaqūlu 'utbatu'inna hādā huwa la-nakdun wa-'inna-hum qad 'ahad

He moved aside and the heavens rained down upon him. 'Utba said: 'This is verily a misfortune, for they have already taken your watercarriers!' (Mag் $\left.\bar{a} z \bar{\imath}, 5^{2}\right)$

(9.36) ințaliq bi-nā 'ilā ’adnā mā̉i l-qawmi fa-'innī 'ālimun bi-hā wa-bi-qulubi$h \bar{a}$

Let us go to the point nearest to the water of the people, for I know it and its wells. (Maj $\bar{a} z \bar{z}, 53)$

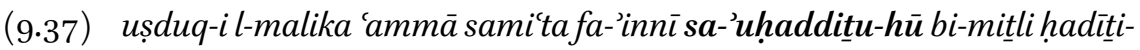
$k a$

Tell the king the truth about what you have heard, for I will give him the same account as yours. (Riwāyāt 2,193)

It is important to note that the explicative meaning may be imparted by other syntactic means, such as the connective $f a$ - The verbal form, too, specifically qad fa'ala which carries a causal meaning, is sufficient in marking the explicative relation. However, unlike the other exponents, 'inna is the only grammatical device which indicates explicitly (unambiguously) the explicative relation.

\subsubsection{Asseverative 'inna la-clauses}

Besides its argumentative function, the operator inna also has an expressive function. The fact that 'inna marks tawkid 'emphasis' was recognized by the Arab grammarians, and it is, in fact, the meaning most commonly associated with this particle. The present discussion is not concerned with the semantics of 'inna; however, some clarifications as to the distribution and use of the emphatic 'inna are deemed necessary.

It should first be stated that 'inna alone does not embody an emphatic meaning, but only when it introduces a nominal clause whose predicate is preceded by the modifier la-. Thus, the emphasis expressed by 'inna la-clauses should be attributed to the overall construction of the clause (and historically, perhaps, to the emphatic la-alone). Secondly, the exact meaning of 'emphasis', which in itself is quite vague, should be examined more closely. Emphasis can be applied 
to various parts of the predication. In the case of a verbal predication, each of its constitutive elements, i.e., the subject, the verbal lexeme, and the predicative link (the 'nexus'), can be emphasized..$^{17}$ It is the latter constitutive element, namely, the predicative relation, that the 'inna la-construction is emphasizing, thereby assigning the clause an asseverative force. The emphasizing of the predicative link, or the 'nexus focusing mechanism', is characterized by Cohen as 'a contrast of polarity applied to the nexus, or in other words, the contrast between the affirmative and the negative or even mere implication of negative, such as doubt'. ${ }^{18}$ The content to which the asseveration reacts may be explicitly stated in the surrounding context or presupposed by the speaker. Nexus focusing is viewed by Cohen as inherently modal, since it 'marks the propositional content as initially in doubt'. ${ }^{19}$ In my general classification of the verbal forms (see above chapter 5), I drew a distinction between modally unmarked (indicative) forms and modally marked forms. The employment of indicative forms in asseverative clauses is thus one case in which these acquire a specialized modal meaning (another case will be discussed in section 9.4 below). However, this meaning cannot be attributed to the verbal form alone, as it emerges from the entire construction of the clause.

The verbal paradigm in asseverative clauses consists of yaf'alu and the participle, to which the modifier $l a$ - is prefixed. Not only with unbounded, but also with bounded lexemes, yaf'alu refers to an ongoing or recurring situation, concurrent with the zero-time of the dialogue:

(9.38) hal tadrūna li-mā qāma muhammadun qà lù lā wallāhi mā nadrīwa-mā tadrì 'anta qāla balā waltawrāti 'innī la-'adrì

Do you know why Muhammad got up? They said: 'By God, we do not know and neither do you!' He said: 'But of course, by the Torah, I do know!' (Maḡa $z \bar{\imath}, 365)$

(9.40) qālat hadīğatu kallā wallāhi mā yuhzī-ka llāhu 'abadan 'inna-ka latașilu l-rahima wa-tahmilu l-kalla wa-tuksibu l-mádūma wa-taqrì ldayfa wa-tu'ìnu 'alā nawä̀ibi l-ḩaqqi

Hadīğa said: 'Never, by God, God will never disgrace you! You bestow upon the relatives, carry the burden, grant the poor with help, receive

17 For the analysis of the verbal complex into three essential constituents, viz. (1) the pronominal theme, (2) the verbal lexeme, and (3) the predicative relation between them, see Goldenberg, Verbal Structure.

18 Cohen, Modal System, 42.

19 Ibid., 67. 
hospitably the guest, and help in fulfilling the ever-recurring duties.' (Șahịh, 3)

The participle, as mentioned before, is generally used to express a static situation. However, in the frame of 'inna la-clauses, this state is interpreted as that characteristic so as to become an inherent attribute or disposition. This may be explained by the fact that nexus focusing, marked by the 'inn a la-pattern, essentially conveys a strong identification between the speaker (or more generally, the subject) and his state. Thus, also with bounded lexemes, the concurrent interpretation of la-fä ilun seems to be called for:

(9.41) wallāhi mā balag̉a-nā 'illà 'anna nabiyya-nā yușallì 'ilā l-šāmi wa-māa nurìdu'an nuhālifa-hū qāla fa-qāla 'innì la-mușallin 'ilay-hā

By God, we are only informed that our Prophet prays towards al-Šām, and we do not want to contradict him. (he said) He said: 'I am surely praying towards it (i.e. the Ka'ba).' (Sirra 1, 294)

The strong ties between asseveration, as marked by the 'inna la-pattern, and reference to present time, did not escape the Arab grammarians. Ibn Ya'ǐš reports on a dispute among the grammarians with regard to the possible future interpretation of la-yaf'alu. ${ }^{20}$ The grammarians allowing for a future reading of la-yaf'alu adduce the following verse from the Qur'ān: wa-inna rabbu-ka la-yahkumu bayna-hum yawma l-qiyāmati (16:124) 'Verily your Lord will judge among them on the Day of Resurrection'. However, such evidence could not be found in my corpus, where all the examples of la-yaf'alu appeared as largely incompatible with a future reading. In my view, this fact is not to be explained by the disambiguating function of $l a$-, which instructs us to interpret yaf'alu as present, the same way as $s a$ - instructs us to interpret yaf'alu as future, as suggested by some grammarians. Rather, the relation between 'inna laclauses and reference to present time stems from the essential function of these clauses, namely, to emphasize the strong identification of the speaker (i.e., the topic entity) with his current state (i.e., his qualification or description). ${ }^{21}$

\subsubsection{Negative Clauses}

The present section on negative clauses in the dialogue is a short addendum to the above discussion of affirmative declarative clauses. To be sure, the topic

\footnotetext{
20 Ibn Ya'ǐ̌s, Šarh al-Mufașșal, 5, 147.

21 Unlike the stressed auxiliary 'do' in English, 'inna la- does not operate in all tenses, but is restricted to the current state of the speaker.
} 
of negation in Classical Arabic, considering both its notional and structural aspects, is worthy of a whole lot more attention. Here I will only make a few notes regarding the issues of compatibility, distribution, and frequency of some negated verbal phrases.

The Arab grammarians defined the negated verbal forms in contrast to their affirmative counterparts. Thus, Sïbawayhi presents a neat correspondence between fa'ala and its negation lam yaf'al, and between la-qad fa'ala and its negation $m \bar{a}$ fa'ala. With yaf'alu, the correspondence goes as follows: $m \bar{a}$ yaf'alu negates the present yaf'alu, whereas la yaf'alu negates both the future yaf'alu and the energetic la-yaf'alanna. ${ }^{22}$ Sibawayhi's discussion of verbal negation offers two important insights. Firstly, it reveals the polyfunctionality of the verbal forms, which-depending on their affirmative or negative realization - can be used to express different meanings. Secondly, it suggests the same connection that was observed above between emphasizing and reference to present time. These two meanings emerge from the interaction of the negative marker $m \bar{a}$ and the verbal forms fa'ala and yaf'alu, respectively. The connection between emphasis and reference to present time was lucidly explained by Wehr. ${ }^{23}$ The negative particle $m \bar{a}$, as noticed by Wehr, is usually found in dialogues, and more specifically, in contexts where an oath, asseveration, or emphasis of some other kind are involved. The primary function of $m \bar{a}$ is accordingly to mark a 'strong emotional form of speech', and to indicate high involvement on the part of the speaking subject. Since the event expressed in the clause is 'affectively stressed', it is felt by the speaker to be 'closer' to his present situation. ${ }^{24}$

The grammarians account of the verbal negation and Wehr's insightful description of $m \bar{a}$ conform with a great part of the data found in my corpus; still, some additional observations and refinements of the ones mentioned above can be offered.

The verbal form yaf'alu, when negated by $l \bar{a}$, may be interpreted as either concurrent or posterior. The time reference of lä yaf'alu is not determined by the corresponding (in fact, presupposed) affirmative form, which, we recall, can indicate both temporal values. Rather, the time reference is derived from the interaction between the verbal lexeme and the grammatical form of the verb. With unbounded lexemes, $l \bar{a}$ yaf'alu is normally interpreted as concurrent:

\footnotetext{
22 Sibawayhi, Kitāb, 1, 408-409.

23 Wehr, Arabischer Negationen.

24 Ibid., 3 .
} 
(9.42) 'ayna 'abū-kiyā binta 'abì bakrin qālat qultu lā 'adrī wallāhi 'ayna 'ab-ī (Sira 1, 329)

Where is your father, O daughter of 'Abū Bakr? (she said) I said: 'I don't know, by God, where is my father.'

Contexts which include an explicit reference to future time induce a posterior reading of lā yaf'alu, also with unbounded lexemes. The negated lā yaf'alu, the same as yaf'alu, is usually not used to convey pure predictions, but to express one's intention to act or not to take action. In the first person, the intention is internal; in the second and third persons, it is projected or conjectured:

\section{(9.43) wa-innā wallāhi lā nu'minu bi-l-rahmmāni 'abadan}

And, by God, we will never believe in al-Raḥmān! (Sïra 1, 189)

As amply demonstrated by Wehr, the negative marker $m \bar{a}$ is used for expressive or 'affective' negation. Indeed, ma $y a f^{\prime} a l u$ is very common in oaths and other asseverative contexts, where reference to a future event is often intended:

\section{(9.44) fa-wallāhi mā yadhulu 'alay-ka'ahadun \\ By God, no one is to enter upon you. (Sïra 1, 249)}

The negated $m \bar{a}$ yaf'alu is also found in non-asseverative contexts. In such cases, it usually occurs with cognitive verbs indicating perception or a certain mental state or disposition. The preference of $m \bar{a}$ with cognitive verbs is to be explained by the egocentric, or better, 'centripetal force' of this negative particle, which brings the situation 'closer' to the speaker, whether this closeness stems from a strong emotional involvement or from the fact that the situation is internally experienced or sensed:

\section{(9.45) wa-mā 'uḥibbu 'an ta'lama qurayšun mā 'aqūlu l-àna} I don't want Qurayš to learn what I say now. (Majā $z \bar{\imath}, 36)$

I adduce one example for the negation of yaf'alu with laysa, which in Classical Arabic prose, as opposed to Qur'ānic Arabic, is not uncommon. ${ }^{25}$ From a structural (and perhaps also historical) point of view, the compatibility of

25 Concluding his discussion of laysa in the Qurān and in Sībawayhi's Kitāb, Sakaedani, Laysa, 170-171, says that since laysa yaf'alu is not attested in the Qurān, nor mentioned by Sîbawayhi, its usage is 'supposed to be relatively recent'. However, the fact that we do 
yaf'alu with laysa - the negative counterpart of both the existential and the copulative kāna -is quite interesting: it hints at the nominal character of this type of verb (see above chapter 2), which essentially indicates nothing more than an indefinite state of affairs, which can be either asserted or denied:

(9.46) Kayfa ra'ayta bna ğāmi'in yā bunay-ya qultu la-hū 'a-wa-túfí-nī ğu'iltu fidā-ka fa-qāla lastu 'u'fi-ka fa-qul (Riwāyāt 1,3$)$

My little son, what is your opinion about Ibn Ğāmi'? I said: 'Will you exempt me [from answering], may I be made your ransom?' He said: 'I will not exempt you, so say [what do you think]!'

The negation of the verbal form fáala via $l \bar{a}$ is highly marked. The negated form la fáala, which occurs in contexts of oaths and asseverations, conveys a strong negation and refers to situations which will not take place under any type of circumstances:

(9.47) fa-qultu wallāhi lā fáaltu wa-in țalaba-nì l-halīfatu I said: 'By God, I shall not do that even if the Caliph asks me to.' (Riwāyāt $1,3)$

The negated form mā fa'ala, the same as māyaf'alu, is very common in contexts of oaths and asseverations. With both static and dynamic lexemes, it refers to situations whose imprints or relevance still abide at the time when the clause is uttered:

(9.48) 'inna-hū wallāti wal'uzzā mā nazala bi-kum 'amrun 'a'zamu min ḋālika By al-Lāt and al-'Uzzā, surely nothing greater than that has come down to you! (Mag் $\bar{a} z \bar{\imath}, 32)$

Due to the 'centripetal force' of $m \bar{a}, m \bar{a}$ fa'ala is commonly used with lexemes denoting situations which are internally perceived or sensed by the speaker:

(9.49) mā ra'aytu min-ka hayran qațtu

I have never seen any good from you. (Sahịh, 15)

find laysa yaf'alu in Classical Arabic prose proves that this is not an innovation of Modern Standard Arabic but, in fact, a fairly old form, even if not found in the corpora described by the grammarians. 
(9.50) yā habīb-ì mā 'aradtu l-wad'a min-ka bi-mā qultu-hü la-ka wa-'innamā 'aradtu tahdība-ka wa-taqwima-ka

My friend, I did not want to disparage you by what I have said, but only to improve and correct you. (Riwāyāt 1, 40)

The most common form of past negation does not involve fa'ala at all. The unmarked form of past negation is lam yaf'al: it may occur with all types of lexemes and it is not text-sensitive. Although cognitive verbs are often negated through mā fa'ala, they may also be negated through lam yaf'al:

(9.51) mā lì 'arā-ka l-yawma habìta l-nafsi wa-lam 'ara-ka mud 'ayyāmin Why is it that I see you today depressed and I haven't seen you for days?! (Kalīla wa-Dimna, 88)

Lastly, I would like to present two examples of negated participial forms. The negation of the participle can be done via $m \bar{a}$, laysa, or gayra (the latter not discussed here). Quite often, the negative particles $m \bar{a}$ or laysa are strengthened by an additional marker prefixed to the participle, namely, the preposition $b i$-. The structure of $m \bar{a}$ /laysa bi- clauses parallels the structure of 'inna la-clauses: in both cases, an operator controlling the entire clause is followed by a modifier preceding the predicate. Also, as far as their function is concerned, $m \bar{a} /$ laysa $b i$ clauses correspond to 'inna la-clauses: while 'inna la-indicates a strong association of the speaker (or agent) with a certain situation or attribute, $m \bar{a} /$ /aysa $b i$ indicates a strong dissociation of the speaker (or agent) from a certain attribute. For instance, in the famous passage quoted in [9.52], the Prophet, declaring that he does not read, dissociates himself not only from a current state of reading, but from the very ability to read:

\section{(9.52) fa-qāla iqra' fa-qultu māa 'anà bi-qārìin}

He said (i.e. the angel): 'Read!' So I Said: 'I do not read.' (Ṣaḥị̣ 5)

When not reinforced by $b i$ - and occurring with bounded lexemes, the negated participle can be interpreted as referring to an immediate future or 'current readiness':

\section{(9.53) wa-qad 'ağartu l-ğamala wa-lastu ġādiran bi-hī}

I have protected the camel and I am not about to betray him. (Kalīla wa-Dimna, 103) 
The verbal form qad facala is not found in negative declarative clauses. This may be explained by the fact that the assertorial meaning of qad is by and large incompatible with negation. However, we do find qad facala in negative interrogatives, as will be discussed and illustrated below (9.5).

\subsection{Performative Clauses}

Performative clauses are here dedicated a separate section although, from a strictly formal point of view, this type of clauses could have been subsumed under the above discussion of declaratives. Indeed, performative clauses do not employ a different mood than declaratives (like imperatives), nor do they operate on the assertive value of the clause (like interrogatives). Also from a pragmatic point of view, the preliminary Austinian distinction between 'performative' and 'constative' is blurred once one recognizes that all clauses bear some kind of illocutionary force, whether that be directly or indirectly expressed. What, then, justifies treating performatives any differently from the normal declaratives discussed above? In my view, this question cannot be settled on theoretical grounds, by espousing either one of the reductive approaches to speech-acts (the 'thesis' or 'antithesis', to use Levinson's formulation). ${ }^{26}$ Rather, it will be proper to speak of a distinct category of performatives if this indeed correlates with a special marking, lexical and/or grammatical. This condition appears to be fulfilled in Classical Arabic as will be shown below.

Performative clauses, as basically defined, are not used to say something but to do something, i.e., to bring about a change in the world, given the proper ('felicitous') conditions allowing for this change. Such a definition is rather general and may apply to a great number of clauses found in dialogues. Thus, in order to distinguish performatives from other types of clauses one must be able to specify which actions in what conditions should be considered as performatives. I define performative clauses as declarations of actions which constitute, i.e., initiate and accomplish, the action in effect. Unlike expressions of internal perception or external observations (see above 9.2.1), these declarations do not simply verbalize situations which are co-extensive with the time of speech, but refer to situations which come about through speech. Unlike imperatives or interrogatives, performatives are not designed to solicit the reaction of a sec-

26 The topic of speech acts is thoroughly discussed in Levinson, Pragmatics, chapter 5. Levinson contrasts two possible ways ('theses') to resolve the theoretical problems brought about by this topic. 
ond party (though they may affect one), but reside entirely in the domain of the speaker's desire and intention.

In Classical Arabic, one can distinguish between two major types of performative clauses: in the first, the verbal form yaf'alu is used; in the second, fa'ala and qad fa'ala are used. This distinction is not only entailed by the grammatical form of the verb, but also by its compatibility with various lexical classes. Thus, yaf'alu-performatives are lexeme-specific and occur only with declaration verbs:

(9.54) yā kašadu hal ra'ayta 'ahadan min 'uyūni muḥammadin fa-yaqūlu 'a ü $\mathbf{d}$ u bi-llāhi wa-'annā 'uyūnu muhammadin bi-l-nahbāri

O Kašad, did you see any of Muhammad's spies? He said: 'God forbid! Why are there spies of Muḥammad in Nahbār'? (Mag்āzī, 2o)

(9.55) 'udakkiru-kum-u llāha wa-dīna-kum wa-nabiyya-kum

I [hereby] remind you of God, your religion, and your Prophet. (Ma$\dot{g} \bar{a} z \bar{l}, 219)$

(9.56) 'aḥlifu bi-llāhi la-qad ğăà-kum 'usaydun bi-ġayri l-wağhi llad̄i d̆dahaba bi-hīmin inda-kum

I swear by God, 'Usayd certainly has come back to you with a different expression on his face than the one he had when he left you. (Sir 1 1, 292)

In contrast, fa'ala/qad fa'ala-performatives occur with all types of lexemes, though rarely with declaration verbs. ${ }^{27}$ This type of performatives are used in contexts where the event at issue calls for both parties' consent. In other words, in order for the event to be successfully carried out, a reciprocal approval, an agreement, is needed. I therefore refer to this type of clauses as 'transactionperformatives':

(9.57) yā rasūla llāhi bal taqsimu-hū li-l-muhāğirīna wa-yakūnūna fì dūri-nā kamā kānū wa-nādat-i l-anșāru raḍinnà wa-sallamnā yā rasūla llāhi O Messenger of God, you may rather apportion it to the Muhäğirūn and they will stay at our homes as they used to. The 'Anșār then called out: 'We are satisfied and approve [it], O Messenger of God.' (Mag்āzī, 379)

27 Grammars do quote a few examples of declaration verbs realized in the facala form, e.g.: 'anšadtu-ka llāha 'I conjure you by God' (Wright, Grammar, 2, 1). Such examples, however, are seldom found in Classical Arabic prose. 
(9.58) yā 'abā 'abdi šamsin wafat dimmatu-ka qad radadtu 'ilay-ka ğiwāra-ka O 'Abū 'Abd Šams, your obligation [to me] is completely fulfilled; I [hereby] renounce your protection. (Sira 1, 243)

(9.59) i’dan lì ahruğ 'ilā bišrin bi-l-irāqi [...] qāla qad 'adintu la-ka Allow me to go to Bišr in Iraq [...] He said: 'I [hereby] allow you.' (Riwāyāt 1, 16)

Unlike 'declaration-performaives', whose successful execution hinges solely on the speaker, without appealing to an external authority (anyone can successfully take an oath, the question of its actual worth is entirely irrelevant), 'transaction-performatives' presuppose the authority of both the speaker and his addressee to reach an agreement, i.e., to offer and accept the matter at hand.

Despite the functional differences outlined above, one cannot help but wonder how is it that yaf'alu, fa'ala, and qad fa'ala can all be used to indicate performativity? In my opinion, the appropriateness of all three forms in performative clauses is not dissociated from their temporal and aspectual meanings in regular declaratives. The form yaf'alu, as was shown above, often has a concurrent reading with speech verbs. The form facala, with stative lexemes, has a tangent point with the present situation of the speaker, and this is apparently the reason why radinna and sallamnā in [9.57] are realized in the fa'ala form rather than in the resultative qad fa'ala form. The use of qad fa'ala with potentially bounded lexemes, as in the last two examples, should be explained by the aspectual meaning of this form, indicating the completion of the verbal situation. The relation between performativity and resultativity is also apparent in the next example, featuring the passive participle:

(9.6o) mal'ūnatun-i l'arḍu llatī huliqta min-hà la'natan ḥattā tatahawwala timāru-hā šawkan

Cursed is the earth from which you were created in such a curse that its fruits will turn into thorns. (Ta'rīh 1,106$)$

There are very few examples in which performativity is expressed through a participial predicate, realizing the order of the verbal clause. The peculiar structure of [9.60] may be explained by the parallel (in fact underlying) Biblical

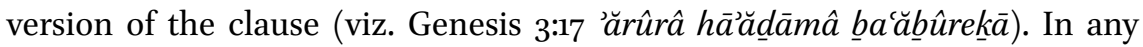
event, mal'ünatun presents us with yet another kind of performative clauses, namely, blessings and curses. When the curse is delivered by the ultimate (divine) authority, as is the case in [9.6o], it gains a performative force: it is effective as of the time of its pronunciation. This case is different from ordinary 
(human) curses, to be discussed in the following section, where the curse is a matter of a (yet unfulfilled) wish. Table 9.2 below summarizes the discussion of the distribution and function of the verbal forms in performative clauses:

TABLE 9.2 The verbal forms in performative clauses

\section{Verbal form Type of performative Temporal-aspectual value}

\begin{tabular}{lll}
\hline yaf'alu & declarative-performative & concurrence \\
fa'ala & transaction-performative & persistence \\
qadfa'ala & transaction-performative & resultativity \\
maf'ūlun & blessings and curses & resultativity
\end{tabular}

\subsection{Optative Clauses}

In Classical Arabic, the expression of wishes is not marked by a special mood, but may be realized through various syntactic means (for instance, the operator layta). What I refer to as optative clauses are but one type of clause expressing a wish. Optative clauses employ as a rule the fa'ala form, followed by the explicit mention of allāh or rabb 'God': [ fa'ala-object pron. llāh/rabb]. In the passive voice, the reference to alläh or rabb is implicit:

\section{(9.61) fa-mā hāăğatu l-'amìri 'ilay-ya ğa'ala-nī llāhu fidā-hu}

What need is there in me for the 'Amīr? May God make me his ransom! (Riwāyāt 1, 246)

\section{(9.62) ̆ǧiltu fidā-ka 'ibil-ı̄wa-'amānati}

May I be made your ransom, [what about] my camels and trusted goods? (Riwāāāt 1, 246)

As discussed earlier (9.2.3), sometimes a modally unmarked (indicative) form has a specialized modal meaning. This is the case with the optative facala (as well as the conditional fa'ala which is not dealt with in the present work). Any attempt to derive the optative meaning of fa'ala from its 'basic' pastperfective meaning is bound to result in circular reasoning. ${ }^{28}$ We might get

28 Wright, Grammar, 2, $2 \mathrm{ff}$., argues that facala - when occurring in promises, oaths, condi- 
closer to understand the optative meaning of fa'ala if we examine the discursive function of these types of clauses. As shown in the examples above, the expression of wish is not intended for its own sake, but as means to show politeness and humbleness, called for in interactions with a person of a higher social stature. Earlier I discussed cases where the current desire of the speaker was expressed through fa'ala. This use of fa'ala was explained too by the indirectness or remoteness associated with fa'ala (see [9.21] above). Yet, in what may look as quite the opposite circumstances, the optative fa'ala is not only used to signal politeness in the face of nobility, but also as means to show friendliness and generosity:

(9.63) fa-qāla 'a-lā 'uhaddị̂-kum bi-mā samitu min rasūli llāhi [...] fa-qulnā balā rahima-ka llāhu

And he said: 'Will I not tell you about what I have heard from the Messenger of God [...]' And we said: 'Certainly, may God have mercy upon you!' (Ta'rīh 1, 63)

In [9.63] the speakers want to encourage their addressee to share with them the words of the Prophet, thus they use the blessing rahima-ka llähu to show rapport. That rahima-ka llähu/rabbu-ka is that conventionalized as an expression of good will is evident in the next example, where God himself is blessing Adam:

(9.64) fa-lammā nafaha fì-hi l-rūḥa fa-dahala l-rūḥu fìra'si-hì atạsa fa-qālat-i l-malāikatu qul-i l-hamdu li-llāhi fa-qāla l-ḥamdu li-llāhi fa-qāla llāhu rahima-ka rabbu-ka

And when He blew into him (i.e. Adam) the spirit and the spirit entered his head he sneezed. The angels said: 'Say "Praise be to God!' 'So he said: 'Praise be to God!' Then God said: 'May your Lord have mercy upon you!' (Ta'rīh 1, 92)

tional sentences, and wishes — has a virtually past or perfective sense, due to the certainty attributed to the occurrence 'represented as having already taken place' or 'as already fulfilled'. If indeed 'certainty' is the semantic feature underlying such uses of fa' ala, then one may rightly wonder how is it that qad fa'ala is never used in these contexts. The fact that in Post-Classical Arabic (cf. Fischer, Classical Arabic Grammar, 103), as well as in Arabic dialects, optative expressions employ as a rule the prefix conjugation rather than the suffix conjugation, is again evidence for the ad hoc validity of some aspectual-modal correlations suggested for Classical Arabic. 
I suggest, then, that the use of fa'ala in optative clauses might not be derived from its past-perfective meaning (at least not in a straightforward manner), but it is rather associated with the indirectness, remoteness, and politeness which is implied by this form..$^{29}$ The fact that optative clauses are also used for illwishing is perhaps to be explained by a generalization of the use of this pattern: once it was established for blessings, it extended to the expression of wishes of all types, including bad ones, as illustrated below: ${ }^{30}$

(9.65) fa-ḩarağa 'ilay-ya 'abū ğahlin fa-qāla marhaban wa-'ahlan yā bna 'uht¿ mā ğăa bi-ka qāla ğìtu 'uhbiru-ka 'annì qad 'āmantu bi-llāhi wa-birasūli-hī muhammadin wa-ṣaddaqtu bi-mā ğăa bi-hī qāla fa-daraba lbāba fì wağh-ì wa-qāla qabbaha-ka llāhu wa-qabbaḥa mā ğita bi-hì Then 'Abū Ğahl came out to me and said: 'Welcome! O my nephew, what has brought you?' He said: 'I came to tell you that I have become a believer in God and His Messenger Muhammad and that I regard as true what he has brought.' (he said) Then he slammed the door in my face and said: 'May God damn you and damn what you have brought!' (Sira 1, 230)

So far we have seen optative clauses in which fa'ala was employed. However, few examples feature the verbal form yaf'alu. Unlike fa'ala, the use of yaf'alu in optative clauses appears to be related in a more straightforward way to its ordinary temporal (non-past) or modal (volitive) meaning. However, by contrast to other desiderative contexts, optative yaf'alu forms are singled out by the clausal pattern in which they are realized [yaf'alu-object pron. lläh/rabb]:

(9.66) halaqa llāhu 'adama bi-yadi-hī wa-nafaha fì-hi min rūhi-hı̄ wa-’amara l-malāikata fa-sağadū la-hū fa-ğalasa fa-'ațasa fa-qāla l-ḥamdu li-llāhi fa-qūla la-hü rabbu-hü yarḥamu-ka rabbu-ka God created Adam with His hand and blew in it some of His spirit and commanded the angels and they prostrated themselves before him. He sat down, then sneezed and said: 'Praise be to God!' His Lord said to him: 'May your Lord have mercy upon you!' (Ta'rīh 1, 156)

29 I do not deny the existence of intrinsic semantic relations between the notions of past, irrealis, indirectness and remoteness. However, I do not find any (historical or other) evidence to support the idea that temporality is more significant or original than the others. In my corpus, blessings are far more common than curses. This may have to do with the literary nature of the texts. Studies of spoken Arabic dialects show that curses are more frequent, creative, and productive than blessings, see Henkin, Cognate Curse, $169 \mathrm{ff}$. 


\section{(9.67) yaġfiru llāhu lì wa-li-l-muslimina}

May God forgive me and the Muslims! (Maj̇̄ zī, 59)

\subsection{Interrogative Clauses}

The interactional nature of dialogues finds one of its most explicit grammatical expressions in interrogative clauses. Interrogatives are 'conventionally associated with the speech act of requesting information.' ${ }^{31}$ Although this is certainly true in many cases, it is yet an oversimplification of the various functions fulfilled by interrogative clauses in discourse of any type.

In dialogues, we find numerous examples where the interrogative clearly serves a different function than 'requesting information'. For instance, an interrogative clause may serve a textural function, by setting the stage for the introduction of a new statement, offer, or request:

(9.68) qāla 'a-fa-là 'adullu-ka 'alā hayrin min deàlika qāla qultu wa-mā huwa Will I not show you a better way than that? (he said) I said: 'And what is it?' (Sira 1, 347)

Interrogatives, specifically those known as rhetorical questions, serve an expressive function. Rather than appealing to a second party to resolve some doubt, such interrogatives are used to make stronger assertions, i.e., to stress the validity or veracity of the content of the clause. Expressive interrogatives may be self-addressed or not addressed at all but merely posed, waiting for no specific answer:

(9.69) yā 'ahla makkata'a-na'kulu l-ța āma wa-nalbasu l-teiyāba wa-banū hāšimin halkā lā yubā'ūna wa-lā yubtāu min-hum

O people of Mecca, are we to eat food and wear clothes while Banū Hāšim are dying, unable to sell or buy?! (Sira 1, 248)

(9.70) 'a-yazunnu muḥammadun 'an yuṣība min-nā mā 'așāba bi-nahlata wa'așhāabu-hū

Does Muhammad think that he can get from us what he and his companions got in Nahla? (Maj̇̄ zī, 39)

$31 \quad$ König and Siemund, Speech Act, 291. 
The fact that not all interrogatives are used to express doubt or to address a second party suggests that these two properties are in fact independent from each other. Lyons accounts for this matter by distinguishing between 'asking a question of someone' and simply 'posing a question'; asking and posing are accordingly two distinct types of speech-acts, each having a different intention and each calling for a different reaction. ${ }^{32}$ Hansen, on the other hand, proposes a unified semantic-pragmatic model in which both properties of interrogatives are represented. According to this model, when asking a question, the speaker (a) 'is signaling that it is relevant for someone to wonder about the validity of the proposition expressed' and (b) 'is appealing to the hearer for a reaction to that proposition' ${ }^{33}$ The advantage of this model is that it is abstract enough to account for all types of interrogatives, whether their function is informative, expressive, or textural.

The following discussion of interrogative clauses in Classical Arabic is hardly exhaustive. I will examine only one type of interrogatives, namely yes-no questions, and focus on the functional oppositions marked by the verbal forms in these clauses.

Yes-no questions are introduced in most cases by the operators ' $a$ - or hal, though some of them are particle-less, and (as it is fair to assume) marked solely by a distinct intonation pattern. The operator ' $a$ - is prefixed to the first element of the clause. Since most interrogatives exhibit the order of the verbal clause, ' $a$ - is prefixed to the verbal form, or with negated forms, to the negation marker ( $h a l$ is also prefixed to the negation marker). In some cases, usually in expressive interrogatives, the connectives $w a$ - and $f a$ - are interposed between ' $a$ - and the (affirmative or negative) verbal form. Interrogative clauses are not marked by a special mood, but use the same indicative forms that are found in declarative clauses (see above 9.2). In the following, ' $a$-interrogatives' will be illustrated and discussed.

With unbounded lexemes, the verbal form yaf'alu in 'a-interrogatives typically indicates concurrence:

(9.71) yā 'abā ḩālidin 'a-tahāâfu 'an yubayyita-nā l-qawmu

O 'Abū Hālid, do you fear that the people will attack us at night? (Maj̄̄āi, 52)

32 Lyons, Semantics, 2, 755 .

33 Hansen, Syntax in Interaction, 467. 
With bounded lexemes, yaf'alu typically refers to posterior events. The interrogative raises doubt as to the possibility of the event to take place in some future time:

\section{(9.72) 'a-takfü-nīl-'araba}

Will you [be able to] protect me from the Arabs? (Riwāyāt 2, 184)

Put in doubt, externalized observations, with both unbounded and bounded lexemes, yield a concurrent reading of yaf'alu:

\section{(9.73) 'a-tadhabu bi-l-tạa'āmi 'ilā banì hāšimim \\ Are you taking the food to Banū Hāšim? (Sirra 1, 232)}

Interrogative clauses in which the verbal form fa'ala is used present the same opposition as in declarative clauses: with stative lexemes, fa'ala indicates persistence; with dynamic lexemes, fáala indicates anteriority. Notice that in [9.75] the interrogative takes the form of the nominal clause, which is far less attested in interrogatives than in declaratives. It may be that this pattern is used in order to lay emphasis on the nominal theme (see above 6.2.1):

(9.74) 'a-'alimta 'anna hubza l-baladìyanbutu 'alay-hi šay'un šabìhun bi-l-țini Did you know that upon the local bread there grows something like soil? (Buhalä, 89)

\section{(9.75) 'a-rabbu-ka 'ahbara-ka bi-hā}

Did your Lord tell you about that? (Sirra 1, 249)

In my corpus, I have encountered almost no examples of the verbal form qad fa'ala in interrogative clauses. The only example I did find was not introduced by ' $a$ - but initiated by the connective $w a-{ }^{34}$ The fact that qad fa'ala seldom occurs in interrogative clauses is explained by its assertorial meaning which is by and large incompatible with the expression of doubt. However, the fact that there exist a few cases in which qad fa'ala is employed in interrogatives suggests

34 In Classical Arabic, there is nothing unusual in the introduction of a new stretch of speech through the connective $w a$-. Obviously, $w a$-in this case does not simply connect one clause to the previous one. Rather, is serves the more abstract function of re-initiating the 'everongoing' dialogue that underlies speech in general (see above 9.1), somewhat like the initial 'so' in Modern English. 
that it is not the verbal situation that is put in doubt, but its strong assertion. In other words, the interrogative does not operate on the facala component but on the qad component:

\section{(9.76) wa-qad ğ $\bar{a} a$ l-hūhu ba'du}

The plums have come in already? (Buhalä', 169)

Participial forms are not encountered very often in interrogative clauses. As opposed to declarative clauses, interrogatives in which the participle is used exhibit the order of the verbal clause. In the next example, the participle occurs with a motion verb and refers to an immediate future; here, as well, it is the possibility of the event to take place that is put in doubt:

\section{(9.77) 'in tubtu wa-'aṣlaḥtu 'a-rāăǧi-ì 'anta 'ilā l-ğannati}

If I repent and improve, you might let me return to Paradise? (Ta'rīh 1, 132)

Negative interrogatives, that is, interrogatives which have in their scope a negated verbal form, are less likely to be used as neutral or open questions, to which both answers, yes or no, may equally apply. In most cases, negative interrogatives are biased toward a positive answer; rather than raising doubt, their function is to provide a certain position with more support. Thus, negative interrogatives often function as expressive interrogatives, making a certain claim and awaiting no response. ${ }^{35}$

In interrogative clauses yaf'alu is negated by $l \bar{a}, m \bar{a}$, or laysa. We observe the same temporal and aspectual meanings, as well as the same lexical preferences (e.g., the preference of $m \bar{a}$ with perception and mental verbs), that are found in declarative clauses:

(9.78) 'a-lā tarḍā yā 'abda llāhi 'anyu'țiya-ka llāhu bi-hā dāran huayran min-hā fì l-ğannati

O 'Abdallāh, are you not pleased that God will give you for it a better house in Heaven? (Sir $a 1,339)$

35 If both doubt and appealing to the hearer for response are not intended in this type of interrogatives, what, then, qualifies them as interrogatives at all? Hansen, Syntax in interaction, 470 (following Anscombre and Ducrot), suggests that such interrogatives should be analyzed as polyphonic, i.e., 'as echoing some actual, or more probably potential, utterance by someone other than the present speaker'. 
(9.79) 'a-fa-mā tarawna mā bi-kum

Don't you see what has happened to you? (Sira 1, 326)

(9.80) 'a-lastum ta'lamūna 'anna-hum 'așhāâu șāhibi-kum

Don't you know that they are the companions of your friend? (Ta'rih 6, 3276)

Negative interrogatives also exhibit the negated forms lamyaf'al and mä fáala. With stative lexemes, these refer to persistent situations, with dynamic lexemes, to anterior ones:

(9.81) 'a-lam ta'lam 'annī'ammantu l-ğamala wa-ğa'altu la-hū dimmatan Didn't you know that I reassured the camel and provided him protection? (Kalïla wa-Dimna, 103)

(9.82) subḥāna llāhi 'a-mà raḥimta-nì mimmā șana ta bì God forbid, had you no pity on me in what you did to me? (Buhalä, 166)

It was noted above that the corpus featured only one example in which qad fa'ala was used in a positive interrogative. In negative interrogatives, on the other hand, qad facala was attested several times. This may be explained by the fact that negative interrogatives are biased toward a positive answer, corroborating the assertive value of the proposition. The next example presents such a case:

(9.83) 'a-wa-laysa qad mäta 'amìru l-mu'minina

Hasn't the Commander of the Faithful died yet? (Riwāyāt 2, 29)

The death of the Caliph is not truly questioned by 'a-wa-laysa qad māta. Indeed, in this case, the question has a provocative function. It is designed to communicate the speaker's absolute repudiation of the Caliph's authority.

\subsection{Summary}

In this chapter, I have discussed the main functions of the indicative forms in dialogue texts. It was shown that although certain temporal and aspectual meanings prevail in many of the examined clause types, there is still a considerable number of semantic nuances which are context-specific, clause-specific, 
or emerge from the interaction of the verbal form with particular lexical classes. In a comprehensive account of the functions of verbs in dialogue, we cannot overlook these contexts, nor can we reduce the cluster of meanings conveyed by each form into strict temporal or aspectual notions. As we have seen, rather than expressing sheer objective temporality, verbs in dialogue are used to signal (relative values of) a variety of inter-subjective categories such as: current relevance and actuality, cognitive evaluation, emotional involvement, personal identification, directness and rapport. It is important to note that despite their correlations with specific temporal and aspectual values (e.g., 'strong emotional involvement' and 'present', or 'indirectness' and 'past'), inter-subjective meanings are not simply derived from or entailed by the more basic notions of tense and aspect. Quite the opposite in fact, they are the very purpose of the utterance in the first place. 


\section{The Verbal Paradigm in the Narrative}

The previous chapter dealt with the distribution and function of the indicative verbal forms in the dialogue. The present chapter is concerned with the verbal paradigm in the narrative and the way in which it shapes the overall structure of the text.

\subsection{Preliminaries}

As one of the most basic and pervasive phenomena of human life, narrative is hard to define in a compact precise fashion. Minimal definitions propose that a narrative is 'a perceived sequence of non-randomly connected events', ${ }^{1}$ and that narration means 'someone telling someone else that something happened'. In the vast literature on narrative structure, each of the elements referred to in these definitions, i.e., events, (ordered) sequence, teller and addressee, was thoroughly studied. Specifically, the relation between the 'real world' (or what we experience as such) and its configuration in narratives has been of special interest to modern theorists. Departing from a naive conception of the narrative as a recapitulation of 'past experience, ${ }^{3}$ Fleischman describes narrativization as the 'carving up of reality into constructs of experience, and the organization of these constructs into a verbal representation through which they acquire meaning. ${ }^{4}$ This understanding of the narrative as a cognitiveverbal construct suggests that narrative, by exploiting a well-defined linguistic schema, has both an objective property and a subjective one, which allows for a multiplicity of possibilities from which the narrator may choose to communicate his story.

Being a verbal construct, the narrative must be related in some way to the linguistic system as a whole. The question as to the specific locus of the narrative in language - either as a sub-system of the langue or as a special form of performance - was dealt with by some linguists and linguistically-minded

1 Toolan, Narrative, 6.

2 Herrnstein Smith, Narrative Versions, 228.

3 Labov and Waletzky, Narrative Analysis, 20.

4 Fleischman, Tense and Narrativity, 95.

(C) MICHAL MARMORSTEIN, 2016 | DOI: 10.1163/9789004310483_011

This is an open access chapter distributed under the terms of the Creative Commons

Attribution-Noncommercial-Non-Derivative 3.0 Unported (CC-BY-NC-ND) License 
literary critics. Assuming that narrative indeed operates in a way different than the one found in ordinary discourse, then one should be able to identify some features that are not only characteristic but also distinctive of narrative discourse. For the most part, it is the use of the tense forms which is taken to provide the most obvious expression of the grammatical distinctiveness of narratives.

That narrating is not to be simply identified with the expression of past occurrences is implicit in the discussion of dedicated 'narrative forms' (such as wayyiqtol in Biblical Hebrew), ${ }^{5}$ or in the postulation of a basic 'narrative function' of a verbal form, such as foreground or background. ${ }^{6}$ However, the identification of the narrative as a system of its own implies that narrating is essentially distinct from other types of communication. Whether it exploits the same signifiers or introduces new ones, the narrative is a separate domain expressing a different set of meanings. This view of the narrative was proposed by linguists such as Benveniste and Weinrich, who set out to explain the underlying logic of the tense system in French (and to a lesser extent, in other European languages), and came to define two separate systems: one of narrative and one of non-narrative texts. For Benveniste, the hallmark of what he terms 'history' is the extensive use of the passé simple, which is by and large absent from the system of 'discourse. ${ }^{7}$ Weinrich goes even further to claim that the preterit does not depict past events, but it is rather an indicator of the erzählte Welt, as opposed to the beschprochene Welt, whose most basic indicator is the present. Both 'worlds' represent different 'speech-attitudes' assumed by the narrator and speaker. The internal opposition within the narrative system, especially between the preterit and the imperfect, is not temporal but comes into play in the dimension of grounding ('relief'). ${ }^{8}$ Hamburger holds a similar view regarding the 'a-temporality' of the preterit, which she considers as the index of narrative texts. For her, however, the subject matter is not the logic of the tense system but that of fiction against 'reality statements'. Fiction, which according to Hamburger is best represented in the third person epic, is by its very nature detached from the coordinates of the 'I-Origo' and hence devoid of

5 Dahl, Tense and Aspect, $113 \mathrm{ff}$.

6 According to Hopper, Aspect and Foregrounding, 217, the foreground-background distinction is 'universal of some kind', and aspectual distinctions, such as the ones found in Romance and Slavic languages, are 'derived from discourse' and not just 'ready-made devices "deployed" in discourse because they happen already to exist'.

7 Benveniste, Correlations of Tense.

8 Weinrich, Tempus, especially $38 \mathrm{ff}$. and $91 \mathrm{ff}$. 
a temporal value. In fiction, the preterit serves to tune the consciousness of the addressee to the situation of a story being told: 'for in the same moment with its appearance the preterit is no longer perceived as stating the past. The figures and events now portrayed "are" here and now'.

While espousing the view that 'languages do not treat narrating and asserting $[\ldots]$ in the same way', Fleischman questions the absolute division between narrative and non-narrative discourse as suggested above. ${ }^{10}$ For one thing, not all languages have a dedicated morphology for narratives; for another, some narratives - especially those which have originated in an oral form-may well disclose traces of ordinary discourse. In fact, the models mentioned above are too narrow and language-specific to serve as universal typologies of narrative discourse. Instead, Fleischman proposes a comprehensive model that is applicable to any type of discourse (see above 4.1). According to this model, each tense form embodies a cluster of concepts which belong to different levels of meaning, i.e., 'referential', 'textual', 'expressive' and 'metalinguistic'. At each level the form has a marked value, which is typical for a certain type of discourse. In narratives, the preterit is not simply a 'past form' or an 'a-temporal index of narrativity'. Rather, it is the unmarked form (as opposed to the marked present), which serves to depict past-perfective-sequential-foregroundedobjective-diegetic occurrences. ${ }^{11}$

Classical Arabic does not have verbal forms dedicated for narration. It does not have a clear signpost of narrativity such as wayyiqtol in Biblical Hebrew or the passé simple in French. Rather, the same forms which are used in narratives are also found in dialogues and generic utterances. Thus, in the search for grammatical indices of narrativity in Classical Arabic, one has to resort to more complex syntactic constructions and examine the way in which these contribute to what Labov and Waletzky have described as 'the overall structure of the narrative.'. ${ }^{12}$ Considering both their syntactic structure and textual function, we can identify three main types of narrative constructions or strategies: (a) the fa'ala-initiated chain, which mainly serves a referential or reportative

9 Hamburger, Logic, 81 .

$10 \quad$ Fleischman, Tense and Narrativity, 118.

11 Ibid., $53 \mathrm{ff}$.

12 Labov and Waletzky, Narrative Analysis. The authors mention two main functions of the narrative: 'referential' and 'evaluative'. The referential function is reflected in the temporal sequence of the narrative. However, a narrative that carries only a referential function 'lacks significance. The evaluative function is reflected in the narrator's attitude towards the content expressed, in his engagement in telling the story so as to convey a certain point. 
function; (b) kāna-clauses and syndetic circumstantial clauses, which constitute the orientation sections of the narrative; (c) mutually dependent constructions, which serve both a referential and an evaluative function. Of course, these constructions do not exhaust all types of clauses which can be found in narratives. However, they provide a defining key (at least from a grammatical point of view), for the presence of these types of constructions is sufficient to identify the text as narrative.

The studied corpus comprises narratives of various kinds: some are strictly fictional (e.g., the Kalila wa-Dimna tales) and some are transmitted in the form of historical records (e.g., Tabarì's Ta'rih $)$. However, as far as their syntactic and textual structure is concerned, both kinds of narratives present great similarity. Obviously, the external frame in which the narrative is embedded may inform us whether the story is real or fabricated, yet the narratives themselves do not disclose, at the formal level, any intrinsic signs for either fictionality or authenticity. ${ }^{13}$ Rather, the difference between both types of narratives resides in the proportions of their referential and evaluative components: the historical 'ahbār tend to be very informative and eventive, while the anecdotes collected in Kitāb al-'Ágannī or which are told by al-Ǧāhịiz are often less eventive and more expositive or impressionistic. This difference is sometimes reflected in the extensive use of expressive language in the latter texts, although expressivity is certainly not absent from the historic chronicles. ${ }^{14}$ As for the parameter which was earlier defined as 'deictic reference' (4.2), both fictional and (ostensibly) factual narratives can be recounted either by an internal and involved ('homodiegetic') first person narrator or by an external and detached ('heterodiegetic') third person narrator. ${ }^{15}$ The significant effect of the (literary) category of 'voice' is also manifested in the degree to which descriptive and expressive language is used in the narrative.

13 This is not to disavow the existence of a distinction between fictional and non-fictional narratives; my only claim is that 'hard-core' syntactic evidence cannot serve to substantiate this distinction, which apparently operates at a different level, lexical and/or rhetoric or pragmatic. For a discussion of the question of fictionality in Classical Arabic prose, specifically in learned literature, see Leder, Conventions.

14 For a short description of the literary structure of the 'ahbār and the narrative techniques through which they are shaped, see Leder and Kilpatrik, Classical Arabic Prose, $10 \mathrm{ff}$.

15 Genette, Narrative Discourse, 228 and 243 ff., distinguishes between different forms of involvement of the narrator in the narrative: the narrator may be 'intradiegetic' or 'extradiegetic', depending on whether his voice is internal or external, 'homodiegetic' or 'heterodiegetic', depending on whether he participates in the plot. 
The following discussion will focus on the three main types of narrative constructions mentioned above. For that purpose, I will not distinguish between fictional and factual narratives; the distinction between first person and third person narratives will be recalled whenever a syntactic particularity can be attributed to it.

\subsection{The Main-line: fa' ala-initiated Chains}

\subsubsection{The fa'ala coNN-fa'ala Pattern}

It was mentioned above that narratives, according to the simplest definitions, serve to convey an ordered sequence of events. Indeed, sequentiality is often considered to be the most basic and indispensable characteristic of narratives. The linguistic exponent of narrative sequence is the chain structure. In Classical Arabic, the chain is most commonly realized in a symmetrical configuration of connected fa'ala forms, formulized as fa'ala conN-facala. ${ }^{16}$ The connective particles are: $w a$ - 'and', $f a$ - 'and then', tumma 'thereafter' and $h a t t \bar{a}$ 'until'. These connectives are distinct from each other in their degree of specificity: $w a$ - is the least marked connective, $f a$ - conveys the general meaning of tartīb 'order', tumma indicates the passage of a certain interval of time, hatta the arrival at the destination or final stage of a series of events (see above 6.1.3). Each fa'ala form stands for a narrative event. Eventhood is often associated with dynamicity and affectedness, with 'happenings' or changes of situations. However, this is not necessarily the case: the event indicated by facala may well be of a static or a-telic nature. Regardless of the inherent structure of the verbal lexeme, the event indicated by fa'ala is interpreted as discrete, particular, and sequential, as illustrated in the following excerpt:

(10.1) fa-rağa'ù 'alā hāmiyati-him ḥattā qadimū l-madinata fa-nazalū-hāa

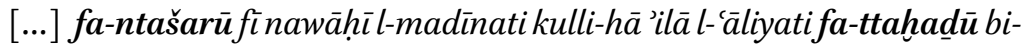
hà l-āạtāma wa-l'amwāla wa-l-mazāri'a wa-labițū bi-l-madinati zamā-

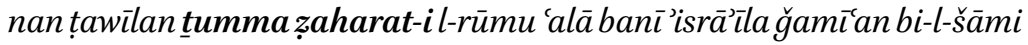
fa-wațiū-hum wa-qatalū-hum

16 In this formulation, conN stands for 'connective'. Since the initial facala can also be preceded by a connective, a more precise way of representation would be (CONN-) fa'ala conN-fa'ala. However, to avoid a cumbersome formula, it will be implicitly assumed that each initial fa'ala also represents (CONN-) fa'ala. By 'symmetrical configuration' I mean that the adjacent clauses have the same syntactic status, and not that their coordination is symmetrical, i.e. reversible. 
Then they went back to their garrison until [finally] they arrived at Medina and stopped over there [...] then they scattered all through Medina as far as al-'̄liya (the upper city), and they got for themselves in it fortified houses, orchards and fields, and they dwelt in Medina for a long time. Then, the Romans overcame all of the Israelites in al-Šām, trampled them down, and killed them. (Riwāyāt 2, 8)

This short narrative demonstrates how the connectives are combined with various types of events recounted in the facala form. The events range from purely static and intransitive situations, such as labit $\bar{u}$ 'they dwelt', to highly dynamic and transitive situations, such as qatalu 'they killed'. That all the events are interpreted as bounded and discrete is not due to the perfective meaning of the unmarked narrative form (see above 10.1, Fleischman's characterization of the preterit): we recall that outside the chain, when facala occurs with stative lexemes it indicates unbounded persistence (see above 9.2.1). Rather, the perfective meaning is imposed by the sequential structure of the narrative chain. For in reality, the events recounted in the quoted passage did not necessarily follow in order, or were even experienced as 'complete events' at all. For instance, the overcoming of the Israelites was obviously not accomplished before they were all trampled down and killed. The verb zaharat serves, in fact, as an abstract for the following wați $\bar{u}$-hum and qatalu-hum, the same way as the verb labitūu serves as a coda for the preceding intašarū and ittahadū.

The quoted passage reports on the settling of the Jews in Yatrib, the historical Medina. The story is set in an historical framework; however, it abounds with fictional and even mythical elements. It is recounted by a third person narrator, who assumes a detached, absent or omniscient position. The point of reference of the narrative is therefore internal. The question of whether the reported events took place in a real time or not is quite irrelevant. As far as its temporality is concerned, this narrative is ageless: it is self-contained and discloses no relation to the situation of narration. This is obviously not the case in the following passage, where the story is related by an involved first person narrator:

(10.2) țumma ndafa'tu fa-ġannaytu l-șawta fa-wațabat-i l-ğāàiyatu fa-qālat limawlā-hā hādā wallāhi 'abū 'uțmāna bnu misğahin fa-qultu 'ì wallāhi 'anā huwa wallāhi lā 'uqìmu inda-ka

Then I burst and sang the song and the maid jumped and said to her master: 'By God, this is 'Utmān b. Misğah.' And I said: 'Indeed, by God, this is me; by God I will not stay with you.' (Riwāyāt 1, 25) 
The first person sets an external point of reference to the narrative. In this case, fa'ala encodes the detachment of the narrative sphere from the situation of narration. Between the two ends of an impersonal third person narrator, as illustrated in [10.1], and a personal first person narrator, as illustrated in [10.2], there are other types of narrative transmission or 'mediacy', to use Stanzel's terms. ${ }^{17}$ It is evident, then, that we cannot say for all narratives that a temporal sense of fa'ala is either absent or given; rather, the temporal interpretation of facala becomes relevant whenever it operates in a relative deictic system, typically constituted by the first person narrator, whether the latter is a real person or is just a creation of the author's imagination.

\subsubsection{The fa'ala yaf'alu/fā'ilan Pattern}

The designation of fa'ala as the narrative form or as eventive should be understood, in line with the above discussion, as referring to the dominant role played by facala in the construction of the narrative chain. This does not mean that fa'ala in all cases depicts the typical (dynamic and transitive) event, or that other verbal forms besides fáala cannot convey narrative events. In fact, we observe two other patterns of narrative chaining which, contrary to the fa'ala conN-facala pattern, are asymmetrical configurations. The first is a chain involving a verbal complex, the second features the pattern fa'ala fa-yaf'alu, which will be dealt with in the following section.

It is often the case that in the historiographical literature several versions of the same story are adduced. This practice is quite useful (also) for our matter, as it brings to the surface the distinction between various manifestations of what literary critics call 'point of view', 'perspective' or 'focalization', to wit, the position from which the events are perceived (rather than told). ${ }^{18}$ As mentioned, in Classical Arabic the narrative most commonly unfolds in the fa'ala CONNfa'ala pattern, signaling an 'event-by-event' pace. However, the same series of events can also be recounted in the form of a verbal complex of the pattern fa'ala yaf'alu or fa'ala fä́ilan. In using the verbal complex, two events are compressed into a single common occasion (see above chapter 8 ). The following examples illustrate these two patterns of narrative transmission; the verbal complex in [10.4] comprises the predicative participle:

17 The term 'mediacy' refers to the indispensable presence of some sort of 'mediator' whenever a story is being told. According to Stanzel, Theory of Narrative, 4, mediacy is 'the generic characteristic which distinguishes narration from other forms of literary art'.

18 The recognition that 'perspective' or 'focalization' ('who sees') and 'voice' ('who speaks') are two distinct categories in narrative structure was given its clearest expression in Genette's Narrative Discourse. 


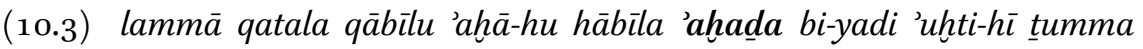
habața bi-hā min ğabali būda fi l-ḥadìdi

After Cain killed his brother Abel he took his sister by the hand and

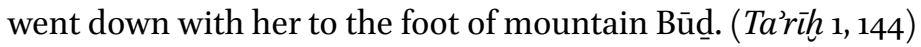

(10.4) fa-ḥasada-hū qābïlu fa-qatala-hū 'inda 'aqabati hirā̄a tumma nazala

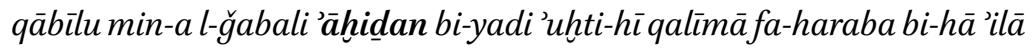
'adana min 'ardi l-yamani

Cain thus envied [Abel] and killed him on the mountain slope of Hirää. Then Cain descended from the mountain, holding his sister Qalīmā by the hand, then he fled with her to 'Adan in the land of Yemen. (Ta'rīh 1 , 144)

The two versions refer to the same tradition: Adam wanted to marry Cain's twin sister to Abel but Cain refused. The two then offered sacrifices of which only Abel's was accepted. Cain thus became envy of Abel, killed him on the top of a mountain and fled with his sister. Though recalling the same tradition, the narrators of [10.3] and [10.4] mold the events into two different patterns: the facala CONN-fa'ala chain in the first, the verbal complex in the latter. Though the difference between both strategies is subtle, a couple of distinctions can still be observed. Firstly, the fa'ala conN-fa'ala chain imposes a certain chronology on the events: Cain first took his sister by the hand and then descended from the mountain. The verbal complex, on the other hand, leaves the exact chronology unspecified and depicts a scene in which the two events, now related in inverse order (first 'descending' then 'taking'), converge. Secondly, the version in [10.3] displays a sheer reportative style. The events, which are all externally observable ('kill', 'take', 'go down'), are condensed into a temporal lammā-clause and a chain of fa'ala forms. The story is thus structured as a flat sequence, in which no event stands out as more important or central than the other. In contrast, the version in [10.4] displays a descriptive and elaborate style. The narrator sets out from describing Cain's emotional state (hasada-hū), which led him to kill Abel. He then employs the verbal complex to linger on the picture of Cain descending from the mountain while holding Qalīmā's hand, after he had 'won' her. By using the verbal complex, the narrator shifts from external to internal focalization, thereby marking a certain scene as a salient moment in the narrative. The next example illustrates the use of a verbal complex comprising the predicative yaf'alu:

(10.5) lammā 'ağma'a 'abū salamata l-hurūğa 'ilà l-madīnati rahala lì ba'îrahū tumma hamala-nı̄ 'alay-hi wa-ḥamala ma'̄ bn-ī salamata bna 'abì 
salamata fi ḥağr-ì țumma harağa bì yaqūdu baìra-hū [...] fa-nazacū hițāma l-baîri min yadi-hì fa-'ahadū-nīmin-hu

When 'Abū Salama had decided to depart to Medina, he saddled his camel for me, then he mounted me on the camel together with my son Salama b. 'Abī Salama [who was] in my arms, then he went out with me leading his camel [...] so they snatched the camel's halter from his hand and took me from him. (Sira 1, 314-315)

The narrator tells the story about her family's migration to Medina, specifying that her husband was leading (yaqüdu) the camel, upon which she and her son were seated, when they first departed. This fact turns later to be significant, when we are told that the camel's halter had been snatched by some tribesmen, thus separating the wife and son from the husband. The narrator uses the verbal complex to portray the scene of departure in details, thereby underscoring the relevance of its specific manner of unfolding to the succeeding narrative. This strategy is not restricted to either the third person or the first person narrator: both employ the verbal complex as a special channel of story transmission, allowing them to inspect more closely the narrated scene.

\subsubsection{The fa'ala fa-yaf'alu Pattern}

So far, two forms of narrative chaining have been discussed: the unmarked fa'ala CONN-fa'ala pattern, and the verbal complex pattern, marking an internally focalized chain of events. A third pattern, far less attested, consists of the sequence fa'ala fa-yaf'alu. In contrast to the fa'ala conN-fa'ala pattern, fa'ala fa-yaf'alu does not exhibit a symmetrical configuration, where each link has the same syntactic status. Unlike the asyndetic yaf'alu in the verbal complex, $f a-$ yaf'alu is not embedded but connected to the previous fa'ala. We may say, thus, that fa-yaf'alu holds an intermediate position between the two other patterns: $f a-y a f^{\prime} a l u$ is dependent on the previous fa'ala, which initiates the chain, yet it is not paradigmatic with the predicative participle and therefore not embedded. Also, as far as its function is concerned, we may define fa-yaf'alu with respect to its two other competitors, fa-fa'ala and $\varnothing$-yaf'alu. Comparing the following set of examples:

(10.6) ̦umma nșarafū fa-wağadū qurayšan bi-bațni rābig̈in

Then they turned and found Qurayš in Bațn Rābig̀. (Mag் $\bar{a} z \bar{l}, 205)$

(10.7) fa-'aqbalū naḥwa-humā yastami'ūna

And they came toward them to listen closely [to their talk]. (Riwāyāt 1, 253) 
(10.8) fa-ndafa'ū tilqā̉al-zuraybifa-yağidūna 'alà tilka l-qalībillatī qāla rasūlu llāhi rawāya à qurayšin fì-hā suqqāu-hum

They proceeded towards al-Zurayb and found at that well, which the Messenger of God mentioned, the watering camels of Qurayš [and] in it their water carriers. (Mag் $\bar{a} z \bar{\imath}, 51)$

We observe that the pattern fa'ala fa-yaf'alu indicates something different than mere sequence. While nșarafü fa-wağadū in [10.6] indicates an 'event-by-event' progression and fa-'aqbalū [...] yastami'üna in [10.7] indicates a compressed dynamic progression, fa-ndafa $\bar{u}$ [...] fa-yağidūna in [10.8] indicates a logical sequel, a relation of consequence, result, or reaction of one event to a previous event. Table 10.1 below summarizes the syntactic and semantic distinctions between these three patterns of narration:

TABLE 10.1 Patterns of main-line sequence in the narrative

\begin{tabular}{|c|c|c|}
\hline Pattern & Syntactic status & Semantic relation \\
\hline fáala fa-fa'ala & independent & chronological sequence \\
\hline $\begin{array}{l}\text { fa'ala fa-yaf'alu } \\
\text { fa'ala yaf'alu }\end{array}$ & $\begin{array}{l}\text { dependent, not embedded } \\
\text { embedding }\end{array}$ & $\begin{array}{l}\text { logical sequel } \\
\text { event integration }\end{array}$ \\
\hline
\end{tabular}

Although of marginal use, the pattern fa'ala fa-yaf'alu did not escape the attention of some Arabists, notably Nöldeke and Nebes. Nöldeke suggested that an imperfect following a narrative perfect serves to indicate a 'concluding action.' ${ }^{19}$ In a footnote he adds that the construction in Arabic is exactly like the waw conversivum in Biblical Hebrew, the only difference is that in Arabic this construction is rare whereas in Hebrew it is the rule.

The resemblance that Nöldeke pointed to between the Arabic and the Hebrew forms appears to me as untenable. The form wayyiqtol in Biblical Hebrew is 'the most usual method in which a series of events is narrated. ${ }^{20}$ As demonstrated by Niccacci, wayyiqtol can be used in both initial and medial positions, and it is not marked particularly for the meanings of consequence or result. ${ }^{21}$ Moreover, the formal resemblance between fa-yaf'alu and wayyiqtol

\footnotetext{
19 Nöldeke, Zur Grammatik, 68.

20 Driver, Treatise, 73.

21 Niccacci, Syntax of the Verb.
} 
(which in itself is not perfect) is no evidence for their functional identity. In fact, the verbal systems of Classical Arabic and Biblical Hebrew are fairly different from each other. A significant point of divergence is reflected indeed in the use of fa'ala versus that of wayyiqtol as an index of the narrative chain, and the use of yaf'alu (in various types of clauses) versus that of qațal to express background information.

Another way to understand the sequence fa'ala fa-yaf'alu was proposed by Nebes. ${ }^{22}$ Nebes endeavors to explain the temporal value of yaf'alu which, in spite of being what he sees as independent form, is interpreted as past rather than present tense. According to Nebes, yaf'alu in these cases obtains the 'fictive' present time of the subject of the narrative, rather than referring to the real time of the narrator or the speaker. This change of perspective, from the narrator to the dramatis personae, is aimed, according to Nebes, to enliven the narrative.

We have seen earlier (10.2.2) that an alternation of chaining patterns may signal a change of perspective in the narrative. The normal fa'ala conn-fa'ala pattern marks a quick pace of narration, while transition to the fa'ala yaf'alu/ făcilan complex reduces the speed to allow lingering on some particularities of the narrated event. When yaf'alu functions as the predicative form in the complex, the time reference of the event is not changed but only its aspectual contour, affecting in turn a change of perspective, from a distanced and external one to a closer and internal one.

The pattern fa'ala fa-yaf'alu, as opposed to fa'ala yaf'alu, does not feature an embedded predicative form but a connected sequential form. Nevertheless, fa-yaf'alu cannot be regarded as syntactically independent, as it can only occur in a subsequent position in the chain, dependent on the initial fa'ala which determines the time reference of the entire chain. Furthermore, the rare, isolated, and contextually restricted environments in which fa-yaf'alu is found make it hard to consider it as an instance of historic present, which is generally unknown in Classical Arabic prose. Rather than marking a temporal/perceptual shift, fa-yaf'alu is employed to stress the (con)sequential relation between two succeeding events. In the reminder of this section, I shall closely examine a variety of examples in which fa'ala fa-yaf'alu is used, in the attempt to better explain both the semantic and textual functions of this pattern of narrative chaining.

The case where a sequential $f a-y a f^{\prime} a l u$, specifically the verb fa-yağidu, follows a motion verb is relatively common. Example [10.9] is another such case. 
This example is extracted from a story about the Prophet asking his 'așhāa, who stayed in Abyssinia, to join him in Medina. After they had come, they found out that - against their expectation — the Prophet was not in Medina, as he had already left to Haybar. The verb 'to find' appears twice: first fa-yağidūna then $f a$-wağadū. The first 'finding' of the 'așhāb is marked as the result of their purposive coming to Medina to meet the Prophet. The second 'finding' is not as sensational, grammatically speaking; it is a further step in the chain of events:

(10.9) hạttā qadimū l-madīnata fa-yağidūna rasūla llāhibi-haybarafa-šahașū 'ilay-hifa-wağadü-hu qad fataha haybara

Until they came to Medina and found out [that] the Messenger of God was in Haybar, and they turned towards him and found out [that] he had already conquered Haybar. (Ibn Sa'd 1/1, 139; Nebes, Kāna Yaf'alu, 196)

In a second group of cases, the sequential fa-yaf'alu follows an action verb. The subject is switched from fa'ala to yaf'alu, so that the sequence expresses an ensuing reaction of one party to the action of another. The pattern facala $f a-y a f^{\prime} a l u$ marks the situation as a salient and dramatic moment in the story. Notice that after the junction of fa'ala fa-yaf'alu the narrative continues in the normal sequence of fácala forms:

(10.10) fa-'ahada l-liwāà bi-l-yusrā fa-'ahmilu 'alāyadi-hìl-yusrā fa-ḍarabtu-hā fa-qațatu-hā

He took the flag in his left hand, so I attacked his left hand and struck it and cut it. (Maḡāzi, 227)

(10.11) fa-qultu sta'sirā fa-'abayā fa-'armì 'ahada-humā bi-sahmin fa-'aqtuluhü wa-sta'sara l-āharu

I said: 'Surrender [you two]!' And they refused [to surrender], so I threw an arrow at one of them and killed him and [then] the other one surrendered. (Sïra 2, 994)

In a third group of cases, the sequential $f a-y a f^{\prime} a l u$ occurs after direct speech: $f a-y a f^{\prime} a l u$ reacts not to a previous action in the narrative, but to the content of the speech, or a certain implication thereof. In [10.12] the look at the gazelle is interpreted as a call for hunting; in [10.13] the speakers intend to make the loud singer silent; and in [10.14] the donkey tries to comply with Noah's order: 
(10.12) lammā kunnā bi-turbāna qāla lì rasūlu llāhi yā sa'du nz̧ur 'ilā l-zabyi qāla fa-'ufawwiqu la-hū bi-sahmin

When we were in Turbān the Messenger of God said to me: 'O Sa'd, look at the gazelle!' (he said) So I aimed an arrow [to throw] at it. (Mag்azi, 26)

(10.13) fa-sami'a-hū l-rukbānu fa-ğa'alū yașịhūna bi-hì yā șāhhiba l-șawti 'a-mā tattaqī llāha qad habasta l-nāsa 'an manāsiki-him fa-yaskutu qalīlan hattā 'idā madaw rafa'a șawta-hū

The riders heard him and started to shout at him: 'O you of [loud] voice (lit. 'owner of voice'), do you not fear God? You have already withheld the people from their rituals of pilgrimage.' So he became silent for a short while until they went away [then] he raised his voice. (Riwāya àt 1 , $51)$

(10.14) fa-lammà ’adhala l-himāra wa-dahala șadru-hū táallaqa 'iblìsu la'anahū llāhu bi-danabi-hì fa-lam tastaqilla riğlà-hu fa-ǧa'ala nūḥu yaqūlu wayhaka dhul fa-yanhaḍ fa-là yastațīu

When he brought in the donkey and its front part was inside, 'Iblīsmay God curse him!- - clung himself to its tail and so its legs could not board [the ark]; Noah started to say: 'Woe to you! Step in!' So [the donkey] rose but could not [go in]. (Ta'rīh 1, 190)

In the last two examples the introduction of speech was made by a verbal complex: ğa'alū yașihhūna, ğa'ala yaqūlu. It is often the case that ğa'ala yaf'alu initiates a chain followed by the sequential fa-yaf'alu. In these cases, too, the meaning of ensuing reaction or result can be discerned: in [10.15] Noah builds the ark on land and this action naturally brings about the reaction of astonishment, and later scorn, of his people; in [10.16] young Abraham asks his father about creatures in the world and his father thus tells him about each creature:

(10.15) țumma ğa'ala ya'malu safinatan fa-yamurrüna fa-yas'alūna-hü fa-yaqūlu' 23 'a'malu-hā safinatan fa-yasharūna min-hu fa-yaqūlūna ta'malu safinatan fì l-barri fa-kayfa tağrì fa-yaqūlu sawfa talamūna

23 Given its specific quotative function and its frequent interchanging with $(f a-) q \bar{a} l a$ (see also below 11.3), the form fa-yaqülu is not regarded as an instance of the $f a-y a f^{\prime} a l u$ chaining pattern. 
Then he started to build an ark and they passed by and asked [what was he doing] so he said: 'I am building an ark from it.' They made fun of him and said: 'You are building an ark on land, how could it float?! So he said: 'You will know.' (Ta'rīh 1, 186)

(10.16) fa-ğa'ala yas'alu 'abā-hu mā hādā fa-yuhbiru-hū 'an-i l-ba'îri 'anna-hū ba'ìrun wa-'an-i l-baqarati 'anna-hā baqaratun wa-'an-i l-farasi 'annahū farasun wa-'an-i l-šāti 'anna-hā šātun

And he started to ask his father what is this, so he told him about the camel that it is camel, and about the cow that it is cow, and about the horse that it is horse, and about the sheep that it is sheep. (Ta'rin 1,258 )

The chains in [10.15] and [10.16] may appear as an extension of the verbal complex, viz.: ğa'ala yas'alu ... fa-yuhbiru-hū. The complex ğa'ala yas'alu indeed indicates a modified event 'he started to inquire'. However, this modification does not apply to yuhbiru which has a different subject. Rather than an inchoative meaning, fa-yuhbiru-hu has an iterative sense which is not affected by ğa'ala, meaning 'to start', but brought about by the plurality of the complements of the verb. That the sequential $f a-y a f^{\prime} a l u$ is not just a second predicate added to the chain can be demonstrated by the next pair of examples:

(10.17) fa-ġannaytu-hū 'iyyā-hu wa-mā zāla yaqtarihu 'alay-ya kulla șawtin ġunniya bi-hī fì šíri-hī fa-'ugianni-hi wa-yašrabu wa-yabkī hattā șāratil-atamatu

I sang it to him and he incessantly demanded of me [to sing] every song that was sung of his [repertoire of] poems, so I sang to him and he was drinking and crying until night has come. (Riwāyāt 1, 4)

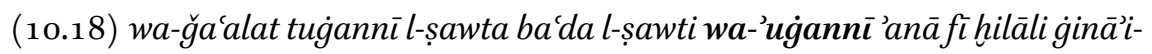
$h \bar{a}$

She started to sing one song after the other and I [too] was singing during her singing. (Riwāyāt 1, 249)

In [10.17] the chain is initiated by the modifying verb $m \bar{a} z \bar{a} l a$ 'to continue'; $f a$ 'uganni-hi reacts to the previous action and complies with the demand to sing. In this case, too, the iterative meaning rises from the plurality of the (elliptic) object, i.e., the entire repertoire of songs. $f a-{ }^{-} u \dot{g} a n n \bar{i}-h i$ is continued by $w a-$ yašrabu wa-yabkī which clearly do not indicate this kind of logical relation. In contrast to that, wa-'ugannī in [10.18] is not ensuing but rather (as indicated by the adverbial $f i$ hiläli) coinciding with the previous event. 
It is not surprising that $f a-$, rather than wa- or tumma, is the connective used to mark this logical relation of result and consequence. We recall that the basic function of $f a$-is to indicate an ordered sequence. However, the precise semantological nature of this sequence is not indicated by $f a$-but left to the specific structure and context. For this reason, $f a$ - may be found in a variety of macro-syntactic structures where the meaning of sequel holds, e.g.: the narrative chain, the ğawāb 'apodosis' of conditional constructions (and other bipartite constructions, such as those discussed above in 8.4), and explicative clauses introduced by fa-inna. It is interesting to note in this regard the structural similarity between the sequential $f a-y a f^{\prime} a l u$ and $f a-y a f^{\prime} a l a$. The indicative form yaf'alu follows the indicative form fa'ala to express the meanings of result and consequence, while the subjunctive yaf'ala follows a modal (or a non-assertive) clause-an imperative, a prohibitive, an interrogative or an optative clause - to express a similar meaning. The occurrence of both yaf'alu and yaf'ala is predetermined by the preceding clause: yaf'alu is never initial in the narrative chain and it is dependent upon fa'ala; yaf'ala is nowhere initial and independent but conditioned by a set of operators and forms (see above $5 \cdot 3) \cdot{ }^{24}$ Table 10.2 summarizes the comparison between both forms:

TABLE 10.2 fa-yaf'alu $v s$. fa-yaf'ala

\begin{tabular}{|c|c|c|c|}
\hline Indicative & fáala & $f a-y a f^{\prime} a l u$ & result \\
\hline Modal & if'al, lāyaf'al, hal ..., layta ..., lā ... & $f a-y a f^{\prime} a l a$ & effect \\
\hline
\end{tabular}

\subsection{The Background}

A narrative is rather dull (and perhaps not a narrative at all) if it consists of a plotline only. The part of the narrative which is not foregrounded is far more complex and diversified, both formally and functionally. Shisha-Halevy, in his discussion of the narrative texteme, calls that part the 'comment mode' (as opposed to the 'evolution mode'), and defines it as 'extrinsic and typically anaphoric to the plot, but often internal to the narrator's perspective'. ${ }^{25}$ The

\footnotetext{
24 Cf. Sadan, Subjunctive Mood. The existence of free yaf'ala forms was acknowledged by some grammarians, however these were always regarded as exceptional (282).

25 Shisha-Halevy, Topics, 34.
} 
comment mode is the domain where the events are explained, resumed and given reasons by the narrator, who always keeps an open (even if implicit) channel for his accompanying voice. The background of a narrative is accordingly 'but one component of the comment mode' and ought to be regarded as 'roughly synonymous to "setting information".,26

In this section I will not deal with the entire complexity of the comment mode, but only make some observations regarding the background or orientation component. Labov and Waltezky define orientation as that section of the narrative which serves to 'orient the listener in respect to person, place, time and behavioral situation. ${ }^{27}$ The orientation typically precedes the plot, although it can be found in other places as well. It may be realized through a great number of syntactic structures, and even be encapsulated in some lexical items. ${ }^{28}$ The orientation is not necessarily presented in an objective or impersonal manner, but may well convey (in a more or less explicit form) the evaluation of the narrator.

In the following, I will discuss two types of clauses which form the greater part of background units in Classical Arabic narratives, i.e., kāna-clauses and syndetic circumstantial clauses. Both types of clauses will be described considering two distinctions: a syntactic one and a functional one. Firstly, a distinction between independent ('free') and dependent background clauses will be drawn. Secondly, I will distinguish between background clauses which are eventive and those which are non-eventive or descriptive.

\subsubsection{Free and Dependent Clauses}

As was earlier discussed (see above 6.1.2), the dependency status of a clause in Classical Arabic is determined by a number of features, such as the position of the clause in the sequence, the (a)symmetrical configuration it assumes relative to the adjacent clause, and its substitution class. Clauses initiated by kāna, as opposed to syndetic circumstantial clauses, can occur as main clauses. Being syntactically independent, they may assume any position in the sequence, initial as well as subsequent. In the narrative, $k \overline{a n} a$-clauses are the typical example of what Labov and Waletzky define as 'free' clauses, i.e., clauses which are not constrained by the temporal sequence of the narrative and thus

\footnotetext{
26 Ibid.

27 Labov and Waletzky, Narrative Analysis, 32.

28 The case of proper names is of particular relevance for that matter. Proper names can connote the full setting of a story in terms of the place, time, culture, persona and even the expected course of events.
} 
can 'range freely through the narrative sequence'. ${ }^{29}$ This should not be taken to mean that kanna-clauses occur randomly in the text: though they do not form part of the chronological sequence, kāna-clauses (like all other clauses in the narrative) are subject to the logical order of narration itself, that is, to the author's decisions as to which information is best suited to which part in order to convey the desired effect. Thus, the text may feature the same information in the beginning, where the orientation is commonly found, or as a comment inserted in the body of the text:

(10.19) kāna ma'badun qad 'allama l-g̈ināa ğāriyatan min ğawārī l-hiğāzi tud'ā zabyata wa-'uniya bi-tahrĭği-hā fa-štarā-hā rağulun min 'ahli l-irāqi

Ma'bad had taught the singing to a maid from Hiǧāz named Ẓabya; he was invested in her becoming an accomplished [singer]. Then, a man from the people of Iraq bought her. (Riwāyāt 1, 9)

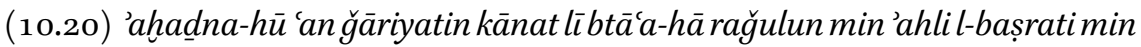
makkata wa-kānat qad 'ahadat 'an 'abì 'abbādin ma'badin wa-'uniya bitahrï̆gi-hā

They learned it (i.e. the song) from a maid I had, whom a man from Basra had bought from Mecca, and she had learned it from 'Abū 'Abbād Mabad; he was invested in her becoming an accomplished [singer]. (Riwāyāt 1, 11)

In [10.19], the details about Macbad and the maid are presented for an introductory purpose: they anticipate the story and bear on the entire text which will follow. By contrast, in [10.20] the same details have an explicative function: they aim to fill a local gap in the state of knowledge of the persons involved in the story. In the first case the kanna-clause serves as general background, in the latter case it serves to answer a specific question.

While kāna-clauses can occur both in an initial and a subsequent position in the sequence and thus serve both an introductory and an elaborative function, syndetic circumstantial clauses are dependent upon the preceding clause and can only serve the latter function. The circumstantial clause, like a subsequent kāna-clause, has a local scope of application, i.e., it elaborates on a certain topic - a situation or an entity - which were previously mentioned in the text. Nevertheless, the circumstantial may exceed the referrential world of the narrative, when conveying an authorial comment or an encyclopedic piece of information. Consider, for instance, the example below: 
(10.21) la-qad rảaytu-nā hìna balaginā l-țaniyyata l-bayḍ̄àa wa-l-țaniyyatu lbayḍāu llatī tuhbițu-ka 'alā fahhin wa-'anta muqbilun min-a l-madīnati I saw us as we reached the white pass, and the white pass is that which brings you down to Fahh as you come from Medina. (Maj $\bar{a} z \bar{z}, 35)$

In [10.21], the point of reference of the circumstantial clause - which elaborates on the geographical location of a place mentioned before-resides outside the narrative sphere: it is located in the here-and-now of the situation of narration itself. Such cases bring to the fore the existence of the 'implied author' of which we are usually unconscious. ${ }^{30}$

Circumstantial clauses which take the form of an 'inna-clause present us with a different case. As noted earlier (see above 8.3), the wa-inna la-pattern has an emphasizing function: it stresses the validity or veracity of the content of the clause in relation to some other implicit or explicit (counter-)assumption. When the wa-inna la- pattern is used it is not the external voice of the author that is expressed; rather, it is an expression of the narrtor's internal stance, whether it be the first person or third person narrator, as illustrated below:

(10.22) ḥattā ’aqbala rağulun min-a l-ğinni min 'asfali makkata yataġannā bi'abyātin min širin gìnāa l-arabi wa-inna l-nāsa la-yattabi'ūna-hū yasma'ūna șawta-hū wa-māyarawna-hū

Until a man of the ğinn approached from the lower part of Mecca, singing verses according to the Arab form of singing; and lo people were following him, listening to his voice though not able to see him. (Sira 1, 330)

Besides a close description of the situation, the wa-inna la- circumstantial conveys an evaluation of its remarkable nature (i.e., the enchanted people were following the man though not able to see him), an evaluation which brings to the fore the presence of an evaluating person.

\subsubsection{Eventive and Descriptive Background}

As already discussed above (10.2.1), the events in the narrative chain are discrete, particular, and sequential. The background is not characterized by any of these properties. Nevertheless, besides pure non-eventive descriptions, the

30 The 'implied author' is further back in the consciousness of the reader than the narrator. It is 'the mental picture of the author that a reader constructs on the basis of the text in its entirety', see Toolan, Narrative, $64 \mathrm{ff}$. 
background does contain events. Background events are distinct from mainline events by being non-sequential: they do not move narrative time forward, but recall an event from the perspective of the main-line zero vantage point. Descriptions, as opposed to both foreground and background events, contain static, continuous, or recurrent situations, which characterize a certain figure or state in the story. They are not time-determined but rather define a certain stretch of time, a state, an epoch, in which certain individuals operate. ${ }^{31}$

In Classical Arabic, the distinction between eventive and descriptive background is marked by both the verbal forms and the clausal type in which they are realized. Generally speaking, the compounds kāna fa'ala and kāna qad fáala serve to indicate background events, whereas kāna yaf'alu and kāna fāilan/maf'ūlan, alongside other nominal and adverbial kāna-compounds, constitute the descriptive background. The next pair of examples illustrates the transition from background units to the main-line and vice versa. In [10.23], the introductory background features the compound form kāna qad ba'ata; the event which is referred to precedes the plot in its entirety. In [10.24], a background unit is inserted within the narrative stream of events, in order to describe the character of Waraqa Ibn Nawfal; it features both eventive and noneventive forms:

(10.23) wa-kāna mūsā bnu 'imrāna qad ba'ața l-ğunūda 'ilā l-ğabābirati min 'ahli l-qurāyaġzū-hum fa-ba'ața mūsā bnu 'imrāna 'ilā l-'amālīqi ğayšan min banī 'isrǟìla wa-'amara-hum 'an yaqtulū-hum ğamīan

Mūsā b. 'Imrān had sent the troops to the tyrants from the people of the villages to attack them, then Mūsā b. Imrān sent an army of the Israelites to the Amalekites and commanded them to kill them all. (Riwāyāt 2, 7)

(10.24) hattā 'atat bi-hì waraqata bna nawfali [...] wa-kāna mrảan tanașsara fì l-ḡāhiliyyati wa-kāna yaktubu l-kitāba l-ibrāniyya fa-yaktubu mina l-inğli bi-l-ibraniyyati mā šăa llāhu 'an yaktuba wa-kāna šayhan kabìran qad 'amiya fa-qūlat la-hū hadïğatu

Until [Hadīğa] went with him to her cousin Waraqa b. Nawfal [...] and he was a man [who] became Christian in the $\breve{G}$ ähiliyya; he used to write

31 Ducrot, L'imparfait, 6, has expressed the same thought with respect to the imparfait in French: Lorsqu'un énoncé est à l'imparfait, son thème est nécessairement temporel [...] l'état ou l'événement constituant son propos sont présentés comme des propriétés, comme des caractéristiques du thème. 
in the Hebrew script and would write in Hebrew whatever God wished him to write from the Gospel. He was an old man who already lost his eyesight. Huadīğa then told him ... (S. Sặḥ, 5)

Not only kāna-clauses, but also circumstantial clauses can interrupt the plot in order to comment on some situation or entity mentioned in it. Circumstantial clauses comprising the form yaf'alu or the participle always exhibit the order of the nominal clause. They are descriptive in nature, referring to an ongoing situation or a state in which a certain person is found. In contrast, circumstantial clauses in which qad fa'ala occurs show, in the main, the order of the verbal clause. Although qad fáala embodies both a dynamic and a static aspect, its function in the narrative is eventive rather than purely descriptive, and therefore qad fa' a la circumstantials realize the order of event-oriented clauses (see above 4.5). The same as kāna qadfa'ala, wa-qad fáala recalls a previous event for the sake of orientation or amplification of the plot; unlike kāna qad fa'ala, the circumstantial wa-qad fa'ala is a dependent clause and thus can only take a subsequent position in the narrative sequence. The next example presents a series of background units. It starts with an introductory kāna fāilan compound followed by two circumstantial clauses, the first is topicalized and descriptive, comprising the form yaf'alu, the second is verb-initiated and eventive, comprising the form qad facala:

(10.25) kuntu 'āhidan bi-yadi rasūli llāhi wa-naḥnu natamāšăă ğamīan naḥwa l-mağribi wa-qad țafalat-i l-šamsu

I was holding the Messenger of God by the hand and we were walking together at sunset time while the sun was already near setting. (Tarih 1,61 )

Table 10.3 summarizes the discussion on free and dependent, eventive and descriptive background clauses in the narrative:

TABLE 10.3 Background clauses in the narrative

Verbal form / clause Dependency Type of background

\begin{tabular}{lll} 
kāna yaf'alu/fāilan & free (initial or subsequent) & descriptive \\
kāna qadfa'ala & free (initial or subsequent) & eventive \\
wa-huwayaf'alu/fä'ilun & dependent & descriptive \\
wa-qadfáala & dependent & eventive \\
\hline
\end{tabular}




\subsection{Setting-presentative Constructions}

The syntactic structure of setting and presentative clauses which involve the predicative paradigm was discussed earlier (8.4). In this section, I would like to make some observations regarding the textual functions of these types of clauses.

Setting and presentative clauses are not found in any type of discourse, but only in narratives. They are therefore different from other structures of orientation and perception, such as circumstantial and complement clauses, which are not text-specific. The following pairs of examples illustrate the distinction between complement and presentative clauses ([10.26]-[10.27]), and between circumstantial and setting clauses $([10.28]-[10.29])$ :

(10.26) lammā ra’aytu bna 'ubayyin ğālisan fin nạhiyati l-bayti

When I saw Ibn 'Ubayy sitting at the corner of the house ... (Majīazi 370)

(10.27) dahaltu l-masğida fa-'id̄à rasūlu llāhi ğālisun waḥda-hū

I entered the mosque and there the Messenger of God was sitting all by himself. (Ta'ihh 1, 152)

(10.28) fa-ǧăàa 'ilà rasūli llāhi wa-huwa ğālisun fíaṣhābi-hī

He came to the Messenger of God while he was sitting with his companions. (Mag்āzī, 370)

(10.29) baynamā huwa ğālisun fi l-masǧidi wa-l-nāsu ma'a-hū ’id 'aqbala talàtatu nafarin

While he was sitting in the mosque and the people were [sitting] with him, suddenly three men approached. (Șahịh, 28)

Complement clauses of perception verbs and presentative clauses both convey a perceived situation. They may refer to the same state of affairs in the world. The difference between them resides in what may be described as the expressive mode in which this state of affairs is represented. A complement clause is a diegetic device: it relates the facts from the neutral (unmarked or 'zero') vantage-point of the speaker/narrator. A presentative clause, by contrast, is a mimetic device: it transmits the situation from the internal point of view of the perceiver (be it the narrator or a character in the narrative). The contrast between complement and presentative clauses comes into play in the narrative: in the first case, the narrator tells the story in a plain neutral manner; in 
the latter case, the events are presented as enacted or experienced, thus the narrative is given a dramatic impact. ${ }^{32}$

In a similar manner, the contrast between plain and dramatic representation appears to determine the choice between circumstantial and setting clauses in the narrative. Both types of clauses, the preposed setting and the postposed circumstantial, provide the frame in which the main event takes place. However, as observed by several linguists, preposed adverbial clauses, being associated with both the preceding and the following text, have a broader scope of reference than those postposed. ${ }^{33}$ This makes them suitable to serve a special function in the narrative, namely, to relate the previous episode to the succeeding one and to indicate the background from which a dramatic development emerges.

Setting and presentative clauses contribute to the creation of the narrative identity or narrativity of the text. Not only do they shape the narrative structure, serving as either grounding or 'relief' devices, but also at the metalinguistic level, setting and presentative clauses are indices of narrativity: their presence in the text marks the message itself as narrative. ${ }^{34}$

\subsubsection{Setting and Preposed Temporal Clauses}

As far as their function in the narrative is concerned, setting clauses introduced by baynā/baynamā can be paired-off with preposed temporal clauses introduced by lammā (see also above 7.4). Both types of clauses share some structural similarities: they take the first position in the complex construction (like conditional clauses) and are followed by fa'ala in the second clause; both lammā and baynā/baynamā can be preceded by the conjunction $f a-$. However, in lammā-clauses the verbal form fa'ala comes right after the operator,

32 The distinction between the plain and the dramatic mode of expression should not be equated with the distinction between an objective and a subjective mode of description. Expressivity, as a reflection of subjectivity in language, is a scalar phenomenon. Lyons, Deixis and Subjectivity, 107-108, for instance, views the distinction between propositional and non-propositional complement clauses (e.g. 'I remember switching off the light' vs. 'I remember that I switched off the light') as having to do with the subjective, in the first case, or objective, in the latter case, mode in which the situation is described. Thus, a plain expressive mode can be more or less subjective; a dramatic mode of expression is by definition subjective.

33 Cf. Chafe, Adverbial Clauses and Ramsay, Functional Distribution.

34 Fleischman, Tense and Narrativity, 78, defines the 'metalinguistic' component of the linguistic system as 'a language's resources for talking about itself'; it includes such functions as the signaling of 'a particular style, register, genre, or type of discourse'. 
while baynā/baynamā-clauses exhibit the order of the nominal clause, where the subject precedes the verbal predicate yaf'alu or the participle. Table 10.4 summarizes the structural properties of lamm $\bar{a}$-clauses and baynā/baynam $\bar{a}-$ clauses:

TABLE 10.4 lammā: baynā/baynamā

\begin{tabular}{|c|c|c|}
\hline Pattern & $\mathbf{A}$ & B \\
\hline preposed temporal clause & (fa-)lammā fáala & fáala \\
\hline setting clause & $(f a-)$ bayna $(m \bar{a}) \mathrm{N}^{\text {nom }}$ yaf'alu/ fāilun & $\left(f a-/{ }^{\prime} i d\right)$ fa'ala \\
\hline
\end{tabular}

Not only in their structure but also in their function, preposed temporal clauses and setting clauses are similar: both convey a backgrounded or expository piece of information that anticipates a dramatic development in the plot. The difference is that lammā-clauses introduce anterior events while baynā/baynam $\bar{a}$ clauses introduce ongoing situations with yaf'alu or states with the participle. Moreover, lammā-clauses are mostly anaphoric, presenting information that is accessible from the previous context. baynā/baynama $\bar{a}$-clauses, on the other hand, are primarily cataphoric, often initiating a new episode of the narrative. ${ }^{35}$ The following examples illustrate the function of these two types of clauses:

(10.30) fa-lammā sāra ġayra baìdin-i 'tarada la-hū dỉbun

After he went not too far, [suddenly] a wolf stood in his way. (Kalìla wa-Dimna, 63)

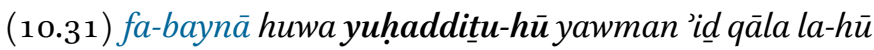

While he was talking to him one day, he suddenly said to him. (Riwāyāt 1, 59)

(10.32) baynā 'anā nā̉imun 'utītu bi-qadahi labanin

While I was sleeping, I was [suddenly] brought a cup of milk. (Șahịh, 33)

35 On the distinction between anaphoric and cataphoric grounding, see Givón, Beyond Foreground, 180-181. 
Example [10.30] follows right after the opening clause of the story, 'inna rağulan salaka mafāzatan 'a man travelled the desert'. The event of 'going' reported in the lammā-clause belongs to the same referrential domain as the 'travelling', and is in fact a specification thereof. By contrast, [10.31]-[10.32] open new episodes in the narrative; they depict the background in which a dramatic happening emerges.

Setting clauses can also take the form of the 'inna la-pattern. As noted earlier (8.4.1), the distinction between this pattern and the regular baynāalbaynamā pattern lies in the domain of expressivity. The 'inna la-pattern allows the first person narrator-who marks an external point of reference-to signal his internal involvement as a character in the narrative:

(10.33) 'innā la-nataraḥhalu 'ilà 'arḍi l-ḥabašati [...] 'id 'aqbala 'umaru bnu lhatțābi

We were departing to Abyssinia [...] when suddenly 'Umar b. al-Huațāa approached. (Sïra, 225)

\subsubsection{Presentative Clauses}

Presentative clauses take the second position in the complex construction. They can be classified into two kinds: dynamic and static. Dynamic presentatives are often introduced by the particle ' $i d$ followed by the verbal form fa'ala. The structure of static presentatives, which are introduces by the particle 'id $\bar{a}$, was presented above (8.4.2). Both 'i $\underline{d}$ and 'id $\underline{\text { a }}$ can be preceded by the conjunction $f a$ - (and occasionally by $w a$-). Table 10.5 summarizes the structural properties of presentatives introduced by 'id and 'id $\underline{i}$ :

TABLE 10.5 'id : 'id̄ā

Pattern A

B

dynamic (fa-)bayna $(m \bar{a}) \mathrm{N}^{\text {nom }}$ yaf'alu/făcilun $\left(f a-/{ }^{\prime} i d\right)$ fa'ala

presentative

static fáala

fa-/wa-'idā Nom yaf'alu/fā'ilun/qad fáala

presentative

Presentative clauses introduced by 'id and 'id̄a express something unexpected, mufāğa'a 'surprise' in traditional terms, a sudden development or realization, perceived or grasped by a certain character. However, while 'id-clauses present 
a further progression in the plot, 'id $\underline{a}$-clauses present an unfolding scene, a tableau, hence the above distinction between dynamic and static presentatives. In both cases the overall construction exhibits what may be described as an aspectual asymmetry. In 'id-initiated presentatives, a static situation (baynā /baynamā-clause) is interrupted by a dynamic peak in the story. In 'id $\bar{a}-$ initiated presentatives, a dynamic step forward in the plot ( fa'ala) is concluded in a static situation. It is this aspectual asymmetry that creates the dramatic moment of surprise in the narrative. The examples below illustrate the distinction between the two types of presentative constructions. In [10.34] the presentative is introduced by 'i $\underline{d}$ while in [10.35]-[10.37], reproducing [8.110][8.112], the presentative is introduced by 'i $\underline{d} \bar{a}$ followed by the predicative forms:

\section{(10.34) baynā 'anā 'amšš 'id samitu șawtan min-a l-samā’i}

While I was walking, all of a sudden I heard a voice from the sky. (Șahịh, 6)

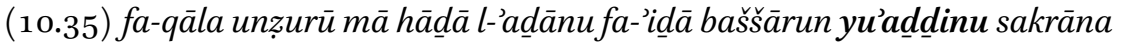
And he said: 'Look what is this call!' And there was Baššār calling for prayer while drunk. (Riwāàāt 1, 261)

(10.36) fa-ğìtu 'ilā 'ibrāhìma l-mawșiliyyi fa-ìdà l-bābu maftūḥun wa-l-dihlīzu qad kunisa wa-l-bawwābu qāंidun

I came to 'Ibrāhìm al-Mawșilī, and behold, the door was opened, the hall was already swept, and the door-keeper was sitting. (Riwāyāt 1, 28)

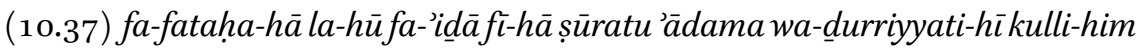
fa-'idà kullu rağulin maktūbun 'inda-hü 'ağalu-hū wa-'id̄a 'àdamu qad kutiba la-hü 'umru'alfi sanatin (Ta'rīh 1, 156)

He opened it (i.e. His hand) for him, and behold, in it there was the picture of Adam and all his progeny, and there was the [life] term of each man written down with Him, and there was Adam, a term of thousand years already written down for him.

\subsection{Generic Narratives}

The hitherto discussion of Classical Arabic narrative structure accounts for the great majority of narratives found in the corpus. Nearly all the narratives consist of a fa'ala-initiated chain of events, which is amplified by background units; some also feature dramatic patterns, such as the setting-presentative 
constructions. Nevertheless, one can occasionally encounter other forms of narration. The following anecdote, extracted from Kitāb al-Buhală' 'The Book of Misers', is a case in point:

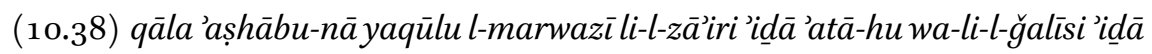
țāla ğulūsu-hū taġaddayta l-yawma fa-'in qāla na'am qāla lawlà 'anna-

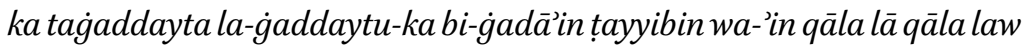

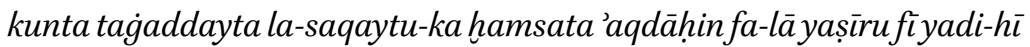
'alā l-wağhayni qalìlun wa-là katìirun

Our friends say: "The Marwazī says to a visitor when he comes to his [house] and to a companion when he extends his stay [with him]: "Have you had your midday meal today?" If he answers "Yes" he says: "If you hadn't already had your midday meal I would have given you a fine midday meal," and if he says "No" he says: "If you had had your midday meal I would have poured you five bowls of a drink." So neither a little nor a lot would come into his hand.' (Buhalä, 37)

The quoted passage seems to fit well Koch's definition of an anecdote:'a shortoriginally orally transmitted—narrative told about a well-known person, either a nationally prominent figure or a local character, to highlight his character or that of a social group or epoch this person represents.' ${ }^{36} \mathrm{Al}-$ Ğāhiz tells the story about the Marwazi in order to demonstrate the miserliness of the people of Khurasan. The story has in it a comic element, which is also inherent to the anecdotal style.

As far as its syntactic structure is concerned, this anecdote presents a great deviation from the narrative structure discussed above. For one thing, the story does not consist of a fa'ala-initiated chain and digression to background units therefrom. For another, the reference point of the story is neither internalthe narrative is not detached and self-contained-nor is it external, referring to the present situation of a particular narrator. Instead, the narrative consists of a sequence of generic verbal clauses: simple clauses comprising the verbal form yaf'alu, and conditional constructions comprising the verbal form fa'ala. Indeed, this narrative is essentially different from an ordinary narrative in being generic: though it does tell us of a sequence of events, these events are not discrete and particular, they did not happen to a certain person at a certain time and place, but would happen to a certain type of person whenever a certain type of situation arises. Generic narratives, according to Fleischman, 'relate

$36 \quad$ Koch, Simple Forms, 7 . 
what used to be the case in the past or what normally occurs in the present'. ${ }^{37}$ I apply this term to anecdotes such as the one quoted, since these set foot in both the domains of the narrative and the generic utterance: on the one hand, they report on a sequence of events in order to make a certain point, thus they have both the cohesive structure of a narrative and its pragmatic motivation; on the other hand, they are not anchored in a particular situation but refer to an always valid state of affairs.

\subsection{Summary}

In this chapter, I have discussed the main types of clauses which are found in Classical Arabic narratives and the way in which they contribute to the shaping of the narrative's overall structure. I have pointed out the major role of fa'ala as the eventive chain-initiating form, and distinguished between three types of chains: (a) the externally reported sequence of events marked by the facala conN-fáala pattern, (b) the internally portrayed complex event marked by the fa'ala yaf'alu/ fácilan pattern, and (c) the consequentially related events indicated by the fa'ala fa-yaf'alu pattern. Further, I have discussed background patterns in the narrative and distinguished between introductory (free) and subsequent (free or dependent) units, and between eventive and descriptive amplifications of the narrative. I have also made some observations regarding dramatic devices such as setting and presentative clauses. It was shown that the preference of a certain narrating strategy is not due to (macro-)syntactic constraints, but follows from the external or internal, involved (subjective and expressive) or uninvolved (objective and plain) position assumed by the narrator.

37 Fleischman, Tense and Narrativity, 104. 


\section{The Verbal Paradigm in the Generic Utterance}

The last two chapters discussed the distribution and function of the verbal forms in two text types: the dialogue and the narrative. In the present chapter I will examine the verbal paradigm in the third text type, the generic utterance.

\subsection{Preliminaries}

Genericity is a mode of reference. As many have observed, the generic meaning is often not inherent in a particular lexical or a grammatical element; rather, it is a reading, an interpretation of the linguistic expression advanced by a certain context. ${ }^{1}$ The generic mode of reference may be applied to either an entity or a state of affairs. A generic entity is one referring to a concept or a kind, rather than a certain object or individual; a generic state of affairs is one referring to a fact or a certain order of things, rather than an event or episode. ${ }^{2}$

Generic reference is distinct from particular reference in that it indicates only an implicit relation to the deictic center of the text. In both dialogue and narrative the reference is established with respect to a particular entity, i.e., the speaking subject/first person narrator or the third person narrator (see above 4.2). Being a particular subject, the speaker/narrator endows a certain element with particularity by locating it in an exclusive relation with respect to himself. ${ }^{3}$ Consequently, this element is anchored in the situation of speech or narration and interpreted in relation to it. It is not the case that in assigning generic reference, the speaker does not have 'a particular referent in mind',

1 Hawkins, Definiteness, 214-217; Ter Meulen, Generic Information, 123; Krifka, Genericity, 8-9; Jacobsson, Notes on Genericity, 151; Shisha-Halevy, Topics, 403.

2 The notion of 'mere fact' or 'order of things' is contrasted with the notion of 'event' or 'episode' in that the latter has a temporal relevance; it addresses 'the tension between situations and changes-of-situations', see Fuchs, Deixis, 102.

3 That a linguistic expression obtains a referential value with respect to the speaking person was recognized by several linguists, cf. Benveniste, Subjectivity, 225, and Coseriu, Determinierung, 269, who says: Die Situierung schliesslich ist der Vorgang, in dem die fest bezeichneten Gegenstände 'situiert'werden, d.h. durch die sie mit den in die Rede einbezogenen 'Personen' verknüpft und durch die sie in Bezug zu den räumlich-zeitlichen Gegebenheiten der Rede gesetzt werden.

(C) MICHAL MARMORSTEIN, 2016 | DOI: 10.1163/9789004310483_012

This is an open access chapter distributed under the terms of the Creative Commons

Attribution-Noncommercial-Non-Derivative 3.o Unported (CC-BY-NC-ND) License 
or that he 'does not have a commitment to its (i.e. the referent's) existence within the relevant universe of discourse. ${ }^{4}$ Rather, the speaker does not locate the referent in an exclusive relation with respect to himself, and therefore the referent is not anchored in the situation of speech, nor dependent upon it for its interpretation.

The fact that generic utterances exhibit only an implicit relation to the speaking subject should not be confused with the notion of objectivity. Generic utterances are often described as 'eternal-truths' or 'law-like' statements, related to the higher level of 'types' rather than 'tokens', reflecting our conceptual organization of reality. ${ }^{5}$ Indeed, generic information is not concerned with the description of particular situations, but, as pointed out by Ter Meulen, 'its purpose is to classify such situations as being of a particular type. ${ }^{6}$ That being said, one should bear in mind that a generic utterance, like any other utterance, is also transmitted by a certain subject whose imprints, even if subtle, may still be discerned in the structure of the clause.

Generic utterances record human knowledge, experience, law or custom. Regardless of their length, they form self-sufficient textual units. I shall use the term generic clauses to refer to the morpho-syntactic realization of generic utterances. A set of generic clauses often constitutes an expository text or, with 'normative' generics (see below 11.4), a codex. Generic clauses can be found in generic speech-situations, e.g., proverbs collections, moral and wisdom literature, or scholarly writing. However, a generic clause can also be called into a particular speech-situation, to support the specific exchange of discourse. In these cases, the generic may precede the particular clause and serve as an exposition, or follow the particular clause and provide an explanation to it. The operator 'inna is often used as an explicit mark of these two inter-clausal semantic relations (see also above 9.2.2), as illustrated in the following examples:

(11.1) ya hanāh 'inna l-nāsa yamzaḥūna wa-yal'abūna wa-lā yu'āhad̄ūna bi-

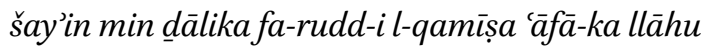

$O$ you, People jest and make fun and they are not reprehended for any of this, [so] hand back the gown, May God keep you in good health! (Buhalä, 63)

4 Hawkins, Definiteness, 215; Givón, Definiteness and Referentiality, 293-294.

5 Dahl, On Generics, 99-100; Kleiber, Phrases habituelles, 28-29.

6 Ter Meulen, Generic Information, 125. 
(11.2) lā tanzuranna 'ilà șig̀ar-ı̀ wa-du'f-ì fa-'inna l-'umūra laysat tağrī 'alā lquwwati wa-l-šiddati wa-l-dufi

Do not look at my smallness and weakness, for the matters are not guided by power, strength, [or] weakness. (Kalïla wa-Dimna 82)

The fact that generic reference may be applied to both a nominal-phrase and a verbal-phrase brings about four possible combinations within clauses whose predicate is a verbal form. Following the terminology suggested by Galmiche, these four types of clauses are listed in table 11.1 below. Notice that only when both the subject and the predicate are generically interpreted a generic clause is obtained: ${ }^{7}$

TABLE 11.1 Episodic, habitual, and generic clauses

\begin{tabular}{|c|c|c|c|}
\hline & & \multicolumn{2}{|c|}{ Verbal predicate } \\
\hline & & particular & generic \\
\hline \multirow{2}{*}{ Nominal subject } & particular & episodic clause & habitual clause \\
\hline & generic & episodic clause & generic clause \\
\hline
\end{tabular}

In the following, I will discuss the verbal forms which are found in main generic clauses and the functional oppositions between them (embedded generic clauses were discussed above in chapter 7 , see [7.11], [7.12], [7.23], [7.57], [7.66], [7.67], [7.88], [7.92], [7.93]). A brief presentation of the overall structure of generic clauses will precede the discussion. The properties of the generic nominal subject will not be dealt with. ${ }^{8}$

7 Galmiche, Phrases génériques, 23, includes in his classification one more type, the jugement générique which predicate an essential property of the kind. In terms of its grammatical characteristics, however, this type rests on a less solid definition, and therefore it is not included here. A similar combinatory approach to generic sentences is outlined in Mumm, Verbale Definitheit, 171-172.

8 For a detailed discussion of the theme in generic verbal clauses in Classical Arabic, see Marmorstein, Verbal Generics. 
Generic clauses are often introduced into discourse by formulas involving the verb qāla, e.g.: wa-qad qüla (Kalīla wa-Dimna, 69) 'It has been said', fa-yuqālu (Buhalä', 41) 'It is said', wa-qad kāna yuquàlu (Kalìla wa-Dimna, 66) on disait, wa$m \bar{a} z a \bar{a} l \bar{u}$ yaqūlūna (Buhalā', 39) 'They [= people] kept on saying'. Such formulas announce a generic clause; however, they do not form part of its internal structure.

Generic clauses may exhibit the structure of either the nominal clause or the verbal clause (see above 4.5), although the first option is far more common. The nominal pattern may be simply signaled by the placing of the subject ahead of the predicate, or it may take the marked form of an 'amma $\mathrm{fa}$ - 'as for ... so' clause, or be headed by the operator 'inna or one of its 'sisters', viz., lākinna 'but', lianna 'since' or 'anna 'that' (introducing the content clause of verbs such as $z a^{\prime} a m a$ 'to maintain', 'alima 'to know', and ra'ä 'to see, comprehend', see above $7.2)$.

Occasionally, generic clauses exhibit the pattern of the verbal clause. This pattern is triggered by the occurrence of the following operators and operations: (a) negation, interrogation, modification particles such as qad and focus particles such as 'innama preceding the verb; (b) emphasizing of a complement of the predicate, brought as such to the beginning of the clause, or emphasizing of the verbal lexeme itself; (c) impersonal verbs like yanbagi 'it is desirable' taking a content clause as their subject; and (d) passive verbs. An accumulation of these elements is also encountered (e.g. 'innamā yanbaji 'an).

\subsection{Indicative Verbal Forms in Generic Clauses}

In the grammatical literature, genericity is usually discussed in relation to nominal determination. However, genericity is also applied to verbal-phrases. In such cases, the generic mode of reference encodes a non-exclusive relation between the situation expressed by the verb and the subject engaged in discourse. In many languages the present tense is employed to signal this type of reference. This, however, cannot be simply explained away by the basic temporal denotation of this tense. The 'actual present' and the 'generic present' are not just distinct in their duration, exhibiting 'a gradual transition from what is more or less momentary to "eternal truths"', as Jespersen puts it, but rather they are distinct in their very nature. The 'actual present' is anchored in the situation of speech, it refers indeed to what is 'valid now', while the 'generic present' is in 
principle incompatible with the notion of 'now', always exclusive and relative with respect to a particular subject. ${ }^{9}$

The generic verb indicates either a static situation, with stative lexemes, or a dynamic situation, a disposition achieved by a frequentative, non-contingent repetition of an action. Frequentative repetition is one that has achieved the force of a law: it does not only refer to actual cases but also to possible and predictable ones. ${ }^{10}$ As defined by Kleiber, frequentative repetition, in contrast to mere iteration, does not take place in an interval of time, but applies for the whole interval of time referred to. ${ }^{11}$ Both generics and habituals denote a frequentative repetition, yet they are distinct from each other, since only in the latter case the interval of time is limited by the presence of a particular subject. ${ }^{12}$

In Classical Arabic, the verbal form yaf'alu is the regular, most common form of verb occurring in generic clauses. As opposed to fáala, yaf'alu is essentially non-eventive. It depicts an ongoing situation rather than a framed episode. As opposed to qadfa'ala, yaf'alu is temporally unbounded. This opposition clearly emerges in the following example:

\section{(11.3) fa-qad ğamáa hādāa l-ismu l-hamda wa-l-māla wa-smu l-buhliyağmáu l-māla wa-l-damma \\ And this noun (i.e. 'generous') has comprised praise and money, while the noun 'miserliness' comprises money and dispraise. (Buhalä', 91)}

In dialogue, the interval of time indicated by yaf'alu is delimited by the presence of a particular, spatiotemporally bounded person: either the first person, i.e., the subject engaged in discourse, or the second and third persons, determined with respect to him. This interval may be further specified by time-

Jespersen, Modern English, 4, 17-18. Kleiber, Phrases habituelles, 109-111, subscribing to the same view, explains the eternal validity of generic verbal sentences as produced by: (a) the neutrality of the present tense, (b) the stability of the predicate and (c) the durativity inherent in the generic noun-phrase. This, however, appears more like a description than an explanation of the generic sense. As a matter of fact, neutrality, stability, and durativity stem all from the lack of subjective anchoring.

10 Dahl, On Generics.

11 Kleiber, Phrases habituelles, 111-116.

12 In a similar fashion, Mumm, Verbale Definitheit, 172, finds the distinction between allgemeinen, ausserzeitlichen Sachverhalte and allgemeine Eigenschaften konkreter individueller Subjekte to relate only to the distinction between zeitgebundenem und zeitungebundenem Verbalhandlungsträger. 
adverbs. When yaf'alu is not a main verb but a predictive (dependent) form, it is temporally limited by the interval of time indicated in the matrix clause. In generic clauses, $y a f^{\prime} a l u$ does not refer to the situation of speech or is dependent on another verb, thus it is left indeterminate to the extent that it almost conveys the pure notion of the verbal lexeme. To put it in Guillaume's terms, yaf'alu in generic clauses reaches the end of maximal extension. ${ }^{13}$

The generic validity of $y a f^{\prime} a l u$ is diminished when a specific interval of time is indicated:

(11.4) wa-'ammā l-fursu fa-inna-hum kānū yủarrihūna bi-mulūki-him wahum l-yawma fi-mā 'álamu yu’arrihūna bi-'ahdi yazdağirda bni šahriyāra

And as for the Persians, they used to date according to [the reigns of] their kings, and today — as far as I know - they date according to the period of Yazdğard b. Šahriyār. (Tảrịn 1, 201)

The modifier qad occasionally precedes the generic yaf'alu. It serves as an explicit mark of the meaning of possible repetition implied by the generic yaf'alu. The modified qadyaf'alu always precedes the subject, thereby realizing the order of the verbal clause:

\section{(11.5) al-ğāhilu lā yakūnu munșifan wa-qad yakūnu l-ālimu mu'ānidan} The ignorant cannot be just whereas the learned may [well] be obstinate. ('Uyūn 2, 140)

Other operators which precede yaf'alu are qallama 'seldom' and rubba $(m \bar{a})$ 'many (a time)'. Like qad, these restrict the meaning of universal or extensive quantification, otherwise implied by the plain yaf'alu, and stress the notion of (high/low) frequency in which the verbal situation is likely to recur:

13 Extension, as defined first by Guillaume, Particularisation et generalisation, is the reference-potential of a lexeme, existing in the langue as a scale ranging between the two ends of particular and universal reference. In the transition to the parole a certain segment of this scale is realized by the operation of a determiner, such as the article in the case of a noun. The generic realization of a lexeme is therefore an approximation to the universal end of the scale, to the end of maximal extension. Wilmet, Contre la généricité, has further elaborated this notion to account not just for the domain of the nominal syntagm, termed by him extensité, but also for the domain of the predication, termed by him extensitude. 
(11.6) wa-qallamā tanğaḥu ḥilatu l-áğalati wa-l-irhāqi The hasty and excessive device seldom succeeds. (Kalìla wa-Dimna, 91)

(11.7) man-i staqalla bi-dā̉i-hì fa-lā yatadāwayanna fa-'inna-hū rubba yūrițu l-däa

He who cares little for his disease and does not treat himself, many [a time] transmits the disease. ('Uyūn 3, 296)

The modifier $l a$-is rarely conjoined with a generic $y a f^{\prime} a l u$. The form la-yaf'alu, as discussed above (9.2.3), occurs in the frame of inna clauses. The clausal pattern 'inna la-marks the predicative relation, the nexus, as focused:

(11.8) wa-mā ḥumqu l-ruba'i wallāhi 'inna-hū la-yağtanibu l-udawā’a wayatba'u 'umma-hū fì l-mar'à wa-yurāwihu bayna l-ațbäi wa-ya lamu 'anna ḥanina-hà ruġäun fa-'ayna ḥumqu-hu

And what is the stupidity of the rubac (i.e., a young camel born in the season called $r a b \bar{\imath})$ ? By God, it surely avoids uneasiness, follows its mother in the pasture, alternates between [its mother's] dugs and knows that its [mother's] yearning [sounds like] grumble, so where is its stupidity? (Hayawān 7,22 )

Focus, as is well known, marks the subjective stance of the speaker. At first sight this might seem contradictory to the notion of genericity. However, a generic utterance, though not anchored in a particular situation of speech, is not devoid of subjectivity. ${ }^{14}$ Subjectivity is explicitly marked in the clausal pattern 'inna laor when the operator 'innamā is employed. It is also marked formally in a clause whose predicate or one of its complements are emphasized and thus fronted to the beginning of the clause. The modal verbal forms, to be discussed below, are naturally colored with subjectivity; however, yaf'alu forms often have a shade of modal meaning as well (see below [11.10]-[11.11]). The difference between focus in particular and generic clauses is that in the first case the pragmatic motivation for the subjective expression is present and evident, while in the second case, due to the transferability of generic utterances (enabled by their non-anchoredness), this motivation is lost along the way.

14 Subjectivity and subjective anchoring are not overlapping terms: the first is much more wide and elusive: it applies not only to the deictic binding of the expression to the situation of discourse, but to any disclosing of the speaker's involvement or attitude marked formally in the structure of the clause, see above 4.2. 
Generic yaf'alu forms are nearly always negated by $l \bar{a}$. Only in rare occasions laysa is used and $m \bar{a}$ was encountered on only one occasion. The negated yaf'alu usually follows a definite subject and precedes an indefinite one:

(11.9) inna-nì la-kum ḍyfun wa-l-dayfu là yușāriúu rabba manzili-hì I am your guest and the guest does not fight with his host (lit. 'the lord of his house'). (Riwāyāt 1, 129)

(11.10) wa-lä yaqtulu mu'minun mu'minan fí käfirin

And a believer shall not kill another believer for the sake of an infidel. (Sìra 1, 342)

However, in certain cases the negated yaf'alu also precedes the definite subject: (a) when the verb is in the passive, or (b) when the content negated is restricted by either 'illa 'except', hattā 'until', or mā l-daymūma 'mā of duration':

(11.11) maktūbun fì l-tawrāti là yựadu l-ḥadịtu marratayni

It is written in the Torah: The story is not to be repeated twice. ('Uyün $2,194)$

(11.12) fa-lā yub'idu llāhu 'illā man zalama

And God does not remove but the one who does wrong. (Buhalä, 150)

(11.13) lā ya'rifu l-rağulu hața'a mu'allimi-hì hattā ya'rifa l-ihtilāfa

The man is not aware of his teacher's mistake until he is acquainted with the disagreeing [opinion]. ('Uyün 2, 143)

(11.14) là yazālu l-mar'u 'āliman mā țalaba l-ilma

The man does not cease to be learned as long as he asks for lore. ('Uyün $2,134)$

Verbs introducing direct speech form a special class of clauses. They may be realized either in nominal clauses, specifying the source of the saying, or in verbal clauses, serving to announce the saying. The verb may take the form of either yaf'alu or fáala. The generic-episodic opposition between the two forms, even if not entirely forgotten, seems to be worn down to a large extant with these verbs:

\section{(11.15) wa-yaz'umu 'ahlu l-tawrāti}

And the people of the Torah maintain ... (Ta'rinh 1,190$)$ 
(11.16) fa-'ammà 'ahlu l-tawräti fa-'inna-hum yaz'umūna As for the people of the Torah, they maintain ... (Ta'rinh 1, 251)

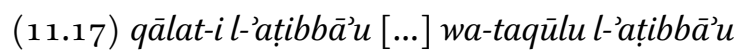
The physicians said $[\ldots]$ and the physicians say ... ('Uyūn 3, 302-304)

Besides conditional structures, the occurrence of fa'ala in generic clauses is rather restricted. The most obvious case in which fa'ala assumes a generic sense is in proverbs. The example 'anğaza hurrun mā wa'ada 'A free man fulfills what he promises' is one repeatedly quoted since de Sacy's grammar in every discussion on the generic use of fa'ala. Other such examples abound in proverb collections such as al-Maydānī's mağma'l-'amtāal, e.g.: 'arafa ḥumayqun ğamala-hū '[Even] a foolish man knows his camel', 'āda l-sahmu 'ilā l-naza'ati 'The arrow comes back to the shooters', taraka l-zabyu zilla-hū 'The gazelle has forsaken its shelter'.

Proverbs, as is well known, form a special kind of generic statements. In terms of their syntactic structure, proverbs, like verse, are allowed much latitude and flexibility, thus manifesting a great variety of patterns. In fact, what identifies a proverb as such is not necessarily a distinct syntactic structure (though typical structural features common to proverbs naturally exist), but rather its being aknowledged as a proverb. In other words, a proverbial statement is defined by its unambiguous generic reading, regardless of its syntactic structure. ${ }^{15}$ The generic interpretation of facala in proverbs is thus advanced by the given generic context, or by what may be described as the 'proverbization' of the clause. ${ }^{16}$

Apart from proverbs, facala seems to assume a generic sense in certain patterns of negation. With a generic subject, fa'ala negated by $m \bar{a}$, occasionally reinforced by qattu, refers not to the non-occurrence of an episode, but to the whole interval of time in which a certain occurrence did not take place. In a similar manner, the negated form lam yaf'al may also be used to indicate such a 'sweeping' negation. As mentioned above, negation triggers as a rule the order of the verbal clause:

15 As pointed out by Taylor, Proverb, 3 , it is 'an incommunicable quality', rather than a certain structural property, that 'tells us this sentence is proverbial and that one is not'.

16 What is meant here by 'proverbization' are the linguistic shaping and stabilization of the proverbial statement, as well as the extralinguistic process of its being aknowledged as such. 
(11.18) mā naqașa mālun qaț̣u min zakātin

Money never grew less through charity. (Buhalä, 50)

(11.19) mā warratatat-i l-'ābāu l-'abnā'a šay'an 'afḍala min-a l-'adabi

Fathers never bequeathed to their sons anything better than fine education. ('Uyūn 2, 136)

(11.20) țumma lam yūlad șabiyyun mahtūnun qațtu

Afterwards, never was a circumcised boy born. (Hayawān 7, 27)

(11.21) fa-lam tazal-i l-suhafầu tastahiffu l-'ulamà'a

The fools never ceased to scorn the wise people. (Kalïlawa-Dimna,120)

Another case in which a generic interpretation of fa'ala suggests itself is the following interrogative clause. In the contour of a rhetoric question, this statement implies that people always waste their money on ghee and honey:

(11.22) wa-hal 'afsada l-nāsu 'amwāla-hum 'illāfíl-samni wa-l-'asali

Did people [ever] lose their wealth but [through spending] on ghee and honey?! (Buhalä, 79)

In one more case fa'ala seems to assume a generic sense: this is when it is preceded by the operator rubbama 'many a time', or its subject is constructed with rubba 'many'. The operator rubba $(m \bar{a})$ does not indicate universal quantification. Nevertheless, rubba(mā) fa'ala conveys the implication that the occurrence which took place several (few/many) times in the past is bound to repeat itself again in the future, as illustrated in the examples below. Notice that in [11.24] fa'ala is followed by yaf'alu, the latter form is referential to the first, indicating a succeeding event:

(11.23) wa-'inna l-ṣaḡira rubbamā 'azuma

The small one many a time turned great. (Kalïla wa-Dimna, 71)

(11.24) wa-'inna l-malika l-hāazima rubbamā 'abj̇ạ̣a l-rağula wa-kariha-hū tumma yuqbilu 'alay-hi wa-yuqarribu-hü

The judicious king many a time hated a man and detested him and afterwards he would turn to him and bring him close. (Kalïla waDimna, 121) 


\section{(11.25) 'inna-hū rubba mutaḥayyilin'awqa'at-hu hî̀latu-hū fı̀ šarrin}

Many a swindler was brought down to worse by his [own] deceit. (Katīla wa-Dimna, 116)

As pointed out above, the form yaf'alu serves to indicate an order of things, an unbounded situation, thus it is very suitable for generic utterances. The form fa'ala, by contrast, is essentially episodic and used to indicate framed situations, thus its use in generic clauses is limited. The generic reading of facala, to summarize the above discussion, is advanced by: (a) a generic contextual frame, such as a proverb; (b) a 'sweeping' negation, i.e., a negation valid for an entire interval of time (in this case, lam yaf'al may also be employed); (c) an interrogative carrying the implication of an experience never contradicted; or (d) the operator rubba $(m \bar{a})$ implying the reoccurring of past occurrences. As opposed to the 'universal' generalizations marked by yaf'alu, fa'ala is used in what may be described as 'existential' generalizations, i.e., generalizations that form a set of actual cases that create a certain commitment or expectation regarding the yet-to-occur cases. That is, while yaf'alu may well have a generic reference, fa'iala, as it appears, can only have a generic inference.

The participle is not often found in generic utterances. As mentioned earlier (5.2.1), the participle assumes a temporal value when it has deictic anchoring, i.e., when it is personally (hence spatiotemporally) bounded. By contrast to a particular participle, which refers to a temporally bounded state, a generic participle is temporally indeterminate; it serves to predicate an inherent property of an entity. Whether active or passive, the generic participle indicates a static aspect, as opposed to the dynamic, frequentative aspect indicated by the generic yaf'alu:

\section{(11.26) wa-l-mālu zähirun nāfíun mukarrimun li-’ahli-hī mu'izzun}

Money is bright, beneficial, endowing honor and esteem to those who own it. (Buhalä, 91)

(11.27) wa-l-zuğăğu 'abqā 'alā l-māi wa-l-turābi min-a l-dahabi l-ibrīzi wahuwa ma'a d̄àlika mașnū un wa-l-dahabu mahlūqun

Glass is more resistant to water and earth than pure gold, though it is artificial while gold is created [by God]. (Buhala $\vec{a}, 42)$ 


\subsection{Modal Verbal Forms in Generic Clauses}

Generic utterances exhibit not only the indicative forms, but also modal forms such as the imperative if'al, the prohibitive $l \bar{a}$ yaf'al and the energetic (la $)$ yaf'alanna. A modal form conveys the meaning of a prescriptive statement rather than a descriptive one. ${ }^{17}$ It serves to express a norm, an ideal, a desired order of things rather than an existing one. The second person, inherent in the imperative, is also very common with the other modal forms. Generic dictations and interdictions often stem from a hutba 'speech', once delivered in front of a particular audience and now transferred to the pages of history for the benefit of the succeeding generations. The following set of examples illustrates the use of modal forms in generic clauses:

(11.28) i'mal li-dunyā-ka 'amala man ya'išu 'abadan wa-'mal li-'āhirati-ka man yamūtu gadan

Do for your life in this world as one who lives forever and do for your life in the hereafter [as] one who dies tomorrow. (Buhalä', 154)

(11.29) lā yarǧuwanna 'abdun 'illā rabba-hū wa-lā yahăfanna 'illā danba-hū The servant of God should not ask [for anyone] but his lord and should not be afraid [from anything] but his sin. ('Uyūn 2, 135)

(11.30) là tahquiranna 'aduwwan wa-'in kāna haqüran da'îfan Do not despise an enemy, even if he is despised and weak. (Kalīla waDimna, 105)

(11.31) lā taṭlub taqwìma mā lā yastaqìmu wa-lā ta'dība mā lā yar'awì Do not try to fix what cannot be fixed and to enlighten what cannot see the light. (Kalīla wa-Dimna, 113)

\subsection{Summary}

In this chapter, I have dealt with a subset of generic utterances in Classical Arabic whose predicate is verbal. Generic reference was defined as the establishment of a non-exclusive relation between the linguistic expression and the

17 For the semantic distinction between descriptive and normative 'nomic' statements, see Dahl, On Generics, 101. 
subject engaged in discourse, providing its deictic center. It was shown that of the two finite indicative forms, the non-episodic yaf'alu displayed a much wider use than the episodic fa'ala. The latter assumed a generic sense (or implication) only in restricted syntactic environments where its episodic meaning was overridden. With normative generic clauses, the modal forms if'al, la $y a f^{\prime} a l$ and $(l \bar{a})$ yaf'alanna were attested. These served to express a desired order of things rather than to describe an existing one. Generic clauses were attested in the corpus either as self-contained textual units or as units integrated in dialogues or commentary parts of the text, supporting as such the particular exchange of discourse. 


\section{Conclusions}

The study of classical languages is challenging for many reasons. Firstly, there are no speakers to consult but only (silent) written texts, often handed down and adapted by a long chain of transmitters and copyists. Secondly, these texts consist of a closed corpus which, even if extensive, represents only some literary and formal genres, though not discourse in its fullest scope. But over and above all, texts written in a classical language are culturally remote from the modern reader, or better yet, interpreter. A clear understanding of the world of notions reflected in them and their particular idiomaticity is thus not trivial in any sense.

All this seems to be even more complicated in the case of Classical Arabic, the literary branch of a language which in a recent study was designated as 'the most interesting language in the world' for the linguist. ${ }^{1}$ The author of these words was obviously aware of the provocative nature of his claim; however, he was correct in pointing out the challenge of studying a language with a great linguistic heritage which is not only 'constitutive of the Arabic-Islamic tradition' but also 'continues to be of central importance in the contemporary teaching of Arabic'.2

This study undertook to examine the problem of the tenses in Classical Arabic. While aware of the long tradition which shaped the discussion of this subject, and building, in fact, on some important insights offered by medieval and modern grammarians, this study has attempted to redefine the discussion and propose a new analysis of the tenses, based on a functional discourseoriented investigation of a large corpus of Classical Arabic prose.

More specifically, the starting point of the analysis was the verbal form yaf'alu. The intriguing thing about yaf'alu is that it is a finite verb which in itself is semantically indefinite or mubham in the traditional terminology. It stands to reason, thus, that in the grammatical literature the semantic content of $y$ af'alu was not positively defined, but rather described with respect to other verbal forms: the Arab grammarians stressed its resemblance (mudāra'a) to the participle, while Western scholars defined it as the opposite of the perfect form fáala.

1 Owens, House of Sound Structure, 1.

2 Ibid., 5 .

(C) MICHAL MARMORSTEIN, 2016 | DOI: 10.1163/9789004310483_013

This is an open access chapter distributed under the terms of the Creative Commons

Attribution-Noncommercial-Non-Derivative 3.o Unported (CC-BY-NC-ND) License 
The definition of yaf'alu as either 'resembling' or 'imperfect' is too abstract and general. It does not account for the functional relationships between yaf'alu and the entire system of the indicative tenses, thus it fails to capture the cluster of meanings conveyed by yaf'alu. Furthermore, such definitions do not consider the extended syntactic patterns in which yaf'alu occurs and the contextual features which affect its interpretation. In other words, they do not provide a satisfying explanation to the question of what defines the meaning of the indefinite form.

In this study, I have tried to offer a comprehensive answer to this question, by examining the syntactic distribution of the indicative verbal forms and their paradigmatic relationships, and by giving due consideration to the relevant discursive, textual, syntactic, and lexical parameters which play distinctive roles in the interpretation of the verbal forms. Table 12.1 presents the system of the indicative (affirmative) verbal forms which were the focus of this study. Table $\mathbf{1 2 . 2}$ below it summarizes the contextual and lexical parameters which were found to affect the interpretation of these forms:

TABLE 12.1 The indicative (affirmative) verbal forms

\begin{tabular}{|c|c|c|c|}
\hline Simple & Modified & Compound & Modified-compound \\
\hline yaf'alu & $\begin{array}{l}\text { qadyaf'alu } \\
\text { sawfa/sa-yaf'alu } \\
\text { la-yaf'alu }\end{array}$ & kāna yaf'alu & qad kāna yaf'alu \\
\hline facala & qad fáala & kāna fáala & $\begin{array}{l}\text { qad kāna fáala } \\
\text { kāna qad fáala }\end{array}$ \\
\hline fāilun/maf'ülun & la-fāilun/maf'ūlun & kāna fāilan/maf'ūlan & qad kāna fāilan/maf'ūlan \\
\hline
\end{tabular}

TABLE 12.2 The contextual parameters

\begin{tabular}{ll} 
Parameter & Internal taxonomy \\
\hline deictic reference & first person : third person narrator : third generic person \\
text type & dialogue : narrative [first person : third person] : generic utterance \\
interdependency & main : dependent : mutually dependent : embedded \\
clause type & verbal clause : nominal clause \\
lexical class & bounded : unbounded [dynamic : static]
\end{tabular}


The interaction between the verbal lexeme (the lexical aspect) and the verbal form (the grammatical aspect) was found to be significant throughout. This interaction to a large extent determines the relative temporal value of the verbal forms. Verbal forms which do not indicate a certain bounding of the verbal situation obtain different values with bounded and unbounded lexemes, whereas verbal forms which indicate such bounding have only one value:

TABLE 12.3 The temporal-aspectual values of the indicative forms ${ }^{3}$

Verbal form Grammatical bounding Lexical bounding

Bounded Unbounded

\begin{tabular}{|c|c|c|c|}
\hline yaf'alu & - & posterior & concurrent-dynamic \\
\hline sawfa/sa-yaf'alu & + & & posterior \\
\hline fa'ala & - & anterior & persistent \\
\hline qadfa'ala & + & \multicolumn{2}{|c|}{ resultative-dynamic } \\
\hline făcilVn & - & posterior & concurrent-static \\
\hline$m a f^{\circ} \bar{u} l V n$ & + & \multicolumn{2}{|c|}{ resultative-static } \\
\hline
\end{tabular}

In my discussion of the verbal paradigms I distinguished between dependent and embedded clauses, analyzed at the complex-clause level, and main clauses and mutually dependent constructions, analyzed at the text level.

The discussion of the verbal paradigms in embedded clauses was divided into content 'anna-clauses, adjectival (or relative) clauses introduced by lladi $\bar{\imath}$, $m \bar{a}$, man, or asyndesis, and adverbial hina-clauses. In most cases, the verbal forms retained their typical temporal-aspectual values; however, these were often conflated with other semantic nuances, specifically with modal meanings. Thus, the posterior yaf'alu was often modally colored, indicating such meanings as possibility, ability, and obligation ([7.25], [7.39]-[7.42], [7.64],

3 The table summarizes the most common and predictable values of the verbal forms. Cases which deviate from the normal use are referred to in the subsequent discussion. 
[7.65], [7.85], [7.86]). Textual and pragmatic features such as repetition, presupposition, and reference type also affected the interpretation of the verbal forms. Thus, the concurrent or posterior reading of yaf'alu was found to be context-derived rather than lexically conditioned in some cases ([7.10], [7.22], [7.62], [7.63], [7.102]). Certain functions of the verbal forms were found to be clause-specific. Thus, a consequential meaning of fa'ala and qad fa'ala was observed in adjectival asyndetic clauses whose antecedent is an internal object ([7.48]-[7.50]). In adjectival man-clauses, on the other hand, fa'ala displayed a loose temporality, which allowed for both anterior and non-anterior readings of the form ([7.91]). Moreover, some embedding operators, such as the adverbial operator hina, were found to have great bearing on the interpretation of the verbal forms, regardless of the nature of their verbal lexeme.

Predicative verbs which participate in complex predications were dedicated a separate discussion. These consist of yaf'alu, the participle, and qad fa'ala, marking an ongoing situation, a state, and an outcome, respectively. All three are co-temporal, either simultaneous or coincidental with the time frame established in the main clause. The predicative paradigm was shown to operate both at the complex-clause level, with verbal complexes (8.2) and dependent circumstantial clauses (8.3), and at the text level, with mutually dependent constructions (8.4). The aspectual and temporal values of the predicative forms are summarized in table 12.4 (reproducing table 8.1 above):

TABLE 12.4 The predicative paradigm

\begin{tabular}{|c|c|c|}
\hline Predicative form & Aspect & Temporal value \\
\hline yaf'alu & dynamic-progressive & simultaneous, coincidental (terminal) \\
\hline$f a \bar{c}^{c} i l V n / m a f^{\prime} \bar{u} l V n$ & static & simultaneous \\
\hline qadfa'ala & resultative & coincidental (initial) \\
\hline
\end{tabular}

The discussion of the verbal paradigms at the text level was divided into dialogue, narrative, and generic text types. In the dialogue, the following types of clauses or speech-acts were examined: plain declarative (9.2.1), argumentative (9.2.2), asseverative (9.2.3), performative (9.3), optative (9.4) and interrogative clauses (9.5); negative clauses were submitted to a limited inspection (9.2.4). In all these, the egocentric and interactional nature of the dialogue was clearly reflected. Rather than plain temporality, the verbal forms were found to signal a variety of inter-subjective categories such as: current relevance and 
actuality, cognitive evaluation, emotional involvement, personal identification, directness and rapport.

In the discussion of narrative texts, three types of plotline structures were distinguished: (a) the unmarked 'event-by-event' fa'ala conN-fa'ala chain (10.2.1); (b) the internally portrayed complex event marked by fa'ala yaf'alu/ fä́ilan (10.2.2); and (c) the consequentially related chain of events marked by fa'ala fa-yaf'alu (10.2.3). In the discussion of background units, a distinction was drawn between free kāna-clauses and dependent circumstantial clauses (10.3.1), and between eventive background involving fa'ala and qad fa'ala and descriptive background involving yaf'alu and the participle (10.3.2). Some observations were made regarding dramatic devices such as setting and presentative clauses (10.4).

The discussion of the verbal paradigm in generic utterances has shown that of the two simple finite tenses, the non-episodic yaf'alu displayed a much wider use than the episodic fa'ala, which assumed a generic sense (or implication) only in restricted syntactic environments ([11.18]-[11.25]). In normative generic clauses, expressing a desired order of things, the modal forms if'al, lā yaf'al and $(l \bar{a})$ yaf'alanna were mostly employed ([11.28]-[11.31]). Generic clauses were attested either as self-contained textual units or as units integrated in dialogues or commentaries, supporting as such the particular exchange of discourse.

Table 12.5 summarizes the main functions of yaf'alu in all three text types, by comparing it to its 'opposite' fa'ala and its 'analogous' fāilVn. Not all the semantic nuances could have been specified in the table, yet it is easy to see on the vertical axis how temporal, aspectual, and modal meanings interact with different text types so as to produce a specific function of the verbal form in each case:

TABLE 12.5 The functions of yaf'alu, fa'ala, and fā'ilVn in different text types

\begin{tabular}{|c|c|c|c|}
\hline Text type & yaf'alu & fa'ala & fāiilVn \\
\hline \multirow[t]{4}{*}{ Dialogue } & concurrent-dynamic & persistent & concurrent-static \\
\hline & posterior-intention & anterior & posterior-readiness \\
\hline & declarative-performative & transaction-performative & \\
\hline & $\begin{array}{l}\text { asseverative-dynamic } \\
\text { (optative) }\end{array}$ & optative & asseverative-static \\
\hline
\end{tabular}




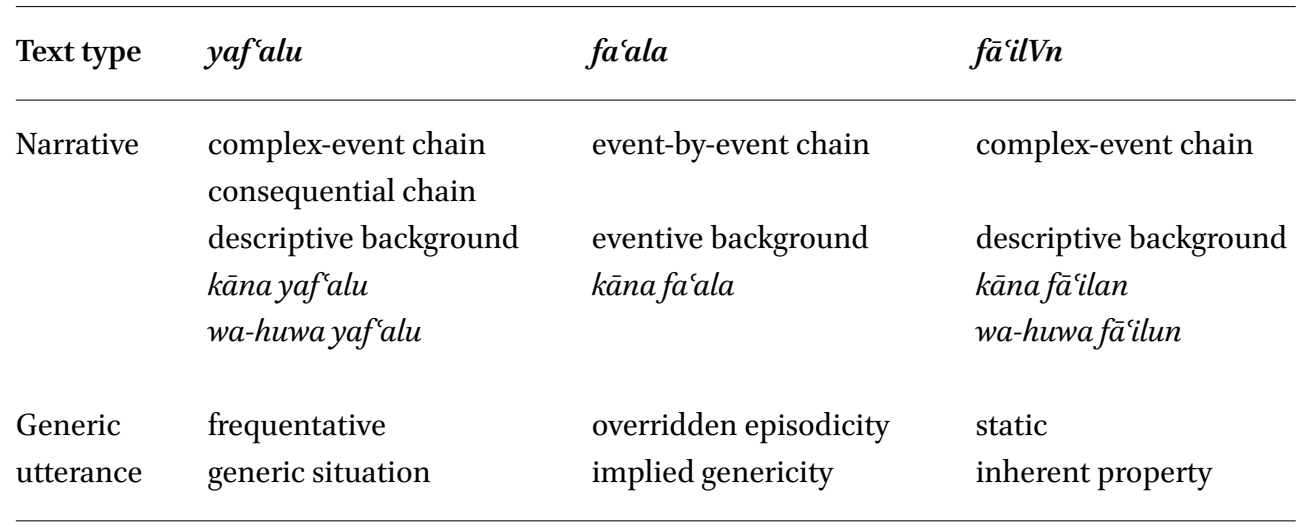

Table 12.5 makes it plain that the question of the meaning of yaf'alu, or for that matter, of any of its mutual opposites, does not have a short satisfying answer. The verbal form yaf'alu is semantically indefinite. Its function is determined by the interaction of its inherent indefiniteness, the specific syntactic environment in which it occurs, and the overall dialogic, narrative, or generic context. To be sure, in a strict formal analysis, the semantic opposition between yaf'alu, fa'ala, and $f \bar{a} i l V n$ could have been reduced to such notions as eventivity and phasality, yaf'alu being the opposite of the eventive facala and the stative $f \bar{c} i l V n$. However, as amply demonstrated in this study, the functional oppositions between yaf'alu and other verbal forms are always more nuanced, delicate, and pragmatically (rather than logically) motivated in actual discourse.

The functional analysis of the semantically indefinite $y a f$ 'alu forces one to go beyond the categories of tense and aspect, and examine the contextual frames in which it is used. This is certainly true in the analysis of tense forms in other Semitic languages as well and, at least to some extent, in other language families. Indeed, it appears that the particularizing effect of context on the interpretation of grammatical forms is universal in nature, inherent in the relationship between language and discourse. It is hoped, then, that the principles of contextual analysis presented in this work can also be of use in the study of tense systems in other languages, thereby bringing us closer to understanding the intricacy of the relationship between the system of language and language use. 
Michal Marmorstein - 978-90-04-31048-3 Downloaded from Brill.come4/26/2023 10:49:57AM via free access 


\section{References}

\section{Primary Sources (corpus)}

Buhalā'-'Abū 'Uțān 'Amr b. Baḥr b. Maḥbūb al-Ǧāḥiẓ, Al-Buhalā’. Ed. 'Abbās 'Abd al-Sātir. Beirut 1993 .

Hayawān-'Abū 'Uțmān 'Amr b. Baḥr b. Mạ̣būb al-Ğāḥiẓ, Kitāa al-Hayawān. 8 vols. Ed. 'Abd al-Salām Muhạmmad Hārūn. Cairo 1965-1969.

Kalīla wa-Dimna —'Abdallāh Ibn al-Muqaffa', Kitāb Kalīla wa-Dimna. Ed. Louis Cheikho. Beirut 1926.

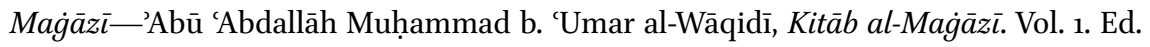
M. Jones. Beirut 1966.

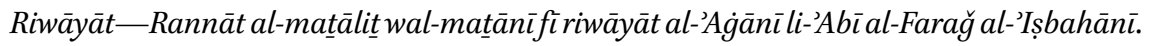
2 vols. Ed. 'Anțūn Șāliḥānī. Beirut 1923 (vol. 1), 1946 (vol. 2).

Ṣaḥịh—'Abū 'Abdallāh Muḥammad b. 'Ismac̄il al-Buhārī, Kitāb al-Ğāmi' al-ṣaḥịh. Vol. 1. Ed. L. Krehl. Leiden 1862.

Sìra-'Abū Muḥammad 'Abd al-Malik b. Hišām, Sìrat Sayyidinā Muḥammad Rasūl Allāh. 2 vols. Ed. F. Wüstenfeld. Göttingen 1858-186o.

Ta'rīh_'Abū Muhammad b. Ğarīr al-Ṭabarī, Ta'rīh al-rusul wa-l-mulūk. 15 vols. Ed. M.J. de Goeje et al. Leiden 1879-1901 (reprint 1964).

'Uyūn al-'ahbār-'Abū Muhammad b. Muslim Ibn Qutayba, 'Uyūn al-'ahbār. 4 vols. Eds. Yūsuf 'Alī Ṭawīl (vols. 1-2) and Mufīd Muhammad Qamīha (vols. 3-4). Beirut 1998.

\section{Secondary Sources}

Aartun, Altarabischer Tempora-K. Aartun, Zur Frage altarabischer Tempora. Oslo 1963.

Abboud, Hāl-Construction-P. Abboud, "The Hāal Construction and the Main Verb in the Sentence". In: The Fergusonian Impact: In Honor of Charles A. Ferguson on the Occasion of His 65 th Birthday. Vol. 1: From Phonology to Society. Ed. J.A. Fishman et al. Berlin 1986, 191-196.

al-'Astarābād̄ī, Šarh al-Kāfiya - Raḍi al-Dīn Muhammad b. al-Ḥasan al-'Astarābāḍī, Šarh Kāfuyat Ibn al-Hāḡib. 5 vols. Ed. Emīl Badī' Ya`qūb. Beirut 2007.

Bahloul, Arabic Verb-M. Bahloul, Structure and Function of the Arabic Verb. London/New York 2008.

Bal, Narratology-M. Bal, Narratology: Introduction to the Theory of Narrative ${ }^{2}$. Toronto/Buffalo 1997 . 
De Beaugrande, Text Linguistics - R. de Beaugrande, "Text Linguistics at the Millennium: Corpus Data and Missing Links". In: Text 20:2 (2000), 153-195.

Beeston, Arabic Language-A.F.L. Beeston, The Arabic Language Today. London 1970. Benveniste, Subjectivity-E. Benveniste, "Subjectivity in Language". In: Problems in General Linguistics. Translated by M.E. Meek. Coral Gables, 1971, 223-230.

Benveniste, Correlations of Tense-E. Benveniste, "The Correlations of Tense in the French Verb". In: Problems in General Linguistics. Translated by M.E. Meek. Coral Gables, 1971, 205-215.

Binnick, Time and the Verb-R.I. Binnick, Time and the Verb: A Guide to Tense and Aspect. New York/Oxford 1991.

Bloch, Presentative Structures-A.A. Bloch, "Presentative Structures and Their Syntactic and Semantic Development". In: Studies in Arabic Syntax and Semantics. Wiesbaden 1986, 54-101.

Bonebakker, 'Adab - S.A. Bonebakker, "Adab and the Concept of Belles-lettres". In: The Cambridge History of Arabic Literature: Abbasid Belles-Lettres. Eds. J. Ashtiany et al. Cambridge 1990, 16-30.

Brockelmann, Grundriss - C. Brockelmann, Grundriss der vergleichenden Grammatik der semitischen Sprachen. 2 vols. Berlin 1908-1913.

Brockelmann, Arabische Grammatik-C. Brockelmann, Arabische Grammatik: Paradigmen, Literatur, Übungsstücke und Glossar ${ }^{16}$. Leipzig 1965.

Brockelmann, "Tempora”—C. Brockelmann, "Die 'Tempora' des Semitischen”. In: Zeitschrift für Phonetik und allgemeine Sprachwissenschaft 5 (1951), 133-154.

Brockelmann, GAL-C. Brockelmann, Geschichte der arabischen Literatur 1. Weimar 1898.

Brown and Yule, Discourse Analysis-G. Brown and G. Yule, Discourse Analysis. Cambridge 1983 .

Bubenik, Hewson and Omari, Tense, Aspect and Aktionsart-V. Bubenik, J. Hewson and O. Omari, “Tense, Aspect and Aktionsart in Arabic". In: Folia Orientalia 50 (2013), 950 .

Bühler, Theory of Language-K. Bühler, Theory ofLanguage: The Representational Function of Language. Translated by D.F. Goodwin. Amsterdam 1990.

Bybee, Perkins and Pagliuca, Evolution-J. Bybee, R. Perkins and W. Pagliuca, The Evolution of Grammar: Tense, Aspect and Modality in the Languages of the World. Chicago/London 1994.

Carter, Mud̄āri-M.G. Carter, "The Term Mud̄āric in the Kitāb of Sībawayhi”. In: Proceedings of the Arabic and Islamic Sections of the 35 th International Congress of Asian and North African Studies (ICANAS). Eds. K. Dévényi and T. Iványi. Budapest 1997, 3-14.

Chafe, Adverbial Clauses - W. Chafe, "How People Use Adverbial Clauses". In: Proceedings of the Berkeley Linguistics Society 10 (1984), 437-449. 
Chomsky, Aspects-N. Chomsky, Aspects of the Theory of Syntax. Cambridge, Mass. 1965.

Cohen, L'aspect verbal —D. Cohen, L'aspect verbal. Paris 1989.

Cohen, Modal System - E. Cohen, The Modal System of Old Babylonian. Winona Lake 2005.

Cohen, Tense-Aspect-E. Cohen, "The Tense-Aspect System of the Old Babylonian Epic". Zeitschrift für Assyriologie 96 (2006), 31-68.

Cohen, Syntax of Neo-Aramaic-E. Cohen, The Syntax of Neo-Aramaic: The Jewish Dialect of Zakho. Piscataway 2012.

Cohen, Conditionals - E. Cohen, Conditional Structures in Mesopotamian Old Babylonian. Winona Lake 2012.

Cohen, Système verbal-M. Cohen, Le système verbal sémitique et l'expression du temps. Paris 1924.

Comrie, Aspect-B. Comrie, Aspect: An Introduction to the Study of Verbal Aspect and Related Problems. Cambridge 1976.

Comrie, Tense-B. Comrie, Tense. Cambridge 1985.

Coseriu, Determinierung - E. Coseriu, "Determinierung und Umfeld". In: Sprachtheorie und allgemeine Sprachwissenschaft, München 1975, 253-290.

Croft, Verbs-W. Croft, Verbs: Aspect and Causal Structure. Oxford 2012.

Dahl, On Generics - Ö. Dahl, “On Generics”. In: Formal Semantics of Natural Languages. Ed. E.L. Keenan. Cambridge 1975, 99-111.

Dahl, Tense and Aspect - Ö. Dahl, Tense and Aspect Systems. Oxford 1985.

Decklerk, When-clauses - R. Declerck, "Tense Choice in Adverbial when Clauses". In: Linguistics 34 (1996), 225-261.

Denz, Verbalsyntax-A. Denz, Die Verbalsyntax des neuarabischen Dialektes von Kwayriš (Iraq): Mit einer einleitenden allgemeinen Tempus- und Aspektlehre. Wiesbaden 1971.

Denz, Tempus und Aspekt-A. Denz, "Tempus und Aspekt? Vorstellung eines noetischen Modells". In: Tempus und Aspekt in den semitischen Sprachen. Ed. N. Nebes. Wiesbaden 1999, 37-41.

Dik, Functional Grammar-S.C. Dik, The Theory of Functional Grammar ${ }^{2}$. Berlin 1997.

Driver, Treatise - S.R. Driver, A Treatise on the Use of the Tenses in Hebrew. Oxford 1892 (reprint 2009).

Ducrot, L'imparfait - O. Ducrot, “L' imparfait en français". In: Linguistische Berichte 60 (1979), 1-23.

Ewald, Grammatica Critica-H. Ewald, Grammatica critica linguae arabicae. Leipzig 1831.

Ewald, Hebrew Syntax - H. Ewald, Syntax of the Hebrew Language of the Old Testament. Translated by J. Kennedy. Edinburgh 1891. 
Firth, Technique - J.R. Firth, “The Technique of Semantics". In: Papers in Linguistics 1934-1951. London 1958, 7-33.

Fischer, Classical Arabic Grammar-W. Fischer, A Grammar of Classical Arabic ${ }^{3}$. Translated by J. Rodgers. New Haven/London 2002.

Fischer, Classical Arabic-W. Fischer, "Classical Arabic". In: Encyclopedia of Arabic Language and Linguistics, 1. Ed. K. Versteegh et al. Leiden 2009, 397-405.

Fleisch, Verbe arabe - H. Fleisch, "Études sur le verbe arabe". In: Mélanges Louis Massignon, 2. Ed. D. Cohen. Damas 1957.153-181.

Fleisch, L'arabe classique-H. Fleisch, L'arabe classique esquisse d'une structure linguistique. Beyrouth 1956.

Fleischer, Kleinere Schriften - H.L. Fleischer, Kleinere Schriften, 1. Leipzig 1885.

Fleischman, Future - S. Fleischman, The Future in Thought and Language: Diachronic Evidence from Romance. Cambridge 1982.

Fleischman, Tense and Narrativity —S. Fleischman, Tense and Narrativity: From Medieval Performance to Modern Fiction. Austin 1990.

Fleischman, Theory of Tense-Aspect-S. Fleischman, "Toward a Theory of Tense-Aspect in Narrative Discourse". In: The Function of Tense in Texts. Eds. J. Gvozdanović, Th.A.J.M. Janssen and Ö. Dahl. Amsterdam/New York 1991, 75-97.

Fuchs, Deixis-A. Fuchs, "Deixis, Relevance and Tense/Aspect". In: The Function of Tense in Texts. Eds. J. Gvozdanović, Th.A.J.M. Janssen and Ö. Dahl. Amsterdam/New York 1991, 99-123.

Galmiche, Phrases génériques-M. Galmiche, "Phrases, syntagmes et articles génériques". In: Langages 79 (1985), 2-39.

Garciá, Grasping the Nettle-E. Garciá, "Grasping the Nettle: Variation as Proof of Invariance". In: New Vistas in Grammar: Invariance and Variation. Eds. L.R. Waugh and S. Rudy. Amsterdam/Philadelphia 1991, 31-59

Gaudefroy-Demombynes and Blachère, Grammaire de l'arabe-M. Gaudefroy-Demombynes and R. Blachère, Grammaire de l'arabe classique ${ }^{3}$. Paris 1952.

Genette, Narrative Discourse-G. Genette, Narrative Discourse: An Essay in Method. Translated by J.E. Lewin. Ithaca 1980.

Genette, Fictional/Factual-G. Genette, "Fictional Narrative, Factual Narrative". In: Poetics Today 11:4 (1990), 755-774.

Gibb, Arabic Literature-H. Gibb, Arabic Literature: An Introduction ${ }^{2}$. Oxford 1963.

Giolfo, Yaqum vs. Qāma-M.E.B. Giolfo, "Yaqum vs. qāma in the Conditional Context: A Relativistic Interpretation of the Frontier between the Prefixed and the Suffixed Conjugations of the Arabic Language". In: The Foundations of Arabic Linguistics: Sibawayhi and Early Arabic Grammatical Theory. Ed. A.E. Marogy. Leiden 2012, 135-160.

Givón, Definiteness and Referentiality - T. Givón, "Definiteness and Referentiality". In: Universals of Human Languages, IV: Syntax. Ed. J.H. Greenberg. Stanford 1978, 293330. 
Givón, Syntax-T. Givón, Syntax: An Introduction ${ }^{2}$. 2 vols. Amsterdam/Philadelphia 2001.

Givón, Beyond Foreground - T. Givón, "Beyond Foreground and Background". In: Coherence and Grounding in Discourse. Ed. R.S. Tomlin. Amsterdam/Philadelphia 1987, $175^{-188 .}$

Goldenberg, Amharic Tense System-G. Goldenberg, The Amharic Tense-System. Jerusalem 1966 [unpublished dissertation, in Hebrew].

Goldenberg, Verbal Structure - G. Goldenberg, "On Verbal Structure and the Hebrew Verb”. In: Language Studies, 1. Jerusalem 1985, 295-348 [in Hebrew; English translation in: Studies in Semitic Linguistics. Jerusalem 1998, 148-196].

Goldenberg, Contribution of Semitic Languages - G. Goldenberg, "The Contribution of Semitic Languages to Linguistic Thinking". In: Jaarbericht van het VooraziatischEgyptisch Genootschap Ex Oriente Lux. Leiden 1987-1988, 107-115 [= Studies in Semitic Linguistics. Jerusalem 1998, 1-9].

Goldenberg, Predicative Adjectives-G. Goldenberg, "On Predicative Adjectives and the Syriac Verb”. In: Bibliotheca Orientalis 48 (1991), 716-726 [= Studies in Semitic Linguistics. Jerusalem 1998, 579-590].

Goldenberg, Allad̄ī al-Mașdariyyah-G. Goldenberg, "Allad̄ī al-Mașdariyyah in Arab Grammatical Tradition". In: Zeitschrift für arabische Linguistik 28 (1994), 7-35 [= Studies in Semitic Linguistics. Jerusalem 1998, 250-285].

Goldenberg, Compound Verbs-G. Goldenberg, "The Structure of Compound TenseForms". Igeret 18 (2000), 15-17 [in Hebrew].

Goldenberg, Verbal Agreement-G. Goldenberg, "On Grammatical Agreement and Verb-Initial Sentences". In: Loquentes linguis: Studi linguistici e orientali in onore di Fabrizio A. Pennacchietti. Eds. P.G. Borbone, A. Mengozzi and M. Tosco. Wiesbaden 2006, 333-339.

Goldenberg, Semitic Languages-G. Goldenberg, Semitic Languages: Features, Structures, Relations, Processes. Oxford 2013.

Götz, Tempora-M. Götz, "Bemerkungen zu den Tempora des Althocharabischen". In: Studien aus Arabistik und Semitistik: Anton Spitaler zum siebzigsten Geburtstag von seinen Schülern überreicht. Eds. W. Diem and S. Wild. Wiesbaden 1980, 8698.

Grimes, Thread of Discourse - J.E. Grimes, The Thread of Discourse. The Hague 1975.

Guillaume, Immanence et transcendence-G. Guillaume, "Immanence et transcendence dans la categorie du verbe". In: Langage et science du langage. Paris 1964 , $46-58$.

Guillaume, Particularisation et generalisation-G. Guillaume, "Particularisation et generalization dans le système des articles français". In: Langage et science du langage. Paris 1964, 143-156.

Haiman and Thompson, "Subordination"-J. Haiman and S.A. Thompson, "'Subordi- 
nation' in Universal Grammar". In: Proceedings of the Berkeley Linguistics Society 10 (1984), 510-523.

Halliday and Hasan, Cohesion-M.A.K. Halliday and R. Hasan, Cohesion in English. London 1976.

Halliday, Text as Semantic Choice-M.A.K. Halliday, "Text as Semantic Choice in Social Contexts". In: Grammars and Descriptions: Studies in Text Theory and Text Analysis. Eds. T.A. van Dijk and J.S. Petöfi. Berlin/New York 1977, 176-225.

Halliday, Functional Grammar-M.A.K. Halliday, An Introduction to Functional Grammar $^{2}$. London 1994.

Halliday, Transitivity - M.A.K. Halliday, "Notes on Transitivity and Theme in English (Part 2)". In: Journal of Linguistics 3:2 (1967), 199-244.

Hamburger, Logic-K. Hamburger, The Logic of Literature ${ }^{2}$. Translated by M.J. Rose. Bloomington/London 1973.

Hansen, Syntax in Interaction-M.-B.M. Hansen, "Syntax in Interaction. Form and Function of Yes/No-Interrogatives in Spoken Standard French". In: Studies in Language 25:3 (2001), 463-520.

Hasan, Systemic-Functional Model-R. Hasan, "Text in the Systemic-Functional Model". In: Current Trends in Textlinguistics. Ed. W.U. Dressler. Berlin/New York 1978, 228246.

Haspelmath, Converb-M. Haspelmath, "The Converb as a Cross-Linguistically Valid Category". In: Converbs in Cross-Linguistic Perspective: Structure and Meaning of Adverbial Verb Forms-Adverbial Participles, Gerunds. Eds. M. Haspelmath and E. König. Berlin 1995, 1-55.

Hawkins, Definiteness - J.A. Hawkins, Definiteness and Indefiniteness: A Study in Reference and Grammaticality Prediction. London 1978.

Henkin, Cognate Curse - R. Henkin, "The Cognate Curse in Negev Arabic: From Playful Punning to Coexistence Conflicts". In: Israel Studies in Language and Society 2:2 (2009), 169-206.

Herrnstein Smith, Narrative Versions - B. Herrnstein Smith, "Narrative Versions, Narrative Theories". In: On Narrative. Ed. W.T.J. Mitchell. Chicago 1981, 209-232.

Hinds, Organizational Patterns - J. Hinds, "Organizational Patterns in Discourse". In: Syntax and Semantics 12: Discourse and Syntax. Ed. T. Givón. New York 1979, 135157 .

Hjelmslev, Prolegomena -L. Hjelmslev, Prolegomena to a Theory of Language. Translated by F.J. Whitfield. Madison 1969.

Holes, Modern Arabic_-C. Holes, Modern Arabic: Structures, Functions, and Varieties ${ }^{2}$. Washington, D.C. 2004.

Hopper, Aspect and Foregrounding - P.J. Hopper, "Aspect and Foreground in Discourse". In: Syntax and Semantics 12: Discourse and Syntax. Ed. T. Givón. New York 1979, 213241. 
Hopper, Emergent Grammar-P.J. Hopper, "Emergent Grammar and the a priori Grammar Postulate". In: Linguistics in Context: Connecting Observation and Understanding. Ed. D. Tannen. Norwood, NJ 1988, 117-134.

Hopper and Thompson, Transitivity-P.J. Hopper and S.A. Thompson, "Transitivity in Grammar and Discourse". In: Language 56:2 (1980), 251-299.

Hymes, Foundations - D. Hymes, Foundations in Sociolinguistics: An Ethnographic Approach. Philadelphia 1974.

Ibn al-'Anbārī, 'Asrār-'Abū al-Barakāt 'Abd al-Raḥmān b. Muhammad al-'Anbārī, 'Asrār al-'Arabiyya. Ed. C.F. Seybold. Leiden 1886.

Ibn al-Sarrāğ, 'Ușūl-_Abū Bakr Muḥammad Ibn al-Sarrāğ, Kitāb al-'Ușūl fí al-naḥw . 3 vols. Ed. 'Abd al-Husayn al-Fatlī. Beirut 1987.

Ibn Yačǐš, Šarḥ al-Mufașșal-Muwaffaq al-Dīn 'Abū al-Baqā’ Ya'ī̌s Ibn Ya'ī̌s, Šarh alMufașsal lil-Zamaḩ̌šrī. 6 vols. Ed. Emīl Badī‘ Ya'qūb. Beirut 2001.

Isaksson, Circumstantial Qualifiers-B. Isaksson (ed.), Circumstantial Qualifiers in Semitic: The Case of Arabic and Hebrew. Wiesbaden 2009.

Jacobsson, Notes on Genericity-B. Jacobsson, "Note on Genericity and Article Usage in English". In: Studia Neophilologica 69 (1997), 139-153.

Jakobson, Shifters - R. Jakobson, "Shifters, Verbal Categories and the Russian Verb". In: Selected Writings 2: Word and Language. The Hague/Paris 1971, 130-147.

Jakobson, Closing Statement-R. Jakobson, "Closing Statement: Linguistics and Poetics”. In: Style in Language. Ed. T.A. Sebeok. Cambridge, Mass. 1960, 350-377.

Janssen, Preterit as Definite-Th.A.J.M. Janssen, "Preterit as Definite Description". In: The Function of Tense in Texts. Eds. J. Gvozdanović, Th.A.J.M. Janssen and Ö. Dahl. Amsterdam/New York 1991, 157-181.

Jespersen, Philosophy - O. Jespersen, The Philosophy of Grammar. London 1924. Jespersen, Modern English-O. Jespersen, A Modern English Grammar on Historical Principles. 7 vols. London 1961.

Khan, Studies - G. Khan, Studies in Semitic Syntax. Oxford 1988.

Kinberg, Qad-N. Kinberg, "Some Modal, Aspectual and Syntactic Constraints on the use of qad in the Verbal System of Classical Arabic". In: Studia Linguistica et Orientalia Memoriae Haim Blanc Dedicata. Eds. P. Wexler, A. Borg and S. Somekh. Wiesbaden 1989, 170-179.

Kleiber, Phrases habituelles-G. Kleiber, Du côté de la reference verbale: les phrases habituelles. Berne 1987.

Koch, Simple Forms - W.A. Koch (ed.), Simple Forms: An Encyclopedia of Simple TextTypes in Lore and Literature. Bochum 1994.

König, Converb Constructions - E. König, "The Meaning of Converb Constructions". In: Converbs in Cross-Linguistic Perspective: Structure and Meaning of Adverbial Verb Forms-Adverbial Participles, Gerunds. Eds. M. Haspelmath and E. König. Berlin 1995, 57-95. 
König and Siemund, Speech Act-E. König and P. Siemund, "Speech Act Distinctions in Grammar". In: Language Typology and Syntactic Description. Volume I: Clause Structure $^{2}$. Ed. T. Shopen. Cambridge 2007, 276-324.

Krifka, Genericity - M. Krifka et al., "Genericity: An Introduction”. In: The Generic Book. Eds. G.N. Carlson and F.J. Pelletier. Chicago/London 1995, 1-124.

Kuryłowicz, Studies in Semitic - J. Kuryłowicz, Studies in Semitic Grammar and Metrics. London 1973 .

Labov and Waletzky, Narrative Analysis - W. Labov and J. Waletzky, "Narrative Analysis: Oral Versions of Personal Experience". In: Essays on the Verbal and Visual Arts. Ed. J. Helms. Seattle 1967, 12-44.

Larcher, Le "segmentateur"-P. Larcher, "Le 'segmentateur' fa-('inna) en arabe classique et modern”. In: Kervan 3 (2006), 51-63.

Leder, Conventions - S. Leder, "Conventions of Fictional Narration in Learned Literature”. In: Story-telling in the Framework of Non-fictional Arabic Literature. Ed. S. Leder. Wiesbaden 1998, 34-6o.

Leder and Kilpartik, Classical Arabic Prose-S. Leder and H. Kilpatrik, "Classical Arabic Prose Literature: A Researchers' Sketch Map”. In: Journal of Arabic Literature 23:1 (1992), 2-26.

Lehmann, Clause Linkage-C. Lehmann, “Toward a Typology of Clause Linkage". In: Clause Combining in Grammar and Discourse. Eds. J. Haiman and S.A. Thompson. Amsterdam/Philadelphia 1988, 181-225.

Levin, kāna-A. Levin, "Sībawayhi's View of the Syntactic Structure of kāna wa'ahawātuhā". In: Jerusalem Studies in Arabic and Islam 1 (1979), 185-213.

Levin, Nominal and Verbal Sentences-A. Levin, "The Distinction between Nominal and Verbal Sentences according to the Arab Grammarians". In: Zeitschrift für arabischen Linguistik 15 (1985), 118-127.

Levin, Kalima -A. Levin, "The Medieval Arabic Term kalima and the Modern Linguistic Term Morpheme: Similarities and Differences". In: Studies in Islamic History and Civilization in Honor of Professor David Ayalon. Ed. M. Sharon. Jerusalem 1986, 423-446.

Levin, Spoken Language - A. Levin, "Sībawayhi's Attitude to the Spoken Language". In: Jerusalem Studies in Arabic and Islam 17 (1994), 204-243.

Levin, Amal - A. Levin, "The Fundamental Principles of the Arab grammarians' Theory of 'amal". In: Jerusalem Studies in Arabic and Islam 19 (1995), 214-232.

Levinson, Pragmatics — S.C. Levinson, Pragmatics. Cambridge 1983.

Lyons, Semantics - J. Lyons, Semantics. 2 vols. Cambridge 1977.

Lyons, Deixis and Subjectivity - J. Lyons, “Deixis and Subjectivity: Loquor ergo sum?". In: Speech, Place, and Action: Studies in Deixis and Related Topics. Eds. R.J. Jarvella and W. Klein. Chichester/New York 1982, 101-124.

Marmorstein, 'Inna-Sentences-M. Marmorstein, 'Inna-Sentences in Classical Arabic. Jerusalem 2008. [unpublished M.A. thesis, in Hebrew]. 
Marmorstein, Review of Waltisberg - M. Marmorstein, "Michael Waltisberg. Satzkomplex und Funktion: Syndese und Asyndese im Althocharabischen". In: Jerusalem Studies in Arabic and Islam 38 (2011), 361-390.

Marmorstein, Verbal Generics-M. Marmorstein, "On Verbal Generic Sentences in Classical Arabic". In: Labor omnia vincit improbus. Miscellanea in Honorem Ariel Shisha-Halevy. Louvain, 1-23, Forthcoming.

Matthiessen and Thompson, Discourse and Subordination-C. Matthiessen and S.A. Thompson, "The Structure of Discourse and 'Subordiantion'”. In: Clause Combining in Grammar and Discourse. Eds. J. Haiman and S.A. Thompson. Amsterdam/Philadelphia 1988, 275-329.

Ter Meulen, Generic Information-A. ter Meulen, "Generic Information, Conditional Contexts and Constraints". In: On Conditionals. Eds. E.C. Traugott et al. Cambridge 1986, pp. 123-145.

Monville-Burston and Waugh, Multiple Meanings-M. Monville-Burston and L.R. Waugh, "Multiple Meanings in Context: The French Present Tense". In: The Function of Tense in Texts. Eds. J. Gvozdanović, Th.A.J.M. Janssen and Ö. Dahl. Amsterdam/New York 1991, 183-196.

Mosel, Syntaktische Terminologie-U. Mosel, Die syntaktische Terminologie bei Sibawaih. München 1975 .

al-Mubarrad, Muqtaḍab -'Abū al-'Abbās Muḥammad b. Yazīd al-Mubarrad, Kitāa alMuqtaḍa. 4 vols. Ed. Muhammad 'Abd al-Ȟāliq 'Uḍayma. Cairo 1965-1968.

Mumm, Verbale Definitheit-P.-A. Mumm, "Verbale Definitheit und der vedische Injunktiv". In: Verba et Structurae: Festschrift Strunk. Eds. H. Hettrich et al. Innsbruck 1995, 169-193.

Narrog, (Inter)subjectification-H. Narrog, "(Inter)subjectification in the Domain of Modality and Mood-Concepts and Cross-Linguistic Realities". In: Subjectification, Intersubjectification and Grammaticalization. Eds. K. Davidse, L. Vandelanotte and H. Cuyckens. Berlin 2010, 385-429.

Nebes, Kāna Yaf'alu-N. Nebes, Funktionsanalyse von kāna yaf'alu: Ein Beitrag zur Verbalsyntax des Althocharabischen mit besonderer Berücksichtigung der Tempusund Aspektproblematik. Hildesheim 1982.

Nebes, Satzschema - N. Nebes, "Das Satzschema fa-huwa yaf'alu/fāilun/Prädikativ für Vergangenheit in frühklassischer arabishcer Erzählliteratur”. In: Tempus und Aspekt in den semitischen Sprachen. Ed. N. Nebes. Wiesbaden 1999, 77-100.

Nebes, Inzidenzschema-N. Nebes, "Das Inzidenzschema im Klassischen Arabischen. Ein Vorbericht”. In: Sachverhalt und Zeitbezug: Semitistische und alttestamentliche Studien Adolf Denz zum 65. Geburtstag. Eds. R. Bartelmus and N. Nebes. Wiesbaden 2001.

Niccacci, Syntax of the Verb-A. Niccacci, The Syntax of the Verb in Classical Hebrew Prose. Translated by W.G.E. Watson. Sheffield 1990. 
Nöldeke, Zur Grammatik—Th. Nöldeke, Zur Grammatik des Classischen Arabisch. Im Anhang: Die handschriftlichen Ergänzungen in dem Handexemplar Theodor Nöldekes, bearbeitet und mit Zusätzen versehen von Anton Spitaler. Darmstadt 1963.

Oomen, Texts and Sentences-U. Oomen, "Texts and Sentences". In: Text vs. Sentence: Basic Questions of Text Linguistics, 1. Ed. J.S. Petöfi. Hamburg 1979, 272-28o.

Owens, House of Sound Structure - J. Owens, "A House of Sound Structure, of Marvelous Form and Proportion: An Introduction". In: The Oxford Handbook of Arabic Linguistics. Ed. J. Owens. Oxford 2013, 1-22.

Palmer, Mood and Modality -F.R. Palmer, Mood and Modality². Cambridge 2001.

Peled, Conditional Structures-Y. Peled, Conditional Structures in Classical Arabic. Wiesbaden 1992.

Petöfi, Beyond the Sentence — J.S. Petöfi, "Beyond the Sentence: Between Linguistics and Logic". In: Style and Text: Studies Presented to Nils Erik Enkvist. Stockholm 1975, 377390.

Petöfi, Text vs. Sentence-J.S. Petöfi (ed.), Text vs. Sentence: Basic Questions of Text Linguistics, 1. Hamburg 1979.

Premper, "Zustandssätze"-W. Premper, Die "Zustandssätze" des Arabischen in typologischer Perspektive. Frankfurt am Main 2002.

Rabin, Ancient West-Arabian, Ch. Rabin, Ancient West-Arabian. London 1951.

Raible, Junktion -W. Raible, Junktion: Eine Dimension der Sprache und ihre Realisierungsformen zwischen Aggregation und Integration. Heidelberg 1992.

Ramsay, Functional Distribution-V. Ramsay, "The Functional Distribution of Preposed and Postposed 'if' and 'when' Clauses in Written Discourse". In: Coherence and Grounding in Discourse. Amsterdam/Philadelphia 1987, 383-408.

Reckendorf, Syntaktischen Verhältnisse-H. Reckendorf, Die syntaktischen Verhältnisse des Arabischen. Leiden 1895-1898.

Reckendorf, Zum Gebrauch des Partizips-H. Reckendorf, "Zum Gebrauch des Partizips im Altarabischen". In: Orientalische Studien: Theodor Nöldeke zum siebzigsten Geburtstag gewidmet von Freunden und Schülern, 1. Ed. C. Bezold. Gieszen 1906, 255265 .

Reckendorf, Arabische Syntax-H. Reckendorf, Arabische Syntax. Heidelberg 1921 (reprint 1977).

Reuschel, Aspekt und Tempus-W. Reuschel, Aspekt und Tempus in der Sprache des Korans. Frankfurt am Main 1996.

Rothstein, Structuring Events - S. Rothstein, Structuring Events: A Study in the Semantics of Lexical Aspect. Malden, MA 2004.

Ryding, Modern Standard Arabic - K.C. Ryding, A Reference Grammar of Modern Standard Arabic. Cambridge 2005.

De Sacy, Grammaire arabe-A.S. de Sacy, Grammaire arabe a l'usage des élèves de l'école special des langues orientales vivantes ${ }^{2}$. Paris 1831 . 
Sadan, Ğawāb-A. Sadan, "The Meaning of the Technical Term ğawāb in Arabic Grammar". In: Jerusalem Studies in Arabic and Islam 37 (2010), 129-137.

Sadan, Subjunctive Mood-A. Sadan, The Subjunctive Mood in Arabic Grammatical Thought. Leiden 2012.

Sakaedni, Laysa-H. Sakaedani, "A Comparison between the Usage of laysa in the Qur'ān and laysa in Sībawayhi's Kitāb". In: The Foundations of Arabic Linguistics: Sībawayhi and Early Arabic Grammatical Theory. Ed. A.E. Marogy. Leiden 2012, 161172.

Sasse, Theory of Aspect-H.-J. Sasse, "Recent Activity in the Theory of Aspect: Accomplishments, Achievements, or just Non-progressive State?”. In: Linguistic Typology 6 (2002), 199-271.

De Saussure, Cours-F. de Saussure, Cours de linguistique générale. Édition critique préparée par Tullio de Mauro. Paris 1972.

Schegloff and Sacks, Opening up Closings —E. Schegloff and H. Sacks, "Opening up Closings". In: Semiotica 7 (1973), 289-327.

Schiffrin, Discourse Markers —D. Schiffrin, Discourse Markers. Cambridge 1987.

Schiffrin, Conditionals as Topics - D. Schiffrin, "Conditionals as Topics in Discourse". In: Linguistics 30:1 (1991), 165-197.

Schiffrin, Approaches -D. Schiffrin, Approaches to Discourse. Oxford 1994.

Shisha-Halevy, Coptic Grammatical Categories-A. Shisha-Halevy, Coptic Grammatical Categories: Structural Studies in the Syntax of Shenoutean Sahidic. Rome 1986.

Shisha-Halevy, Structural Sketches-A. Shisha-Halevy, "Structural Sketches of Middle Welsh Syntax (I)". In: Studia Celtica 29 (1995), 127-223.

Shisha-Halevy, Topics - A. Shisha-Halevy, Topics in Coptic Syntax: Structural Studies in the Bohairic Dialect. Leuven 2007.

Sībawayhi, Kitāb-'Abū Bišr 'Amr b. 'Uțmān Sībawayhi, Kitāb Sübawayhi. Le livre de Sîbawaihi: Traité de grammaire arabe. 2 vols. Ed. H. Derenbourg. Paris 18811889.

al-Sīrāfî, Šarh Kitāb-’Abū Sa'īd al-Sīrāfī, Šarh Kitāb Sübawayhi. 5 vols. Eds. 'Ahmmad Hasan Mahdalī and 'Alī Sayyid 'Alī. Beirut 2008.

Stanzel, Theory of Narrative-F.K. Stanzel, A Theory of Narrative. Translated by Ch. Goedsche. Cambridge 1984.

al-Suyūṭ̂̀, Ham' - Ǧalāl al-Dīn 'Abd al-Raḥmān b. 'Abī Bakr al-Suyūṭī, Ham'al-hawāmic fı̌ šarḥ̆Ğam'al-ğawāmi'. 7 vols. Eds. 'Abd al-Salām Muhạmmad Hārūn and 'Abd al-'Āl Sālim. Beirut 1992.

Tannen, Talking Voices - D. Tannen, Talking Voices: Repetition, Dialogue and Imagery in Conversational Discourse. Cambridge 1989.

Taylor, Proverb - A. Taylor, The Proverb. Cambridge, Mass. 1931.

Testen, Asseverative la-D. Testen, Asseverative la- in Arabic and Related Semitic Particles. Chicago 1995. 
Toolan, Narrative - M. Toolan, Narrative: A Critical Linguistic Introduction ${ }^{2}$. London/ New York 2001.

Troupeau, Lexique-index-G. Troupeau, Lexique-index du "Kitāb" de Sïbawayhi. Paris 1976.

Vachek, The Linguistic School-J. Vachek, The Linguistic School of Prague: An Introduction to its Theory and Practice. Bloomington/London 1966.

Van Valin, Syntactic Relations - R.D. Van Valin, "A Typology of Syntactic Relations in Clause Linkage". In: Proceedings of the Berkeley Linguistics Society 10 (1984), 542-558.

Versteegh, Greek Elements-C.H.M. Versteegh, Greek Elements in Arabic Linguistic Thinking. Leiden 1977.

Waltisberg, Satzkomplex-M. Waltisberg, Satzkomplex und Funktion: Syndese und Asyndese im Althocharabischen. Wiesbaden 2009.

Waugh, Marked and Unmarked-L.R. Waugh, "Marked and Unmarked: A Choice between Unequals in Semiotic Structure". In: Semiotica 38:3/4 (1982), 299-318.

Waugh, Introduction - L.R. Waugh, "Introduction". In: New Vistas in Grammar: Invariance and Variation. Eds. L.R. Waugh and S. Rudy. Amsterdam/Philadelphia 1991, 1-7. Waugh, Tense-Aspect-L.R. Waugh, "Tense-Aspect and Hierarchy of Meanings: Pragmatic, Textual, Modal, Discourse, Expressive, Referential". In: New Vistas in Grammar: Invariance and Variation. Eds. L.R. Waugh and S. Rudy. Amsterdam/Philadelphia 1991, 241-259.

Wehr, Arabischer Negationen-H. Wehr, "Zur Funktion arabischer Negationen". In: Zeitschrift der Deutschen Morgenländischen Gesellschaft 103 (1953), 27-39.

Weinrich, Tense and Time-H. Weinrich, "Tense and Time". In: Archivum Linguisticum NS 1 (1970), 31-41.

Weinrich, Tempus-H. Weinrich, Tempus. Besprochene und erzählte Welt ${ }^{2}$. Stuttgart 1971.

Weiss, Parts of Speech-B. Weiss, "A Theory of the Parts of Speech in Arabic (Noun, Verb and Particle): A Study in 'Ilm al-Wa ${ }^{\prime \prime " . ~ I n: ~ A r a b i c a ~} 23$ (1976), 23-36.

Wilmet, Contre la généricite-M. Wilmet, “Contre la généricité". In: Lingua 75 (1988), 231-250.

Wright, Grammar -W. Wright, A Grammar of the Arabic Language ${ }^{3} .2$ vols. 1896-1898 (reprint 2004).

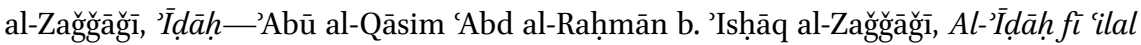
al-naḥw. Ed. Māzin al-Mubārak. Cairo 1959.

al-Zamahšarī, Mufașşal-'Abū al-Qāsim Maḥmūd b. 'Umar al-Zamahš̌arī, Al-Mufașșal, opus de re grammatica Arabicum. Ed. J.P. Broch. Christiania 1879. 


\section{Index}

'a 87, 189-190

a-temporality 195,196

Aartun, K. 38

Abboud, P. 135

absolute tenses $\quad 45$

action verbs 165,205

actual present $\quad 224-225$

actuality $\quad 162$

'adab $\quad 16$

adjacency, pairs 49

adjacency, temporal $\quad 115^{-116,117}$

adjectival clauses $\quad 78-79,85$

verbal forms in $96-115,118,237$

adjectives 126,128

adverbial clauses $\quad 53-54,85,151$

verbal forms in $115^{-117}, 118,15^{2}$

agent nouns $\quad 28-31,32-33$

aggregation 53

agreement, grammatical $\quad 82-83$

Aktionsart $5^{8}$

'ammā 87, 88, 109, 224

'an 69

anaphoric grounding $\quad 216$

'anna clauses $85,88,141$

verbal forms in $90-96$

anteriority

with fa'ala $\quad 92,102,107-108,168,172,190$, 192, 216, 236, 237

in kāna-clauses/compounds $\quad 69,94,99$, 103-104, 109, 129

with qad $\quad 125,129,170,172$

aorist tense 35

apocopate forms $70,72,73$

apodosis $\quad 151$

appointment expressions 139

Arabic see Classical Arabic

argumentative clauses $\quad$ 173-175 $^{-175}$

argumentative function $\quad 161$

aspect

grammatical and lexical $\quad 58-59$

Arabic 22, 36-39

of verbal forms $120,156,157,162-163,193$,

237

aspectual asymmetry $\quad 218$

assertorial 169n12, 170, 190

asseverative clauses $\quad 175^{-177,179,180}$
al-'Astarābād̄ī, Raḍī al-Dīn Muhammad b. al-

Ḥasan 22, 23-24

asyndesis/asyndetic clauses $\quad 78,79-80$

adjectival 96, 100-105

circumstantial 146

see also syndetic clauses

attributes 128,139

verbal 156

attributive clauses $\quad 79$

authors

implied 210n3o

see also narrators

autonomous meanings/grammatical systems 5

auxiliary verbs $\quad 61,62,68-69,123-131$

see also kāna (compounds)

'ahbār 17, 197

'ayna/'ayy 87

background forms $\quad 52,129,146,195 \mathrm{n} 6,208$ $213,220,238$

Bahloul, M. $\quad 38-39,169 n 12$

baynā/baynamā-clauses $\quad 87,116-117,15^{2-154}$, $156,215^{-217}$

Beaugrande, R. de $41 \mathrm{n}_{5}$

Beeston, A.F.L. $\quad 38,57,64 n 3,91 n 5,116$

belles lettres $\quad 15^{-16}$

Benveniste, E. 46n2o, 48n29, 5on36, 195

bi- 74,181

Biblical Hebrew $\quad$ 196, 203-204

bidirectional clauses see mutual dependency

bina $\bar{a}^{\prime}$ (no-declension) $\quad 24-26$

binary oppositions

semantic $\quad 5,6$

in verb system of Semitic languages $\quad 2-3$, $35^{-}-38,39$

Binnick, R.I. 4

bipartite constructions $\quad 54-55$

Blachère, R. $\quad 37$

blessings $184,185,186$

Bloch, A.A. $\quad 154 n 48$

Bonebakker, S.A. $\quad 16 \mathrm{n} 28$

bounding 59, 91-92, 236

Brockelmann, C. $\quad 32,33 n 59,35,36,37$

Brown, G. 9 nn2o 
Bubenik, V. $\quad 39 n 28$

Bühler, K. 46n19

Bybee, J. 71n21, 165ng, 171n13

Carter, M.G. $\quad 27,28,31,32$

cataphoric grounding $\quad 216$

causal $\quad 170-171,175$

certainty $37,104,106,111,186 \mathrm{n} 28$

chains 76

in narratives 198, 204

positions in

of clauses $\quad 54-55,77,78$

of verbal forms 204, 208

Chomsky, N. $41 \mathrm{n} 6$

circumstantial clauses $\quad 135,145^{-150,153,155}$

in narratives $197,210-211,213,215$

Classical Arabic 1-4, 13-14, 234

poetry 14

prose $11,14-18$

see also grammars/grammarians, Arabic

clauses 9,47

complex 109, 119-121

dependency status of $\quad 52-56,76-77,78$, 121n5, 209-211, 213, 235

mutually dependent $\quad 77,151-155,197$

linking of $\quad 78-81,120,140,146-147,198$

operators $83-88$

patterns of $149,150,152,163,190,216,224$

position in chain $\quad 54-55,77,78$

types of $\quad 56-58,82,235$

adjectival $78-79,85,96-115,118,237$

adverbial $53^{-54}, 85,115^{-117}, 118,151$,

152

argumentative $\quad 173^{-175}$

asseverative $\quad 175^{-177}$

asyndetic $\quad 78,79-80$

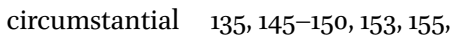

197, 210-211, 213, 215

complement 141, 214

conditional $\quad 15^{1-15^{2}}$

content (substantival) $\quad 85,90-95,118$

declarative 161-182

embedded $52,53-54,55-56,77,78$,

$84-86,88,89-118,236-237$

final 135,137

free $209-210$

generic $89,97-98,104-105,107,113$,

218-220, 222-223, 224-233

normative $222,233,238$ interrogative $188-192,230$

negative $\quad 177^{-182}$

nominal $57-58,82-83,190,224$

optative $\quad 185^{-188}$

performative $182-185$

presentative $87,154-155,156,214-215$, $217-218$

setting $152-154,156,214-217$

simple 56,76

temporal $115^{-117}, 215^{-217}$

verbal $\quad 56-58,82,224$

cognitive verbs 165,179

Cohen, D. 37

Cohen, E. $\quad 151 n 40,176$

Cohen, M. 37

cohesion, in discourse 160

coincidence $\quad 115^{-116}, 120,135^{-136,} 237$

comment mode $\quad 208-209$

commutation 56

completion expressions $\quad 98,103-104,125,129$, 135,170

complex signs $\quad 9,10$

complex verbal forms see compound verb forms

components 9

compound verb forms $\quad 61,68-71,99,103$, 109-110, 114-115, 121-123, 155, 235

modifying 131-134, 235

in narratives $\quad 200-202,206-207$

negated 75

see also kāna (compounds)

Comrie, B. 5, 39, 44n17

concomitant $112,147,148$

concurrence

with fáala $\quad 168-169$

negated $94-95,104,178-179$

with participles $172,173,236$

with yaf'alu 93, 97, 100-101, 105-106, 107, $111,164,166-167,172,184,185,190,236$

conditionals/conditional clauses $\quad 69-70$, $15^{-1}-15^{2}$

conjugations $\quad 62-63,186 \mathrm{n} 28$

conjunctive pronouns $\quad 96$

consequential 105, 117, 204, 237, 238

context 11, 41-43

analysis of 239

structure of 43,60

contextual meanings $\quad 4,6,7$

contextualization, of classical texts

$43-44$ 
continuation $\quad$ 133-134

contrastive relation 147

converbs 119n2

conversation $\quad 158-159$

coordination $\quad 5^{2-53}, 84$

coreferentiality $\quad 115 \mathrm{n} 18$

Cours de linguistique générale, (Saussure) 8

curses $\quad 184-185,187$

declaration verbs $\quad 183$

declarative-performatives $\quad 184,185$

declension

of Arabic words 24-27

and resemblance $\quad 31^{-32}$

Declerck, R. $\quad{ }_{115} \mathrm{n} 18$

declinability see declension

deictic reference $\quad 44-46,197,221,235$

Denz, A. 38

deontic modality $\quad 71-72$

dependency status of clauses $\quad 5^{2-56,76-77}$, 78, 121n5, 209-211, 213, 235

mutually dependent $\quad 77,151^{-155}, 197$

descriptions $215 \mathrm{n}^{2}$

background 212-213

descriptive function 37,161

desiderative verbs 95

destination $81,134,136,139,198$

dialects, Arabic $\quad 13^{-14}$

dialogues 48-49, 50, 158-161

verbal forms in $192-193,237-238$

see also discourse

diegetic devices 214

direct speech $\quad 205^{-206,228}$

subjectivity in 46

discourse analysis 8

discourse

cohesion in 160

deictic center of 44

structure of 59

types of 46,196

see also dialogues

dissociation 181

DMG (Deutsche Morgenländische Gesellschaft) transcription system 19

Ducrot, O. 212n31

duration 131, 133-134

dynamic lexemes $\quad 98,102,107-108,112-113$, 114-115, 124, 137, 166, 167, 168, 169, 180, 190, 192 egocentric nature of dialogue $\quad 160,163$

Egypt $13 n 23$

elements 9

embedding/embedded clauses $\quad 52,53-54$, $55^{-} 56,77,78,89$

operators of $84-86,88$

verbal forms in $89-118,236-237$

see also non-embedded clauses

emphasis/emphatic meanings $67,175^{-176}$, 178

epic fiction $\quad 45 \mathrm{n} 18$

episodic 223, 228-229, 231, 233, 238

evaluation 211

events $221 \mathrm{n} 2$

in background $\quad 211-213$

narrated 198

eventive 209, 211-213

fáala 153n45, 168, 200

non-eventive 209, 211, 225

Ewald, H. $\quad 35,36$

explicative clauses $\quad 174,175$

expository clauses 173

expository discourse see generic utterances

expressive functions/expressivity $\quad 215^{\mathrm{n}} 32$,

217

of dialogue $\quad 159^{-160}$

of 'inna-clauses $\quad 175$

of interrogatives 188

of narratives 197

extension 226ni3

$f a-\quad 80-81,109,146,151-152 n 43,198,208$

fáala 203

yaf'ala 208

yaf'alu $\quad 202-208$

facala verb form $\quad 11,21,25 \mathrm{n} 28,32,57,62,69-$ $70,73,83,90,156-157,235,236,238-239$ in compound with kāna $\quad 98,99,103,109$, 114-115, 129-131, 212, 235

in dialogues $\quad 168-169,172,173-175,183$, $184,185^{-187}, 190$

in embedded clauses $\quad 91-92,94,95,98$, 102-103, 107-108, 112-114, 116, 237

in generic clauses $\quad 228-229,230-231,233$, 238

meanings of $98,117,120-121,161-162$

modified forms of 66,67

in narratives $168,196-197,198-208,212$, $215^{-216}, 217,218-219,220,238$ 
negated forms of $74,145,178,180-181,192$, 229-230

predicative form of $134,135,139,144,151^{-}$

$152,155,156,237$

and yaf'alu form $\quad 2-4,39-40,156,239$

fäilan verb form

in compound with kāna $109,126-128$, 212, 213, 235

in narratives $\quad 200-202,212,213,220,238$

fãilun verb form $108,155,156,171-172,173$, 177, 235

fä ilVn verb form $\quad 90-91,120,236,237,238-$ 239

featural oppositions $\quad 10$

fiction 46n21, 5on36, 195-196, 197

fil see verbs

finality expressions $\quad 137,139$

Firth, J.R. 4106

Fleisch, H. $\quad 37-38$

Fleischer, H.L. $\quad 36$

Fleischman, S. 6-7n14, 42-43, 5on37, 165ng, 194, 196, 215n34, 219-220

focus $86,154 \mathrm{n} 45,176-177,227$

focus particle $88,130,224$

foreground forms $\quad 52,146,195 \mathrm{n} 6$

French, verbal system in $6 n 13$

frequentative $97-98,99,123-124,225,226-$ $227,230-231$

friendliness 186

future tense $\quad 21-22,32,165 \mathrm{ng}, 177$ and present tense $\quad 23-24$

futurity $91,98,101-102,103,106-107,108,110$, 111, 114, 164-166, 167, 171, 177, 191

ğa'ala 131-132

al-Ğāhiz $\quad$ 197, 219

Galmiche, M. 223

García, E. $\quad 5$ n8

Gaudefroy-Demombynes, M. 37

ğawāb $67 \mathrm{n} 7$

gayr 74,128

generic present $\quad 224-225$

generic utterances $\quad 48,50-51,160,221-224$, $227,232-233,238,239$

generic verbs 225

generosity 186

Genette, G. 5on36, 197n15, $200 n 18$

Gesamtbedeutung 5

Giolfo, M.E.B. $\quad 72 n 25$
Givón, T. $\quad 54,121 n_{5}, 140 n_{30}$

goals

of conversation/dialogue 159-16o

indication of $\quad 136-137,139$

Goldenberg, G. 34, 55

Götz, M. $\quad 38$

grammars/grammarians

Arabic

modern/Western 1, 34-40, 135

traditional $1,20-33,57,79,122,126 \mathrm{n} 16$, 135,140 31, 177,178

Greek 20, 23n17, 33n6o

grammatical frame of discussion, on Arabic verbs $24-32$

Greek, grammatical traditions in $20,23 \mathrm{n} 17$, $33 n 60$

Guillaume, G. $\quad 226$

habar 57, 79, 122

hadīt 15

Haiman, J. 5 52-53

hal 87,189

häl 79, 135, 145-146

Halliday, M.A.K. $\quad 6 \mathrm{n} 14,42,47,5^{2 n} 39$

Hamburger, K. $\quad 45 \mathrm{n} 18,46 \mathrm{n} 21,50 \mathrm{n} 36,51 \mathrm{n} 38$, $195^{-196}$

Hansen, M.-B.M. $\quad$ 189, $191 n 35$

Hasan, R. 6n14, 42, 47

Haspelmath, M. $119 n 2$

hattā 81, 198

Hewson, J. $39 n 28$

hina 85,237

clauses $\quad 115^{-117}, 118$

Hinds, J. 47n26, 48n27

historical narratives, chronicles $\quad 15,48,197$, 199

Hopper, P.J. $\quad 7,59 n 67,60,195 n 6$

Hymes, D. 42

hypotaxis $53-54$

hypothetic meanings 109,110

I-Origo 45n18, 195

I-Origines $45 \mathrm{n} 18$

Ibn al-'Anbārī, 'Abū al-Barakāt 'Abd al-

Raḥmān b. Muhammad 20-21

Ibn al-Sarrāğ, 'Abū Bakr Muhammad 21, 23, 25n26, $3^{1}$

Ibn Ya'ǐš, Muwaffaq al-Dīn 'Abū al-Baqā' Ya'īš 23-24, 27, 28, 31, 122n8, 177 


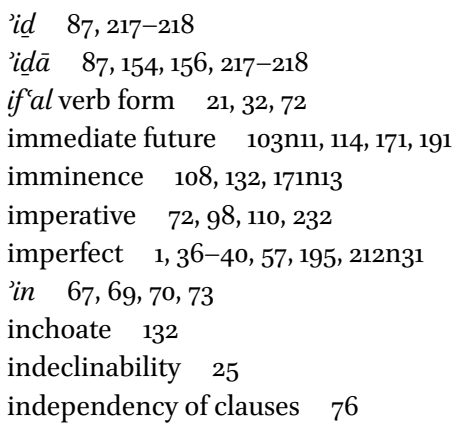

Kleiber, G. $\quad 225$

Koch, W.A. 219

König, E. $\quad 147$ n38

Kuryłowicz, J. $\quad 38$ lā 74, 128n18

fa'ala 180

yaf'alu 99, 104, 110, 115, 126, 137, 141, 148, 178-179, 191, 228

la- $\quad 65,67-68,149-150,176,177,227$

fa'ala 68

fāilun 177, 235

qad 125-126, 128

fáala $67-68,15$ on 39,178

yaf'alanna 178

yaf'alu $65 \mathrm{n} 6,177,227,235$

la'alla 86

Labov, W. 196, 209-210

lākinna 86

lam 74

yaf'al 95, 99-100, 105, 110-111, 112, 131, 145, $178,181,192,229$

lammā-clauses $\quad 116-117,215^{-217}$

law 70

laysa $74,179,181$

yaf'alu 179-180, 191

layta 86

Leder, S. 15n27, 17n29

Lehmann, C. 53,120

Levinson, S.C. $\quad 182 n 26$

lexical classes $\quad 58-60,235$

Lexique-index 27

li-yaf'al verb form $\quad 72$

linguistics 8-9, 41 context concept in $\quad 42-43$

linking devices $\quad 78-81$

literature

dialogues in 159-160

lladī $85,96-100$

Lyons, J. 42, 44n16, 48n29, 65n5, 71n18, 158n1, 165n9, 189, 215n32

$m \bar{a} \quad 74,84,85,96,178,179,181$

clauses 105-111

fáala 94, 95, 105, 178, 180-181, 192, 229

yaf'alu 104, 178, 179, 191

$m \bar{a}(\underline{d} \bar{a}) \quad 87$

maf'ūl (tāani) 79

maf'ülan verb form 126-128, 212, 235

maf'ülun verb form $\quad 155,156,171,172,173,185$, 235

$m^{\prime} f^{\prime} \bar{u} l V n$ verb form $\quad 91,92,120,236,237$

main clauses $54,72,77,80-81,95,120,123$

negation in 74 
man $85,87,96$

clauses $\quad 111-115,117,237$

markedness $5,6,43$

matā 83

Matthiessen, C. $\quad$ 52n39, 56

al-Maydānī 229

meaning 10

mediacy 200n17

mental comprehension/perception $\quad 140,144$

methodologies, linguistic $\quad 8-9$

Meulen, A. ter 222

mimetic devices 214

min-phrases 105

modality/modal verbal forms $19,62,71-73$, $208,227,232,233,235,238$

modifiers 60,61

verbal $64-68,125,128,131-134,167,207$, 235

Monville-Burston, M. $6 \mathrm{n} 13$

moods $61-62,64,71$

see also modality/modal verbal forms

Mosel, U. 22

motion verbs $79,80,127,132,134-140,165$, 204-205

al-Mubarrad, 'Abū al-'Abbās Muhammad b.

Yazīd 28

muḍāri'/muḍāra'a (resemblance) 27-32

Mumm, P.-A. $\quad 225 \mathrm{n} 12$

mutual dependency $\quad 77,151-155,197$

narratives $\quad 48-50,160,194-198$

background/foreground forms in 129 , 146, 195n6, 208-213, 220, 238

deictic references of $\quad 45^{-46,197}$

first person $\quad 45,48,50,153,199-200,217$

functions of $196 \mathrm{n} 12$

generic person $\quad 45^{-46}$

historical $15,48,197,199$

third person $\quad 45,46,50,199$

verbal forms in 170-171, 196-197, 198-208, 209-220, 238, 239

narrators $45^{-46}, 5^{0}, 153,197,214-215,221$ see also authors

Narrog, H. 71n19, n21

Nebes, N. 123, 153n45, 204

negation $\quad 62,73-75,116$ n19

particles 62,74

verbal forms $73-75,94-95,104-105,110-$ $111,112,126,128,131,133 n 22,141,177-182$ fáala $74,145,178,180-181,192,229-$

230

qadfa'ala 182, 192

yaf'al 99-100, 131, 192, 229-230

yaf'alu 74, 99-100, 104, 110, 115-116, 126, 133n22, 137, 141, 148, 178-18o, 191-192, 228

Niccacci, A. 203

Nöldeke, Th. 203

non-embedded clauses $\quad 86-88$

non-fiction 197

nouns $21,22,25,26$

oaths $67,170,179,180$

objective/objectivity notion $44 \mathrm{n} 17,222$

Omari, O. $39 n 28$

omniscient epistemological position 45

oppositions 10

organizational patterns of texts 48

orientation components 209

Pagliuca, W. 71n21, 165n9, $171 n 13$

Palmer, F.R. $\quad 61 n 1,65 n 5,71 n 20$

paradigmatic oppositions 10

paradigms $10,55,158$

paragraphs $47 \mathrm{n} 26$

participles $64,98-99,103,108,110,114$,

$154 \mathrm{n} 48,156$

in dialogues $\quad 171-172,173,177,184,191$

in generic utterances $\quad 231$

negated forms of 74,181

predicative 120, 126-128, 133-134, 137-

139, 142-143, 145, 148-149, 152, 153n45,

155

particles 21

connective $80-81,146-147,190034,198-$ 199

indeclinability of $\quad 25,26$

negation $62,74,94-95,181$

past tense $\quad 21-22,32,99$

in narratives $\quad 195^{-196}$

negated forms $100,105,110-111$

Peled, Y. 73n28, 152n43

perception verbs $140-145,155,167$

perfect $1,36-40,57$

performativity/performative clauses $\quad 168-$ $169,182-185$

Perkins, R. 71n21, 165ng, 171n13

permission verbs $\quad \mathbf{1 4 0}-\mathbf{1 4 5}$ 
persistence $102,112,113,168,172,185,190,192$, 236

perspective changes 204

politeness 169,186

polyfunctionality, of verbal forms 178

polyphony 49n3o, 191 n35

polysemy $29,147 \mathrm{n}_{3} 8$

Post-Classical Arabic 14

posteriority

with fa'ala 112-113

in kāna compounds 69

with lā yaf'alu $\quad$ 94, 179

with participles $91,103,108,171,173,236$

with sa-yaf'alu $\quad 91,142,168,172,236$

with yaf'alu 91, 106-107, 111, 164, 167, 172, 236,237

Prague School 8nig

Pre-Classical Arabic 14

predicative verbal forms $79,119,155^{-15} 6,157$, 237

in circumstantial clauses $\quad 145^{-15^{0}}$

in complex clauses $\quad 119-121$

in compound verb forms 121-145

in mutually dependent clauses $\quad 151^{-155}$

in narratives 201-202

predictions $\quad 106-107,111,142,165$

prefixed verb forms $35,36,39,62-63,186$ n 28

prescriptive statements 232

present tense $\quad 21,23-24,32,166,167,177,178$, 224-225

presentative clauses $87,154-155,156,214-$ $215,217-218$

presupposition $\quad 93,97$

preterit tense $\quad 35,195^{-196}$

proper names $209 n 28$

prosody 159 n 4

protasis $\quad 151$

Proto-Semitic 35

proverbs 229

punctuation $159 n_{4}$

qad $\quad 65^{-66,91 n_{5}, 125,128,169 n 12,226}$

fa'ala verb form $11,65,66,67,91,98,102-$ $103,108,117,120,156-157,235,236,237$

in compound with kāna $103^{-104,128-}$

129, 212, 213, 235

in dialogues $169-171,172,173-175,182$,

$183,184,185,190-191,192$

in narratives $\quad 170-171,212,213$ negated forms of 182,192

predicative form of $140,143,145,149$,

$15^{0}, 15^{2-153}, 155,156,237$

yaf'alu verb form $\quad 65,66,90,167,226,235$

qāla 224

qallamā 226-227

qatal/qatala verb form $35,3^{8}$

qațu 229-230

qiyās (regularities) $\quad 28$

questions $\quad 188,189$

see also interrogatives

Qur’ān 14, 177, 179-18on25

ra'ā 142

Rabin, Ch. 13 n22

Raible, W. 53

raising mechanisms/constructions $\quad 140,141$

readiness $171,172,173,181,238$

Reckendorf, H. $\quad$ 1nı, 34, 36-37, 64n3, 116

reference $44-46$

notion $44 \mathrm{n} 16$

regularities in language 9 n2o

relative tenses $\quad 45$

remoteness $169,186,187$

repetition 93,97

report $5^{0}$

resemblance $\quad 27-32,156$

resultativity $169,184,185,236$

Reuschel, W. $\quad 37 \mathrm{n} 15$

rhetoric questions 188

Rothstein, S. $\quad 58 \mathrm{n} 63$

rubba $(m \bar{a}) \quad 226,227,230-231$

Rundgren, F. $\quad 37 \mathrm{n} 15$

Ryding, K.C. $\quad 3^{2}$

sa- $\quad 65,68,177$

yaf'alu verb form $\quad 68,90,91,121,142,155$, $168,172,174-175,235,236$

Sacy, A.S. de $\quad 35,36,229$

Sadan, A. $\quad 67 \mathrm{n} 7$

Șahịh 95

Sasse, H.-J. $\quad 5^{8}$

Saussure, F. de 8

sawfa- 65,68

yaf'alu verb form $\quad 168,172,235,236$

Schiffrin, D. $\quad 43,159 n_{3}, 160,173,174 n 16$

semantic invariance $5^{-6}$

semanto-logical frame of discussion, on

Arabic verbs $\quad 20-23$ 
$\begin{array}{cc}\text { Semitic languages } & 8,34 \\ \text { verb system in } & 35,37\end{array}$

sentences 47

sequentiality of narratives $\quad 198,206-208$

Shisha-Halevy, A. 8n18, 49n31, 52n40, 208

Sībawayhi, 'Abū Bišr 'Amr b. 'Uțmān 20, 21-22, 24, 26-27, 28-31, 32, 36ng, 79n4, 178

signs, linguistic $\quad 9,46 \mathrm{n} 19$

functions of 10

simultaneity $116,120,135,136-137,141,237$

Sira (Prophet's life) 15

al-Sīrāfì, 'Abū Sa'īd 29

social function of conversation 159

speakers $177,179,181,221-222$

specificity 138,145

speech

acts $\quad 189$

direct $46,205^{-206,228}$

tripartite division of $20-21,24$

verbs $145,167,184$

Stanzel, F.K. $\quad 200 n 17$

state verbs $\quad 134-140$

stative lexemes $\quad 225$

with facala 91, 92, 98, 102, 107, 112, 114-115, 139-140, 168-169, 184, 190, 199, 239

with participles $\quad 126,127,133,137,239$

with yaf'alu $\quad 94-95,100,104,124$

stative verbs 64,68

Structuralism 8

structure

of context 43,60

of dialogues 161

of texts $\quad 48-51$

šubbiha (similar) 31

subjectivity $45,46,48,71,215 \mathrm{n} 32,227$

subjects, in circumstantial clauses $146 \mathrm{n}_{35}$

subjunctive 72

subordination $\quad 5^{2-54}, 84$

substantival clauses see content clauses

substitution class $10,55^{-56,77}$

suffixed verb forms $35,36,39,62-63$, $186 \mathrm{n} 28$

surprise $\quad 217-218$

al-Suyūṭī, Ğalāl al-Dīn 'Abd al-Raḥmān b.'Abī

Bakr 21, 29

symmetrical relations/symmetry, between

clauses $\quad 55,76,77$

see also asymmetry syndetic clauses, circumstantial $\quad 146,197$

syntagms $\quad 9^{-10}$

inter-clausal $\quad 55,76-81,88,151$

intra-clausal $\quad 82-88$

Tannen, D. 49n30, 158n2, 159

Ta'rīh (annalistic literature) 15

tawkid see emphasis

taxis 59

telicity see bounding

temporal clauses $115^{-117}, 215^{-217}$

temporal value see time/temporal value

temporality $129-130,157$

tenses $\quad 239$

absolute and relative $\quad 45$

in Classical Arabic 1-4, 234

Arabic grammatical tradition on 2124,32

Western scholars on $\quad 34-40$

and meanings $\quad 5,162-163,193$

in narratives $195^{-196,204}$

termination 137,139

texts/text types $10,12,47-51,54,158,235$,

$237,238-239$

and aspect $\quad 59$

classical, contextualization of $\quad 43-44$

see also dialogues; generic utterances;

narratives

third person clauses 82

Thompson, S.A. $\quad 5^{2-53}, 56,60$

time/temporal value

of utterances $\quad 166$

and verbs/verbal forms $\quad 6-7,21-23,32$, $36,39,135,157,163-164,237$

topicalization clauses/structures $51,57 \mathrm{n} 56$, $82,88,213$

tradition

grammatical

Arab $1,20-33,57,79,122,126 \mathrm{n} 16,135$, 140n31, 177, 178

Greek 20, 23n17, 33n6o

transaction-performatives $\quad 183^{-184,185}$

transitivity of verbs $\quad 22,60,156$

in predicative clauses $\quad 127,148$

translocal verbs see motion verbs

Troupeau, G. 27

tumma 81,198

unexpectedness $\quad 217-218$ 
unidirectional dependent clauses $\quad 77$

units, linguistic 9

Vachek, J. $8 \mathrm{n} 19$

Valin, R.D. van $5^{2}$

Vendler, Z. $\quad 58 \mathrm{n} 63$

verbal complexes see compound verb forms

verbal syntagms $\quad 55$

verbal systems

Classical Arabic $1,32,33,61-75,156-157$

French $6 \mathrm{n} 13$

Versteegh, C.M.H. $\quad$ 22, 32, 33n6o

voice 197

wa- $80-81,146-147,155,190 n 34,198,211$

Waletzky, J. 196, 209-210

Waltisberg, M. 54, 55n52, 76, 79, 131n20, 135 , $138,140{ }^{30}$

Waugh, L.R. 6nı3, 43

wayyiqtol 196, 203-204

Wehr, H. $\quad 178,179$

Weinrich, H. $\quad 7,48 \mathrm{n} 29,195$

when-clauses $\quad 115 \mathrm{n} 18$

Wilmet, M. 226n13

wish $185,186,187$

words

order of $\quad 82-83$

types of, tripartite division of $\quad 20-21,24$

Wright, W. $37,67 \mathrm{n} 10,185^{-186 n 28}$

$y$-aqtul verb form (Proto-Semitic) 35

yaf'al verb form $\quad 72,74,95$

negated forms of $99^{-100,131,192,229-}$

230

predicative use of $15^{-15^{2}}$

yaf'ala verb form $72,73,74,208$

yaf'alu verb form $\quad 11,12,32,57,62,83,90,123^{-}$ $124,156,234-235,236,238-239$ agent noun resemblances of $\quad 28-31,3^{2-}$ 33

in compound with kāna 99, 109-110, 114,

$123,124-125,212,235$

in dialogues

declarative clauses $\quad 164-167,172,173-$ 175,176

interrogative clauses $\quad 189-190$

optative clauses $\quad 187$

performative clauses $183,184,185$

in embedded clauses $\quad 90-91,93-94,95$,

97-98, 99, 100-101, 105-107, 111-112, 116, 236-237

and fa'ala form $\quad 2-4,39-40,156,239$

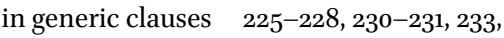
238

meanings of $\quad 161-162,236-237,239$

in narratives $200-208,212,213,216,219$,

220, 225-226, 238

negated forms of $74,99-100,104,110,115^{-}$ $116,126,133 n 22,137,141,148,178-180$, 191-192, 228

predicative form of $120,124-126,131-132$, $133,135^{-138}, 141-142,143,145,147-148$,

$152,153 \mathrm{n} 45,155,156,201-202,237$

as present/future tense form $21,22,2^{-}$ 24

yakun/kāna 69

yaqtulu verb form 38

yes-no questions $\quad 189$

Yule, G. $\quad 9$ n2o

al-Zağğgaăğî, 'Abū al-Qāsim 'Abd al-Raḥmān

b.'Ishāāq 21, 23

al-Zamahšarī, 'Abū al-Qāsim Mahmūd

b.'Umar 21

zero-time 163,171

zero-vantage point $\quad 212,214$ 